UNIVERSIDADE DE SÃO PAULO

ESCOLA DE ENGENHARIA DE SÃO CARLOS

DEPARTAMENTO DE ENGENHARIA MECÂNICA

\title{
ESTUDO DE IMPACTO USANDO ELEMENTOS FINITOS E ANÁLISE NÃO LINEAR
}

\author{
Eng $^{\circ}$ CÉSAR ANTONIO APARICIO SÁNCHEZ
}

Dissertação apresentada à Escola de Engenharia de São Carlos da Universidade de São Paulo, como parte dos requisitos para obtenção do título de Mestre em Engenharia Mecânica

ORIENTADOR: Prof. Dr. João Lirani 
A mi madre Margarita, mis hermanas Noemi y Virginia, mi esposa Maria Inez e hija Larissa dedico como tributo de vida a mi abuelo Marcos. 


\section{Agradecimentos}

Ao Professor João Lirani, por ter me dado a oportunidade, orientação e amizade.

Aos Professores Paulo Varoto, Jonas de Carvalho e Domingos Alves Rade, pelas oportunas sugestões e contribuições dadas a este trabalho.

Ao meu amigo Prof. Milton (Buda) pela orientação e amizade.

Aos colegas e amigos Neilor, Mariano e Toddy, pelo valioso apoio dado para o desenvolvimento deste trabalho.

Aos colegas dos grupos CAD/CAE e COMPÓSITOS, Giovanni, Amauri, Zilda Geraldo, Hubinger, Volnei, C. Torres e R. Canto, pelo apoio e amizade.

Aos amigos Rodrigo, Bila, Kelen, Fabiana, Gi, Lu, Dinho, Klaus e Jorge Peren, pelo apoio e convivência neste período.

Às secretárias da pós-graduação Beth e Ana Paula, por sua paciência e competência.

Ao André, que conseguiu recuperar os arquivos desta tese e, a todos aqueles que contribuíram direta ou indiretamente na realização deste trabalho.

Ao CNPq - Conselho nacional desenvolvimento cientifico e tecnológico, pela bolsa de estudo, que permitiu dedicação integral ao programa de mestrado, e sem a qual seria impossível a realização deste trabalho.

À EESC-USP, pela oportunidade de continuar meus estudos neste prestigiado e reconhecido centro do saber. 


\section{Sumário}

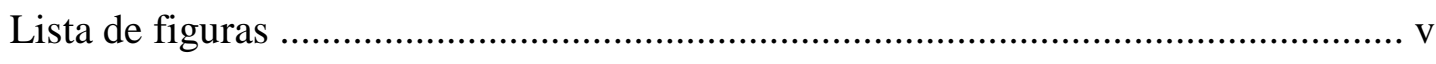

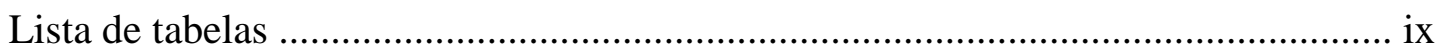

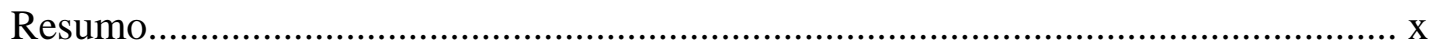

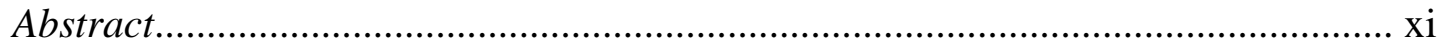

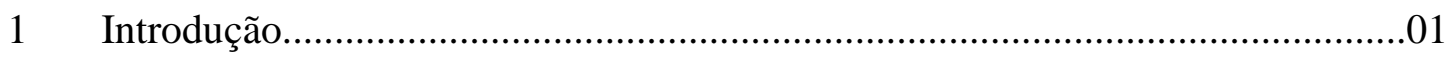

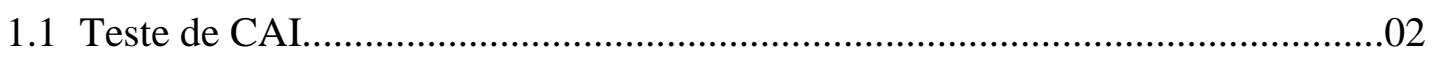

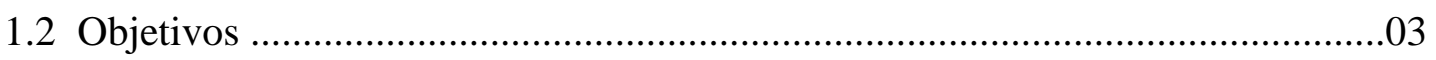

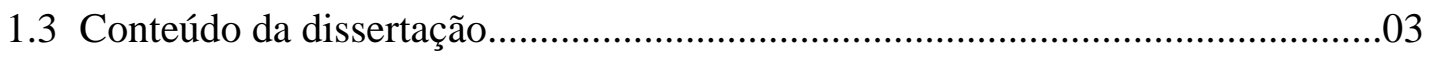

2 Tópicos do método dos elementos finitos e análise não-linear ……..................05

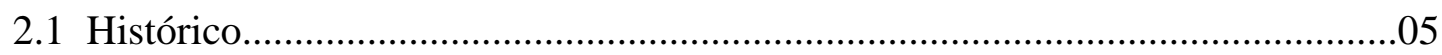

2.2 Tópicos do método de análise por método de elementos finitos........................06

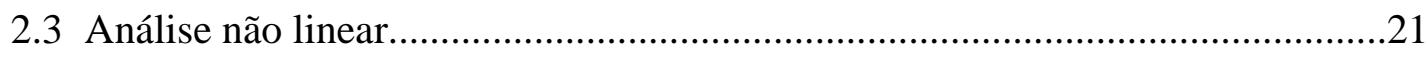

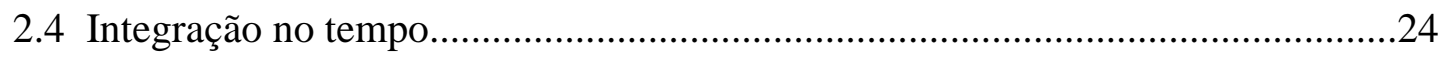

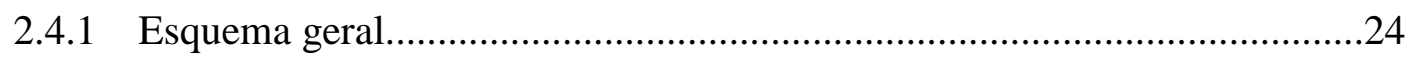

2.5 Integração no tempo pelo método das diferenças centrais.................................24

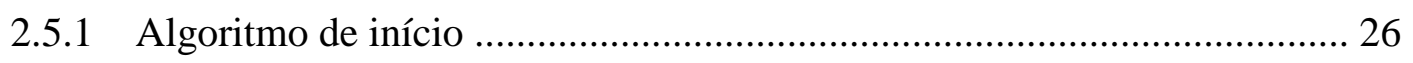

2.6 Integração implícita no tempo (algoritmo dinâmico implícito)......................... 27

2.6.1 Vantagens do algoritmo dinâmico implícito ........................................... 29

2.6.2 Desvantagens do algoritmo dinâmico implícito ......................................... 29

2.7 Integração explícita no tempo (algoritmo dinâmico explícito)............................30 
2.7.1 Vantagens do algoritmo dinâmico explícito............................................... 31

2.7.2 Desvantagens do algoritmo dinâmico explícito....................................... 31

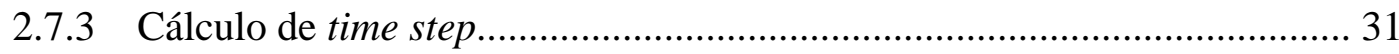

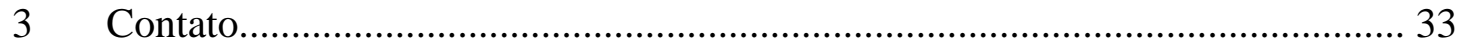

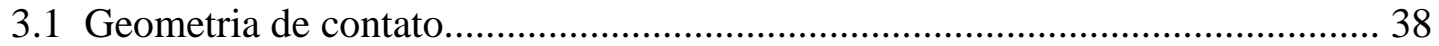

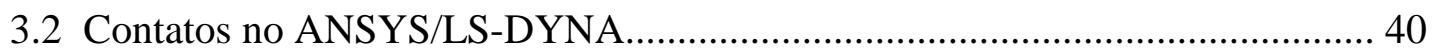

3.2.1 Tipos de contato do ANSYS/LS-DYNA ................................................. 41

3.2.2 Opções de contato do ANSYS/LS-DYNA............................................ 41

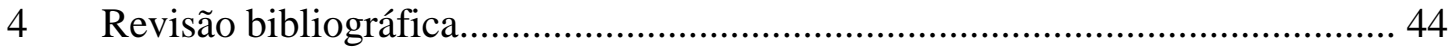

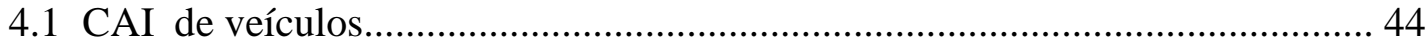

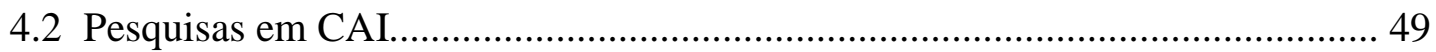

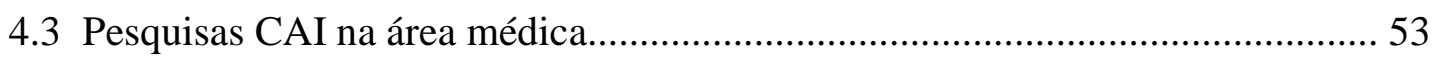

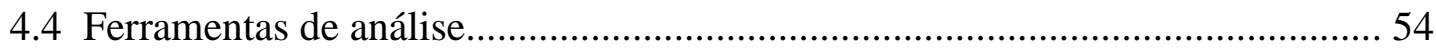

4.4.1 Método dos parâmetros agrupados ....................................................... 54

4.4.2 Método dos elementos finitos - FEM …............................................... 55

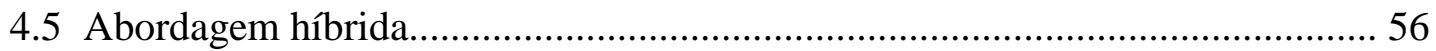

4.6 Comportamento de componentes estruturais.............................................. 57

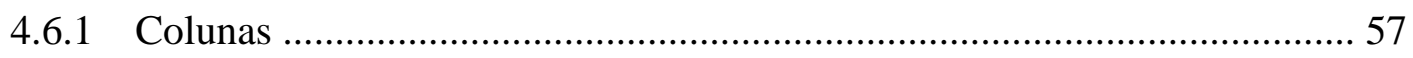

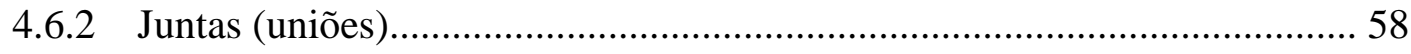

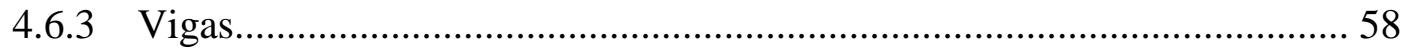

4.7 Geração de modelos computacionais para testes de colisão usando programas de

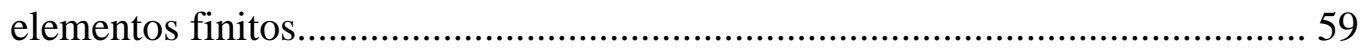

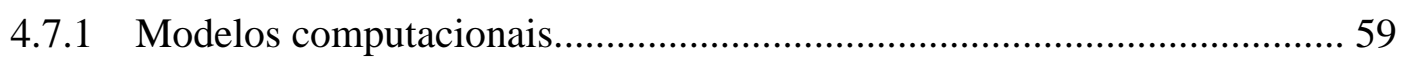

4.7.2 Utilizando softwares CAD e CAE ........................................................... 59 


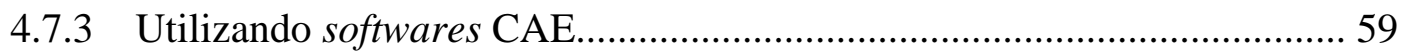

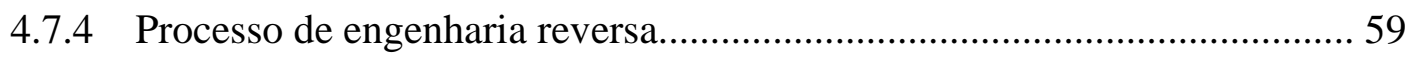

4.8 Modelos físicos para testes de colisão usando métodos destrutivos................... 61

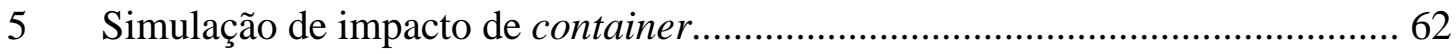

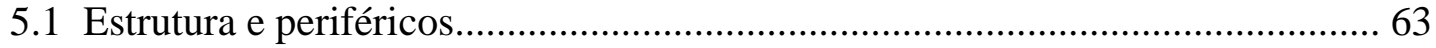

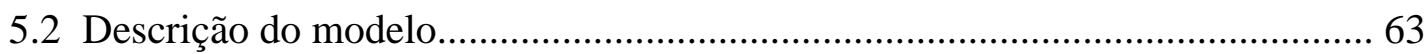

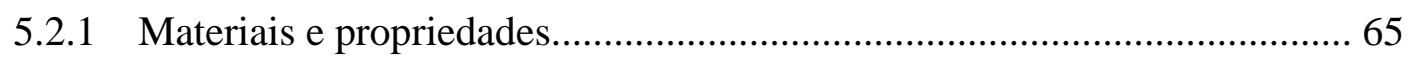

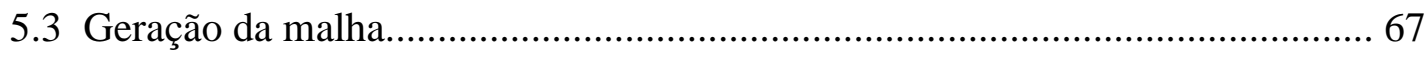

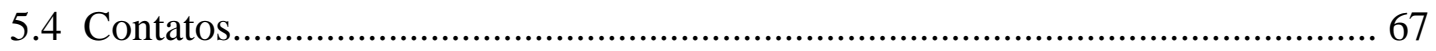

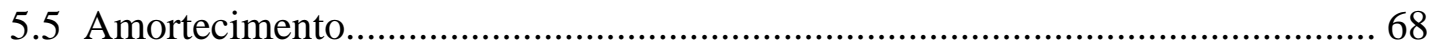

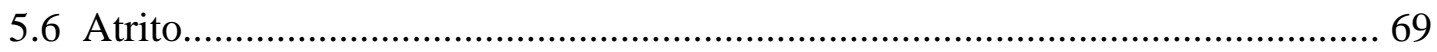

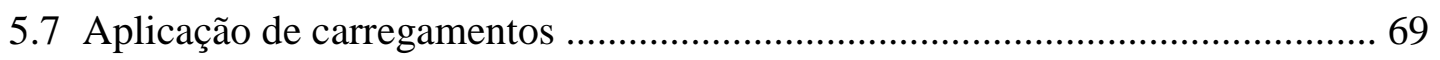

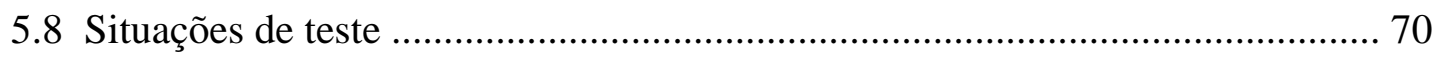

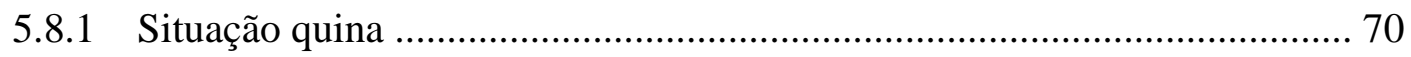

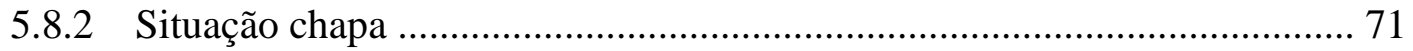

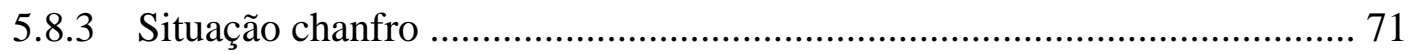

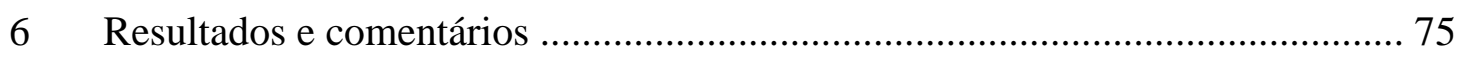

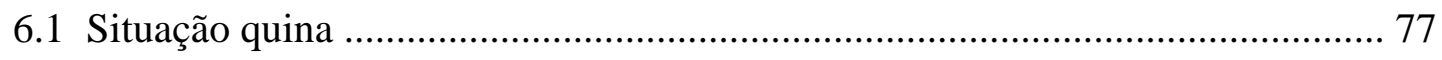

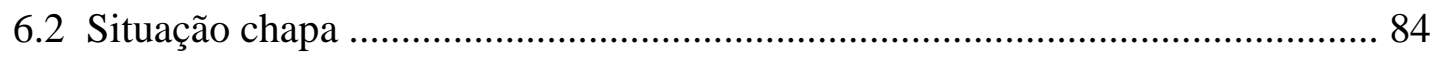

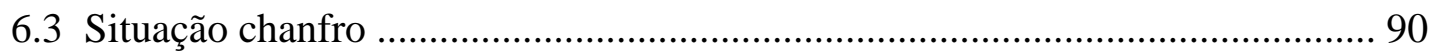

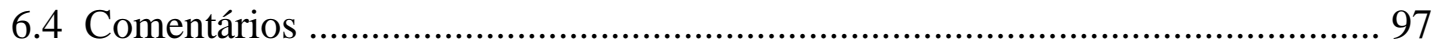

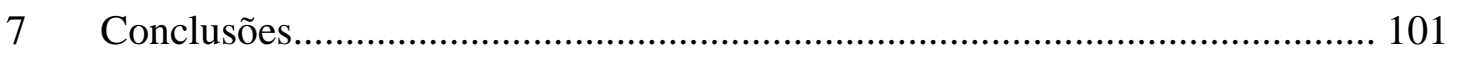

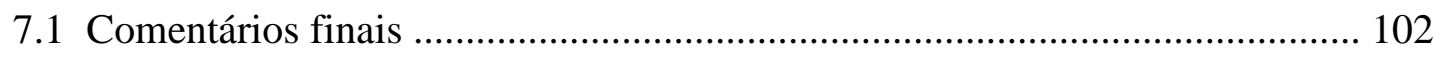

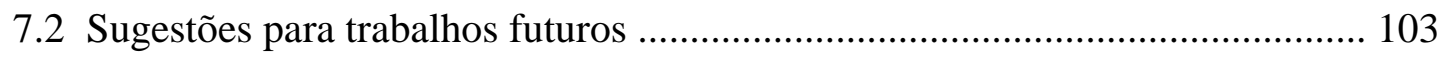




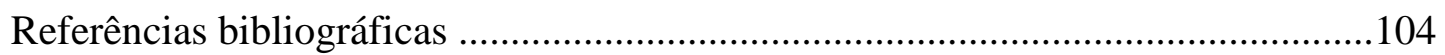

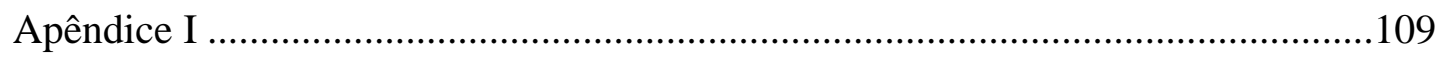

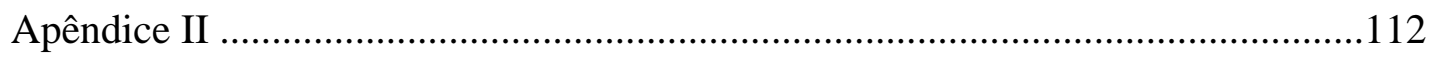

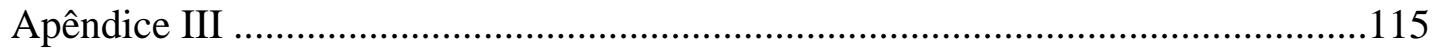




\section{Lista de Figuras}

FIGURA 2.1 Tópicos de elementos finitos para análise de colisão de dois veículos

FIGURA 2.2 Processo de análise por elementos finitos, (BATHE, 1996) ........... 09

FIGURA 2.3 Modelo (contínuo) discretizado por elementos finitos .................. 10

FIGURA 2.3.1 Elemento triangular para cálculo de tensões .............................. 13

FIGURA 2.4 Exemplos comuns do comportamento não linear (ANSYS USER GUIDE)

FIGURA 2.5 Método das diferenças centrais utilizado pelo ANSYS/LS-DYNA (guia de usuários do ANSYS/LS-DYNA)

FIGURA 3.1 Corpos em contato no instante t (BATHE, 1996) ......................... 33

FIGURA 3.2 Definições usadas em análise de contato (BATHE, 1996) ............. 39

FIGURA 4.1 Colisão frontal .................................................................... 46

FIGURA 4.2 Colisão frontal parcial ............................................................... 47

FIGURA 4.3 Teste de colisão lateral (PALUSZNY 1992) ................................. 47

FIGURA 4.4 Chassi de automóvel feito de segmento de alumínio ..................... 50

FIGURA 4.5 Variáveis que influenciam o esmagamento e absorção de energia de materiais compósitos (HAMADA \& RAMAKRISHNA) ........... 52

FIGURA 4.6 a) estrutura da cabeça em corte b) detalhe do crânio (JOHNSON, 1990)

FIGURA 4.7 Modelo típico de parâmetros agrupados usado para um choque frontal, (GANDHI 1996)

FIGURA 4.8 Tipos de carregamentos dominantes cara componentes, (REID 1996) 
FIGURA 4.9 (a) Modelo físico de veículo (Plymouth 1996). (b) modelo gerado do veículo usando um braço digitalizador . 60

FIGURA 5.1 Componentes do container e dimensões do modelo [m] 64

FIGURA 5.2 Comportamento de material bilenear isotrópico 65

FIGURA 5.3 Comportamento da espuma de poliuretano (GRUDA \& YORK, 1996) 66

FIGURA 5.4a Situação quina após geração da malha 70

FIGURA 5.4b Situação quina, modelo em corte transversal, após geração da malha

FIGURA 5.5 Situação chapa, vista frontal e vista em corte transversal, após geração da malha 71

FIGURA 5.6 Componentes do container (situação chanfro) e dimensões [m] .. 72

FIGURA 5.7 Vistas da situação chanfro 73

FIGURA 5.8 Vistas em corte da situação chanfro 73

FIGURA 6.1 Exemplo de queda livre de um corpo elástico 75

FIGURA 6.2 Gráficos de deslocamento, velocidade e aceleração contra tempo [ms], da queda livre de um corpo elástico

FIGURA 6.3 Sequiência da simulação do container (em corte transversal), situação quina

FIGURA 6.4 Vista frontal do modelo no passo 273 e tempo de 0,0068 segundos, no qual ocorre a maior tensão

FIGURA 6.5 Vistas do modelo no passo 273 que mostram onde ocorre a maior tensão

FIGURA 6.6 Vista frontal do componente cápsula no passo 344 e tempo de 0,0086 segundos, onde ocorre a maior tensão para este componente

FIGURA 6.7 Vistas do componente cápsula no passo 344 onde ocorre a maior tensão para este componente

FIGURA 6.8 Vistas em corte do componente cápsula mostrando a localização do nó de referência dentro da cápsula, em todas as situações ........

FIGURA 6.9 Aceleração na direção vertical Y do nó 12 do cilindro $\left[\mathrm{m} / \mathrm{s}^{2}\right]$ através dos 1000 passos da simulação 
FIGURA 6.10 Aceleração na direção vertical Y do nó 1437 da cápsula [m/s²] através dos 1000 passos da simulação

FIGURA 6.11 Aceleração na direção vertical Y do nó 1259, nó de referência da cápsula $\left[\mathrm{m} / \mathrm{s}^{2}\right]$ através dos 1000 passos da simulação 83

FIGURA 6.12 Seqüência da simulação do container da situação chapa 85

FIGURA 6.13 Vista frontal do modelo na situação chapa no passo 241 e tempo de 0,006 seg., no qual ocorre a maior tensão ao modelo ....

FIGURA 6.14 Vista frontal do componente cápsula da situação chapa no passo 374 e tempo de 0,009325 segundos, onde ocorre a maior tensão para este componente ....................................................... 86

FIGURA 6.15 Vistas do componente cápsula no passo de simulação 374 ........ 87

FIGURA 6.16 Aceleração vertical Y do nó 32, mostra um pico máximo de aceleração de $297432 \mathrm{~m} / \mathrm{s}^{2}$

FIGURA 6.17 Aceleração vertical Y do nó 1918, mostra um pico máximo de $-61894 \mathrm{~m} / \mathrm{s}^{2}$

FIGURA 6.18 Aceleração vertical do nó de referência 1259, mostra um pico máximo de aceleração de $35308 \mathrm{~m} / \mathrm{s}^{2}$

FIGURA 6.19 Sequiência da simlação do container da situação chanfro

FIGURA 6.20 Vista frontal do modelo da situação chanfro no passo 284 no qual ocorre a maior tensão no modelo

FIGURA 6.21 (a) Vista frontal do modelo no passo 284 onde é mostrada a maior tensão no modelo, (b) vista em corte de todos os componentes do modelo no passo 284

FIGURA 6.22 Vista do componente cápsula no passo 348 no qual ocorre a maior tensão para este componente

FIGURA 6.23 Vistas do componente cápsula no passo 348. Mostra tensões no componente no instante em que ocorre a maior tensão

FIGURA 6.24: Aceleração vertical Y do nó 2 do cilindro (situação chanfro), através dos 1000 passos da simulação. Mostra pico máximo de $258334 \mathrm{~m} / \mathrm{s}^{2}$ 
FIGURA 6.25: Aceleração vertical Y do nó 1089 do componente cápsula (situação chanfro), através dos 1000 passos da simulação. Valor máx. de $89884 \mathrm{~m} / \mathrm{s}^{2}$

FIGURA 6.26: Aceleração vertical Y do nó 587 (no de referência do componente cápsula da situação chanfro), através dos 1000 passos da simulação. Mostra valor máximo de $31733 \mathrm{~m} / \mathrm{s}^{2} \ldots \ldots \ldots \ldots . \quad 96$

FIGURA 6.27 Gráficos apresentados por GRUDA \& YORK .......................... 99

FIGURA AI - 1 Elemento SHELL 163 _....................................................... 109

FIGURA AI - 2 Elemento SOLID 164 ................................................... 110 


\section{Lista de Tabelas}

TABELA 2.1 Áreas de aplicação do método dos elementos finitos, (RAO, 1989)

TABELA 2.2 Métodos alternativos de integração

TABELA 3.1 Tipos de contato e opções (em destaque recomendados pelo programa)

TABELA 4.1 Regulamentação de CAI de veículos em vigor em vários países (National organitation for automotive safety \& victims aid)

TABELA 4.2 Peso relativo do alumínio e do aço em estruturas veiculares,

(McGREGOR, et al, 1993) 50

TABELA 5.1 Volume e peso de cada componente 64

TABELA 5.2 Propriedades dos materiais que compõem o container 66

TABELA 5.3 Materiais e elementos atribuídos aos componentes do container ... 67

TABELA 5.4 Definição de contatos dinâmicos explícitos .................................. 68

TABELA 5.5 Volume e peso de cada componente do modelo modificado ......... 74

TABELA 6.1 Valores de aceleração obtidos filtrando os gráficos de aceleração.. 99 


\section{RESUMO}

APARICIO SÁNCHEZ, C. A.(2001). Estudo de impacto usando elementos finitos e análise não linear. São Carlos. 126p. Dissertação (Mestrado) - Escola de Engenharia de São Carlos, Universidade de São Paulo.

Quando ocorre uma colisão, o comportamento estrutural de veículos, componentes ou sistemas mecânicos é analisado através de um parâmetro chamado crashworthiness, conceituado como a capacidade ou habilidade de uma estrutura, ou parte dela, de absorver energia cinética (resultante de impacto) e manter o colapso sob controle, mantendo a integridade no espaço do(s) ocupante(s). Este parâmetro pode também ser determinado para outro tipo de estruturas, como por exemplo, dispositivos de armazenamento de material (containers). Esta dissertação apresenta uma revisão bibliográfica sobre crashworthiness e o comportamento de estruturas quando submetidas a ensaios de impacto. Apresentam-se conceitos, histórico, evolução e principais áreas envolvidas. Destaca-se a utilização de programas de modelamento por elementos finitos na simulação e análise de colisão. Simula-se e analisa-se o impacto de modelos simplificados de container, típicos para o armazenamento de material radioativo, em queda livre contra uma superfície rígida, utilizando o software de elementos finitos ANSYS/LS-DYNA numa análise dinâmica explícita, apresentando-se resultados e conclusões e sugestões para trabalhos futuros.

Palavras chave: crashworthiness, impacto, FEM, crash test, drop test. 


\section{ABSTRACT}

APARICIO SÁNCHEZ, C. A.(2001). Impact study using finite elements and nonlinear analysis. São Carlos. 126p. Dissertação (Mestrado) - Escola de Engenharia de São Carlos, Universidade de São Paulo.

The structural behavior of a vehicle or a mechanical system during collision is a very complex event. To analyze this behavior it's necessary to submit them to crash tests. These tests are made for the determination of the structure behavior and measure the kinetic energy absorption capability of a structure produced during a collision. This parameter is known as crashworthiness. In this work it is made a bibliographical review about crashworthiness and the behavior of structures under impact tests. Also, concepts, historical, evolution and the main involved areas are presented. The use of software's of finite elements in modeling and analyze of impact tests its highlighted. The drop test of a model of container, typical to storage of radioactive waste, is performed using the software of finite element ANSYS/LS-DYNA in an explicit analysis. Results, conclusions and comments for futures works are presented.

Keywords: crashworthiness, impact, FEM, crash test, drop test. 


\section{INTRODUÇÃO}

No projeto de veículos, um item de extrema importância é o que diz respeito à segurança do(s) ocupante(s) quando ocorre um impacto. Para que um veículo seja considerado seguro, ele deve satisfazer dois parâmetros fundamentais: prevenir o envolvimento em colisões e, minimizar o grau de lesões quando este se envolver numa.

O envolvimento em colisões veiculares é, em muitos casos, decorrente de fatores que não podem ser controlados, como por exemplo: acidentes ocasionados por imprudência própria ou de terceiros, falhas mecânicas, entre outros. Quando um impacto ocorre, o comportamento do veículo é analisado através de um parâmetro chamado Crashworthiness; conceituado como a capacidade ou habilidade da estrutura ou parte do veículo de absorver a energia cinética resultante de um impacto e manter a integridade no espaço do(s) ocupante(s). Esta caraterística visa prevenir da melhor maneira o(s) ocupante(s) de lesões graves decorrentes de um acidente, minimizar segundas colisões dentro do veículo, prevenir ejeção e reduzir risco de fogo. Devemos esclarecer que crashworthiness ou capacidade de absorver impacto CAI, e veículo seguro não são a mesma coisa. Estes dois tópicos devem ser distinguidos. A segurança oferecida por um veículo depende tanto do CAI como caraterísticas que evitem o envolvimento em acidentes tais como: freios $\mathrm{ABS}$, dirigibilidade, pneus largos, etc. Por exemplo, um veículo pode ser mais seguro em comparação com outro, porém, possuir defeito de CAI.

No estudo de CAI estão envolvidas principalmente as áreas de: engenharia mecânica, naval e aeronáutica, devido a que dependem desta caraterística para cumprirem normas e requisitos de projeto, tanto de veículos como de componentes. 
Alguns destes estudos são feitos por organismos governamentais com o objetivo de orientar pessoas sobre quais veículos cumprem as normas e quais são mais seguros. Outros trabalhos são desenvolvidos na área médica, onde são expostos dados importantes sobre tipos e gravidade de lesões ocasionadas por colisões e é analisada a eficiência do comportamento CAI em veículos. Todas estas pesquisas têm como objetivo principal avaliar o grau de segurança de veículos quando da ocorrência de colisões, o que é importante quando se tenta salvar vidas e evitar acidentes com lesões graves.

O conceito de CAI não se aplica apenas a veículos, pode ser estendido para componentes, sistemas mecânicos (ex.: containers) e estruturas que, de acordo com o seu funcionamento e utilidade precisam apresentar esta caraterística.

Neste trabalho foi dedicada atenção a um problema de CAI em container de armazenamento de material radiativo.

\subsection{Teste de CAI}

Na construção de veículos, aeronaves, navios e plataformas, as estruturas são normalmente formadas utilizando colunas e painéis de paredes finas e juntas, as quais podem ser de vários tipos de materiais, formas e tamanhos. Estes componentes estruturais são os que absorvem a maior quantidade de energia durante um impacto. Em sistemas mecânicos e estruturas em geral, o objetivo é permitir que os mesmos deformem-se o necessário para manter o colapso sob controle enquanto uma quantidade suficiente de energia de impacto seja absorvida. Em veículos tripulados, além do anterior, deve ser evitada invasão do espaço de sobrevivência e geração de desacelerações muito elevadas às quais o ocupante possa ser exposto.

Para avaliar o comportamento CAI de estruturas, sistemas mecânicos ou de veículos e componentes, é preciso submetê-los a ensaios de impacto.

Até muito recentemente o único método de se fazer ensaios de impacto era através de testes físicos. Testes físicos são feitos utilizando modelos reais completos ou parciais, os quais podem ser de tamanho real ou em escala. Porém, este tipo de teste resulta caro em conseqüência do custo do modelo e a impossibilidade de reutilização. Devido a isto e à necessidade de redução do ciclo de desenvolvimento 
de produtos, nos últimos anos, surgiu a alternativa do teste com auxílio de ferramentas de análise numérica computacional em projeto e simulação de impacto, aplicadas na solução de problemas complexos. Uma das ferramentas de análise numérica mais utilizadas é o método dos elementos finitos (FEM - Finite Element Method). Numa análise computacional, de acordo com o objetivo estudado, é possível realizar simplificações que venham facilitar a modelagem e principalmente poupar tempo. As simplificações devem ser realizadas criteriosamente para que não venham alterar ou afetar a qualidade e acuracidade dos resultados.

É importante salientar que soluções analíticas têm aplicação limitada a situações específicas onde uma solução matemática da estrutura pode ser encontrada.

Apesar do método dos elementos finitos fornecer soluções aproximadas, é uma poderosa ferramenta à disposição de projetistas para encontrar as respostas que procuram.

Neste trabalho apresentam-se simulações do impacto de um container (drop tests), típico de armazenamento de material radiativo, utilizando o software comercial de elementos finitos ANSYS/LS-DYNA.

\subsection{Objetivos}

- Apresentar revisão bibliográfica sobre crashworthiness (CAI);

- Apresentar conceitos sobre o método dos elementos finitos e sua utilização para substituir testes destrutivos;

- Fazer aplicações práticas de estudos, através da simulação do impacto de uma estrutura.

\subsection{Conteúdo da dissertação}

Esta dissertação está estruturada da seguinte forma:

CAPÍTULO 1: Introdução

CAPÍTULO 2: Método dos Elementos Finitos - Apresenta-se uma revisão bibliográfica sobre as origens e a evolução do método dos elementos finitos. Explicase de forma breve como funciona o método, o que é não linearidade e como os pacotes de elementos finitos resolvem este tipo de problemas. 
CAPÍTULO 3: Contato - Explica-se de forma mais detalhada problemas não lineares devido ao contato.

CAPÍTULO 4: Revisão bibliográfica sobre CAI - Apresenta-se revisão bibliográfica sobre crashworthiness; aspectos que influenciam este comportamento, tipos de testes e normas que regulamentam.

CAPÍTULO 5: Simulação de impacto de container - Apresenta detalhes sobre simulação de um container típico de armazenamento de material radiativo.

CAPÍTULO 6: Resultados - São mostrados resultados e comentários com relação aos resultados obtidos.

CAPÍTULO 7: Conclusões - Apresentam-se conclusões, comentários finais e sugestões para trabalhos futuros.

REFERÊNCIAS BIBLIOGRÁFICAS - Lista de referências utilizadas e consultadas para a elaboração deste trabalho.

APÊNDICE I: Breve explicação sobre os elementos utilizados na simulação e suas principais caraterísticas.

APÊNDICE II: São apresentadas rotinas utilizadas para a obtenção de dados das simulações realizadas.

APÊNDICE III: São apresentadas gráficos obtidos usando "filltros numéricos". 


\section{TÓPICOS DO MÉTODO DOS ELEMENTOS FINITOS E ANÁLISE NÃO-LINEAR.}

\subsection{Histórico}

As idéias e teorias que deram origem ao que hoje conhecemos como método de elementos finitos surgiram no início deste século. Não se atribui a ninguém especificamente a autoria deste método, nem a data precisa em que surgiu. Contudo, Matemáticos, Físicos e Engenheiros trabalharam desde o início na elaboração e evolução do método

Segundo HUEBNER (1982) "em engenharia este método foi usado pela primeira vez em 1960 por Clough num estudo sobre problemas de elasticidade plana”. Originalmente o método foi implementado no estudo de tensões em aeronaves. A partir do trabalho de Clough no início dos anos 60, o método de elementos finitos foi usado extensivamente para análise de tensões lineares, deflexão e vibração em diversas áreas da engenharia, já que na época começava a se reconhecer a eficácia do método. Mesmo assim, seu uso em análise de CAI era muito limitado até poucos anos atrás.

O método dos elementos finitos em simulação de colisão teve grande evolução nos últimos anos devido à evolução paralela da computação (que disponibilizou novos programas e hardware compatível), um melhor entendimento do comportamento de plasticidade de chapas metálicas e o surgimento de novos materiais. Desde então o método tem sido utilizado extensivamente em análise de tensões, deformações, vibração, condução de calor, problemas lineares e não-lineares e CAI entre outros. Um exemplo da utilização de programa de elementos finitos é apresentado na figura 2.1 . 
HUEBNER (1982) afirma que "FEM é uma técnica de análise numérica para se obter soluções aproximadas para uma ampla variedade de problemas de engenharia".

Para GANDHI (1996) “A maior vantagem deste método é a capacidade de representar detalhes geométricos, materiais da estrutura, assim como a aplicação de múltiplos conceitos de projeto. Sua maior desvantagem é o custo/tempo". Desenvolver um modelo típico de choque frontal pode levar de 2 a 4 meses e, cada simulação de 10 a 20 horas de CPU, aproximadamente, em estações de trabalho.

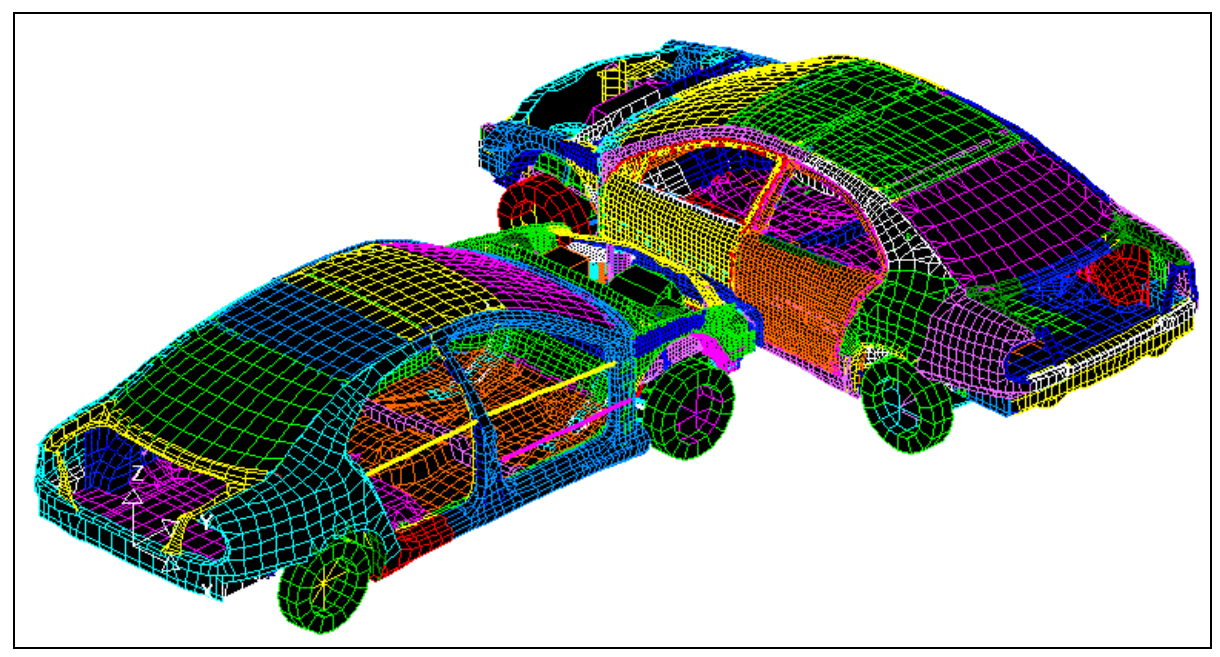

FIGURA 2.1: Modelo de elementos finitos para análise de colisão de dois veículos

\subsection{Tópicos do método de análise por método de elementos finitos}

O Método dos elementos finitos considera a região (contínuo) de solução do problema formada por pequenos elementos interligados entre si. A região em estudo é modelada ou aproximada por um conjunto de elementos discretos pré-definidos. Uma vez que estes elementos podem ser colocados juntos em um número incontável de diferentes configurações, pode-se modelar formas geométricas bastante complexas. Além disso, possibilita que o projetista tenha bastante flexibilidade na aplicação de cargas e condições de contorno, o que torna este método o mais amplamente utilizado para análises estruturais.

O Método dos Elementos Finitos pode ser aplicado numa grande faixa de problemas de engenharia que envolvem valores de contorno. Em um problema de 
valor de contorno, uma solução é procurada na região do corpo (domínio), enquanto nos contornos desta região os valores das variáveis dependentes (ou suas derivadas) são conhecidos.

Segundo RAO (1989) e HINTON \& OWEN (1980) os problemas que podem ser resolvidos pelo método dos elementos finitos podem ser classificados em:

- Problemas de equilíbrio (exemplo, análise estática estrutural)

- Problemas de autovalor (exemplo, análise dinâmica estrutural)

- Problemas de propagação (exemplo, análise transiente no tempo).

TABELA 2.1 : Áreas de aplicação do método dos elementos finitos, RAO (1989)

\begin{tabular}{|c|c|c|c|}
\hline Área de estudo & $\begin{array}{c}\text { Problemas de } \\
\text { equilíbrio }\end{array}$ & $\begin{array}{c}\text { Problemas de } \\
\text { autovalores }\end{array}$ & $\begin{array}{c}\text { Problemas de } \\
\text { propagação }\end{array}$ \\
\hline $\begin{array}{l}\text { Engenharia civil } \\
\text { estrutural. }\end{array}$ & $\begin{array}{l}\text { Análise estática de } \\
\text { estruturas civis. }\end{array}$ & $\begin{array}{l}\text { Frequiências naturais e } \\
\text { modos de vibrar de } \\
\text { estruturas. } \\
\text { Estabilidade de estruturas. }\end{array}$ & $\begin{array}{l}\text { Propagação de ondas de } \\
\text { tensão. } \\
\text { Resposta de estruturas a } \\
\text { cargas aperiódicas. }\end{array}$ \\
\hline $\begin{array}{l}\text { Estruturas } \\
\text { aeronáuticas. }\end{array}$ & $\begin{array}{l}\text { Análise estática de } \\
\text { estruturas de aviões, } \\
\text { foguetes, mísseis e } \\
\text { espaçonaves. }\end{array}$ & $\begin{array}{l}\text { Freqüências naturais e } \\
\text { estabilidade de estruturas } \\
\text { aeronáuticas }\end{array}$ & $\begin{array}{l}\text { Resposta de estruturas de } \\
\text { aviões a cargas } \\
\text { aleatórias. Resposta } \\
\text { dinâmica de aviões e } \\
\text { espaçonaves a cargas } \\
\text { aperiódicas. }\end{array}$ \\
\hline Condução de calor & $\begin{array}{l}\text { Estado de distribuição } \\
\text { de temperatura em } \\
\text { sólidos e fluídos }\end{array}$ & & $\begin{array}{l}\text { Transientes de fluxo de } \\
\text { calor em bocais de } \\
\text { foguetes, motores de } \\
\text { combustão interna, } \\
\text { turbinas e estruturas de } \\
\text { edifícios. }\end{array}$ \\
\hline Geomecânica & $\begin{array}{l}\text { Análise de escavações, } \\
\text { muros de arrimo, túneis, } \\
\text { problemas de interação } \\
\text { de estruturas de solos e } \\
\text { rochas. Análise de } \\
\text { tensões em solos, pilares } \\
\text { e fundações de máquina. }\end{array}$ & $\begin{array}{l}\text { Freqüências naturais e } \\
\text { modos de vibrar de } \\
\text { sistemas de reservatórios } \\
\text { e problemas de interação } \\
\text { solo-estrutura. }\end{array}$ & $\begin{array}{l}\text { Transientes de problemas } \\
\text { de interação solo- } \\
\text { estrutura. Transientes em } \\
\text { solos e rochas. Ondas de } \\
\text { propagação de tensão em } \\
\text { solos e rochas. }\end{array}$ \\
\hline
\end{tabular}


TABELA 2.1 (continuação) : Áreas de aplicação do método dos elementos finitos, RAO (1989)

\begin{tabular}{|c|c|c|c|}
\hline $\begin{array}{l}\text { Engenharia hidráulica e } \\
\text { de recursos hídricos. }\end{array}$ & $\begin{array}{l}\text { Análises de potencial de } \\
\text { fluxos, fluxos de } \\
\text { superfícies livres, } \\
\text { fluxos viscosos, } \\
\text { problemas } \\
\text { aerodinâmicos } \\
\text { transônicos. Análise de } \\
\text { estruturas hidráulicas. }\end{array}$ & $\begin{array}{l}\text { Períodos naturais e } \\
\text { modos de vibrar de } \\
\text { lagos e portos. } \\
\text { Movimento de líquidos } \\
\text { em reservatórios rígidos } \\
\text { e flexíveis. }\end{array}$ & $\begin{array}{l}\text { Análises de problemas } \\
\text { de propagação de ondas } \\
\text { e fluxos instáveis de } \\
\text { fluídos. } \\
\text { Transientes em meios } \\
\text { porosos. } \\
\text { Dinâmica de gases } \\
\text { rarefeitos. } \\
\text { Fluxos magneto- } \\
\text { hidrodinâmicos. }\end{array}$ \\
\hline Engenharia nuclear & $\begin{array}{l}\text { Análise de níveis de } \\
\text { pressão nuclear e } \\
\text { estruturas de contenção. } \\
\text { Estado de distribuição } \\
\text { de temperatura em } \\
\text { componentes de } \\
\text { reatores. }\end{array}$ & $\begin{array}{l}\text { Freqüências naturais e } \\
\text { estabilidade de } \\
\text { estruturas de } \\
\text { concentração. } \\
\text { Distribuição de fluxo de } \\
\text { nêutrons. }\end{array}$ & $\begin{array}{l}\text { Resposta de estruturas } \\
\text { de contenção a cargas } \\
\text { dinâmicas. } \\
\text { Transientes de } \\
\text { distribuição de } \\
\text { temperatura e análise } \\
\text { viscoelástica e térmica } \\
\text { de estruturas de } \\
\text { reatores. }\end{array}$ \\
\hline Engenharia biomédica & $\begin{array}{l}\text { Análises de tensão de } \\
\text { ossos e dentes. } \\
\text { Capacidade de carga em } \\
\text { implantes e sistemas } \\
\text { protéticos. Mecanismo } \\
\text { das válvulas do } \\
\text { coração. }\end{array}$ & & $\begin{array}{l}\text { Análise de impactos em } \\
\text { articulações. Dinâmica } \\
\text { de estruturas } \\
\text { anatômicas. }\end{array}$ \\
\hline Projeto mecânico & $\begin{array}{l}\text { Problemas de } \\
\text { concentração de tensões } \\
\text { em dutos, pistões, } \\
\text { materiais compósitos, } \\
\text { acoplamentos e } \\
\text { engrenagens. }\end{array}$ & $\begin{array}{l}\text { Freqüências naturais e } \\
\text { estabilidade de } \\
\text { acoplamentos, } \\
\text { engrenagens e } \\
\text { máquinas ferramentas. }\end{array}$ & $\begin{array}{l}\text { Problemas de quebras e } \\
\text { fraturas sob cargas } \\
\text { dinâmicas. }\end{array}$ \\
\hline
\end{tabular}


O processo de análise por Elementos Finitos é esquematizado na figura 2.2 (BATHE, 1996).

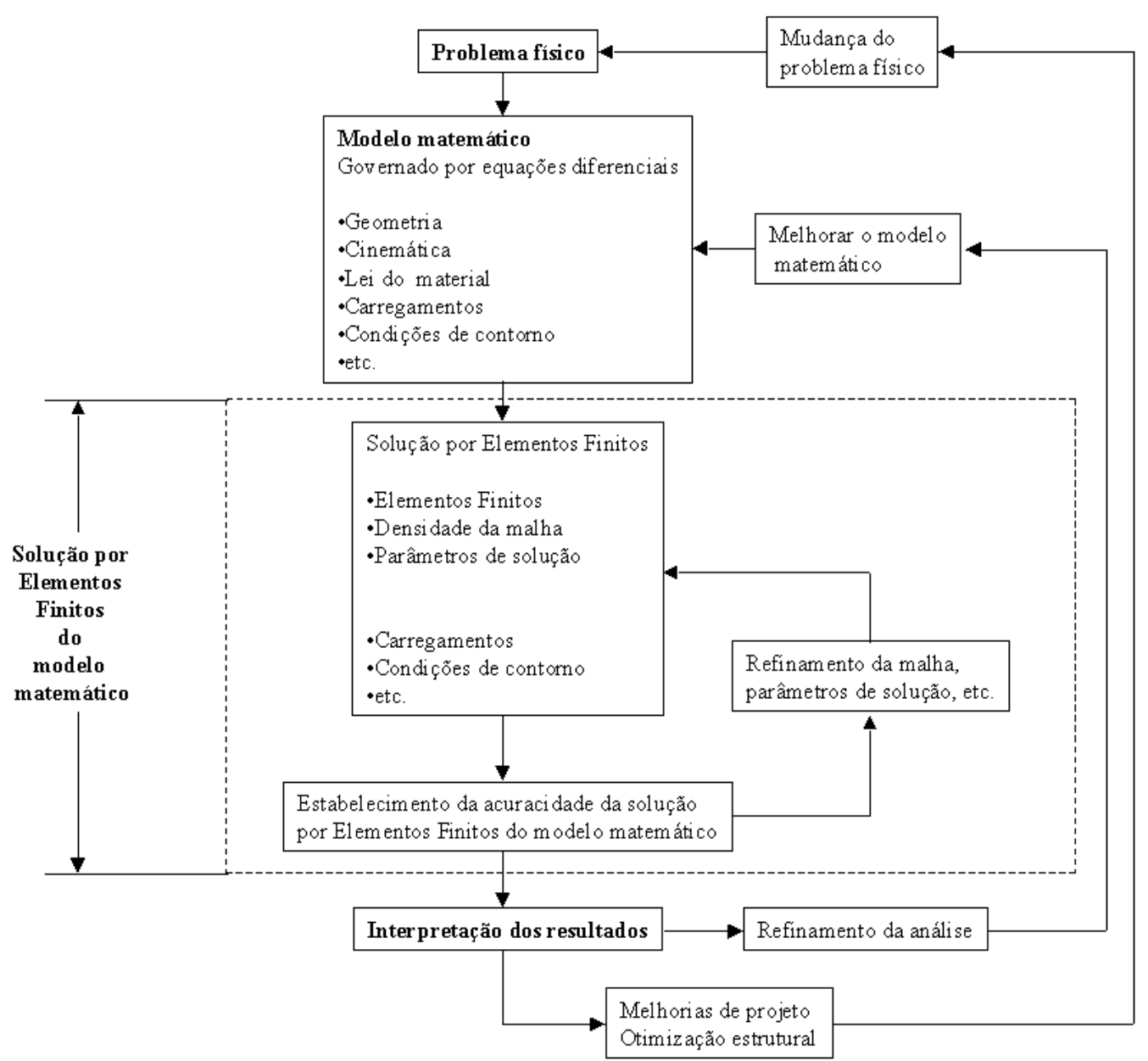

FIGURA 2.2: Processo de análise por Elementos Finitos BATHE (1996).

De acordo com HUEBNER (1994) o método de elementos finitos pode ser resumido essencialmente em 3 etapas: pré-processamento, solução e pósprocessamento.

\section{Pré-processamento}

É a etapa onde se prepara o problema que será solucionado. Modela-se o fenômeno, introduzem-se condições iniciais e de contorno, carregamentos, escolhese os elementos, propriedades dos materiais e são feitas simplificações que venham a 
facilitar a análise sem influir negativamente nos resultados. Esta etapa subdivide-se em:

- Discretização do modelo: O modelo ou contínuo é subdividido em um número equivalente de elementos finitos (figura 2.3), os quais podem ser triângulos ou quadriláteros para problemas em duas dimensões ou tetraedros e hexaedros para três dimensões. Os elementos possuem nós, os quais podem ser internos ou externos, isto é, pertencem ao interior do elemento ou estão localizados nas arestas do mesmo. Assume-se que estes elementos são interligados entre si por nós localizados no contorno dos mesmos (os deslocamentos destes nós são as incógnitas básicas do problema). O processo de discretização do contínuo depende primordialmente do iulramento e do sonherimento do engenheiro.

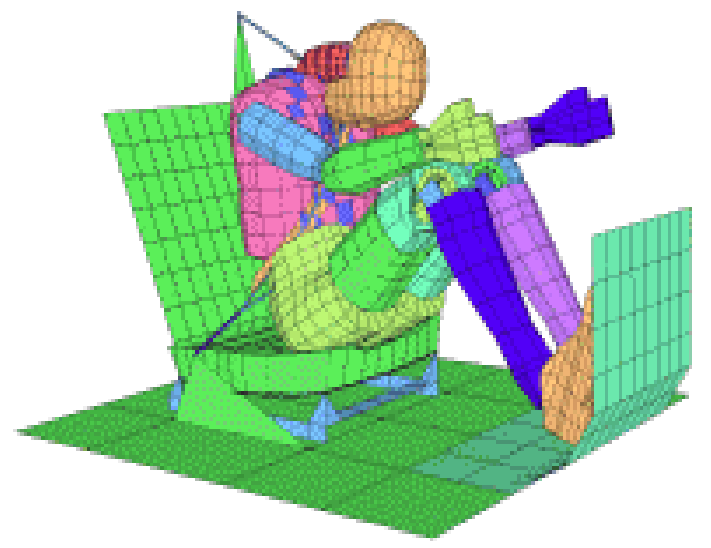

FIGURA 2.3: Modelo (contínuo) discretizado por elementos finitos.

- Seleção das funções de interpolação: De acordo com o tipo de elemento escolhido na primeira etapa, existem funções de interpolação ou deslocamento associadas classicamente aceitas. Portanto, não é preciso determiná-las para cada problema. As funções assumidas representam aproximadamente a distribuição exata ou real dos deslocamentos. Geralmente, a forma adotada para as funções de interpolação é a polinomial, pela simplicidade de manipulação matemática. Existem três fatores inter-relacionados que influenciam a seleção da função de interpolação: escolha do tipo e do grau da função (como normalmente o tipo adotado é o polinomial, apenas o grau deve ser escolhido), o tipo das variáveis de campo que descrevem o modelo (normalmente, os deslocamentos nos nós ou 
suas derivadas) e finalmente, o modelo deve satisfazer certos requisitos que garantam que o resultado numérico se aproxime da solução correta.

\section{Solução (Solver)}

Esta etapa depende da configuração do modelo na etapa anterior. A solução baseia-se num algoritmo numérico que objetiva solucionar eficientemente uma equação diferencial com todas as restrições (condições) impostas ao modelo na primeira etapa. Esta etapa subdivide-se em:

- Obtenção da matriz de rigidez elementar: A matriz de rigidez é constituída pelos coeficientes das equações de equilíbrio derivadas das propriedades geométricas e do material de um elemento e pode ser obtida pelo uso do princípio da mínima energia potencial. A rigidez relaciona os deslocamentos nodais às forças aplicadas nos nós. A relação de equilíbrio entre a matriz de rigidez [k], o vetor força nodal $\{\mathrm{F}\}$ e o vetor deslocamento nodal $\{\mathrm{u}\}$ é expressa como um conjunto de equações algébricas lineares simultâneas, $\{\mathrm{F}\}=[\mathrm{k}][\mathrm{u}\}$. A matriz de rigidez para um elemento depende da função de interpolação, da geometria do elemento e das propriedades locais do material selecionadas na etapa anterior.

- Montagem das equações algébricas para todo o domínio: Inclui a montagem da matriz de rigidez global para todo o modelo a partir das matrizes de rigidez elementares e do vetor força global a partir dos vetores força elementares. A base para um método de montagem é a exigência das interconexões nodais. Os deslocamentos em um nó devem ser os mesmos para todos os elementos adjacentes.

- Soluções para os deslocamentos desconhecidos: As equações algébricas montadas no passo anterior são resolvidas para os deslocamentos desconhecidos. Em problemas lineares, esta é uma aplicação relativamente direta das técnicas de álgebra matricial. Entretanto, para problemas não-lineares, as soluções desejadas 
são obtidas por uma seqüência de passos, cada qual envolvendo a modificação da matriz de rigidez e/ou do vetor força.

- Cálculo das deformações e tensões elementares a partir dos deslocamentos nodais: Em certos casos (deformação de corpos elásticos), os deslocamentos nodais são as variáveis em estudo para a solução. Muitas vezes, entretanto, outras quantidades derivadas das variáveis desconhecidas, tais como tensões e deformações, devem ser calculadas. Em geral, tensão e deformação são proporcionais às derivadas dos deslocamentos.

\section{Pós-Processamento}

É a última etapa do método. Depende somente das necessidades do engenheiro que está modelando o problema. Pode fornecer dados como:

- Deslocamentos nodais;

- Deformações da geometria;

- Gradientes de tensão de acordo com o critério de resistência escolhido;

- Gradientes de temperatura;

- Deslocamentos nodais ao longo do tempo;

- Frequiências naturais e modos de vibrar da estrutura.

A seguir é mostrado um exemplo do cálculo de tensões num elemento.

O primeiro passo é transferir os deslocamentos nodais para um ponto qualquer interno ao elemento, utilizando as funções de interpolação ou de deslocamento:

$$
\{u\}=[N]\{u\}_{n}
$$

onde: $\{u\}=$ vetor deslocamento interno ao elemento

$[N]=$ matriz de funções de deslocamento

$\{u\}_{\mathrm{n}}=$ vetor dos deslocamentos nodais

O desenvolvimento será feito utilizando um triângulo linear mostrado na

figura 2.3.1. 


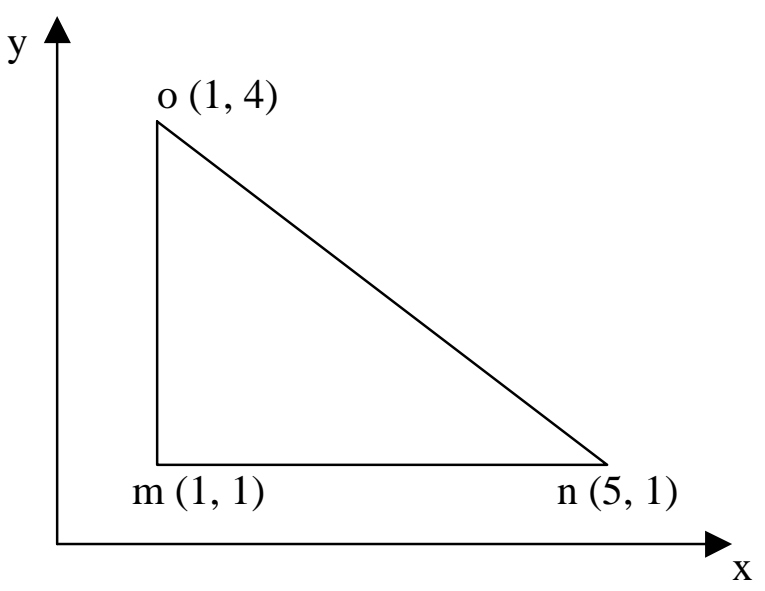

FIGURA 2.3.1: Elemento triangular para cálculo de tensões.

Consideremos um caso de deformação plana, coordenadas (x,y), as funções de deslocamento para um triângulo de 3 nós podem ser expressas como:

$$
\begin{aligned}
& u=a_{1}+a_{2} x+a_{3} y \\
& v=a_{4}+a_{5} x+a_{6} y
\end{aligned}
$$

Os coeficientes $a_{i}$ são determinados substituindo as coordenadas nodais dentro da equação 2.2 e utilizando a condição de contorno seguinte:

$$
u=u_{i} \text { e } v=v_{i}
$$

Assim, temos para $u$ :

$$
\begin{array}{ll}
u_{m}=a_{1}+a_{2}+a_{3} & x=x_{m} ; y=y_{m} \\
u_{n}=a_{1}+a_{2} 5+a_{3} & x=x_{n} ; y=y_{n} \\
u_{o}=a_{1}+a_{2}+a_{3} 4 & x=x_{o} ; y=y_{o}
\end{array}
$$

Calcula-se o determinante do sistema de equações 2.3:

$$
\Delta=\left[\begin{array}{lll}
1 & 1 & 1 \\
1 & 5 & 1 \\
1 & 1 & 4
\end{array}\right]=12
$$

São obtidas as constantes $a_{i}$ substituindo a coluna respectiva $a_{i}$ pelo vetor $\{\mathrm{u}\} \mathrm{e}$ dividindo pelo determinante. 


$$
\begin{aligned}
& a_{1}=\frac{\left[\begin{array}{lll}
u_{m} & 1 & 1 \\
u_{n} & 5 & 1 \\
u_{o} & 1 & 4
\end{array}\right]}{12}=\frac{\left(19 u_{m}-3 u_{n}-4 u_{o}\right)}{12} \\
& a_{2}=\frac{\left[\begin{array}{lll}
1 & u_{m} & 1 \\
1 & u_{n} & 1 \\
1 & u_{o} & 4
\end{array}\right]}{12}=\frac{\left(-3 u_{m}+3 u_{n}\right)}{12} \\
& a_{3}=\frac{\left[\begin{array}{lll}
1 & 1 & u_{m} \\
1 & 5 & u_{n} \\
1 & 1 & u_{o}
\end{array}\right]}{12}=\frac{\left(-4 u_{m}+4 u_{o}\right)}{12}
\end{aligned}
$$

Substituindo os valores de $a_{\mathrm{i}}$ das equações $2.4,2.5$ e 2.6 na função de deslocamento (equação 2.2), temos:

$$
\begin{aligned}
& u=\frac{1}{12}\left(19 u_{m}-3 u_{n}-4 u_{o}\right)+\frac{1}{12}\left(-3 u_{m}+3 u_{n}\right)+\frac{1}{12}\left(-4 u_{m}+4 u_{o}\right) \\
& u(x, y)=\frac{1}{12}(19-3 x-4 y) u_{m}+\frac{1}{12}(-3+3 x) u_{n}+\frac{1}{12}(-4+4 y) u_{o}
\end{aligned}
$$

De forma análoga obtêm-se $v(x, y)$ :

$$
\begin{aligned}
& v(x, y)=\frac{1}{12}(19-3 x-4 y) u_{m}+\frac{1}{12}(-3+3 x) u_{n}+\frac{1}{12}(-4+4 y) u_{o} \\
& N_{m}=\frac{1}{12}(19-3 x-4 y) \\
& \text { Chamando: } \\
& N_{n}=\frac{1}{12}(-3+3 x) \\
& N_{o}=\frac{1}{12}(-4+4 y)
\end{aligned}
$$


Colocando na forma matricial, temos:

$$
\{u\}=\left\{\begin{array}{l}
u(x, y) \\
v(x, y)
\end{array}\right\}=\left[\begin{array}{cccccc}
N_{m} & 0 & N_{n} & 0 & N_{o} & 0 \\
0 & N_{m} & 0 & N_{n} & 0 & N_{o}
\end{array}\right]\left\{\begin{array}{c}
u_{m} \\
v_{m} \\
\vdots \\
u_{o}
\end{array}\right\}=[N]\{u\}_{n}
$$

Assim, voltamos a ter a equação 2.1. Desta forma, dados os deslocamentos nodais, pode-se obter o deslocamento de qualquer ponto interno ao elemento.

Quando se trata com outros tipos de elementos, as equações de deslocamento são diferentes, porém, o procedimento é o mesmo.

A seguir, obtém-se as deformações de um ponto interno ao elemento. Utilizando a teoria da elasticidade temos que:

$$
\{\varepsilon\}=[L]\{u\}
$$

Onde: $\{\varepsilon\}=$ vetor de deformações

$$
\begin{aligned}
& {[L]=\text { operador diferencial }} \\
& \{u\}=\text { vetor de deslocamentos }
\end{aligned}
$$

Através de relações da teoria da elasticidade, as deformações $\{\varepsilon\}$ podem ser relacionadas com os deslocamentos $\{u\}$, a seguir:

$$
\begin{array}{ccc}
\varepsilon_{x}=\frac{\partial u_{x}}{\partial x}, & \varepsilon_{y}=\frac{\partial u_{y}}{\partial y}, & \varepsilon_{z}=\frac{\partial u_{z}}{\partial z} \\
\gamma_{x y}=\left(\frac{\partial u_{x}}{\partial y}+\frac{\partial u_{y}}{\partial x}\right), & \gamma_{y z}=\left(\frac{\partial u_{y}}{\partial z}+\frac{\partial u_{z}}{\partial y}\right), & \gamma_{z x}=\left(\frac{\partial u_{z}}{\partial x}+\frac{\partial u_{x}}{\partial z}\right)
\end{array}
$$

Para os casos de tensão plana, como o deste exemplo, temos:

$$
\varepsilon_{x}=\frac{\partial u_{x}}{\partial x}, \quad \varepsilon_{y}=\frac{\partial u_{y}}{\partial y}, \quad \gamma_{x y}=\left(\frac{\partial u_{x}}{\partial y}+\frac{\partial u_{y}}{\partial x}\right)
$$


Ou, na forma matricial:

$$
\left\{\begin{array}{l}
\varepsilon_{x}(x, y) \\
\varepsilon_{y}(x, y) \\
\gamma_{x y}(x, y)
\end{array}\right\}=\left[\begin{array}{cc}
\partial / \partial x & 0 \\
0 & \partial / \partial y \\
\partial / \partial y & \partial / \partial x
\end{array}\right]\left\{\begin{array}{l}
u(x, y) \\
v(x, y)
\end{array}\right\}
$$

Substituindo a equação 2.1 em 2.11, temos:

$$
\begin{gathered}
\{\varepsilon\}=[L][N]\{u\}_{n} \\
\left\{\begin{array}{l}
\varepsilon_{x}(x, y) \\
\varepsilon_{y}(x, y) \\
\gamma_{x y}(x, y)
\end{array}\right\}=\left[\begin{array}{cc}
\partial / \partial x & 0 \\
0 & \partial / \partial y \\
\partial / \partial y & \partial / \partial x
\end{array}\right]\left[\begin{array}{cccccc}
N_{m} & 0 & N_{n} & 0 & N_{o} & 0 \\
0 & N_{m} & 0 & N_{n} & 0 & N_{o}
\end{array}\right]\left\{\begin{array}{c}
u_{m} \\
v_{m} \\
\vdots \\
u_{o}
\end{array}\right\}
\end{gathered}
$$

Se fazemos $[\mathrm{B}]=[\mathrm{L}][\mathrm{N}]$, temos:

$$
[\mathrm{B}]=\left[\begin{array}{cccccc}
(\partial / \partial x) N_{m} & 0 & (\partial / \partial x) N_{n} & 0 & (\partial / \partial x) N_{o} & 0 \\
0 & (\partial / \partial y) N_{m} & 0 & (\partial / \partial y) N_{n} & 0 & (\partial / \partial y) N_{o} \\
(\partial / \partial y) N_{m} & (\partial / \partial x) N_{m} & (\partial / \partial y) N_{n} & (\partial / \partial x) N_{n} & (\partial / \partial y) N_{o} & (\partial / \partial x) N_{o}
\end{array}\right]
$$

Substituindo os valores de $\mathrm{N}_{\mathrm{m}}, \mathrm{N}_{\mathrm{n}}, \mathrm{N}_{\mathrm{o}}$ dentro de [B] fica:

$$
[B]=\frac{1}{12}\left[\begin{array}{cccccc}
-3 & 0 & 3 & 0 & 0 & 0 \\
0 & -4 & 0 & 0 & 0 & 4 \\
-4 & -3 & 0 & 3 & 4 & 0
\end{array}\right]
$$

Desta forma chegamos à seguinte equação:

$$
\{\varepsilon\}=[\mathrm{B}]\{u\}_{n}
$$


A partir desta equação, dados os deslocamentos nodais, podem ser obtidas as deformações para qualquer ponto interno ao elemento.

Para obter as tensões num ponto qualquer, utilizamos relações da teoria da elasticidade (lei de Hooke), onde, para o caso unidimensional, temos:

$$
\sigma=\mathrm{E} \varepsilon
$$

As tensões $\{\sigma\}$ no caso tridimensional podem ser relacionadas com as deformações $\{\varepsilon\}$ através das seguintes equações:

$$
\begin{array}{lll}
\varepsilon_{x}=\left(\frac{1}{E}\right)\left[\sigma_{x}-v\left(\sigma_{y}+\sigma_{z}\right)\right], & \varepsilon_{y}=\left(\frac{1}{E}\right)\left[\sigma_{y}-v\left(\sigma_{x}+\sigma_{z}\right)\right], & \varepsilon_{z}=\left(\frac{1}{E}\right)\left[\sigma_{z}-v\left(\sigma_{x}+\sigma_{y}\right)\right] \\
\gamma_{x y}=\left(\frac{1}{G}\right) \tau_{x y}, & \gamma_{y z}=\left(\frac{1}{G}\right) \tau_{y z}, & \gamma_{z x}=\left(\frac{1}{G}\right) \tau_{z x}
\end{array}
$$

Onde: $\mathrm{E}=$ módulo de elasticidade (Young)

$\mathrm{G}=$ módulo de cisalhamento $=\mathrm{E} /[2(1+\mathrm{v})]$

$v=$ coeficiente de Poisson

$\sigma=$ tensões normais nas direções $\mathrm{x}, \mathrm{y}$ e $\mathrm{z}$

$\tau=$ tensões de cisalhamento nos planos xy, yz e zx.

Para tensão plana temos:

$$
\begin{aligned}
& \varepsilon_{x}=\left(\frac{1}{E}\right)\left[\sigma_{x}-v \sigma_{y}\right] \\
& \varepsilon_{y}=\left(\frac{1}{E}\right)\left[\sigma_{y}-v \sigma_{x}\right] \\
& \gamma_{x y}=\left(\frac{1}{G}\right) \tau_{x y}
\end{aligned}
$$


Colocando as tensões em evidência temos:

- Tensões de cisalhamento

$$
\tau_{x y}=\frac{E}{2(1+v)} \gamma_{x y}=\frac{E}{(1+v)^{2}} \cdot \frac{(1+v)}{2} \gamma_{x y}
$$

- Tensões normais

$$
\begin{aligned}
& E \varepsilon_{x}=\left\lfloor\sigma_{x}-v \sigma_{y}\right\rfloor \\
& E \varepsilon_{y}=\left\lfloor\sigma_{y}-v \sigma_{x}\right\rfloor \Rightarrow \sigma_{y}=E \varepsilon_{y}+v \sigma_{x}
\end{aligned}
$$

Substituindo (2.24) em (2.23) e manipulando matematicamente temos:

$$
\begin{gathered}
E \varepsilon_{x}=\sigma_{x}-v\left(E \varepsilon_{y}+v \sigma_{x}\right) \\
E \varepsilon_{x}=\sigma_{x}-v E \varepsilon_{y}-v^{2} \sigma_{x} \\
E \varepsilon_{x}+v E \varepsilon_{y}=\left(1-v^{2}\right) \sigma_{x} \\
\sigma_{x}=\frac{E}{1-v^{2}}\left(\varepsilon_{x}+v \varepsilon_{y}\right)
\end{gathered}
$$

Da mesma forma obtém-se $\sigma_{\mathrm{y}}$ :

$$
\sigma_{y}=\frac{E}{1-v^{2}}\left(\varepsilon_{x}+v \varepsilon_{y}\right)
$$

Colocando na forma matricial temos:

$$
\left\{\begin{array}{l}
\sigma_{x} \\
\sigma_{y} \\
\tau_{x y}
\end{array}\right\}=\frac{E}{1-v^{2}}\left[\begin{array}{ccc}
1 & v & 0 \\
v & 1 & 0 \\
0 & 0 & \frac{1-v}{2}
\end{array}\right]\left\{\begin{array}{c}
\varepsilon_{x}(x, y) \\
\varepsilon_{y}(x, y) \\
\gamma_{x y}(x, y)
\end{array}\right\}
$$


Fazendo:

$$
\frac{E}{1-v^{2}}\left[\begin{array}{ccc}
1 & v & 0 \\
v & 1 & 0 \\
0 & 0 & \frac{1-v}{2}
\end{array}\right]=[\mathrm{D}]
$$

temos:

$$
\{\sigma\}^{(e)}=[\mathrm{D}]^{(e)}\{\varepsilon\}^{(e)}
$$

Onde, ${ }^{(e)}$ indica que a equação é específica para o elemento.

Se o material escolhido para o elemento for um aço, com um coeficiente de Poisson de 0,3 , e módulo de Young de $2,1 \times 10^{11}\left[\mathrm{~N} / \mathrm{m}^{2}\right]$, a matriz [D] para o exemplo fica:

$$
[D]=10^{11}\left[\begin{array}{ccc}
2,31 & 0,69 & 0 \\
0,69 & 2,31 & 0 \\
0 & 0 & 0,81
\end{array}\right]\left[\mathrm{N} / \mathrm{m}^{2}\right]
$$

Substituindo (2.18) em (2.27), temos:

$$
\{\sigma\}^{(e)}=[\mathrm{D}]^{(e)}[\mathrm{B}]^{(e)}\{u\}_{n}^{(e)}
$$

Fazendo o produto matricial [D] [B]temos:

$$
\begin{gathered}
{[D][B]=10^{11}\left[\begin{array}{ccc}
2,31 & 0,69 & 0 \\
0,69 & 2,31 & 0 \\
0 & 0 & 0,81
\end{array}\right] \times \frac{1}{12}\left[\begin{array}{cccccc}
-3 & 0 & 3 & 0 & 0 & 0 \\
0 & -4 & 0 & 0 & 0 & 4 \\
-4 & -3 & 0 & 3 & 4 & 0
\end{array}\right]} \\
{[D][B]=\frac{10^{11}}{12}\left[\begin{array}{cccccc}
-6,93 & -2,76 & 6,93 & 0 & 0 & 2,76 \\
-2,07 & -9,24 & 2,07 & 0 & 0 & 9,24 \\
-3,24 & -2,43 & 0 & 2,43 & 3,24 & 0
\end{array}\right] \mathrm{N} / \mathrm{m}^{3}}
\end{gathered}
$$


Se considerarmos um vetor deslocamento igual a:

$$
\{u\}_{n}=10^{-6} \cdot\left\{\begin{array}{l}
-2 \\
-2 \\
+2 \\
-2 \\
+2 \\
+2
\end{array}\right\} \mathrm{m}
$$

Substituindo (2.30) e (2.31) em (2.29), obtemos as tensões para qualquer ponto interno para um elemento triangular a tensão plana:

$$
\begin{gathered}
\{\sigma\}=\frac{10^{11}}{12}\left[\begin{array}{cccccc}
-6,93 & -2,76 & 6,93 & 0 & 0 & 2,76 \\
-2,07 & -9,24 & 2,07 & 0 & 0 & 9,24 \\
-3,24 & -2,43 & 0 & 2,43 & 3,24 & 0
\end{array}\right] \times 10^{-6}\left\{\begin{array}{l}
-2 \\
-2 \\
+2 \\
-2 \\
+2 \\
+2
\end{array}\right\} \\
\{\sigma\}=10^{6}\left\{\begin{array}{l}
0,323 \\
0,377 \\
0,108
\end{array}\right\} \mathrm{N} / \mathrm{m}^{2}
\end{gathered}
$$

Pode-se notar que, para o calculo de tensões, não foi preciso indicar a posição do ponto interno ao elemento devido a que a os termos da matriz de deslocamento [N] são independentes desta posição. Isto é, seja qual for a posição do ponto interno ao elemento, serão achados os mesmos valores de tensão.

Este equacionamento nos leva a um estado de tensão constante dentro do elemento. Isto acontece devido à limitação na escolha das funções $\mathrm{N}_{\mathrm{i}}$ para elementos triangulares de três nós. Utilizando elementos com maior número de nós e, conseqüentemente, funções de deslocamento de ordem superior, poderão ser obtidos resultados melhores. 


\subsection{Análise não-linear}

Uma caraterística que deve ser levada em conta quando se propõe realizar simulações que envolvem colisões é o comportamento não linear do fenômeno. A não linearidade ocorre por várias causas (plasticidade, grandes deslocamentos, grandes rotações, deformações não-infinitesimais e os efeitos derivados do contato e atrito entre as chapas), as quais podem ser agrupadas em três categorias:

- Não linearidade geométrica;

- Não linearidade de material;

- Mudanças de estatus (contato).

Podemos observar o fenômeno da não-linearidade quando grampeamos papéis, o metal do grampo sempre se dobra de diferentes formas (figura 2.4 (a)) ou se sobrecarregarmos uma prateleira de madeira, com o passar do tempo está irá cedendo (figura 2.4 (b)) ou ainda, se for adicionado peso a um carro, o contato superficial entre os pneus e o pavimento muda de acordo com o carregamento adicionado (figura 2.4 (c)). Nos gráficos de carregamento/deflexão de cada um destes exemplos, podem-se notar as caraterísticas fundamentais do comportamento de não linearidade estrutural, pela mudança de rigidez estrutural.

A não linearidade torna o processo tão complexo que requer o auxílio de sofisticados algoritmos numéricos e de poderosos recursos computacionais.

BATHE (1996) atribui o comportamento não linear a três causas principalmente:

- Comportamento não linear do tipo cinemático devido a grandes deslocamentos, rotações e deformações que ocorrem no processo;

- Comportamento linear do tipo constitutivo, devido ao caráter inelástico (plástico, viscoplástico, degradação) que caracteriza as deformações do material;

- Caráter não linear das condições de contorno devido à interação (contato e atrito) que se produz entre os sólidos que atuam no processo ao longo de uma superfície de contato que não é conhecida inicialmente e que varia ao longo do processo. 


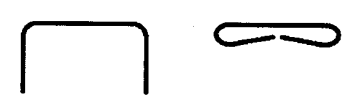

(a) Grampo

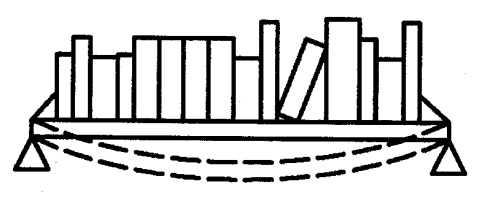
(b) Prateleira de
madeira
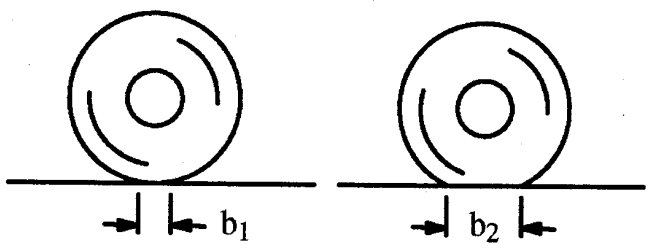

(c) Pneu
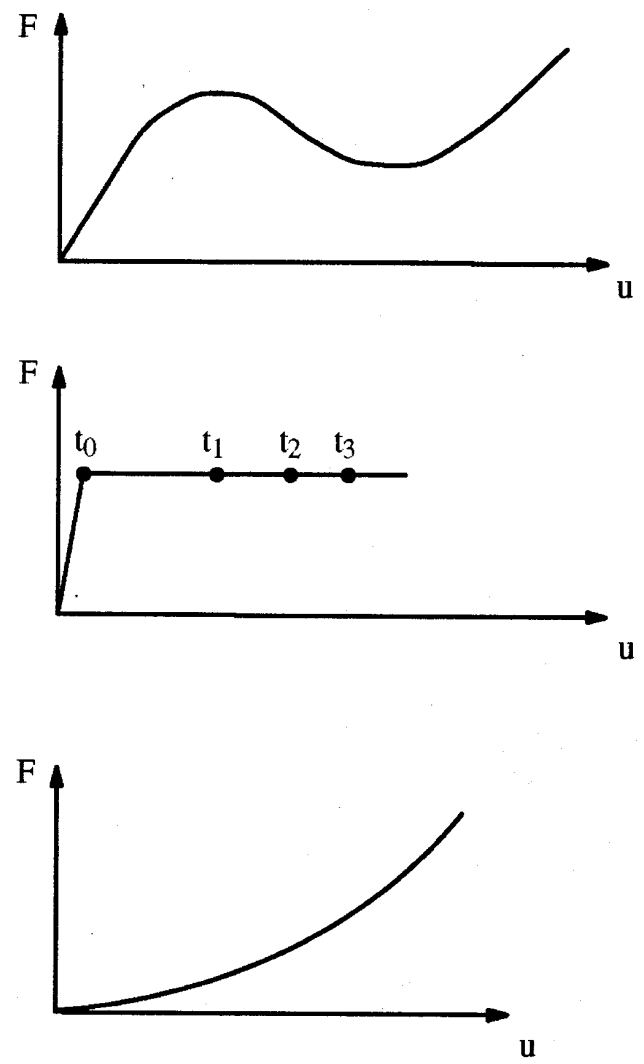

FIGURA 2.4: Exemplos comuns do comportamento não linear (ANSYS USER GUIDE).

Para solução de problemas dinâmicos utiliza-se a equação do movimento (BATHE, 1996):

$$
[M]\{\ddot{u}\}+[C]\{\dot{u}\}+[K]\{u\}=\left\{F^{a}\right\}
$$

Onde: $[M]=$ matriz de massa;

$[C]=$ matriz de amortecimento;

$[K]$ matriz de rigidez;

$\{\ddot{u}\}$ vetor aceleração;

$\{\dot{u}\}$ vetor velocidade;

$\{u\}$ vetor deslocamento;

$\left\{F^{\mathrm{a}}\right\}$ vetor de forças aplicadas. 
Se o problema for do tipo estático os vetores de aceleração e velocidade são assumidos nulos a equação (2.3.1a) fica:

$$
[K]\{u\}=\left\{F^{a}\right\}
$$

As equações (2.33a) e (2.33b) tornam-se não lineares quando a matriz de rigidez [K] é dependente do deslocamento $\{\mathrm{u}\}$ ou de suas derivadas. Assim as equações (2.33a) e (2.33b) ficam respectivamente da seguinte forma:

$$
\begin{gathered}
{[M]\{\ddot{x}(t)\}+[C]\{\dot{x}(t)\}+[K(x(t))]\{x(t)\}=\{F(t)\}} \\
{[K(x(t))]\{x(t)\}=\{F(t)\}}
\end{gathered}
$$

Segundo BATHE (1996), matematicamente a equação (2.33a) representa um sistema de equações lineares de segunda ordem e, em princípio, a solução para tais equações pode ser obtida através de procedimentos padrões de solução de equações diferenciais. Contudo, a solução do sistema pode tornar-se difícil se a ordem das matrizes for muito grande. Neste ponto entram os procedimentos alternativos para solução de equações.

Estes procedimentos alternativos podem ser divididos em dois grupos: métodos de integração direta no tempo e métodos de superposição de modos (tabela 2.2). Os métodos de superposição de modos são muito usados em análise de vibrações, quando a geometria básica não muda. Nos casos que envolvem plasticidade e contato, os modos de vibrar mudam durante o processo e inviabilizam a utilização destes métodos.

TABELA 2.2: métodos alternativos de integração

\begin{tabular}{|l|l|}
\hline \multicolumn{1}{|c|}{ Métodos de integração direta } & \multicolumn{2}{c|}{ Métodos de superposição de modos } \\
\hline \hline - Método de Newmark & - Mudança de bases para deslocamento \\
- Método de diferenças centrais & modal generalizado \\
- Método de Houbolt $\theta$ de Wilson & Análise desconsiderando \\
& - Anortecimento \\
& Análise considerando amortecimento \\
\hline
\end{tabular}




\subsection{Integração no tempo}

A integração no tempo é feita por passos de tempo que, pela velocidade, transformam-se em incrementos de deslocamentos:

$$
\dot{x}(t)=\frac{\Delta x(t)}{\Delta t}
$$

\subsubsection{Esquema geral}

Aqui se juntam os interesses da plasticidade e do contato, problemas que são resolvidos através de incrementos de deslocamentos. A cada passo da integração no tempo acha-se o incremento de deslocamento que é usado para calcular o contato, o qual permite achar as deformações e tensões.

A integração no tempo nos dá:

$$
\Delta t \quad, \quad x(t) \quad, \quad \dot{x}(t)=\frac{\Delta x(t)}{\Delta t} \quad \mathrm{e} \quad \ddot{x}(t)=\frac{\Delta \dot{x}(t)}{\Delta t}
$$

Em problemas que envolvem contato, com o valor de $\Delta x(t)$ calcula-se a nova situação de contato e a nova matriz de rigidez $[\mathrm{K}(x(\mathrm{t}))]$

Em problemas de plasticidade, com o valor de $\Delta x(t)$ calcula-se $\Delta \varepsilon^{\text {elast }}, \Delta \varepsilon^{\text {plast }}$ e novamente $\left[\mathrm{K}\left(\Delta x(\mathrm{t}), \Delta \varepsilon^{\text {elast }}, \Delta \varepsilon^{\text {plast }}\right)\right]$

\subsection{Integração no tempo pelo método das diferenças centrais}

Da equação do movimento (2.34) no instante $t_{n}$ aceleração e velocidade podem ser escritas respectivamente como [ANSYS/LS-DYNA User's Guide. (1998)]:

$$
\begin{aligned}
& \{\ddot{u}\}=\frac{1}{(\Delta t)^{2}}\left\{u_{n+1}-2 u_{n}+u_{n-1}\right\} \\
& \{\dot{u}\}=\frac{1}{2 \Delta t}\left\{u_{n+1}-u_{n-1}\right\}
\end{aligned}
$$


Onde:

$\Delta t=$ incremento de tempo ou intervalo dividido em instante próximo $\left(u_{n+1}\right)$, atual $\left(u_{n}\right)$ e anterior $\left(u_{n^{-1}}\right)$. Substituindo (2.41) e (2.42) em (2.33a) temos:

$$
[M]\left\{\frac{u_{n+1}-2 u_{n}+u_{n-1}}{(\Delta t)^{2}}\right\}+[C]\left\{\frac{u_{n+1}-u_{n-1}}{2 \Delta t}\right\}+[K]\{u\}=\left\{F^{a}\right\}
$$

Rearranjando fica:

$$
\left[[M]+\frac{\Delta t}{2}[C]\right] u_{n+1}=\left\{\left(\Delta t^{2}\right)\left(-[K]\left\{u_{n}\right\}+[F]\right)+2[M]\left\{u_{n}\right\}-\left([M]-\frac{\Delta t}{2}[C]\right) u_{n-1}\right\}
$$

Portanto o instante próximo $\left(u_{n+1}\right)$ no lado esquerdo da equação (2.39) é a incógnita a ser obtida, os demais termos do lado direito são todos conhecidos.

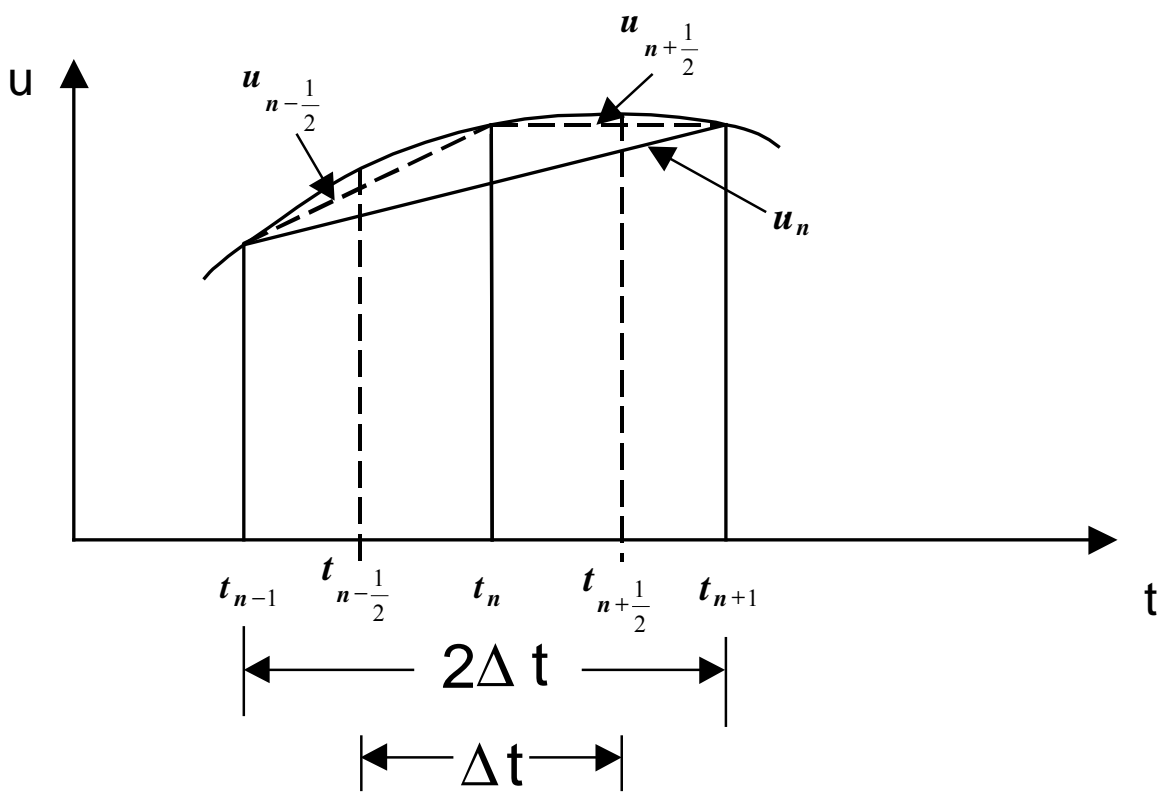

FIGURA 2.5: método das diferenças centrais utilizado pelo ANSYS/LS-DYNA [ANSYS/LS-DYNA User's Guide. (1998)] 
Em outras palavras o deslocamento no instante $t_{n}+\Delta t$ e dado explicitamente de acordo com os deslocamentos nos instantes $t_{n}$ e $t_{n}-\Delta t$.

Se a matriz de massa [M] e de amortecimento [C] são diagonais, a inversão destas torna-se uma solução trivial para a equação (2.39).

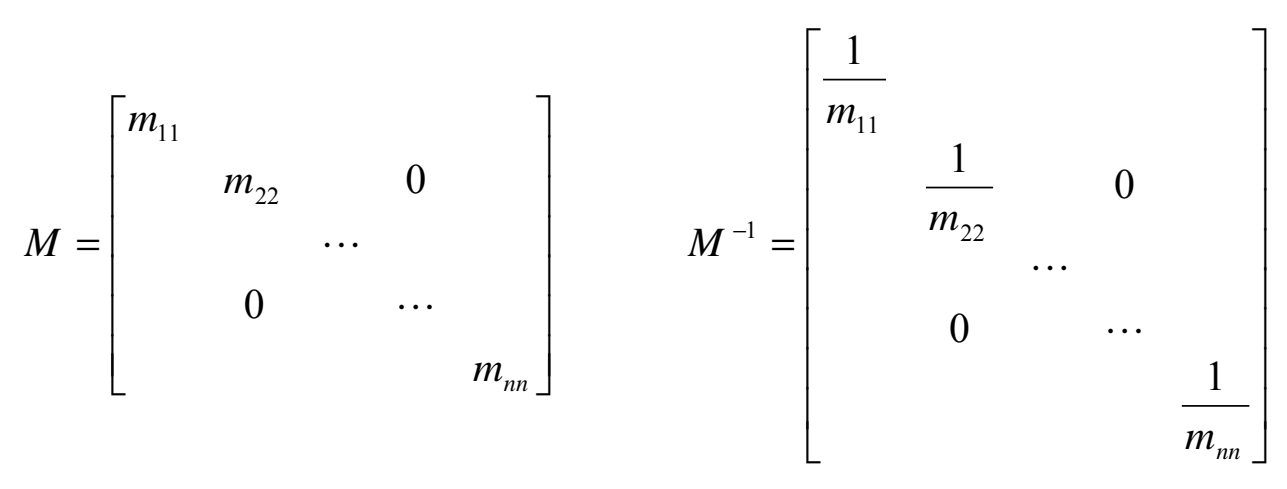

Temos então para tensão e deformação plana as seguintes equações:

$$
\begin{gathered}
\left(u_{x i}\right)_{n+1}=\left(m_{i i}+\frac{\Delta t}{2} c_{i i}\right)^{-1}\left[\left\{\Delta t^{2}\left(F_{x i}\right)_{n}\right\}-\left\{\Delta t^{2}\left(K_{x i}\right)_{n}-2 m_{i i}\right\}\left(u_{x i}\right)_{n}-\left(m_{i i}-\frac{\Delta t}{2} c_{i i}\right)\left(u_{x i}\right)_{n-1}\right] \\
\left(u_{y i}\right)_{n+1}=\left(m_{i i}+\frac{\Delta t}{2} c_{i i}\right)^{-1}\left[\left\{\Delta t^{2}\left(F_{y i}\right)_{n}\right\}-\left\{\Delta t^{2}\left(K_{y i}\right)_{n}-2 m_{i i}\right\}\left(u_{y i}\right)_{n}-\left(m_{i i}-\frac{\Delta t}{2} c_{i i}\right)\left(u_{y i}\right)_{n-1}\right]
\end{gathered}
$$

Onde:

Para o nó $i, u_{x i}$ e $u_{y i}$ são os componentes de deslocamentos $u$ nas direções $x$ e $y$;

$F_{x i}$ e $F_{y i}$ são as componentes das forças nodais aplicadas nas direções $x$ e $y$;

$K_{x i}$ e $K_{y i}$ são as forças nodais de resistência interna nas direções $x$ e $y$;

$m_{i i}$ e $c_{i i}$ são os termos diagonais da matriz de massa e amortecimento respectivamente.

\subsubsection{Algoritmo de início}

Como vimos, as equações governantes de equilíbrio no instante $t+\Delta t$ dependem de $\mathrm{t}$ e $t-\Delta t$. Um algoritmo inicial é necessário, e das condições iniciais o valor $u(0-\Delta t)$ pode ser obtido. De (2.37) temos a seguinte condição: 


$$
\begin{aligned}
& \dot{u}(0)=\frac{u(0+\Delta t)-u(0-\Delta t)}{2 \Delta t} \\
& \text { ou } \\
& u(0-\Delta t)=-2 \Delta t \dot{u}(0)+u(0+\Delta t)
\end{aligned}
$$

Se esta aproximação é substituída dentro de (2.40), podemos escrever a seguinte expressão:

$$
\left(u_{x i}\right)_{1}=\left(m_{i i}+\frac{\Delta t}{2} c_{i i}\right)^{-1}\left[\begin{array}{l}
(\Delta t)^{2}\left\{-\left(K_{x i}\right)_{0}+\left(F_{x i}\right)_{0}\right\}+2 m_{i i}\left(u_{x i}\right)_{0} \\
-\left(m_{i i}-\frac{\Delta t}{2} c_{i i}\right)\left\{-2 \Delta t\left(u_{x i}\right)_{0}+\left(u_{x i}\right)_{1}\right\}
\end{array}\right]
$$

\subsection{Integração implícita no tempo (algoritmo dinâmico implícito)}

A equação (2.39) tem a forma: $[\bar{K}]\{x\}_{n+1}=\{\bar{F}\}_{t}$

com:

$[\bar{K}]=\frac{1}{\Delta t^{2}}[M]+\frac{1}{2 \Delta t}[C]$

$\mathrm{e}$

$$
\{\bar{F}\}_{t}=\{F(t)\}_{t}-\left[[K(x)]-\frac{2}{\Delta t^{2}}[M]\right]\{x\}_{t}-\left[\frac{1}{\Delta t^{2}}[M]-\frac{1}{2 \Delta t}[C]\right]\{x\}_{n-1}
$$

Onde $[\bar{K}]$ é uma matriz de rigidez efetiva e $[\bar{F}]$ é um vetor de carga efetiva.

Se usarmos matrizes de massa e amortecimento consistentes (isto é, densamente povoadas de números, ou ainda, não-diagonais), então a equação acima caracteriza um conjunto de equações acopladas. então a equação acima caracteriza um conjunto de equações acopladas. Isto leva a um algoritmo implícito, desde que um conjunto de equações algébricas simultâneas tem que ser resolvido a cada passo (step). Ou seja porque as equações estão acopladas é preciso inverter $[\bar{K}]$ em cada passo. 
Programas de elementos finitos que utilizam este tipo de integração, tais como o ANSYS utilizam a equação do movimento (2.33a) para solução de problemas dinâmicos lineares e não lineares através de análise dinâmica implícita..

Particularmente o ANSYS usa o método (alternativo) de integração direta de Newmark para solucionar problemas. Usando expansão de diferenças finitas no intervalo $\Delta \mathrm{t}$, no qual é assumido que:

$$
\begin{aligned}
& \left\{\dot{u}_{n+1}\right\}=\left\{\dot{u}_{n}\right\}+\left[(1-\delta)\left\{\ddot{u}_{n}\right\}+\delta\left\{\ddot{u}_{n+1}\right\}\right] \Delta t \\
& \left\{u_{n+1}\right\}=\left\{u_{n}\right\}+\left\{\dot{u}_{n}\right\} \Delta t+\left[\left(\frac{1}{2}-\alpha\right)\left\{\ddot{u}_{n}\right\}+\delta\left\{\ddot{u}_{n+1}\right\}\right] \Delta t
\end{aligned}
$$

Onde: $\alpha, \delta$ são parâmetros de integração de Newmark, $\Delta t=\mathrm{t}_{\mathrm{n}+1}-\mathrm{t}_{\mathrm{n}},\left\{u_{n}\right\}_{\text {vetor }}$ nodal de deslocamento no instante $\mathrm{t}_{\mathrm{n}},\left\{\dot{u}_{n}\right\}$ vetor nodal de velocidade no instante $\mathrm{t}_{\mathrm{n}}$, $\left\{\ddot{u}_{n}\right\}$ vetor nodal de aceleração no instante $\mathrm{t}_{\mathrm{n}},\left\{u_{n+1}\right\}$ vetor nodal de deslocamento no instante $\mathrm{t}_{\mathrm{n}+1},\left\{\dot{u}_{n+1}\right\}$ vetor nodal de velocidade no instante $\mathrm{t}_{\mathrm{n}+1},\left\{\ddot{u}_{n+1}\right\}$ vetor nodal de aceleração no instante $t_{n+1}$.

Como o objetivo é achar o deslocamento $\left\{u_{n+1}\right\}$, a equação (2.33a) no instante $t_{n+1}$ fica:

$$
[M]\left\{\ddot{u}_{n+1}\right\}+[C]\left\{\dot{u}_{n+1}\right\}+[K]\left\{u_{n+1}\right\}=\left\{F^{a}\right\}
$$

A solução para o deslocamento no instante $t_{n+1}$ é obtida rearranjando as equações (2.44) e (2.45):

$$
\begin{aligned}
& \left\{\ddot{u}_{n+1}\right\}=a_{0}\left(\left\{u_{n+1}\right\}-\left\{u_{n}\right\}\right)-a_{2}\left\{\dot{u}_{n}\right\}-a_{3}\left\{\ddot{u}_{n}\right\} \\
& \left\{\dot{u}_{n+1}\right\}=\left\{\dot{u}_{n}\right\}+a_{6}\left\{\ddot{u}_{n}\right\}-a_{7}\left\{\ddot{u}_{n+1}\right\}
\end{aligned}
$$

Onde:

$$
a_{0}=\frac{1}{\alpha \Delta t^{2}} ; \quad a_{1}=\frac{\delta}{\alpha \Delta t^{2}} ; \quad a_{2}=\frac{1}{\alpha \Delta t} ; \quad a_{3}=\frac{1}{2 \alpha}-1 ;
$$




$$
a_{4}=\frac{\delta}{\alpha}-1 ; \quad a_{5}=\frac{\Delta t^{2}}{2}\left(\frac{\delta}{\alpha}-2\right) ; \quad a_{6}=\Delta t(1-\delta) ; \quad a_{7}=\delta \Delta t
$$

$\left\{\ddot{u}_{n+1}\right\}$ da equação (2.47) pode ser substituído dentro da equação (2.48) e $\left\{\dot{u}_{n+1}\right\}$ pode ser expressado apenas em termos dos desconhecidos $\left\{u_{n+1}\right\}$. As equações resultantes são combinadas com a equação (2.46), que fica:

$$
\begin{aligned}
& \left(a_{0}[M]+a_{1}[C]+[K]\right)\left\{u_{n+1}\right\}=\left\{F^{a}\right\}+[M]\left(a_{0}\left\{u_{n}\right\}+a_{2}\left\{\dot{u}_{n}\right\}+a_{3}\left\{\ddot{u}_{n}\right\}\right)+ \\
& {[C]\left(a_{1}\left\{u_{n}\right\}+a_{4}\left\{\dot{u}_{n}\right\}+a_{5}\left\{\ddot{u}_{n}\right\}\right)}
\end{aligned}
$$

Uma vez que é obtida a solução para $\left\{u_{n+1}\right\}$, as velocidades e acelerações são atualizadas como descrito nas equações (2.47) e (2.48).

O método de Newmark é incondicionalmente estável para:

$$
\alpha \geq \frac{1}{4}\left(\frac{1}{2}+\delta\right)^{2}, \quad \delta \geq \frac{1}{2}, \quad \frac{1}{2}+\delta+\alpha>0
$$

\subsubsection{Vantagens do algoritmo dinâmico implícito}

- É incondicionalmente convergente: a convergência é garantida independente do tamanho do passo de tempo (time step);

- É a solução natural e completa do problema: não faz simplificações (matrizes não são diagonais) e a solução tem embutida todo o fenômeno

\subsubsection{Desvantagens do algoritmo dinâmico implícito}

- Utiliza mais recursos computacionais : mais potência computacional, mais memória.

- É mais lento

- É mais sensível que o explícito a instabilidade quando em situações especiais a matriz de rigidez tende à singularidade (instabilidade elástica) 


\section{$\underline{\text { Resumo da seqüência de solução para o algoritmo implícito }}$}

- Cálculos Iniciais

1. Forme as matrizes elementares $[M]^{(e)},[C]^{(e)}, e[K]^{(e)}$

2. Inicialize $\{x\}_{t}$ e $\{\dot{x}\}_{t}$ no tempo $\mathrm{t}=0$.

3. Selecione $\Delta \mathrm{t}$.

4. Monte a matriz de rigidez efetiva $[\bar{K}]$

5. Modifique $[\bar{K}]$ para as condições de contorno

6. Fatore $[\bar{K}]$.

- A cada time step

1. Forme o vetor de carga elementar efetivo $\{\bar{F}\}_{n+1}^{(e)}$

2. Monte o vetor de carga efetivo $\{\bar{F}\}_{n+1}$

3. Modifique o vetor efetivo para as condições de contorno

4. Resolva para os deslocamentos $\{x\}_{n+1}$ no tempo $\mathrm{n}+\Delta \mathrm{t}$

5. Resolva para velocidades e acelerações $\{\dot{x}\}_{n+1}$ e $\{\ddot{x}\}_{n+1}$

\subsection{Integração explícita no tempo (algoritmo dinâmico explícito)}

Se usarmos matrizes de massa e amortecimento agrupadas, (ou seja: diagonais), por exemplo usando parâmetros agrupados, $[\bar{K}]$ se torna uma matriz diagonal e as equações se desacoplam, resultando num algoritmo explícito. A forma do algoritmo explícito é:

$$
[\bar{K}]\{x\}_{n+1}=\{\bar{F}\}_{t} \text { (explícito) }
$$

com:

$$
[\bar{K}]=\frac{1}{\Delta t^{2}}[M]_{\text {diag }}+\frac{1}{2 \Delta t}[\mathrm{C}]_{\text {diag }}
$$

$\mathrm{e}$

$$
\{\bar{F}\}_{t}=\{F(t)\}_{t}-\left[[K(x)]-\frac{2}{\Delta t^{2}}[M]_{\text {diag }}\right]\{x\}_{t}-\left[\frac{1}{\Delta t^{2}}[M]_{\text {diag }}-\frac{1}{2 \Delta t}[C]_{\text {diag }}\right]\{x\}_{n-1}
$$

Obs.: $[M]_{\text {diag }},[C]_{\text {diag }},[K]_{\text {diag }}$ são matrizes diagonais. 
2.7.1 Vantagens do algoritmo dinâmico explícito

- Algoritmo robusto e mais simples de programar;

- É mais rápido que o algoritmo estático implícito

- Requer menos memória que o algoritmo estático implícito

- Pode ser paralelizado

- Têm bom desempenho para instabilidade da rigidez e portanto prevê bem o surgimento de rugas

2.7.2 Desvantagens do algoritmo dinâmico explícito

- Algoritmo é condicionalmente convergente

- Para melhorar a convergencia, passos extremamente pequenos são freqüentemente necessários.

\subsubsection{Cálculo de time step}

O ANSYS/LS-DYNA checa todos os elementos para calcular o tamanho do time step. O time step pode ser estimado usando a seguinte fórmula:

$$
\begin{gathered}
\Delta t \leq \Delta t_{\text {critico }} \\
\Delta t_{\text {critico }}=\min \left\{\frac{\mathrm{L}}{\mathrm{c}} ; \frac{2}{\omega_{\mathrm{M}}}\right\}
\end{gathered}
$$

Onde:

$\mathrm{L}=$ largura do menor elemento

$\mathrm{c}=$ velocidade do som no material

$\mathrm{E}=$ módulo de elasticidade do material

$\rho=$ densidade do material

$v=$ coeficiente de Poisson

$\omega_{\mathrm{M}}=$ maior freqüência natural a ser significante para o problema (geralmente é $<$ $1000 \mathrm{~Hz}$, e portanto $\left.\omega_{\mathrm{M}}=6000 \mathrm{rad} / \mathrm{s}\right)$;

- Para elementos casca (shell):

$$
\mathrm{c}=\sqrt{\frac{\mathrm{E}}{\rho\left(1-v^{2}\right)}}
$$


- Para elementos sólidos:

Hexaédro 8 nós: $\mathrm{L}=\frac{\mathrm{v} \text { (volume) }}{\mathrm{A} \text { (maior área) }}$

Tetraedro 4 nós: $\mathrm{L}=$ menor altura

$$
c=\sqrt{\frac{\mathrm{E}(1-v)}{(1+v)(1-2 v) \rho}}
$$

- Para elementos do tipo viga:

$\mathrm{L}=$ comprimento do elemento

$$
\mathrm{c}=\sqrt{\frac{\mathrm{E}}{\rho}}
$$

$\underline{\text { Resumo da seqüência de solução para o algoritmo explícito }}$

- Cálculos Iniciais

1. Forme as matrizes elementares $[M]^{(e)},[C]^{(e)}, e[K]^{(e)}$

2. Inicialize $\{x\}_{t}$ e $\{\dot{x}\}_{t}$ no tempo $\mathrm{t}=0$.

3. Selecione $\Delta \mathrm{t}<\Delta \mathrm{t}_{\text {critico }}$.

4. Monte a matriz de rigidez efetiva $[\bar{K}]$

5. Modifique $[\bar{K}]$ para as condições de contorno

6. Calcule $\{x\}_{-\Delta t}$.

- A cada instante passo

1. Forme o vetor de carga elementar efetivo $\{\bar{F}\}_{n+1}^{(e)}$

2. Monte o vetor de carga efetiva $\{\bar{F}\}_{n+1}$

3. Modifique o vetor efetivo para as condições de contorno

4. Resolva para os deslocamentos $\{x\}_{n+1}$ no tempo $\mathrm{n}+\Delta \mathrm{t}$

5. Resolva para velocidades e acelerações $\{\dot{x}\}_{n+1}$ e $\{\ddot{x}\}_{n+1}$ no tempo $\mathrm{t}$ 


\section{CONTATO}

Colisão, impacto, assim como processos de conformação de metais são eventos altamente não-lineares. Como citado no capítulo anterior, a não-linearidade nestes fenômenos acontece não somente por não-linearidade geométrica ou de material, mas também por condições de contorno. O contato que se produz entre sólidos nestas situações resulta num comportamento não-linear particularmente difícil de analisar. A faixa de problemas de contato envolve desde o contato sem atrito em pequenos deslocamentos até o contato com atrito em condições de grandes deformações inelásticas.

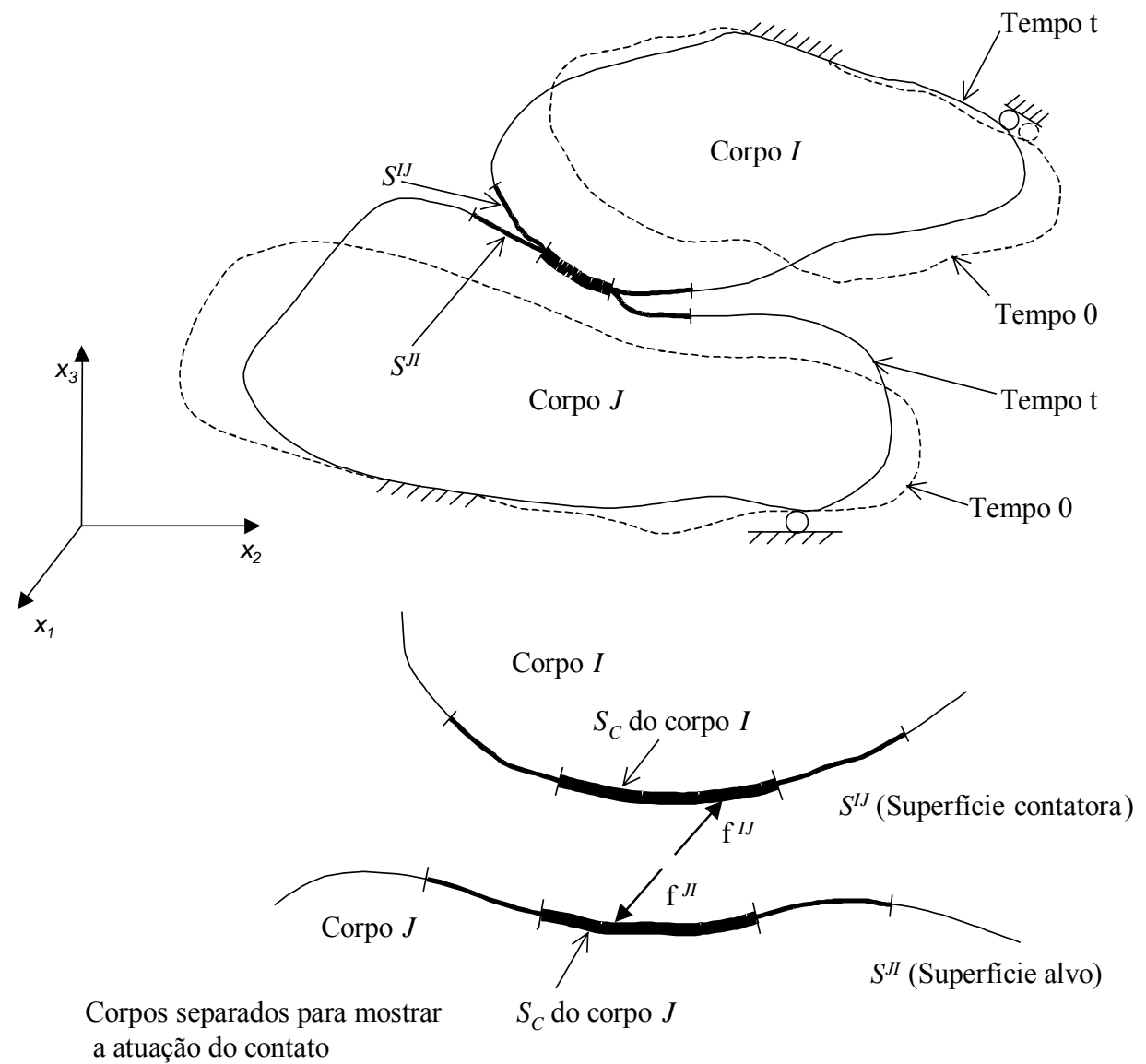

FIGURA 3.1: Corpos em contato no instante t, BATHE (1996). 
Considere-se $N$ corpos que estão em contato no tempo $t$. Seja $S_{C}$ a área completa de contato para cada corpo $L, L=1, \ldots, N$. O princípio dos trabalhos virtuais para $N$ corpos, no tempo $t$ fornece:

$$
\sum_{L=1}^{N}\left\{\int_{V} \tau_{i j} \delta_{t} e_{i j} d V\right\}=\sum_{L=1}^{N}\left\{\int_{V} \delta u_{i} f_{i}^{B} d V+\int_{S_{f}} \delta u_{i}^{s} f_{i}^{S} d S\right\}+\sum_{L=1}^{N} \int_{S_{C}} \delta u_{i}^{C} f_{i}^{C} d S
$$

onde os termos entre chaves correspondem aos termos usuais e o último somatório corresponde à contribuição das forças de contato. $\mathrm{O}$ efeito das forças de contato é incluído como uma contribuição às forças de superfície aplicadas externamente.

Seja $f^{I J}$ o vetor contendo as forças devido ao contato no corpo $I$ causado pelo corpo $J$, e $f^{I J}=-f^{J I}$, conforme notação utilizada na figura 3.1. O trabalho virtual devido às forças de contato pode ser escrito como:

$$
\int_{S^{I J}} \delta u_{i}^{I} f_{i}^{I J} d S^{I J}+\int_{S^{J I}} \delta u_{i}^{J} f_{i}^{J I} d S^{J I}=\int_{S^{I J}} \delta u_{i}^{I J} d S^{I J}
$$

onde $\delta u_{i}^{I}$ e $\delta u_{i}^{J}$ são os componentes de deslocamento virtual sobre as superfícies de contato dos corpos $I$ e $J$ respectivamente, e

$$
\delta u_{i}^{I J}=\delta u_{i}^{I}-\delta u_{i}^{J}
$$

Pode-se chamar $S^{I J}$ e $S^{J I}$ de par de superfícies em contato e estas superfícies não têm necessariamente o mesmo tamanho. Contudo, a efetiva área de contato em um tempo $t$ para os corpos $I$ e $J$ é $S_{C}$, e em cada caso esta área é parte de $S^{I J}$ e $S^{J I}$, respectivamente chamadas de "superfície contatora" e "superfície alvo". O lado direito da equação (3.2) pode ser interpretado como o trabalho virtual que as forças de contato produzem sobre o deslocamento virtual relativo do par de superfícies em contato.

O caráter não-linear das condições de contato superficiais permite que apenas alguns problemas sejam resolvidos analiticamente, por isto é freqüentemente usual a solução numérica de problemas de contato. Os aspectos não-lineares, devidos às condições de contorno, têm um papel muito importante na simulação computacional deste tipo de processo. 
A análise de problemas que envolvem contato entre sólidos é dividida em duas etapas [AGELET DE SARACIBAR e OÑATE (1991)]:

- Busca e localização dos contatos produzidos pelo impacto.

- Introdução de formulação de contato que assegure que não aconteçam penetrações entre os sólidos que interagem.

O contato pode ser considerado como contato generalizado, onde ocorre interação entre sólidos deformáveis, ou contato unilateral, onde o contato ocorre entre sólidos deformáveis e sólidos rígidos.

Do ponto de vista computacional, segundo AGELET DE SARACIBAR e OÑATE (1991), um dos aspectos mais importantes é a otimização dos algoritmos e procedimentos de busca e deteç̧ão dos contatos, para que se possa introduzir a formulação do problema de contato no contexto geral de análise por Elementos Finitos, de modo a verificar as condições de compatibilidade cinemática impostas pelas restrições de contato, assegurando-se que não haja penetrações entre os sólidos que interagem.

Existem dois métodos bem estabelecidos na literatura e nos programas comerciais de Elementos Finitos para considerar o problema de contato entre sólidos [AGELET DE SARACIBAR e OÑATE (1991)]. São eles: o método dos multiplicadores de Lagrange e o método de penalização.

O método dos multiplicadores de Lagrange obriga que as restrições de contato se verifiquem de forma exata, através dos multiplicadores de Lagrange. Este método tem como inconvenientes o aumento do número de incógnitas e o aparecimento de zeros na diagonal principal da matriz de rigidez associada aos multiplicadores de Lagrange, o que pode trazer dificuldades num processo de solução direta.

Exemplo de aplicação do método de multiplicadores de Lagrange:

- Quando se quer estacionar um funcional com restrições adicionais impostas.

Seja o funcional: $\Pi=2 x^{2}-x y+18 x+6 y$ 
Deve ser estacionado: $\frac{\partial \Pi}{\partial x}=\frac{\partial \Pi}{\partial y}=0$, com restrição inicial: $x-y=0$

A solução obvia é substituir $\mathbf{y}$ por $\mathbf{x}$ no funcional

$$
\begin{aligned}
& \Pi=2 \mathrm{x}^{2}-\mathrm{x}^{2}+18 \mathrm{x}+6 \mathrm{x} \Rightarrow \Pi=\mathrm{x}^{2}+24 \mathrm{x} \\
& \frac{\partial \Pi}{\partial \mathrm{x}}=0 \Rightarrow 2 \mathrm{x}+24=0 \quad \longrightarrow \mathrm{x}=\mathrm{y}=-12
\end{aligned}
$$

\section{Solução por multiplicadores de Lagrange}

Aumenta-se o tamanho do problema adicionando-se incógnitas $\boldsymbol{\lambda}$ (multiplicadores).

Define-se um novo funcional aumentado:

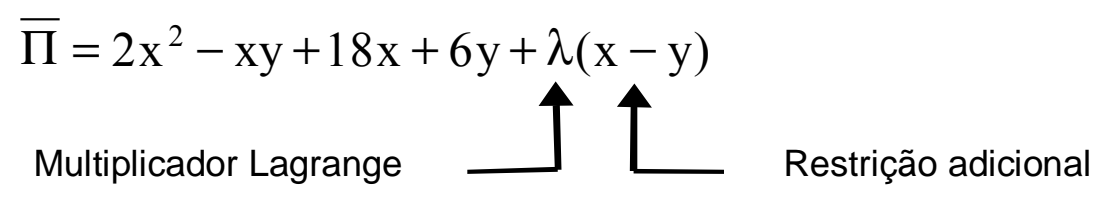

$$
\begin{aligned}
& \text { Agora para estacionar : } \quad \frac{\partial \bar{\Pi}}{\partial \mathrm{x}}=0 \quad \frac{\partial \bar{\Pi}}{\partial \mathrm{y}}=0 \quad \text { e } \frac{\partial \bar{\Pi}}{\partial \lambda}=0 \\
& \begin{array}{|lcl|}
\frac{\partial \bar{\Pi}}{\partial x}=0 \Rightarrow 4 x-y+18+\lambda=0 & \text { SOLUÇÃO } \\
\frac{\partial \bar{\Pi}}{\partial y}=0 \Rightarrow-x+0+6-\lambda=0 & 4 x-y+\lambda=-18 & x=y=-12 \\
\frac{\partial \bar{\Pi}}{\partial \lambda}=0 \Rightarrow x-y+0-0=0 & -x+0 y-\lambda=-6 & \text { e } \lambda=18 \\
\end{array}
\end{aligned}
$$

O método de penalização impõe que as condições de contato se verifiquem de forma aproximada, por meio do fator de penalização. Este método não conduz a um aumento do número de incógnitas, mas leva a um mau condicionamento da matriz de rigidez. Do ponto de vista prático, o problema fundamental deste método está na escolha de um valor apropriado para tal fator. Pode-se dizer que este valor depende da precisão do computador, número total de incógnitas do sistema de equações e da rigidez do menor dos elementos envolvidos no contato. 
Características do método da penalização

-As restrições de contato são impostas de modo simples, obtendo-se uma matriz de rigidez tangencial positiva definida

- A matriz de rigidez pode obter um mau condicionamento, através de valores altos do número de condição, à medida que aumenta o fator de penalização.

- Por outro lado, um fator de penalização muito pequeno pode levar a penetrações inaceitáveis de um sólido em outro.

- Um problema relevante passa a ser a escolha adequada do fator de penalização

- Fatores influentes: precisão do computador, número total de incógnitas do sistema de equações e das menores rigidezas dos elementos envolvidos no contato.

- Este método não conduz o problema para um maior número de incógnitas.

Considerando-se novamente o problema de estacionar o funcional $\Pi$ com um conjunto de equações restritivas $\mathbf{C}(\mathbf{u})=\mathbf{0}$ no domínio $\Omega$, nota-se que o produto:

$$
\mathrm{C}^{\mathrm{T}} \mathrm{C}=\mathrm{C}_{1}{ }^{2}+\mathrm{C}_{2}{ }^{2}+\ldots \quad \text { onde: } \quad \mathrm{C}^{\mathrm{T}}=\left[\mathrm{C}_{1}, \mathrm{C}_{2}, \ldots\right]
$$

será sempre um valor positivo ou nulo. Para que seja nulo, as restrições devem ser satisfeitas e a variação $\delta\left(\mathrm{C}^{\mathrm{T}} \mathrm{C}\right)=0$ se aplica quando o produto atinge um valor mínimo.

Pode-se então escrever o funcional: $\overline{\bar{\Pi}}=\Pi+\alpha \int \mathrm{C}^{\mathrm{T}}(\mathrm{u}) \cdot \mathrm{C}(\mathrm{u}) \mathrm{d} \Omega$, em que $\alpha$ é um fator de penalização, requerendo-se estacionar este funcional para obter-se a solução do problema submetido às restrições impostas.

Se $\Pi$ já é um mínimo do conjunto solução, então $\boldsymbol{\alpha}$ deve ser um número positivo.

A solução obtida pelo estacionamento do funcional $\overline{\bar{\Pi}}$ irá satisfazer as restrições de modo aproximado. Valores elevados de $\alpha$ contribuem para melhores soluções para as restrições.

Exemplo: toma-se como referência o caso anterior.

$$
\overline{\bar{\Pi}}=2 x^{2}-x y+18 x+6 y+\alpha(x-y)^{2}
$$


fazendo-se $\frac{\partial \overline{\bar{\Pi}}}{\partial \mathrm{x}}=0$ e $\frac{\partial \overline{\bar{\Pi}}}{\partial \mathrm{y}}=0$ obtém-se um sistema de 2 equações e conforme $\alpha \rightarrow \infty$ chega-se a solução correta:

\begin{tabular}{|l|l|r|r|r|r|r|}
\hline \multicolumn{1}{|l|}{$\alpha$} & 1 & 2 & 6 & 10 & 100 \\
\hline $\mathrm{X}$ & lamda1 & $-12,00$ & $-12,00$ & $-12,00$ & $-12,00$ & $-12,00$ \\
\hline $\mathrm{y}$ & lamda2 & $-13,50$ & $-13,00$ & $-12,43$ & $-12,78$ & $-12,03$ \\
\hline
\end{tabular}

\subsection{Geometria de contato}

Neste tópico se apresenta o algoritmo que permite determinar se foi ou não produzida penetração de um sólido em outro (figura 3.2).

Será apresentada uma formulação para problemas de contato em 3D utilizando segmentos triangulares de 3 nós. A extensão a outro tipo de segmento ou a particularização a problemas de contato em 2D pode ser realizada de forma simples.

A posição relativa do nó $\mathrm{s}$ com respeito ao segmento da superfície principal considerada, pode ser colocada como:

$$
\mathrm{x}_{\mathrm{s}}=\mathrm{N}_{\mathrm{i}}(\xi, \eta)\left(\mathrm{x}_{\mathrm{i}}-\mathrm{a} \zeta \varsigma_{\mathrm{i}}\right)
$$

Onde:

- $\mathbf{N}_{\mathbf{i}}(\xi, \eta)$ é a função de forma do nó $\mathbf{i}$ do segmento em função de coordenadas naturais $\xi$ e $\eta$.

- $\mathbf{x}_{\mathbf{i}}$ representa as coordenadas do nó $\mathbf{i}$ do segmento da superfície principal considerada e $\eta_{\mathbf{i}}$ é a normal no nó i do segmento, a é uma espessura fictícia nodal na direção da normal interior e $\zeta$ é a coordenada natural na direção da espessura.

A equação não-linear (3.4) pode ser resolvida de forma local mediante o método de Newton-Raphson, sendo o resíduo:

$$
G(\xi, \eta, \zeta)=N_{i}(\xi, \eta)\left(x_{i}-a \zeta \zeta_{i}\right)-x_{s}
$$


A solução da equação (3.5) dá a posição relativa do nó $\mathrm{s}$ ou coordenadas naturais $(\xi, \eta, \zeta)$ do elemento fictício construído a partir do segmento. As condições de penetração do nó s com respeito ao segmento considerado podem agora ser expressas em função das coordenadas naturais $(\xi, \eta, \zeta)$ como:

$$
\left\{\begin{array}{c}
0 \leq \xi \leq 1 \\
0 \leq \eta \leq 1 \\
0 \leq 1-\xi-\eta \leq 1 \\
0 \leq \varsigma
\end{array}\right.
$$

As coordenadas do ponto $\mathbf{m}$ obtido como projeção do nó $\mathbf{s}$ sobre o segmento segundo a normal no ponto, são:

$$
\mathrm{x}_{\mathrm{m}}=\mathrm{N}_{\mathrm{i}}(\xi, \eta) \mathrm{x}_{\mathrm{i}}
$$

A distância do nó ao segmento de contato pode ser expressa como:

$$
g_{s}=-a_{\zeta \varsigma_{i}}(\xi, \eta) n_{i}
$$

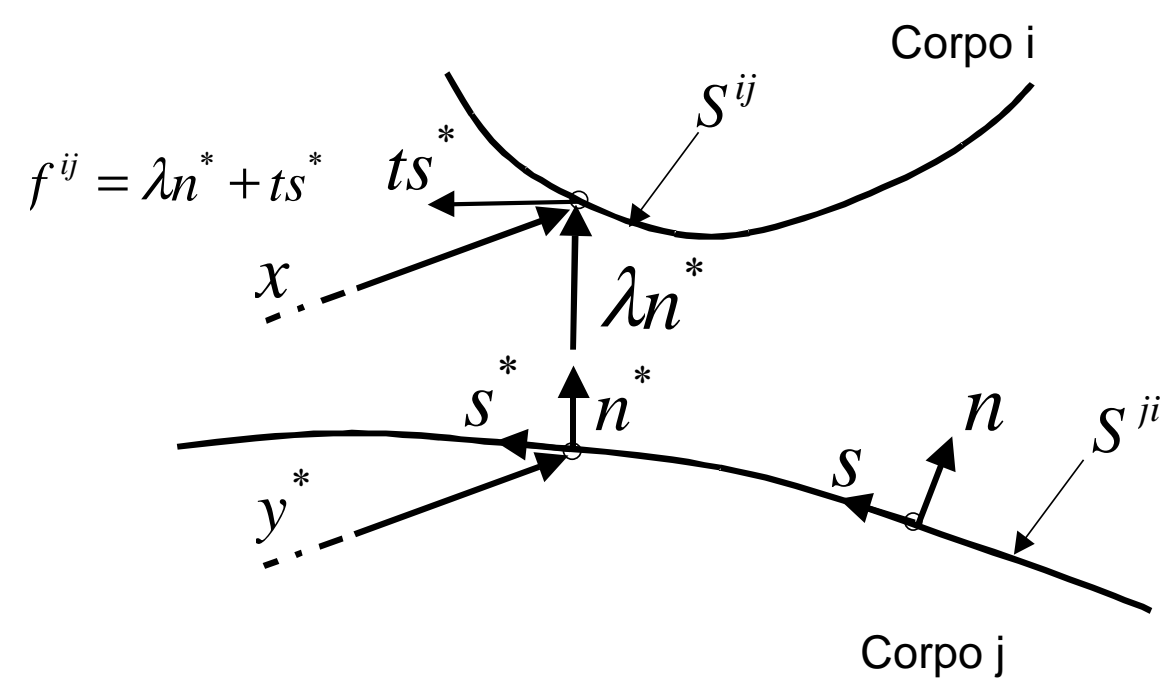

FIGURA 3.2: Definições usadas em análise de contato, BATHE (1996).

Definimos $\lambda$ e $t$ como as componentes normais e tangenciais das forças superficiais. 
A distância g também pode ser definida como:

$$
\mathrm{g}(\mathrm{x}, \mathrm{t})=\left(\mathrm{x}-\mathrm{y}^{*}\right)^{\mathrm{T}} \mathrm{n}^{*}
$$

onde: $\mathrm{n}^{*}$ é o vetor normal unitário que usamos em $\mathrm{y}^{*}(\mathrm{x}, \mathrm{t})$ e $\mathrm{n}^{*}, \mathrm{~s}^{*}$ correspondem ao ponto $\mathrm{x}$. A função $\mathrm{g}$ é a função de distância para o par de superfícies em contato.

Com estas definições, a condição para o contato normal pode agora ser escrita como:

$$
\mathrm{g} \geq 0 ; \quad \lambda \geq 0 ; \quad \mathrm{g} \lambda=0,
$$

onde a última equação expressa o fato de que se $\mathrm{g}>0$, então nós devemos ter $\lambda=0$, e vice versa.

\subsection{Contatos no ANSYS/LS-DYNA}

Com o objetivo de descrever a interação entre corpos durante impactos dinâmicos, uma grande quantidade de opções são disponíveis pelo ANSYS/LSDYNA (tabela 3.1).

TABELA 3.1 :Tipos de contato e opções (em destaque recomendados pelo programa)

\begin{tabular}{|l|l|l|l||}
\hline & Superficie simples & Nós x superfície & Superfície x superfície \\
\hline Geral & SS & NTS & STS, OSTS \\
\hline Automático & ASSC & ANTS & ASTS \\
\hline Rígido & & RNTR & ROTR \\
\hline Tied & & TDNS & TDSS \\
\hline Tiebreak & & TNTS & TSTS \\
\hline Eroding & ESS & ENTS & ESTS \\
\hline Drawbead & & DRAWBEAD & \\
\hline \hline
\end{tabular}




\subsubsection{Tipos de contato do ANSYS/LS-DYNA}

- Contato de superfície simples: este tipo de contato é estabelecido quando a superfície de um corpo entra em contato consigo mesma ou com a superfície de outro corpo. Este tipo de contato é o mais simples de ser definido já que não é necessário definir superfície alvo e superfície contatora. A maioria das simulações de impacto e colisão requerem que seja definido este tipo de contato.

- Contato de nós contra superfície: estabelecido quando um nó contator penetra uma superfície alvo. É um tipo de contato geralmente usado entre duas superfícies.

- Contato de superfície conta superfície: Estabelecido quando a superfície de um corpo penetra a superfície de um outro. É o tipo de contato mais geral e é comumente usado entre corpos com formas arbitrárias e que possuem áreas de contato relativamente grandes.

\subsubsection{Opções de contato do ANSYS/LS-DYNA}

Para cada um dos tipos de contato disponíveis no ANSYS/LS-DYNA, há várias opções que podem ser combinadas.

- Contato geral: esta opção utiliza o mais simples dos algoritmos de contato porém é utilizada numa ampla faixa de aplicações. A principal vantagem de sua utilização é ser um algoritmo rápido e robusto. Quando a superfície de contato é feita de elementos do tipo casca (shell) é necessário orientar a superfície de contato, definindo que lado da superfície é solido e qual é ar. Para elementos sólidos, a orientação é feita automaticamente.

- Contato automático: Junto com a família de contato geral, esta opção é a mais utilizada. Diferencia-se da opção anterior pela orientação automática da superfície de contato feita de elementos casca. 
- Contato eroding: este tipo de contato é necessário quando os elementos sólidos que formam uma ou ambas superfícies exteriores sofrem dano durante o contato. $\mathrm{O}$ contato permite continuar com os elementos internos remanescentes.

- Contato rígido: Esta opção é similar à opção de contato geral com a exceção de que o contato geral usa uma rigidez linear para resistir a penetração, enquanto que neste tipo de contato uma curva de força-deflexão deve ser definida. Utilizado para análise de multicorpos.

- Contato Tied: Cola os nós da superfície de contato à superfície alvo após o contato.

- Contato Tiebreak: Cola os nós da superfície de contato à superfície alvo apenas até que um critério de falha seja alcançado.

- Contato Drawbead: Contato usado tipicamente em processos de conformação de metais nos quais cuidado especial deve ser tomado para restringir o blank. Utilizado para projeto de prensa chapas.

O LS-DYNA utiliza dois diferentes algoritmos de busca de contatos para determinar qual superfície alvo esta sendo contatada por qual superfície contatora. Os algoritmos são:

- Trilha de Conectividade de Malha: este algoritmo de procura de contato usa nós compartilhados de segmentos elementares vizinhos para identificar possíveis fontes de contato. Este método é útil porque é muito rápido, mas tem a desvantagem de requerer que a malha seja contínua para o algoritmo de contato trabalhar corretamente. Este algoritmo é usado pelas opções de contato NTS, OSTS,TSTS, TNTS e TDNS (tabela 3.1).

- Método da Ordenação Cúbica: este algoritmo, usado para qualquer outra opção de contato além das anteriormente especificadas, divide a região da superfície alvo 
em cubos. Nós em contato podem contatar qualquer segmento da superfície alvo no mesmo cubo ou em cubos adjacentes. O método de ordenação cúbica é extremamente robusto, mas pode ficar um pouco mais lento que o método anterior se a superfície alvo contém um elevado número de elementos.

Após o contato ser localizado, o ANSYS/LS-DYNA utiliza o método de penalização para assegurar-se de que não aconteçam penetrações entre os sólidos que interagem. Sem uma rigidez de contato, os corpos passariam um através do outro. A relação de contato é gerada através de uma mola elástica que é colocada entre os dois corpos que colidem, onde a força de contato é igual ao produto da rigidez de contato $(k)$ e a penetração $(\delta)$. A quantidade de penetração $(\delta)$, ou incompatibilidade entre os dois corpos depende portanto da rigidez $\mathrm{k}$. Idealmente não deveria haver penetração entre corpos mas, isto implicaria em $\mathrm{k}=\infty$, o que leva a instabilidade numérica.

Escolha do fator penalidade para segmentos sobre elementos sólidos

$$
k=\frac{\text { fs. } \mathrm{A}^{2} \cdot \mathrm{K}}{\text { volume do elemento }}
$$

Escolha do fator penalidade para segmentos sobre elementos do tipo casca

$$
k=\frac{\text { fs.área.K}}{\text { min diagonal do elemento }}
$$

Onde: $\quad k=$ rigidez de contato

$\mathrm{A}=$ área do segmento de contato

$\mathrm{K}=$ compressão volumétrica (bulk modulus) do elemento contatado

$\mathrm{fs}=$ fator de penalidade 


\section{REVISÃO BIBLIOGRÁFICA SOBRE CAPACACIDADE DE ABSORVER IMPACTO (CRASHWORTHINESS)}

O termo crashworthiness foi utilizado pela primeira vez em 1950 e primeiramente foi associado à segurança de aeronaves (PALUSZNY, 1992). Este termo se refere à capacidade ou habilidade de um veículo ou componente de absorver energia resultante de uma colisão, mantendo o colapso sob controle, e proporcionar proteção ao(s) ocupante(s). Contudo, a capacidade de absorver impacto (CAI) não se aplica apenas a veículos. Existem outros tipos de estruturas projetadas para apresentar este tipo de comportamento, como por exemplo containers de armazenamento, que devido ao seu conteúdo, devem ser capazes de absorver impacto ao sofrerem algum impacto.

\subsection{CAI de veículos}

A CAI de veículos é regido por quatro conceitos básicos:

- Controle sobre níveis de tolerância das forças que são aplicadas ao ocupante;

- Providenciar formas de absorver energia de colisão mantendo ao mesmo tempo a segurança dentro do espaço de sobrevivência do ocupante(s);

- Manter o(s) ocupante(s) dentro do espaço de sobrevivência durante a colisão evitando ejeção do mesmo;

- Proteger o(s) ocupante(s) de riscos após a colisão.

Existem normas que regulamentam a CAI de veículos, navios e aeronaves. Nesta revisão bibliográfica deu-se ênfase em CAI de veículos, componentes e sistemas mecânicos. Foram encontradas normas estadounidenses, australianas, japonesas e 
da Comunidade Européia (tabela 4.1). Contudo não foram localizadas normas brasileiras que regulamentam este comportamento. As primeiras citadas foram as mais acessíveis e foram localizadas na Internet no site de: Federal Motor vehicle safety standards, FMVSS's, e são regulamentadas por The National Highway Traffic Safety Administration (NHTSA), uma agência ligada ao departamento de transportes dos Estados Unidos. A seguir, citamos brevemente algumas:

- Proteção a ocupantes de impactos interiores - FMVSS 201

Esta norma estabelece parâmetros de projeto para áreas específicas no interior do veículo com o objetivo de evitar lesões e/ou fatalidades decorrentes de segundas colisões do ocupante dentro do veículo.

- Deslocamento da coluna de direção - FMVSS 204

Esta norma especifica limites para o deslocamento da coluna de direção contra o motorista e visa reduzir a probabilidade de lesões no peito, pescoço ou cabeça como resultado de uma colisão.

- Travas de portas e retenção de componentes - FMVSS 206

Esta norma especifica caraterísticas para travas de portas laterais, trincos e dobradiças, etc., com o objetivo de minimizar a probabilidade de ejeção de ocupante(s) como resultado de uma colisão.

- Bancos - FMVSS 207

Devido a que o banco pode ter um importante papel na segurança de ocupantes(s) durante um colisão veicular, esta norma estabelece requisitos para a fixação, instalação e componentes dos mesmos.

- Montagem e fixação de cintos de segurança - FMVSS 210

Esta norma estabelece requisitos para a fixação e montagem de cintos de segurança de forma a assegurar uma localização apropriada para uma efetiva proteção do ocupante e reduzir o risco de sua falha. 
- Montagem de parabrisa - FMVSS 212

Esta norma estabelece requisitos para montagem de parabrisa no veículo com o objetivo de minimizar a probabilidade de que o ocupante seja ejetado através deste durante uma colisão frontal severa.

Existem normas que regulamentam testes de colisão de modelos físicos para avaliar CAI de veículos.

- Colisão frontal contra uma barreira rígida (figura 4.1) - FMVSS 208

Consiste em submeter toda a parte frontal do veículo a uma colisão contra uma parede rígida, conforme norma FMVSS 208 (Federal motor vehicle protection - 49 CFR part 571.208). Isto proporciona ao modelo uma desaceleração muito alta que permite avaliar efeitos sobre ocupantes e desempenho de cintos e air bags.

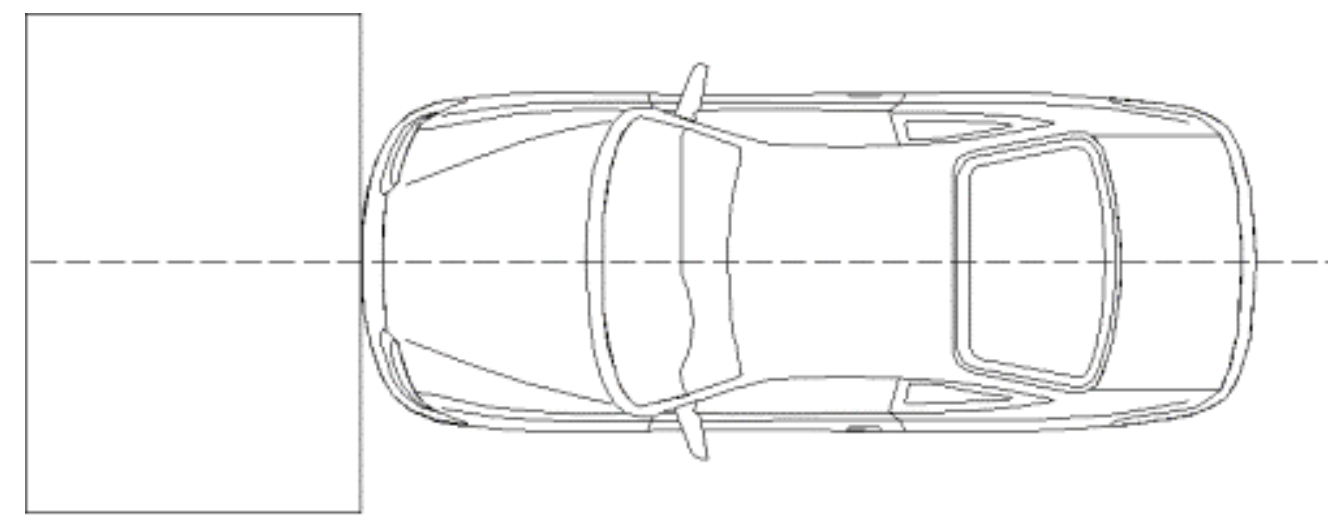

FIGURA 4.1: Colisão frontal

A mesma norma ainda estabelece requerimentos para teste de colisão frontal parcial (offset crash test) contra uma barreira deformável (figura 4.2)

Consiste em submeter o lado do motorista do veículo a uma colisão frontal contra uma barreira de alumínio (feita de células do tipo colmeia) que pode ser deformada durante a colisão, conforme norma FMVSS 208 (Federal motor vehicle protection - 49 CFR part 571.208). Neste tipo de teste, a maior parte do impacto será absorvido pela estrutura do veículo e o impacto no ocupante será pouco, porém 
haverá grande deformação da estrutura do veículo, tornando o teste conveniente para avaliar-se lesões causadas por invasão ao espaço de sobrevivência do(s) ocupante(s).

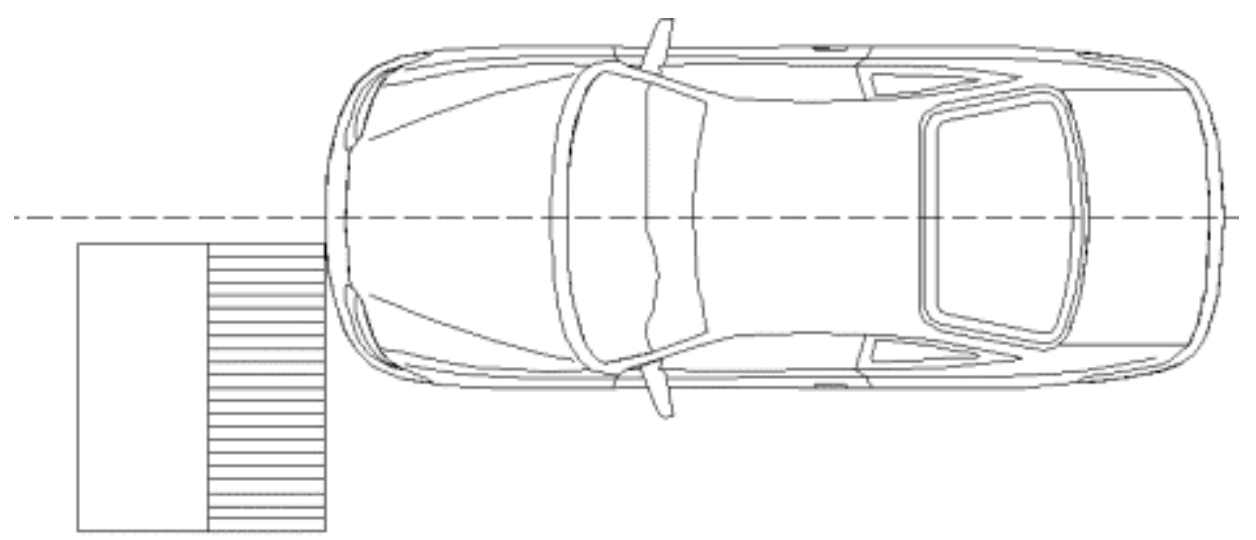

FIGURA 4.2: colisão frontal parcial.

- Teste de impacto lateral - FMVSS 214

Neste teste, o veículo estacionado é colidido por um carrinho (trolley) que possui um painel de alumínio (feito de células do tipo colmeia) que pode ser deformado durante a colisão. A colisão é realizada contra o lado do motorista (figura 4.3); conforme norma FMVSS 214 (Federal motor vehicle protection - 49 CFR part $571.214)$.

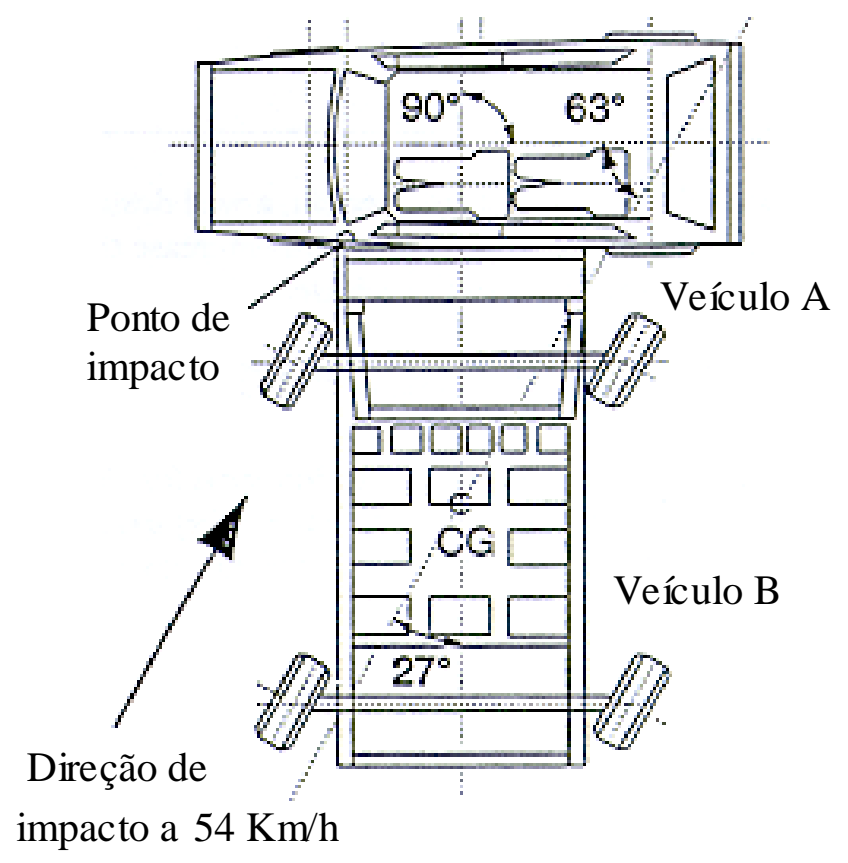

FIGURA 4.3: teste de colisão lateral (PALUSZNY, 1992). 
TABELA 4.1: Regulamentação de CAI de veículos em vigor em vários países (National organitaition for automotive safety \& victims aid)

\begin{tabular}{|c|c|c|}
\hline País & Norma & Método de teste \\
\hline \multirow[t]{2}{*}{ Estados Unidos } & $\begin{array}{l}\text { Colisão frontal (FMVSS 208) } \\
\text { (frontal impact) }\end{array}$ & $\begin{array}{l}\text { Contra barreira rígida, colisão frontal } \\
\text { total, velocidade de } 48 \mathrm{~km} / \mathrm{h}\end{array}$ \\
\hline & $\begin{array}{l}\text { Colisão lateral (FMVSS 214) } \\
\text { (side impact) }\end{array}$ & Barreira móvel, velocidade de $54 \mathrm{~km} / \mathrm{h}$ \\
\hline \multirow[t]{3}{*}{ Austrália } & Colisão frontal (ADR 69) & $\begin{array}{l}\text { Contra barreira rígida, colisão frontal } \\
\text { total, velocidade de } 48 \mathrm{~km} / \mathrm{h}\end{array}$ \\
\hline & $\begin{array}{l}\text { Colisão frontal parcial } \\
\text { (offset frontal crash) }\end{array}$ & $\begin{array}{l}\text { Contra uma barreira deformável, } \\
\text { velocidade de } 64 \mathrm{~km} / \mathrm{h}\end{array}$ \\
\hline & Colisão lateral & $\begin{array}{l}\text { Barreira móvel (trolley) de 950kg, } \\
\text { velocidade de } 50 \mathrm{~km} / \mathrm{h} \text {. }\end{array}$ \\
\hline \multirow[t]{2}{*}{ União Européia } & $\begin{array}{l}\text { Colisão frontal (EC Directive } \\
\text { 96/79/EC) }\end{array}$ & $\begin{array}{l}\text { Contra barreira deformável, colisão } \\
\text { frontal parcial, velocidade de } 56 \mathrm{~km} / \mathrm{h}\end{array}$ \\
\hline & $\begin{array}{l}\text { Colisão lateral (EC Directive } \\
\text { 96/27/EC) }\end{array}$ & Barreira móvel, velocidade de $50 \mathrm{~km} / \mathrm{h}$ \\
\hline \multirow[t]{2}{*}{ Japão } & $\begin{array}{l}\text { Colisão frontal (Article 18, } \\
\text { Safety Regulations for Road } \\
\text { Vehicles) }\end{array}$ & $\begin{array}{l}\text { Contra barreira rígida, colisão frontal } \\
\text { total, velocidade de } 50 \mathrm{~km} / \mathrm{h}\end{array}$ \\
\hline & $\begin{array}{l}\text { Colisão lateral (Article 18, } \\
\text { Safety Regulations for Road } \\
\text { Vehicles) }\end{array}$ & Barreira móvel, velocidade de $50 \mathrm{~km} / \mathrm{h}$ \\
\hline
\end{tabular}

- Resistência do teto do veículo a esmagamento - FMVSS 216

Esta norma estabelece a mínima resistência estática que o teto do veículo deve ter com o objetivo de reduzir a probabilidade de lesões resultantes do esmagamento do teto para dentro do espaço de sobrevivência do passageiro(s) durante acidentes com capotagem. Para veículos de passeio a norma estabelece uma resistência cinqüenta porcento maior em relação ao peso do veículo vazio, aproximadamente $2500 \mathrm{Kg}$, e permite um esmagamento de até $122,5 \mathrm{~mm}$. 
- Integridade do sistema de combustível - FMVSS 301

Esta norma especifica qual deve ser o comportamento do sistema do combustível de veículos a motor durante colisão frontal ou lateral a velocidades acima ou iguais a $48 \mathrm{Km} / \mathrm{h}$. O veículo deve proteger o sistema de combustível de ruptura e limitar o derramamento para evitar o risco de fogo durante e após a colisão.

CAI de veículos é diretamente influenciado pelo tamanho, peso e até mesmo pelo estilo (design) do veículo. Esta influência faz com que a indústria automobilística projete desde o início veículos considerando estas caraterísticas com o objetivo de proteger o ocupante e ganhar mercado oferecendo aos clientes conforto e segurança.

\subsection{Pesquisas em CAI}

Autores como REID (1996), MAMALIS (1996) e McGREGOR et al. (1993), entre outros, concordam que a estrutura de veículos (carros, aeronaves, navios) é responsável pela maior parte de absorção de energia resultante de colisão. Estas estruturas são formadas essencialmente por segmentos do tipo viga (colunas, tubos, etc.), painéis, soldas e uniões.

São vários os fatores que influenciam a eficiência de absorção de energia deste tipo de componentes e da estrutura como um todo:

- Tipo de material - metais, materiais compósitos, etc.;

- Tipo de carregamento - axial, combinado;

- Geometria - a escolha adequada irá determinar a eficiência da seção.

Dentre as muitas pesquisas desenvolvidas em CAI existem as que baseiam-se no estudo do comportamento de metais (aço, alumínio, etc.). REID (1996) observou que com aço, para uma tensão específica, uma mudança de $10 \%$ na espessura resulta em $14 \%$ de mudança na absorção de energia e, para uma espessura específica, uma mudança de $10 \%$ na tensão resulta em mudança de $7 \%$ na absorção de energia.

Outros trabalhos destacam o desempenho CAI de componentes feitos de alumínio; principalmente quando comparado com similares feitos de aço (figura 4.4). O alumínio, em relação ao aço, oferece peso significativamente menor (tabela 4.2) e 
tem-se mostrado capaz de oferecer boa resistência mecânica e ótimo desempenho estrutural, assim como resistência a corrosão e a vantagem de ser reciclável. Estas vantagens têm chamado a atenção da indústria automobilística, naval e aeronáutica.

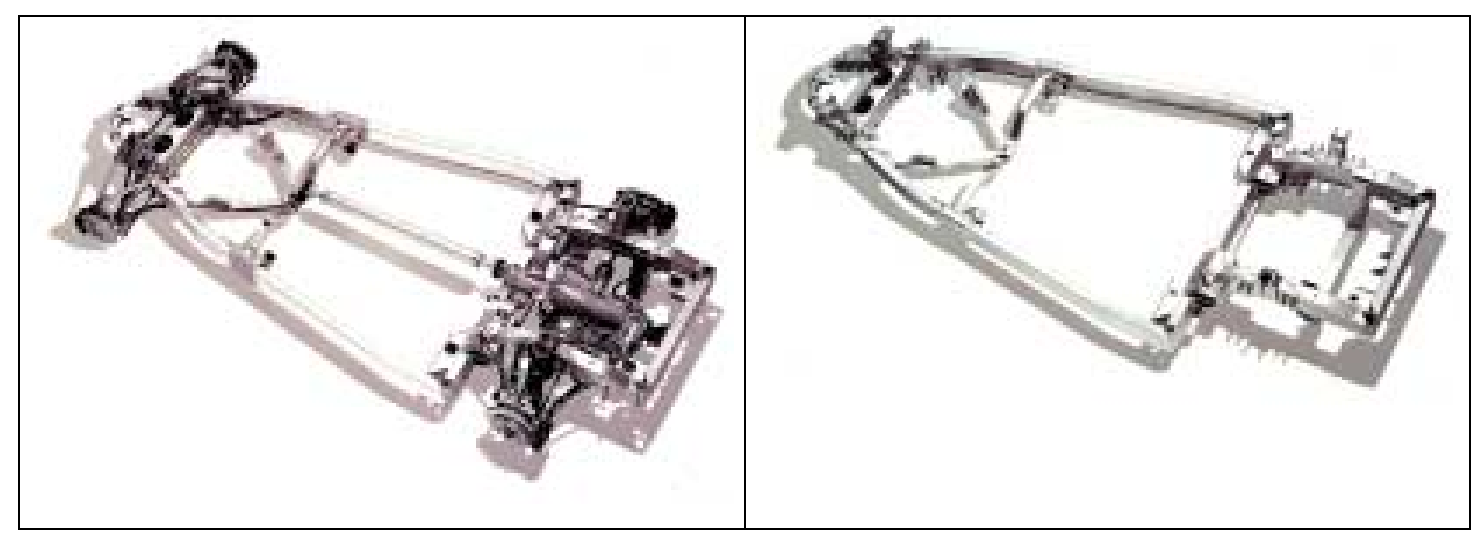

FIGURA 4.4: Chassi de automóvel feito de segmentos de alumínio (Manufacturing process design - http://www.psc.edu/science/Chu/chu.html)

TABELA 4.2: Peso relativo do alumínio e do aço em estruturas veiculares (McGREGOR et al., 1993)

\begin{tabular}{|l|c|c|c|c|}
\hline \multicolumn{1}{|c|}{ Veículo } & $\begin{array}{c}\text { Peso do aço } \\
(\mathrm{Kg})\end{array}$ & $\begin{array}{c}\text { Peso do } \\
\text { alumínio } \\
(\mathrm{Kg})\end{array}$ & $\begin{array}{c}\text { Economia de } \\
\text { peso (\%) }\end{array}$ & $\begin{array}{c}\text { Rigidez torsional dos } \\
\text { novos componentes em } \\
\text { relação aos componentes } \\
\text { de aço (\%) }\end{array}$ \\
\hline Pontiac Fiero & 444 & $303^{*}$ & 32 & ---- \\
\hline Ferrari 408 & 99 & 68 & 31 & 115 \\
\hline BL Metro & 137 & $74^{*}$ & 46 & 76 \\
\hline Honda NSX & 350 & 210 & 40 & --- \\
\hline
\end{tabular}

* veículos onde as pecas de aço foram substituídas por alumínio

Muitos dos trabalhos realizados com componentes metálicos têm como objetivo estabelecer falhas sob modos de colapso axial e dobramento. Frequientemente estes modos de colapso são responsáveis pela maior parte da energia absorvida e, portanto, é importante identificar e entender as variáveis que influenciam o comportamento de 
componentes nestes modos de falha. Porém um entendimento amplo sobre este tópico ainda é incompleto.

Por outro lado, outras pesquisas têm como objetivo determinar o comportamento CAI de novos materiais, especialmente de materiais compósitos (figura 4.5), já que "materiais compósitos proporcionam capacidade de absorção de energia de impacto superior em relação a metais quando comparados sob critério de peso" (MAMALIS \& ROBINSON, 1997). Além disso, os materiais compósitos oferecem flexibilidade de projeto e baixo custo de fabricação, caraterísticas que têm chamado a atenção da indústria automobilística e de aeronaves. 


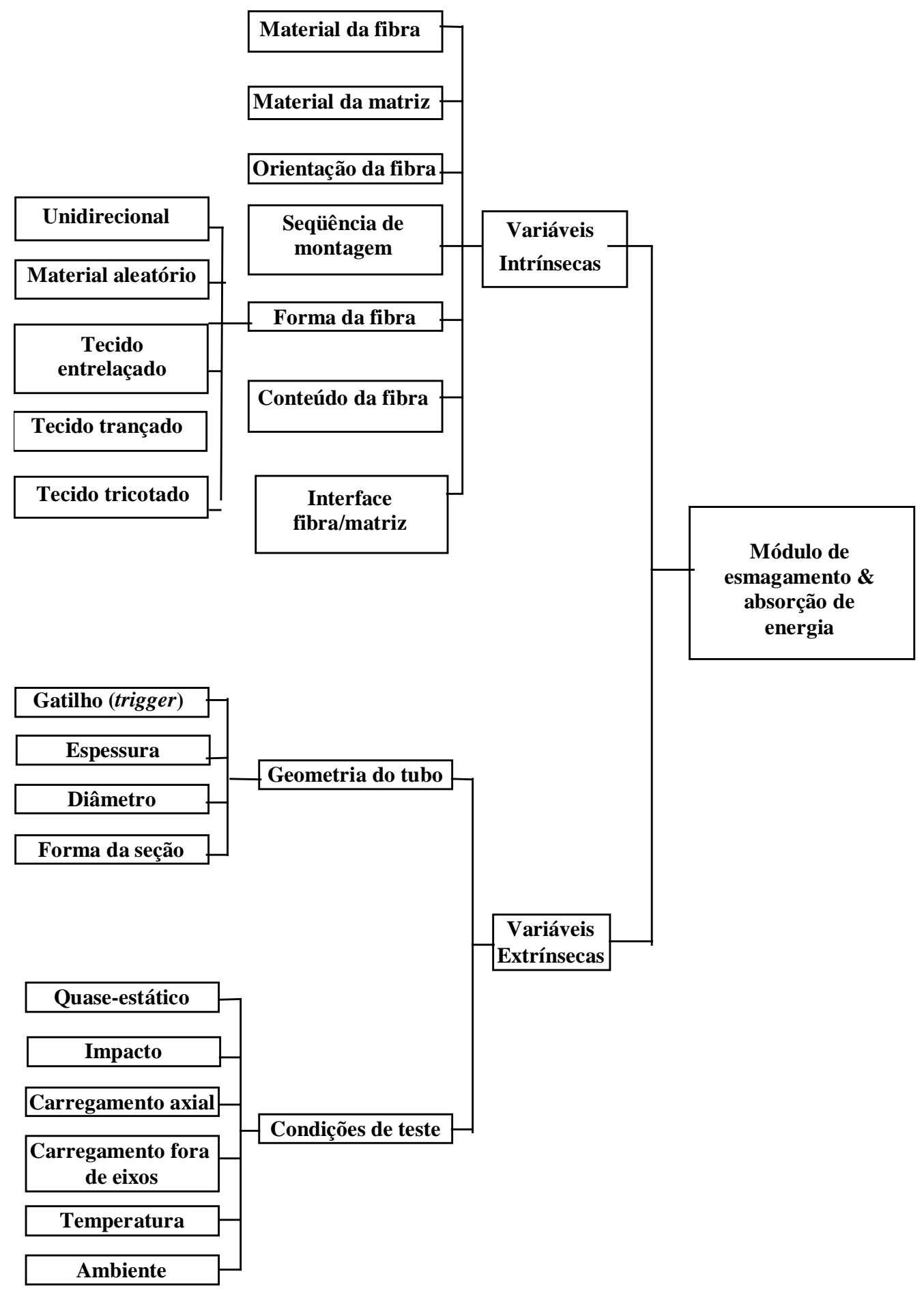

FIGURA 4.5: Variáveis que influenciam o esmagamento e absorção de energia de materiais compósitos (HAMADA \& RAMAKRISHNA, 1997). 


\subsection{Pesquisas de CAI na área médica}

Estudo médicos e estatísticos indicam que cerca de 75 por cento de todos os acidentes veiculares fatais envolvem lesões cerebrais.

Quando um veículo colide podem ocorrer lesões a ocupantes, as quais podem ser evitadas e/ou minimizadas dependendo do tipo de colisão, da velocidade do veículo no momento de impacto e da CAI do mesmo. Atenção especial é dada à cabeça e à coluna cervical. Estudos médicos comprovam que, quando o crânio é atingido por um impacto direto e/ou sofre uma desaceleração muito brusca, energia é transferida ao cérebro, o que pode ocasionar lesões cerebrais. A literatura clínica reporta que cérebro pode ser lacerado por tensão e/ou compressão devida a força do impacto.

JOHNSON (apud), apresenta um índice (GSI - Gadd Severity Index) que se aplica para a aceleração linear da cabeça na região occipital (Figura 4.6), este índice é calculado pela equação 4.1, onde para adultos, se este índice exceder a 1000, traumatismo craniano letal e/ou fratura pode ocorrer.

$$
\mathrm{GSI}=\int_{0}^{\mathrm{T}} \mathrm{a}^{2.5} \mathrm{dt}
$$

Onde: $a=f / g$
$\mathrm{f}$ : aceleração linear
$\mathrm{g}$ : constante gravitacional
t: tempo
T: duração do pulso 


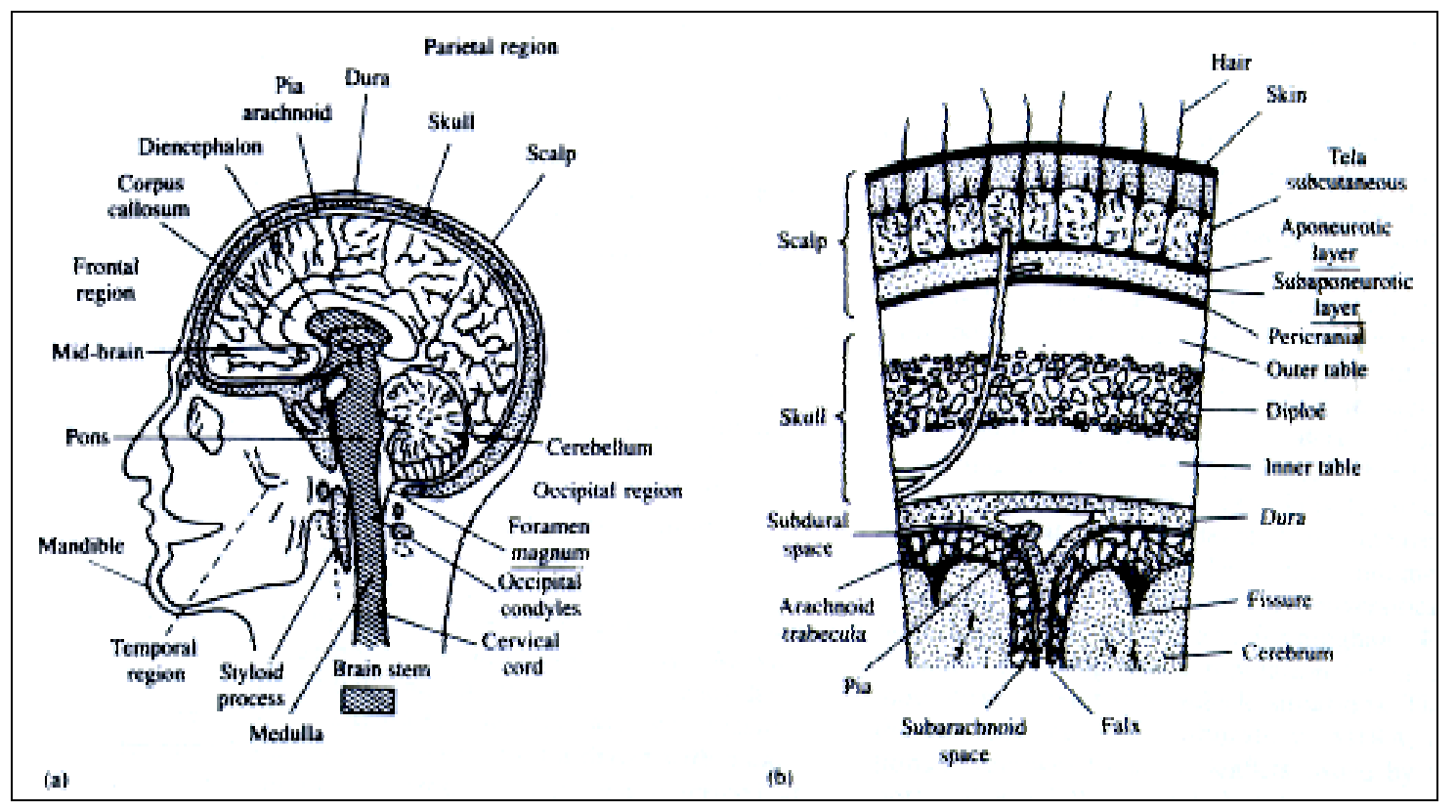

FIGURA 4.6: a) estrutura da cabeça em corte b) detalhe do crânio (JOHNSON, 1990).

\subsection{Ferramentas de análise}

Os projetistas contam com poderosas ferramentas de análise que auxiliam no projeto de sistemas e componentes estruturais. Dentre estas ferramentas as mais populares são: o método dos parâmetros agrupados (LPM - Lumped Parameters Method) e método dos elementos finitos (FEM - Finite Element Method).

\subsubsection{Método dos parâmetros agrupados - LPM}

O uso do método dos parâmetros agrupados para análise de CAI começou na indústria aeroespacial e foi gradualmente estendido para a indústria automobilística.

O primeiro modelo de parâmetros agrupados bem sucedido para o choque de um veículo foi desenvolvido por Kamal na General Motors em 1970 (GANDHI \& HU, 1996). Desde então esta técnica foi extensamente utilizada na indústria automobilística. 
Esta técnica consiste em representar o veículo por uma combinação de massas, molas e amortecedores. A relação dinâmica em torno dos parâmetros agrupados é estabelecida usando as leis de Newton do movimento e então, um grupo de equações diferenciais são resolvidas usando técnicas de integração numérica.

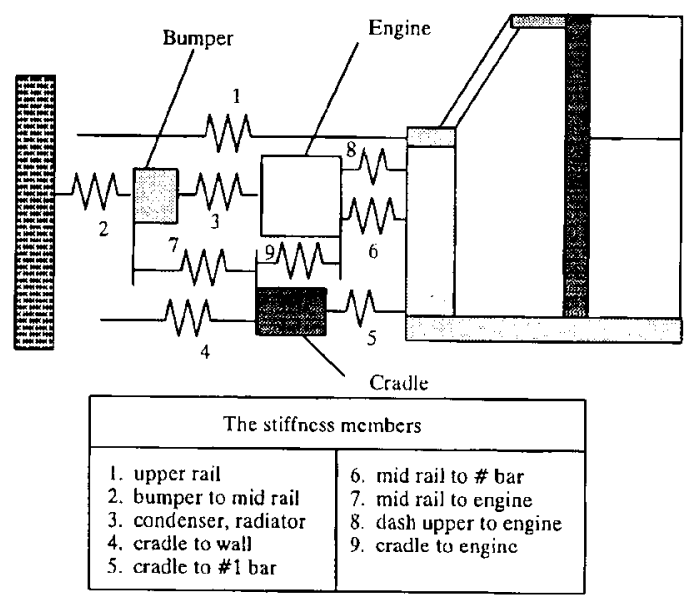

$* * * * * * * * *$

FIGURA 4.7: Modelo típico de parâmetros agrupados usado para um choque frontal (adaptado de GANDHI \& HU, 1996).

A maior vantagem na utilização desta técnica é a simplicidade do modelo e a baixa demanda de recursos computacionais.

\subsubsection{Método dos elementos finitos - FEM}

Com o objetivo de identificar o comportamento estrutural de veículos formados por componentes metálicos e/ou compósitos, os projetistas contam com o auxílio de uma poderosa ferramenta de análise computacional; mais especificamente programas de análise por elementos finitos que podem resolver problemas lineares e nãolineares provocados por grandes deformações, condições de contorno (atrito e contato) ou ainda por não-linearidade de material. Este tipo de ferramenta tem sido usado com sucesso em projeto de CAI (crashworthiness) com vantagens sobre testes físicos. Esta foi a ferramenta utilizada para a projeto e análise do container submetido a queda livre que será apresentado como parte desta monografia. No 
capítulo anterior foram apresentados detalhes e tópicos concernentes a esta ferramenta.

\subsection{Abordagem híbrida}

O termo híbrido é utilizado quando a estrutura de um veículo é decomposta em segmentos e, o comportamento mecânico destes é analisado separadamente para logo serem montados com o objetivo de determinar o comportamento geral da estrutura.

Quando se trata com problemas de CAI, os seguintes princípios são muito importantes:

- Qualidade da informação suprida: é necessário que os dados introduzidos sejam acurados para guiar o projeto na direção correta assegurando compatibilidade com a produção e orçamento.

- Assuntos técnicos básicos: aplicar conceitos básico de engenharia, software e hardware devem ser ajustados à necessidades do projeto, utilização de procedimentos adequados de análise e olhar o problema de distintos ângulos pode gerar novas idéias para solucioná-lo.

- Assuntos organizacionais básicos: realizar análises seguindo normas aceitas (ex. ISSO, SAE, etc.).

- Abordagem de sistemas: fazer simplificações no modelo que venha economizar tempo/custo e, que não venha influenciar negativamente nos resultados. Contudo, isto depende do conhecimento e habilidade do engenheiro.

- Abordagem híbrida: tratar componentes de uma estrutura completa (vigas, uniões, etc.) separadamente durante o desenho, análise e teste. Os dados obtidos dos componentes podem ser introduzidos num modelo simplificado da estrutura completa.

KECMAN (1997) afirma que tratar separadamente os componentes tem as seguintes vantagens: 
- Mesmo em nível de componentes podem existir erros que não podem ser previstos até com poderosos programas de elementos finitos e com malhas muito refinadas.

- Dados de colapso de componentes indicam onde se localiza resistência e fraqueza (dados freqüentemente escondidos em testes de grande escala).

- Erros de projeto são mais fáceis de corrigir antes de produzir a estrutura e tamanho real.

- Uma vez que as propriedades de colapso de componentes são conhecidas, é possível conhece-las para modelos simplificados da estrutura completa.

- Modelos simplificados possibilitam rápidos estudos paramétricos para identificar uma ótima distribuição das propriedade de colapso dos componentes, fixando assim objetivos prioritários de projeto.

Este método é particularmente efetivo nas fases iniciais do projeto quando as mais importantes decisões no geral e alguns conceitos detalhados sobre distribuição ótima das propriedades de colapso são feitas.

\subsection{Comportamento de componentes estruturais.}

Numa colisão, a maior parte da energia resultante do impacto é absorvida por segmentos do tipo coluna (similares) e suas juntas; que são comuns na estrutura de aeronaves, automóveis, ônibus, helicópteros, navios e plataformas petrolíferas.

\subsubsection{Colunas}

O colapso de colunas devido a forças de compressão e momentos ocorre principalmente de duas formas, colapso axial e dobramento (combinado). Em colisões veiculares onde a geometria de colunas e condições de contorno são complexas, o colapso geralmente ocorre pela combinação de ambas formas e freqüentemente não se repete da mesma forma (figura 4.8). 


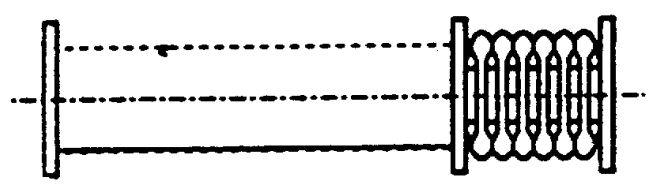

(a) colapso axial

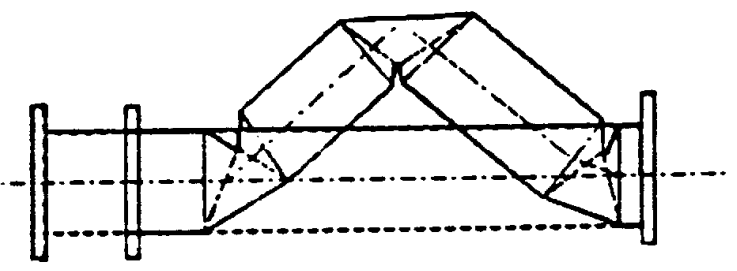

(b) colapso combinado

FIGURA 4.8: Tipos de carregamentos dominantes para componentes (REID, 1996).

\subsubsection{Juntas (uniões)}

O colapso de juntas é mais freqüente que o de vigas e esquadrias e, é influenciado diretamente pela forma como estas são manufaturadas. Uniões que interligam uma estrutura, se fracas, podem reduzir drasticamente a resistência a choque da mesma se comparado com a capacidade nominal de segmentos do tipo vigas que a compõem.

Segundo KECMAN (1997) as falhas em juntas, devidas a problemas de projeto e/ou manufatura, ocorrem principalmente pelas seguintes razões:

- Concentração de tensões que causam separação de material em pontos de solda, rebites, furos, soldas fracas, etc.;

- Concentração de deformação que causam também separação de material (ex.: em regiões afetadas por calor próximas de soldas em aços de alta resistência);

- Instabilidade elasto/plástica;

- Separação de superfícies ligadas;

- Outras formas de falhas associadas com componentes compósitos.

\subsubsection{Vigas}

Falhas em vigas ocorrem primariamente pelas seguintes razões: 
- Instabilidade elasto/plástica (mais freqüentemente), a qual pode ser causada por efeitos locais tais como desenho de junta, bolhas, etc.

- Flambagem total

- Flambagem local

- Concentração de tensões e deformação de materiais compósitos.

\subsection{Geração de modelos computacionais para testes de colisão usando programas de elementos finitos.}

\subsubsection{Modelos computacionais}

Podem ser construídos através de várias formas: utilizando softwares $\mathrm{CAD}, \mathrm{CAE}$ ou através de processos de engenharia reversa. A maior vantagem deste tipo de modelo é sua capacidade de representar detalhes geométricos estruturais; sua maior desvantagem é o tempo e custo para a construção do modelo.

\subsubsection{Utilizando softwares CAD e CAE}

De posse de detalhes geométricos (desenho) o modelo pode ser construído usando um software CAD e exportando posteriormente para um software CAE onde após gerada malha, introduzidas as condições de contorno e aplicados carregamentos, será realizada a análise.

\subsubsection{Utilizando software CAE}

Um modelo pode ser criado usando um software CAE (ex. ANSYS/LSDYNA) onde será criada a geometria e malha, introduzidas as condições de contorno, aplicação de carregamentos e será realizada a análise.

\subsubsection{Processo de engenharia reversa}

O processo completo de engenharia reversa consiste de 4 etapas: 
- Obtenção de dados:

$\mathrm{O}(\mathrm{s})$ componente(s) de um determinado modelo (ex. figura 4.9) são desmontados e medidos utilizando-se ferramentas de digitalização (ex. braço digitalizador) que obtém os dados e os armazenam dentro de um formato que um software CAE possa manipular posteriormente. Os dados coletados nesta fase incluem massa, centros de gravidade, geometria e propriedades dos materiais (as não conhecidas podem ser obtidas através de testes destrutivos de resistência).

- Construção do modelo de elementos finitos:

Os dados geométricos coletados na etapa anterior e armazenados num software CAD (ex. AutoCAD, Pro Engineer) são transferidos para um software CAE (ex. ANSYS, LS-DYNA3D) onde, é gerada a malha e introduzidos os demais dados.

- Validação do modelo:

O modelo de elementos finitos ou parte deste é submetido à análise conforme determinada norma (ex. drop test). Os resultados são comparados com resultados obtidos através de testes físicos para verificação de acuracidade.

- Implementação do modelo:

Se os resultados obtidos na simulação forem coerentes com os resultados de testes físicos o modelo é aceito e pode ser utilizado normalmente.

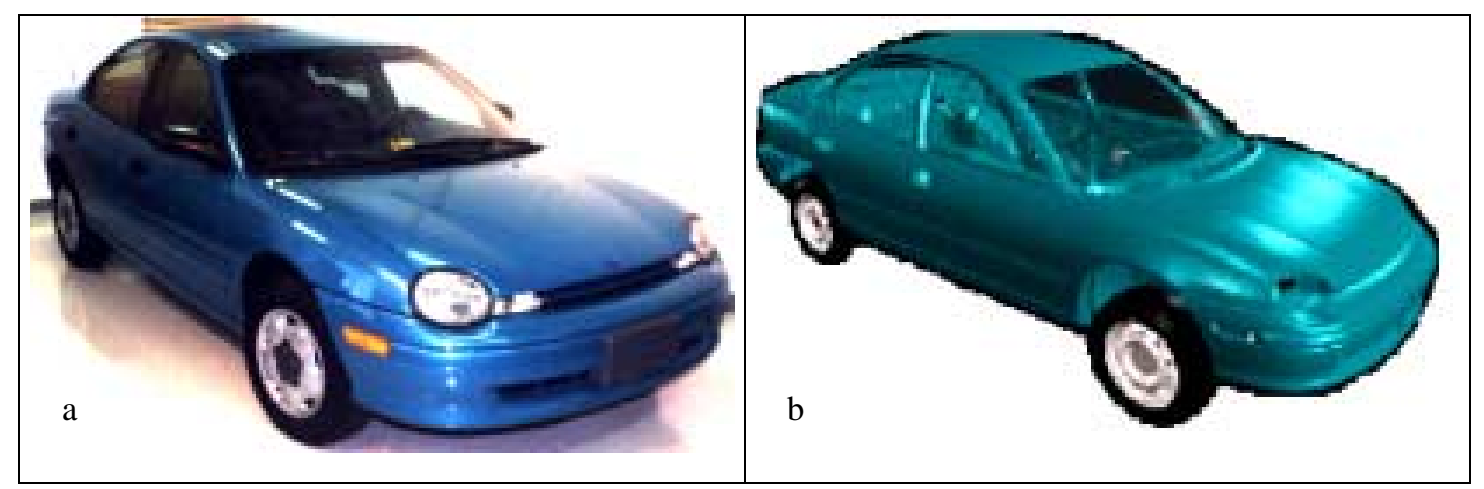

FIGURA 4.9: a) Modelo físico de veículo (Plymouth Neon 1996); b) modelo gerado do veículo usando um braço digitalizador. Os dados foram importados para um pré-processador onde foram introduzidos todos os parâmetros iniciais. (National Crash Analysis Center - http://www.ncac.gwu.edu/ncac, 2000). 


\subsection{Modelos físicos para testes de colisão usando métodos destrutivos.}

Modelos físicos são construídos em tamanho real ou em escala, podem ser modelos parciais ou completos. São utilizados para ensaios destrutivos de colisão para avaliar a adequação do veículo às normas. A maior desvantagem deste tipo de modelo é que apenas podem ser usados uma vez, além de seu alto custo. São recomendados para analisar e fazer comparações finais que possam validar análises feitas através de ensaios computacionais. 


\section{SIMULAÇÃO DE IMPACTO DE CONTAINER}

Como parte deste trabalho foram submetidos modelos de container, típico para o armazenamento de lixo radiativo, a testes de impacto (drop tests). O teste consistiu em liberar o modelo de uma altura de dez metros, em queda livre, para impactar contra uma superfície rígida. Durante o desenvolvimento dos ensaio computacionais foram realizadas diversas simulações. Nesta dissertação serão apresentadas três situações: "quina”, “chapa", “chanfro".

O modelo do container utilizado nas simulações foi baseado no artigo de GRUDA \& YORK (1996); no qual os autores seguem as recomendações da norma 10 CFR 71 (Título 10 do código de regulamentação federal dos Estados Unidos, parte 71).

Para realizar as simulações foi utilizado o software de elementos finitos ANSYS/LS-DYNA.

De acordo com a proposta de HUEBNER citada no capitulo 2 desta dissertação, o problema foi modelado e solucionado seguindo as três etapas essenciais na utilização do método dos elementos finitos: pré-processamento, solução (solver) e pós processamento.

O primeiro objetivo da simulação é verificar a absorção do impacto (CAI) pela estrutura e verificar se ocorrem danos à capsula interna do container (componente crítico que contém o material) quando o modelo colide contra a superfície. O segundo objetivo é realizar simulações com modelos modificados do container para se obter um modelo ótimo em relação ao modelo original. 


\subsection{Estrutura e Periféricos}

O presente trabalho foi desenvolvido no Laboratório de CAD/CAE do Departamento de Engenharia Mecânica, USP/São Carlos.

No Laboratório de CAD/CAE são utilizados os seguintes equipamentos para a simulação pelo método dos elementos finitos:

\section{Hardware}

- Estação de trabalho IBM RISC 39H, 128Mb de memória e 4,5Gb de HD.

- PC IBM Netfinity 3000 com processador Pentium II, 400MHz, $128 \mathrm{Mb}$ de memória RAM e $24 \mathrm{~Gb}$ de HD.

\section{$\underline{\text { Software }}$}

- CAE (Computer Aided Engineering)

plataforma UNIX (AIX) - ANSYS 5.2/5.5/5.6, ANSYS/LS-DYNA 5.6.

plataforma WindowsNT - ANSYS/LS-DYNA 5.5/5.6.

- CAD (computer aided design) plataforma UNIX (AIX) - Pro Engineer 2000.

\subsection{Descrição do modelo}

O container (figura 5.1) tem diâmetro de $0,5 \mathrm{~m}$ e altura de $0,76 \mathrm{~m}$. Foi modelado da seguinte forma: cilindro formado por chapas de alumínio de $2 \mathrm{~mm}$ de espessura que formam uma cavidade preenchida com espuma de poliuretano, tampas superior e inferior de alumínio com espessura de $2 \mathrm{~mm}$, inserto superior e inferior formado por chapas de alumínio de $2 \mathrm{~mm}$ de espessura que formam uma cavidade preenchida com espuma de poliuretano e cápsula feita de alumínio com $8 \mathrm{~mm}$ de espessura. Este modelo foi utilizado nas situações de quina e chapa.

$\mathrm{Na}$ tabela 5.1 são apresentadas massa e volume de cada componente do container. 
TABELA 5.1: Volume e massa de cada componente.

\begin{tabular}{|c|c|c|c|}
\hline Componente & $\begin{array}{c}\text { Volume da } \\
\text { espuma }\left(\mathrm{m}^{3}\right)\end{array}$ & $\begin{array}{c}\text { Volume do } \\
\text { alumínio }\left(\mathrm{m}^{3}\right)\end{array}$ & $\begin{array}{c}\text { Massa de cada } \\
\text { componente }(\mathrm{kg})\end{array}$ \\
\hline Cilindro + tampas & 0,054827 & 0,00519 & 40,73 \\
\hline Insertos (cada) & 0,015765 & 0,00078 & $9,72(\mathrm{x} 2)$ \\
\hline Cápsula & ------- & 0,01513 & 17,47 \\
\cline { 2 - 4 } & \multicolumn{2}{|l}{ Peso total do container $\rightarrow$} & $\mathbf{6 7 , 9 2}$ \\
\cline { 2 - 4 }
\end{tabular}

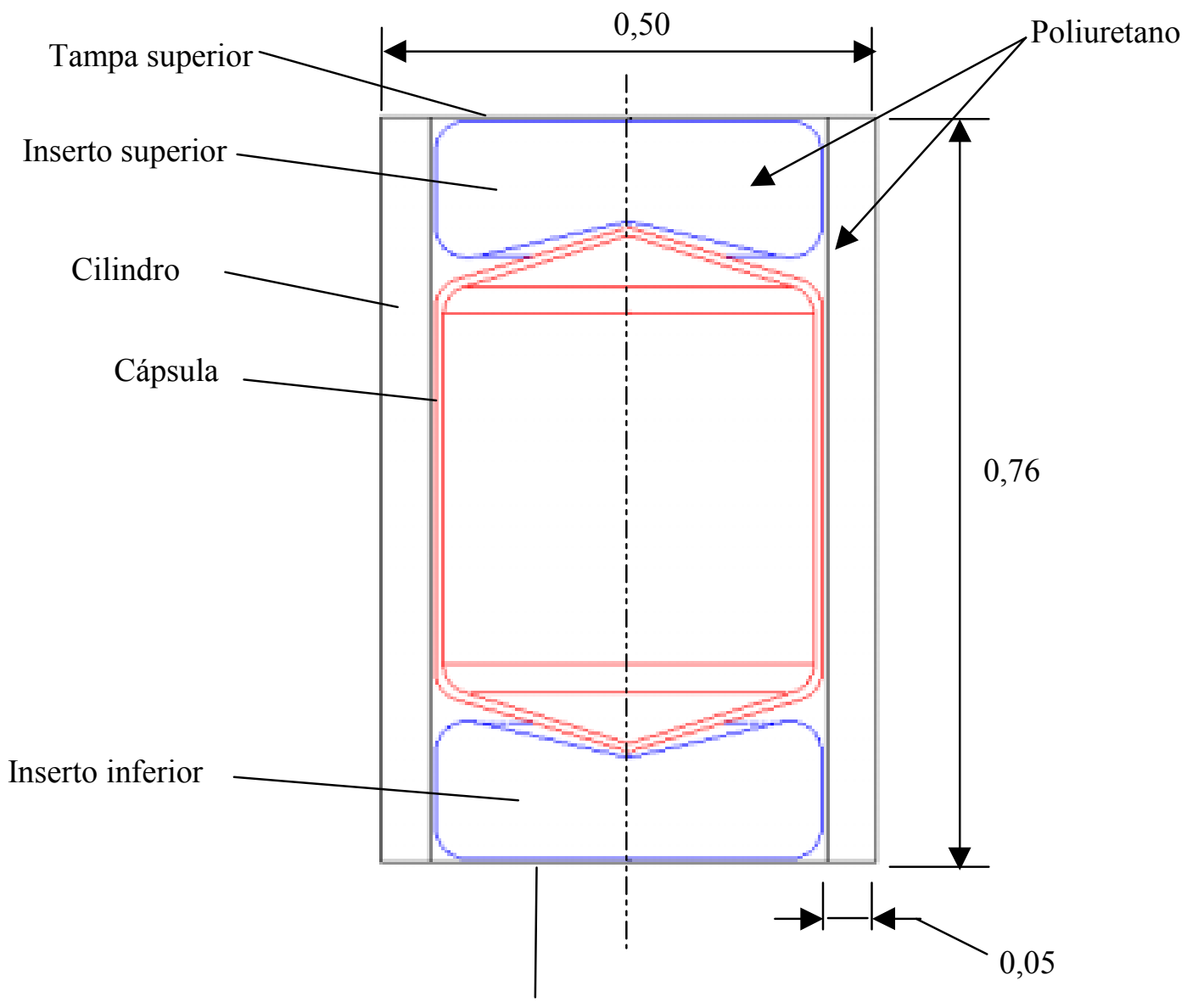

Tampa inferior

FIGURA 5.1: Componentes do container e dimensões do modelo [m]. 


\subsubsection{Materiais e propriedades:}

Da biblioteca do ANSYS/LS-DYNA foram escolhidos três tipos diferentes de materiais:

- Alumínio - foi escolhido para a modelagem do container o Alumínio 2024 (tabela 5.2). $\mathrm{Na}$ análise este material é considerado isotrópico e são necessárias algumas das suas caraterísticas principais: módulo (de elasticidade) de Young $(E)$, coeficiente de Poisson ( $v$ ) e densidade $(\rho)$. O comportamento do material no regime de escoamento plástico adotado é o chamado BISO (bilinear isotrópico), que pode ser visto na figura 5.2. Para definir este comportamento é necessário o valor no qual o escoamento plástico se inicia (limite de escoamento $\sigma_{\mathrm{y}}$ ) e o encruamento, dado pelo módulo tangente de encruamento.

Estes valores são utilizados de acordo com a bibliografia pesquisada para exemplos de estiramento ensaiados anteriormente por outros pesquisadores e assim ser possível comparar estes resultados com os obtidos pela rotina implementada.

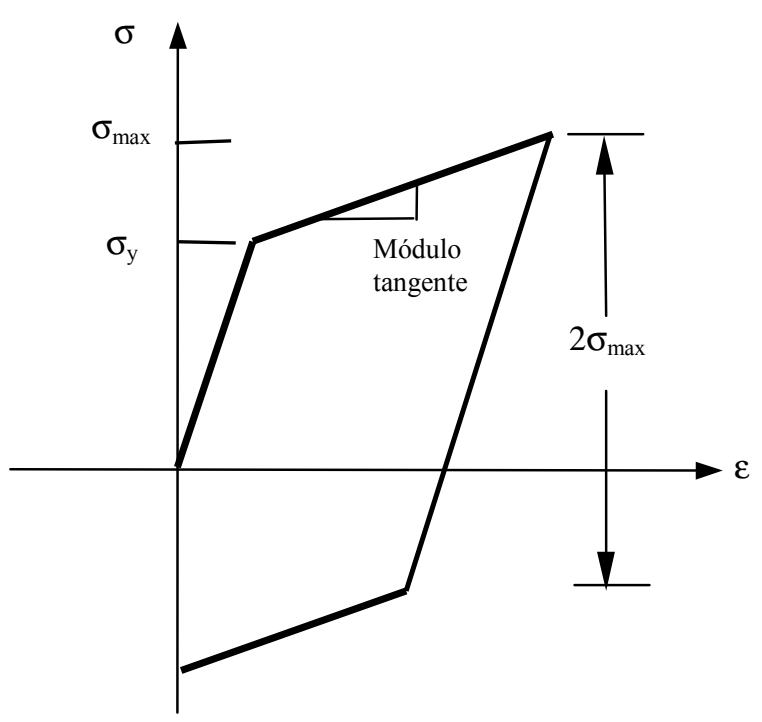

FIGURA 5.2: Comportamento de material bilinear isotrópico.

- Espuma - Outro material utilizado na modelagem foi uma espuma de baixa densidade também extraída da biblioteca do ANSYS/LS-DYNA. Para esta opção de material o programa nos fornece os valores do módulo de elasticidade (E) e densidade ( $\rho)$ (ver tabela 5.2). Valores de tensão e deformação desta espuma foram extraídos da curva tensão/deformação do artigo de GRUDA \& YORK (1996). Estes 
valores foram fornecidos ao programa através de uma tabela com o objetivo de simular o comportamento da espuma (figura 5.3).

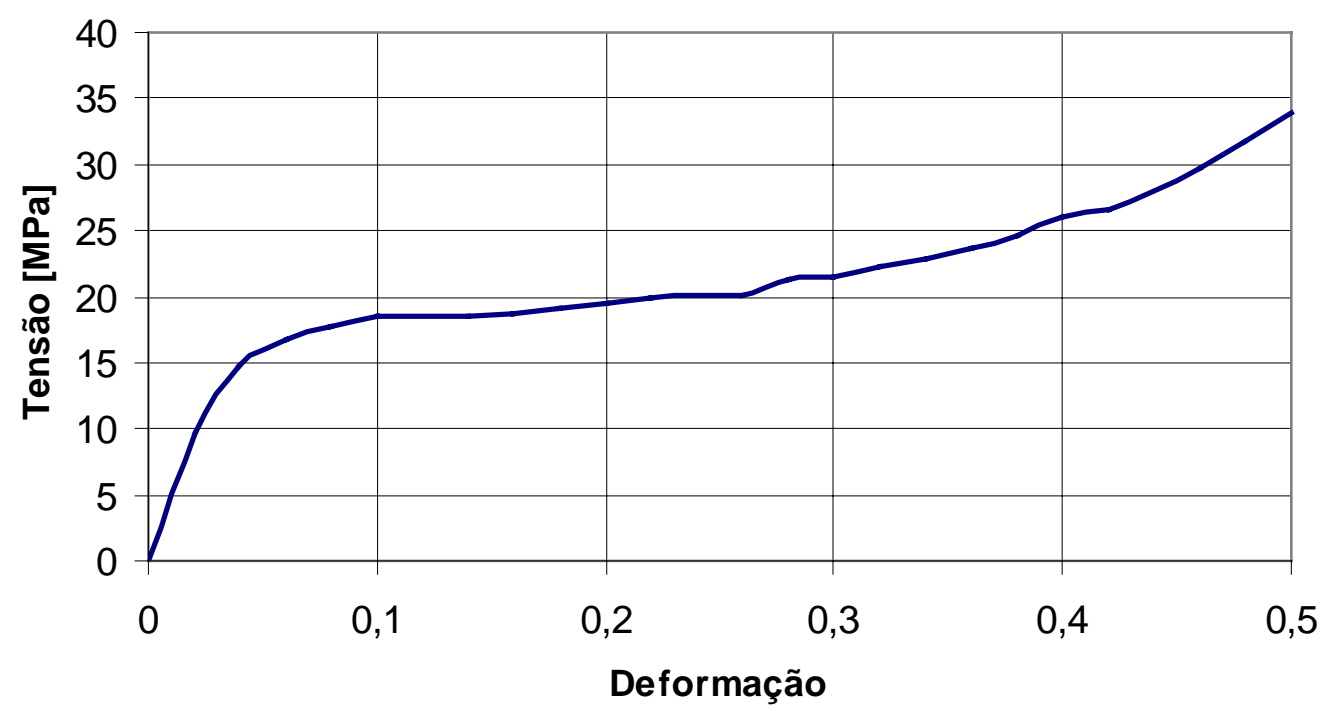

FIGURA 5.3: Comportamento da espuma de poliuretano (GRUDA \& YORK, 1996).

- Aço ABNT 1020- Este material foi escolhido para modelar a superfície com a qual o container colidiria. As propriedades deste material são mostradas na tabela 5.2 .

Obs.: $\mathrm{Na}$ simulação, a superfície é adotada como corpo rígido. Portanto, as constantes de material não influenciam no processo.

TABELA 5.2: Propriedades dos materiais que compõem o container.

\begin{tabular}{|l|c|c|c|c|}
\hline \multicolumn{1}{|c|}{ Material } & $\begin{array}{c}\text { Módulo de } \\
\text { elasticidade } \\
{\left[\mathrm{N} / \mathrm{m}^{2}\right]}\end{array}$ & $\begin{array}{c}\text { Tensão de } \\
\text { escoamento } \\
{[\mathrm{MPa}]}\end{array}$ & $\begin{array}{c}\text { Densidade } \\
{\left[\mathrm{Kg} / \mathrm{m}^{3}\right]}\end{array}$ & $\begin{array}{c}\text { Coeficiente de } \\
\text { Poisson }\end{array}$ \\
\hline Alumínio 2024-T3 & $73 \times 10^{9}$ & 345 & 2771 & 0,33 \\
\hline Aço ABNT 1020 & $207 \times 10^{9}$ & 350 & 7850 & 0,29 \\
\hline Espuma & $0,405 \times 10^{9}$ & ----- & 480 & ----- \\
\hline
\end{tabular}




\subsection{Geração da malha:}

No modelo foi gerada uma malha mapeada utilizado dois tipos de elemento: elemento shell (casca) de 4 nós e elemento sólido de 8 nós. Detalhes sobre estes tipos de elementos são mostrados no apêndice I desta monografia.

A modelagem do container e da superfície rígida é mostrada na figura 5.4. $\mathrm{O}$ modelo foi discretizado usando um total de 2107 elementos, dos quais 1000 elementos shell e 1107 elementos sólidos. A tabela 5.3 mostra os materiais e elementos escolhidos da biblioteca do ANSYS/LS-DYNA para cada um dos componentes do container.

TABELA 5.3: Materiais e elementos atribuídos aos componentes do container (ANSYS/LS-DYNA).

\begin{tabular}{|l|l|l|}
\hline \multicolumn{1}{|c|}{ Componente } & \multicolumn{1}{|c|}{ Material } & \multicolumn{1}{c|}{ Elemento - Tipo } \\
\hline \hline \multirow{2}{*}{ Cilindro } & Alumínio 2024-T3 & Shell 163 - quadrilátero \\
\cline { 2 - 3 } & Espuma & Sólido 164 - hexaedro \\
\hline Tampas & Alumínio 2024-T3 & Shell 163 - quadrilátero \\
\hline Insertos & Alumínio 2024-T3 & Shell 163 - quadrilátero \\
\cline { 2 - 3 } & Espuma & Sólido 164 - hexaedro \\
\hline Cápsula & Alumínio 2024-T3 & Sólido 164 - hexaedro \\
\hline Superfície & Aço 1020 & Sólido $164-$ hexaedro \\
\hline
\end{tabular}

\subsection{Contatos:}

A modelagem de contatos é, sem duvida, uma das tarefas mais complexas numa simulação de impacto usando o método dos elementos finitos. Geralmente não se conhecem todas as regiões que entrarão em contato até rodar o programa, além de que, em problemas de contato, precisa ser levado em conta o atrito entre superfícies. Contato e atrito são responsáveis pelas não linearidades citadas nos capítulos 2 e 3 desta monografia, onde são apresentados tópicos específicos ao tema de nãolinearidade. 
Devido a que o modelo do container é feito de vários componentes e estes, durante a simulação, colidem entre si e contra uma superfície rígida, foram utilizados 3 tipos de contatos disponíveis no ANSYS/LS-DYNA (tabela 5.4) e, sugeridos por HALLQUIST (1993).

TABELA 5.4: Definição de contatos dinâmicos explícitos.

\begin{tabular}{|l|l|l|}
\hline \multicolumn{1}{|c|}{ Tipo de contato } & \multicolumn{1}{|c|}{ Componente contator } & Componente alvo \\
\hline \multirow{2}{*}{ Contato Automático de Superfície } & Inserto superior & --------- \\
\hline \multirow{2}{*}{$\begin{array}{l}\text { Contra superfície } \\
\text { conto automático de nós }\end{array}$} & Inserto inferior & ---------- \\
\cline { 2 - 3 } & Cilindro* & ---------- \\
\cline { 2 - 3 } & Cápsula & ---------- \\
\hline \multirow{2}{*}{$\begin{array}{l}\text { Contato geral de nós contra } \\
\text { superfície }\end{array}$} & Inserto inferior & Cilindro* \\
\cline { 2 - 3 } & Inserto superior & Cilindro* \\
\cline { 2 - 3 } & Capsula & Cilindro* \\
\hline
\end{tabular}

*Inclui tampas **Inclui cilindro, tampas, insertos e cápsula.

\subsection{Amortecimento}

Para evitar oscilações indesejáveis durante a simulação, decorrentes do contato, o ANSYS/LS-DYNA sugere especificar um coeficiente de amortecimento de contato calculado como:

$$
\xi=\frac{\mathrm{VDC}}{100} . \xi_{\mathrm{CRTT}}
$$

Onde:

$\mathrm{VCD}=$ coeficiente de amortecimento viscoso (valor a ser introduzido no menu)

$\xi_{\text {CRIT }}=2 \mathrm{m \omega}$ (amortecimento crítico calculado pelo programa)

onde:

$$
\mathrm{m}=\min \left(\mathrm{m}_{\text {contatora }}, \mathrm{m}_{\text {alvo }}\right)
$$




$$
\omega=\sqrt{k \cdot \frac{\mathrm{m}_{\text {contatora }}+\mathrm{m}_{\text {alvo }}}{\mathrm{m}_{\text {contatora }} \cdot \mathrm{m}_{\text {alvo }}}}
$$

\subsection{Atrito}

Assim como para contato entre superfícies, o ANSYS/LS-DYNA permite que seja especificado um coeficiente de atrito de contato $\left(\mu_{\mathrm{c}}\right)$ entre superfícies utilizando a seguinte fórmula:

$$
\mu_{c}=\mathrm{FS}+(\mathrm{FS}-\mathrm{FD}) \mathrm{e}^{-\mathrm{DC} \cdot \mathrm{v}_{\mathrm{rel}}}
$$

Onde:

$$
\begin{aligned}
& \mathrm{FS}=\text { atrito estático } \\
& \mathrm{FD}=\text { atrito dinâmico } \\
& \mathrm{DC}=\text { coeficiente exponencial de decaimento } \\
& \mathrm{V}_{\text {rel }}=\text { velocidade relativa }
\end{aligned}
$$

Obs.: Não foi estipulado nenhum coeficiente de amortecimento nem de atrito, isto é, o valor dos coeficientes de amortecimento viscoso e de atrito foram zero. Isto ocorreu por não termos dados precisos sobre coeficientes de amortecimento e de atrito entre materiais.

\subsection{Aplicação de carregamentos}

A simulação que foi elaborada trata-se de um drop test (queda livre) da altura de 10 m. Com o objetivo de facilitar a simulação e visualização do modelo, optamos por modelar o container próximo à superfície de colisão e aplicamos nele uma velocidade inicial vertical de $15 \mathrm{~m} / \mathrm{s}$. Aplicando esta velocidade inicial compensamos o tempo que levaria ao modelo para colidir da altura de $10 \mathrm{~m}$.

$$
\text { Para queda livre temos: } h=\frac{V^{2}}{2 g}
$$




\subsection{Situações de teste}

Como foi comentado no inicio deste capítulo serão apresentado três situações: "quina", "chapa" e "chanfro". Todas as situações foram simuladas utilizando as mesmas condições iniciais. Nas situações quina e chapa, geometria e discretização do modelo são iguais. A situação chanfro possui todas as caraterísticas da situação quina, apenas apresenta um modificação geométrica. A seguir serão apresentadas as três situações mais detalhadamente.

\subsubsection{Situação quina}

Nesta situação o container colide contra a superfície rígida com ângulo de 60 graus (figura 5.4b)

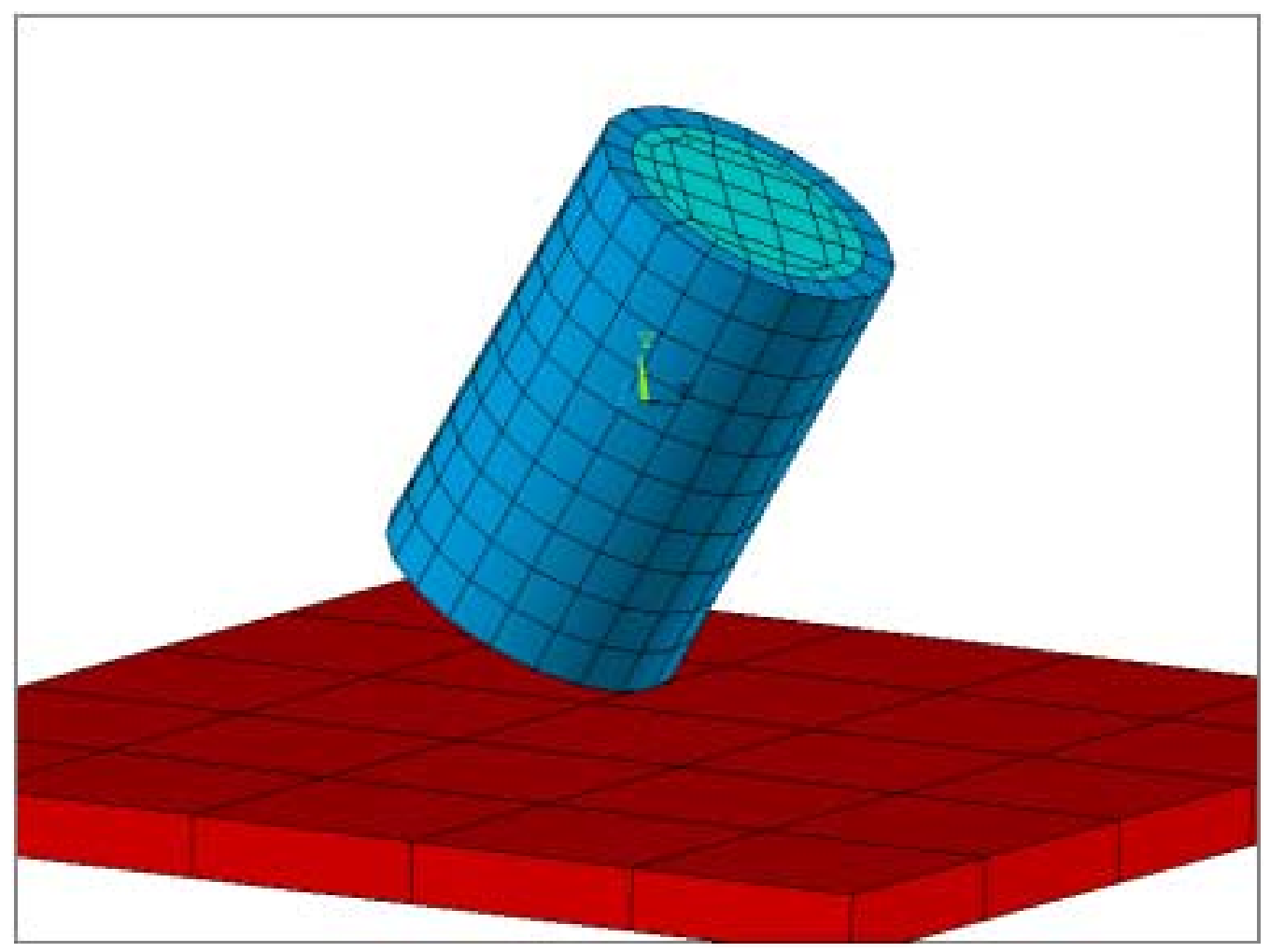

FIGURA 5.4a: Situação quina após geração da malha. 


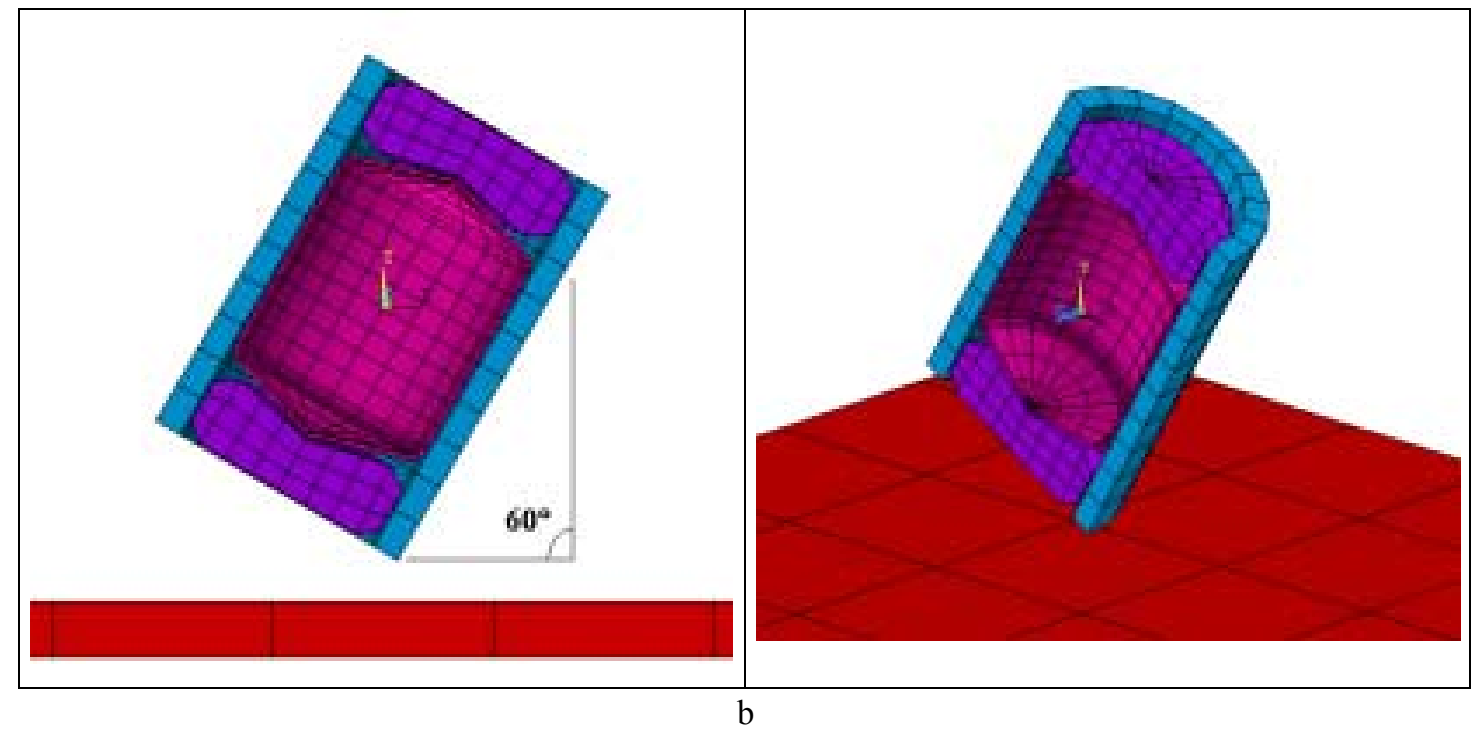

FIGURA 5.4b: Situação quina, modelo em corte transversal, após geração da malha.

\subsubsection{Situação chapa}

Nesta situação a parte inferior do container colide paralela à superfície de contato.

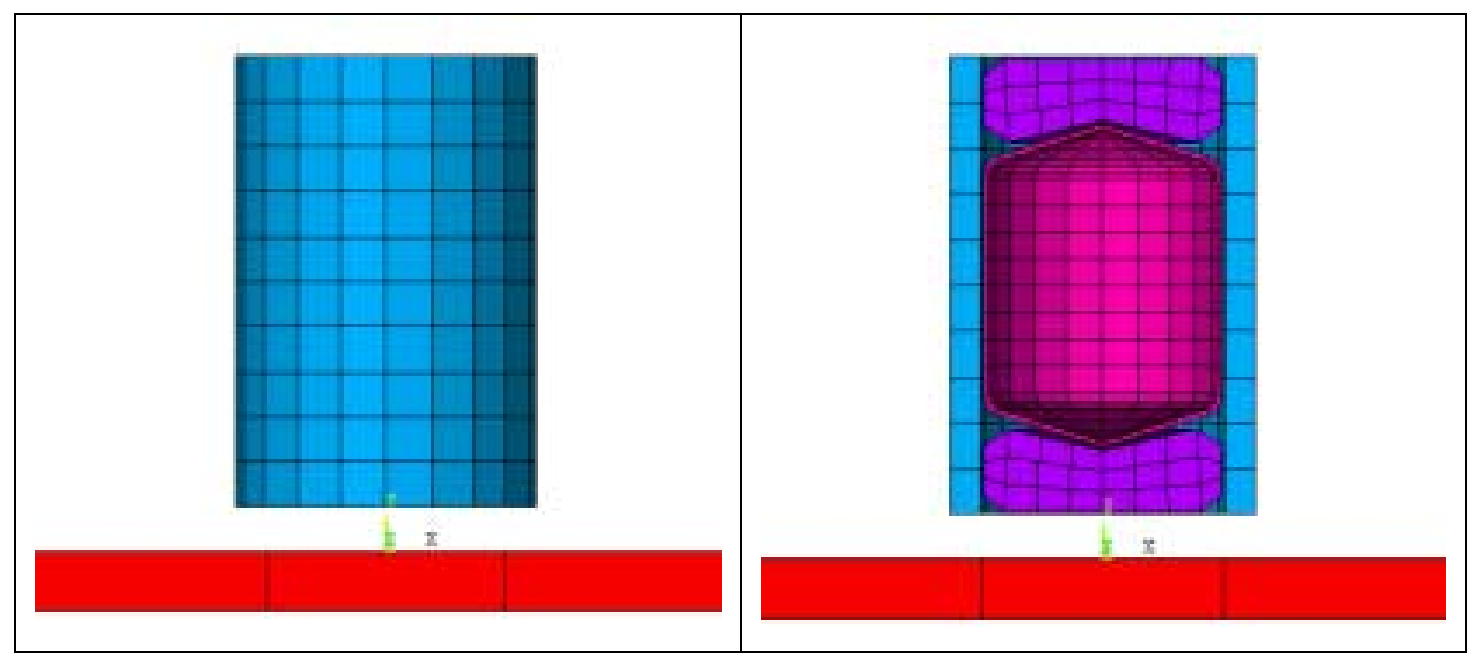

FIGURA 5.5: Situação chapa, vista frontal e vista em corte transversal, após geração da malha.

\subsubsection{Situação chanfro}

Após terem sido simulados com sucesso os modelos do container nas situações quina e chapa, foi realizada a simulação do modelo na situação chanfro. O modelo do container foi modificado com a adição de um anel na parte inferior do mesmo (figura 
5.6). Este anel possui um chanfro paralelo à superfície de colisão e foi concebido para avaliar a possibilidade de diminuição de tensão no modelo e manter o componente crítico cápsula dentro do limite de escoamento do material.

$\mathrm{O}$ anel foi modelado de duas formas diferentes:

1. Feito de alumínio e modelado com elementos sólidos;

2. Feito de chapas de alumínio (shell 163 ) de $2 \mathrm{~mm}$ de espessura que formam uma cavidade preenchida com espuma (sólida) de poliuretano.

Através de sucessivas simulações realizadas, foi constatado que o anel feito de alumínio sólido mostrou-se menos eficiente do que o construído de chapas de alumínio, com cavidade preenchida de espuma. Isto sob o critério de diminuição de tensão no componente crítico.

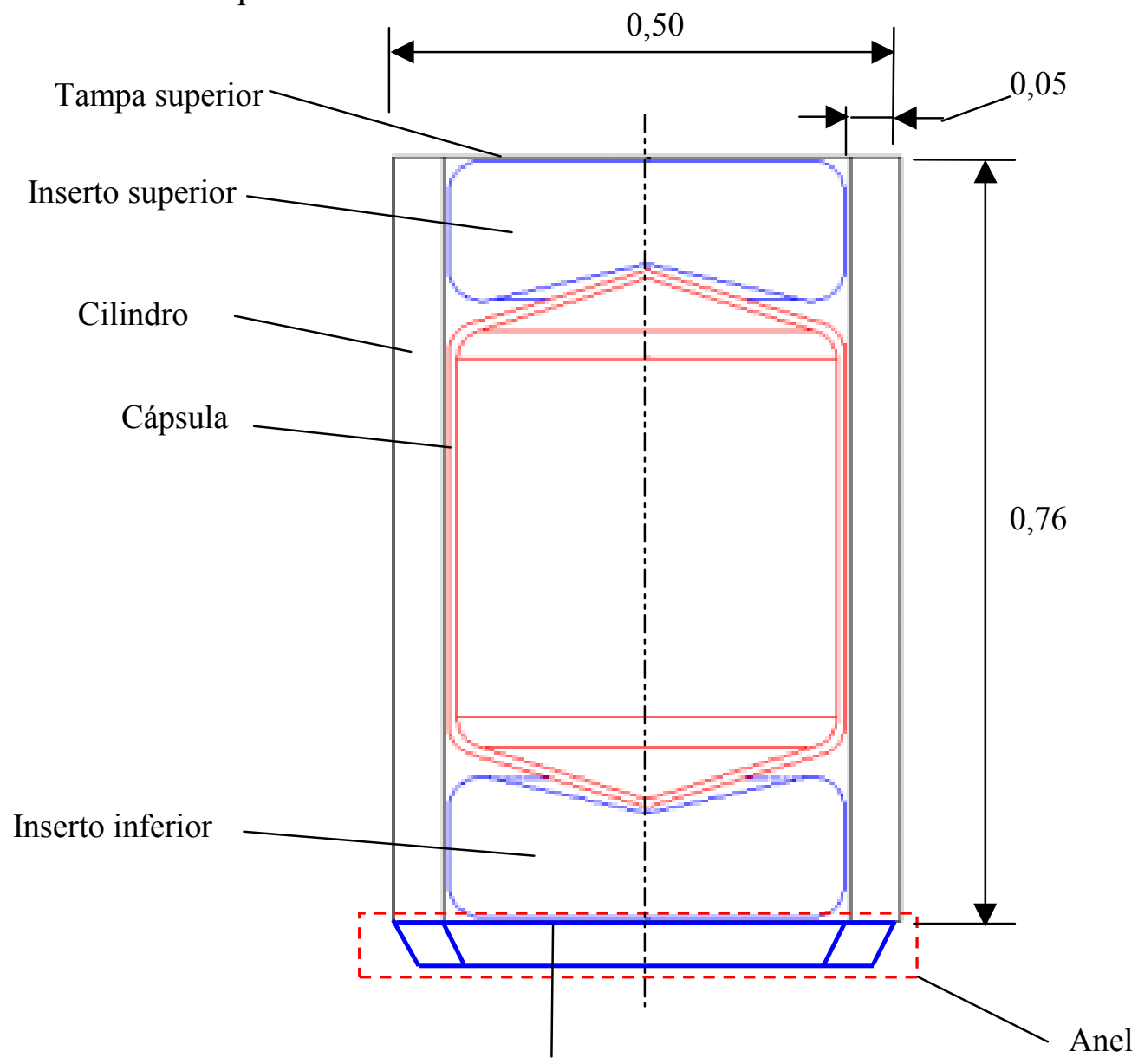

Tampa inferior

FIGURA 5.6: Componentes do container (situação chanfro) e dimensões [m]. 
As propriedades dos materiais assim como os modelos de comportamento não foram alterados em relação às situações anteriores. O material utilizado para a modelagem do anel, alumínio e espuma, são os mesmos que foram utilizados para outros componentes do container.

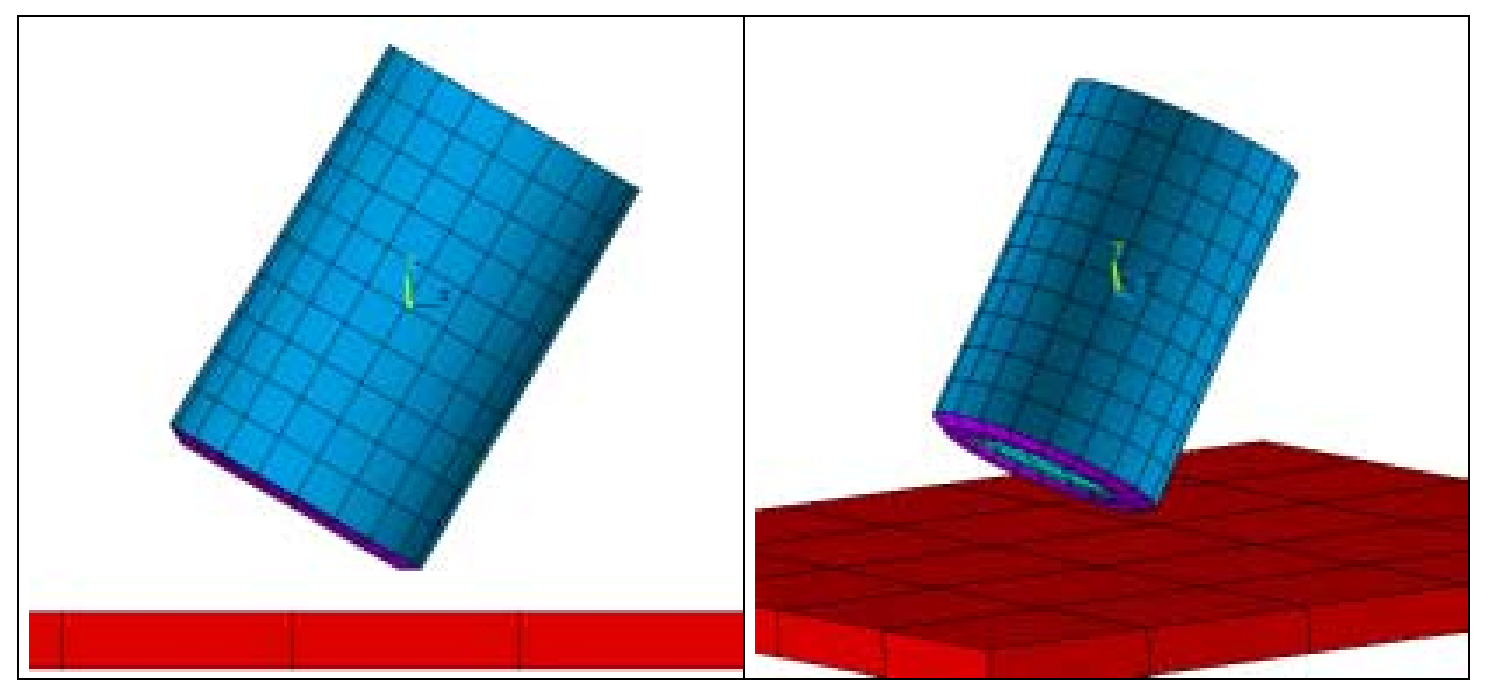

FIGURA 5.7: Vistas da situação chanfro.

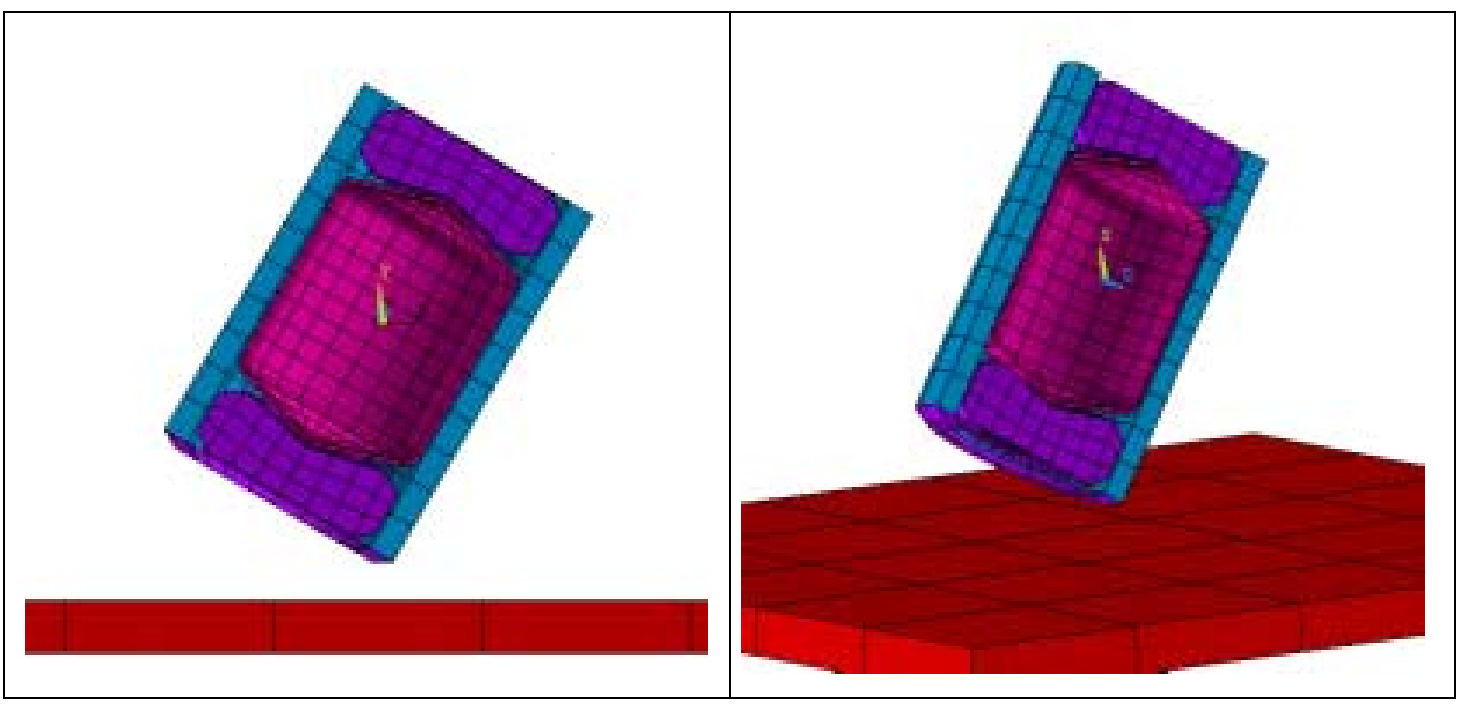

FIGURA 5.8: Vistas em corte da situação chanfro. 
TABELA 5.5: Volume e massa de cada componente do modelo modificado.

\begin{tabular}{|c|c|c|c|}
\hline Componente & $\begin{array}{c}\text { Volume da } \\
\text { espuma }\left(\mathrm{m}^{3}\right)\end{array}$ & $\begin{array}{c}\text { Volume do } \\
\text { alumínio }\left(\mathrm{m}^{3}\right)\end{array}$ & $\begin{array}{c}\text { Massa de cada } \\
\text { componente }(\mathrm{kg})\end{array}$ \\
\hline Cilindro + tampas & 0,054827 & 0,00519 & 40,73 \\
\hline Insertos (cada) & 0,015765 & 0,00078 & 9,72 \\
\hline Cápsula & ------- & 0,01513 & 17,47 \\
\hline Anel & 0,0012432 & 0,15369 & 1,45 \\
\hline & \multicolumn{2}{|c|}{ Peso total do container $\rightarrow$} & $\mathbf{6 9 , 3 7}$ \\
\cline { 2 - 4 }
\end{tabular}

O modelo da situação chanfro possui aproximadamente 3\% de peso a mais comparado com os modelos das situações quina e chapa. 


\section{RESULTADOS E COMENTÁRIOS}

Antes de serem apresentados os resultados finais das simulações realizadas será apresentada uma interpretação de um modelo genérico de queda livre de um corpo elástico (Figura 6.1). Esta interpretação simples será útil para a análise dos resultados do trabalho e para o levantar discussões ao respeito.

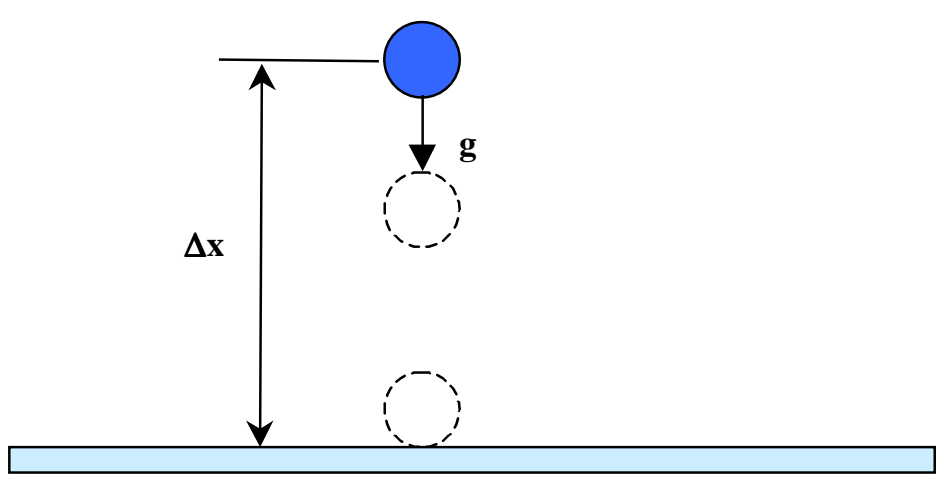

FIGURA 6.1: Exemplo de queda livre de um corpo elástico.

Na figura 6.2 são apresentado gráficos de deslocamento, velocidade e aceleração (todos estes gráficos contra o tempo) de um corpo em choque inelástico.

Na figura 6.1 e no gráfico de deslocamento da figura 6.2 pode ser notado que o corpo cai de um altura $\Delta \mathrm{x}$ e colide contra uma superfície num intervalo de tempo $\Delta \mathrm{t}$. O corpo volta a se deslocar e colidir até que num determinado tempo fica em repouso.

No gráfico de velocidade da figura 6.2 pode ser notado como, inicialmente, o corpo ganha velocidade até chegar a uma velocidade máxima no instante da primeira colisão, assim como a inversão do sinal nos instantes em que o corpo se desloca novamente na vertical em sentido oposta ã queda.

O gráfico de aceleração (figura 6.2) mostra picos de aceleração devidos aos impactos do corpo conta a superfície. 


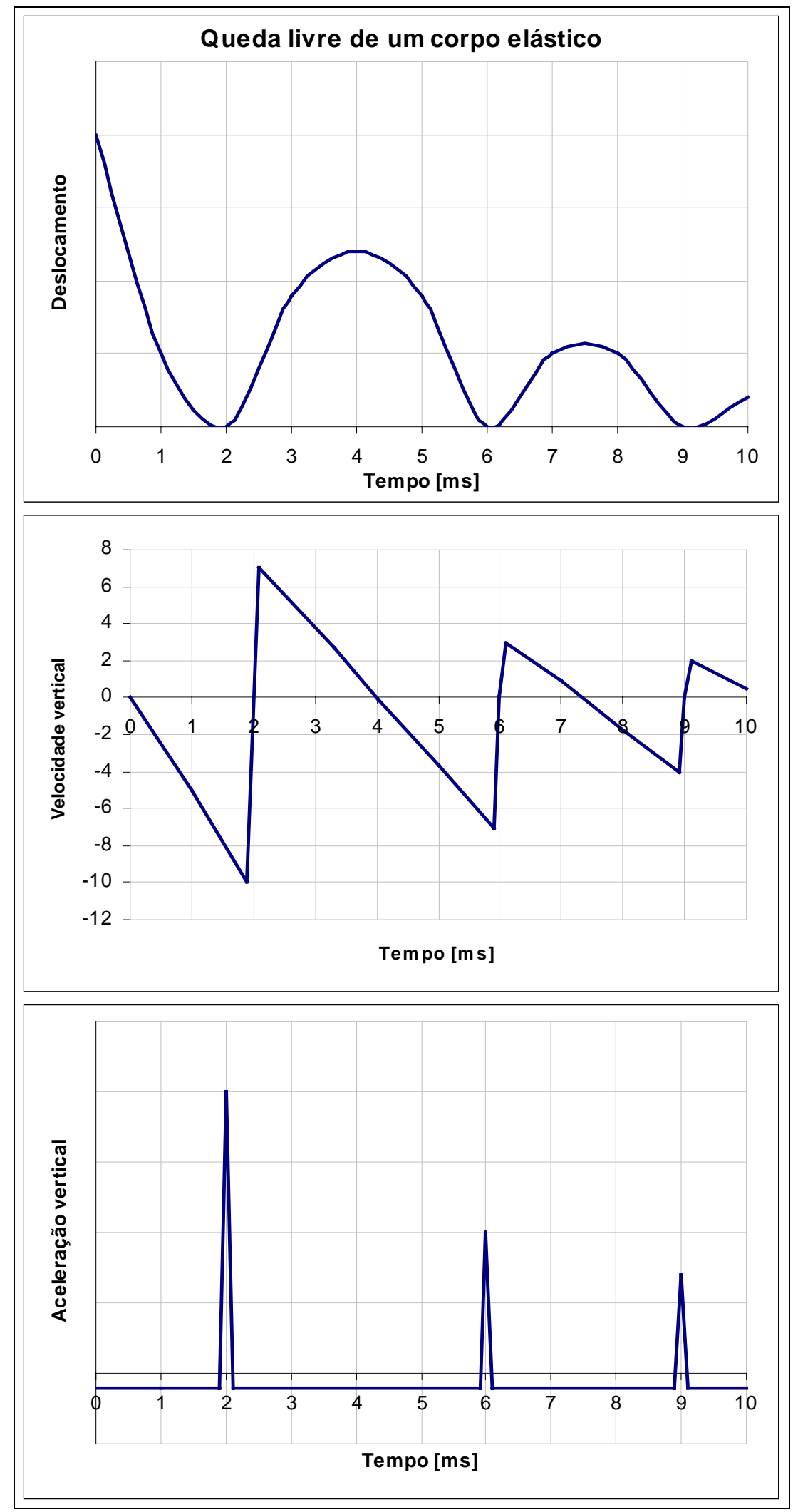

FIGURA 6.2: Gráficos ilustrativos de deslocamento, velocidade e aceleração contra tempo [ms], da queda livre de um corpo elástico. 
Este é o caso de uma colisão bastante idealizada, apresentada para visualizar o problema. Agora será visto o caso da queda do container sendo analisado.

Todas as simulações apresentadas foram realizadas com tempo de 0,025 segundos, suficiente para permitir o primeiro impacto, o qual gera a maior tensão. Os resultados de cada simulação foram armazenados em 1000 passos.

Utilizando uma linguagem computacional própria do ANSYS/LS-DYNA (APDL - ANSYS Parametric Design Language), foram implementadas, pelo autor, rotinas que permitiram determinar qual a maior tensão à qual foi submetido o modelo, em que passo (sub step) aconteceu, qual o nó mais solicitado (tensionado) e qual o componente que o possui. Tais rotinas utilizam dados armazenados num arquivo de resultados (*.rst) que o ANSYS/LS-DYNA cria após rodar uma simulação. No Apêndice II desta dissertação são apresentadas as rotinas implementadas para a obtenção destes dados.

Para simular as várias severidades do impacto, foram estudados 3 casos, conforme comentado no capítulo anterior: quina, chapa e chanfro.

\subsection{Situação quina}

Os resultados da situação quina são mostrados nas figuras 6.3 a 6.11 .

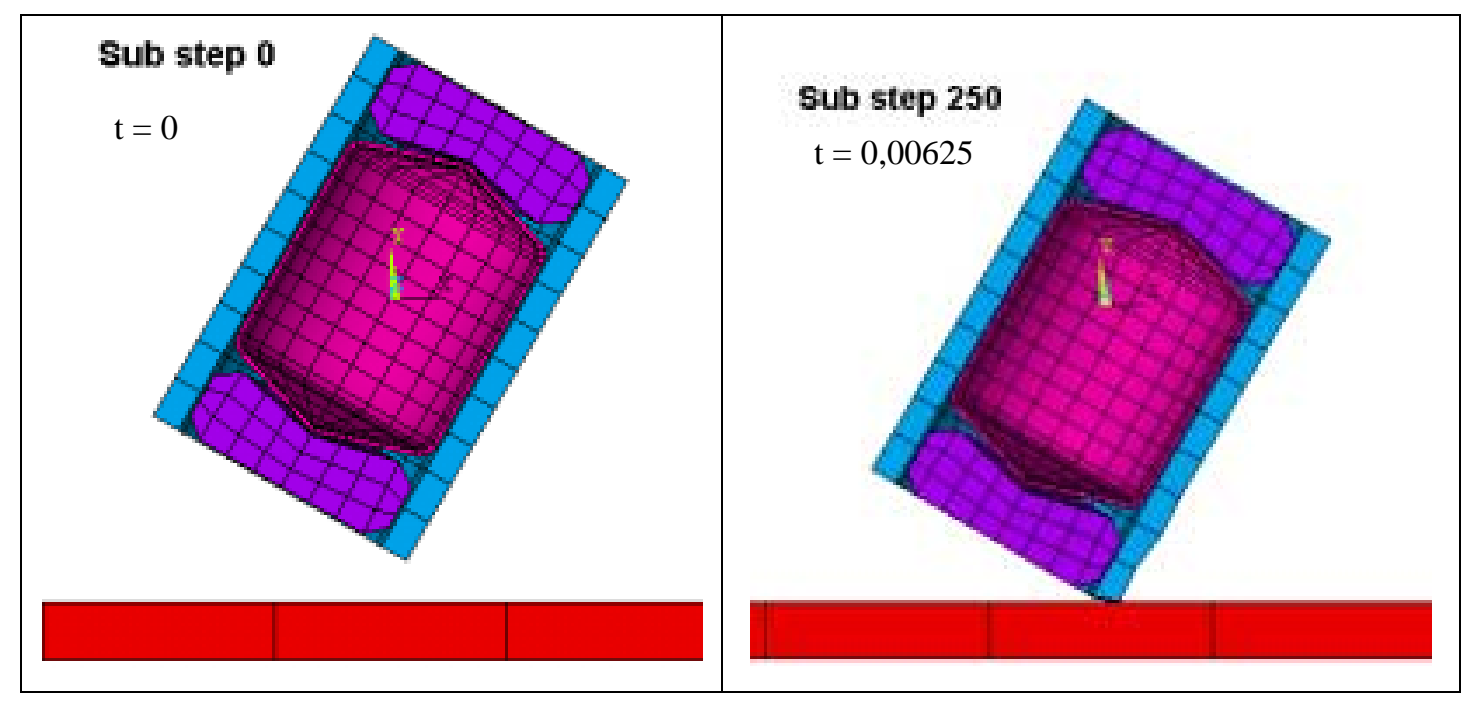




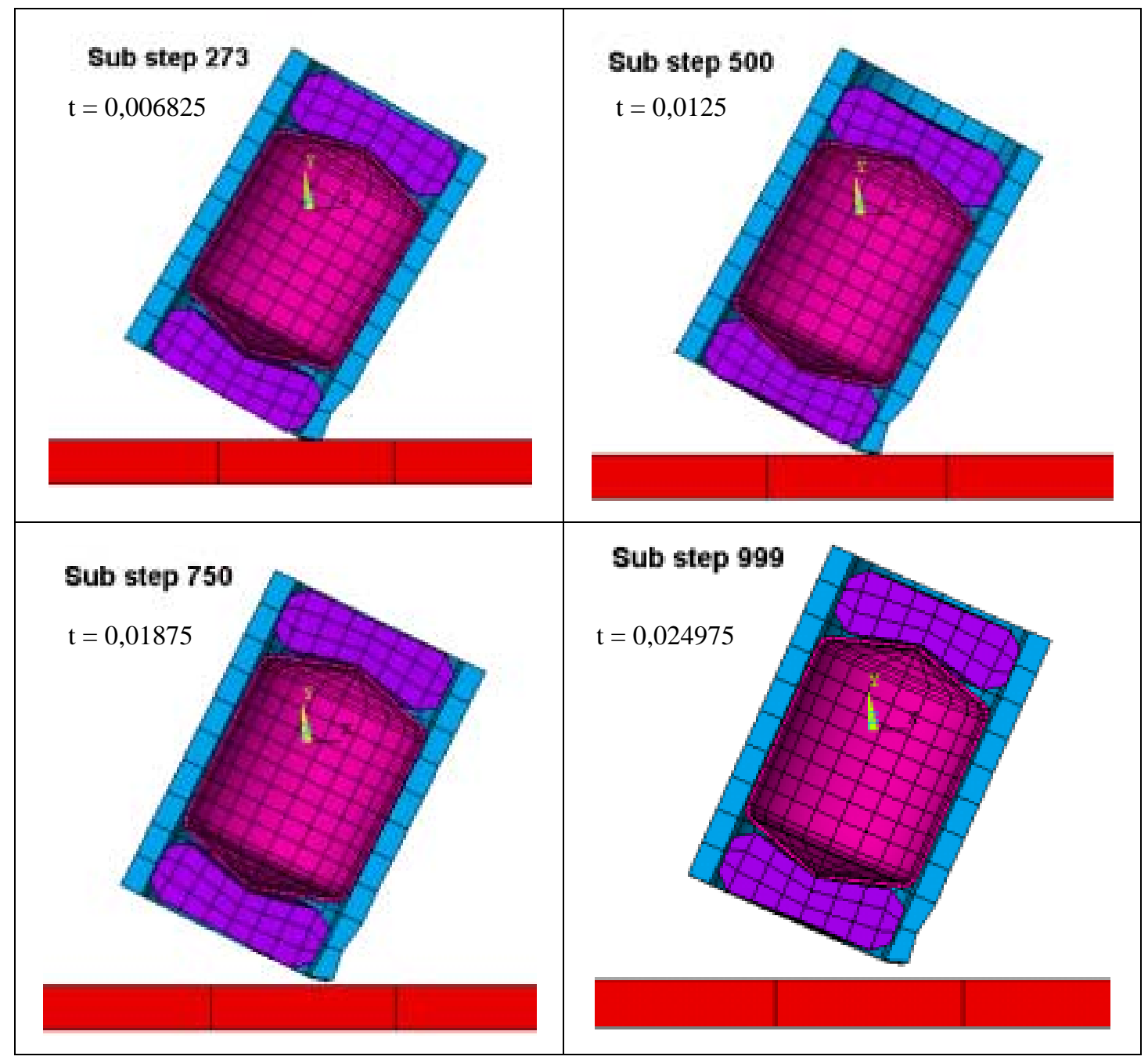

Figura 6.3: Mostra sequiência da simulação do container (em corte transversal) com tempo de duração de 0,025 segundos e dividida em 1000 passos. Nesta seqüência pode ser notado o container colidindo, mantendo-se em contato contra a superfície por um período de tempo e se deslocando verticalmente novamente.

As rotinas implementadas proporcionaram os seguintes resultados:

\begin{tabular}{|l|c|}
\hline Sub Step onde ocorre a maior tensão* & 273 \\
\hline Nó no qual ocorre a maior tensão* & 12 \\
\hline Valor da maior tensão* [MPa] & 578,4 \\
\hline Componente onde ocorre a maior tensão* & Cilindro \\
\hline Maior tensão no componente cápsula [MPa]* & 310,6 \\
\hline Nó da cápsula no qual ocorre a maior tensão* & 1437 \\
\hline
\end{tabular}

*Tensão de von Mises 


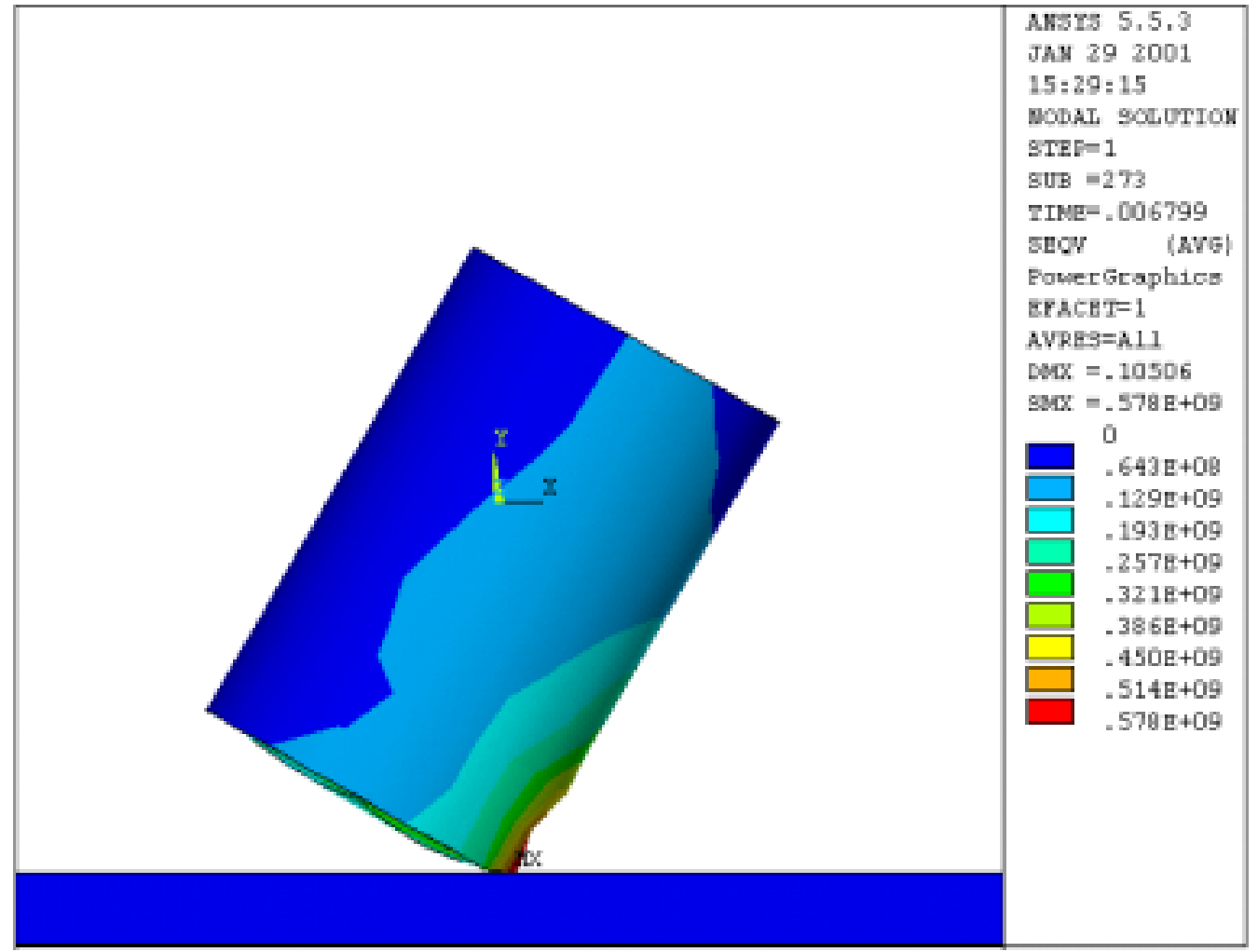

FIGURA 6.4 : Vista frontal do modelo no passo 273 e tempo de 0,0068 segundos, no qual ocorre a maior tensão (578 MPa).

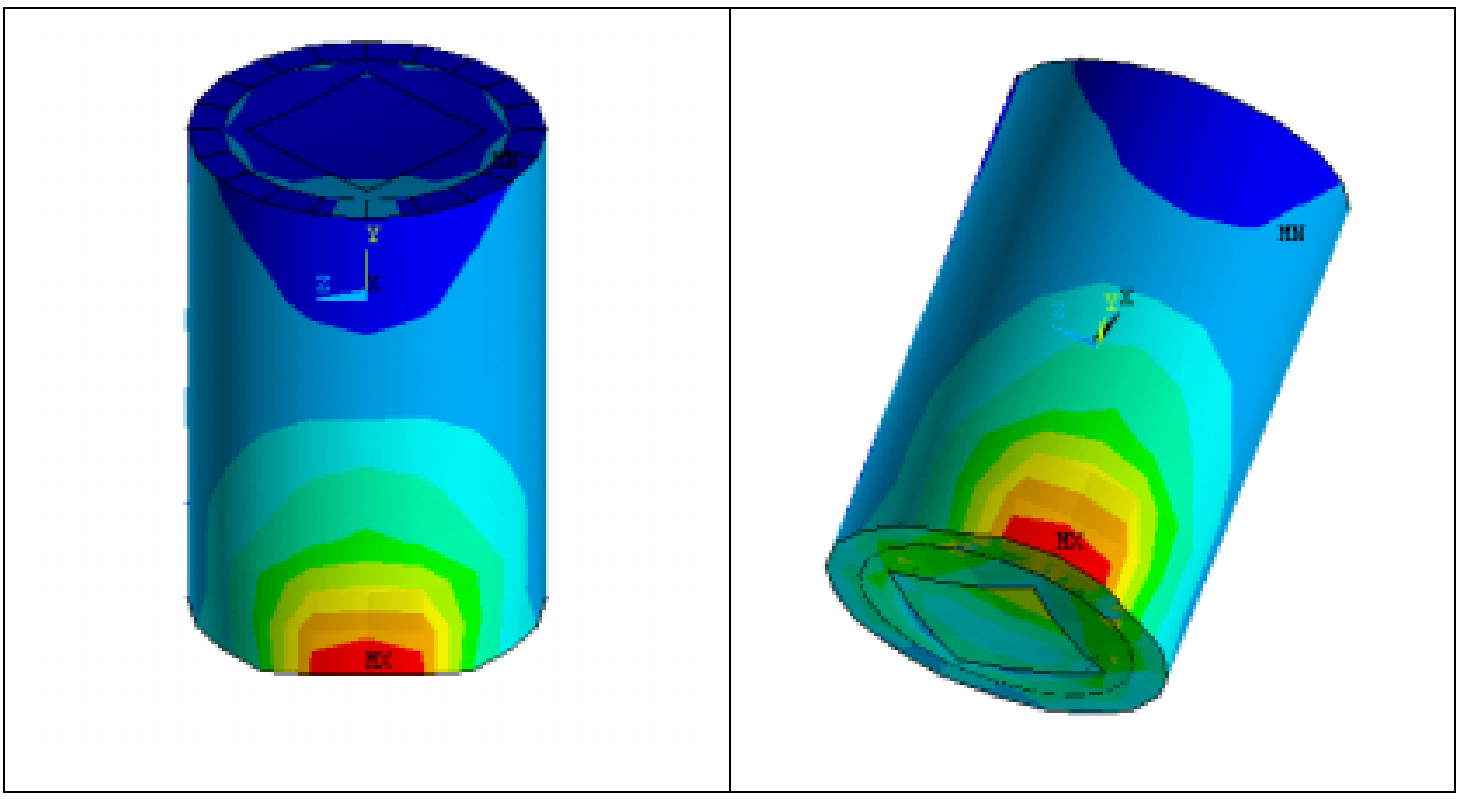

FIGURA 6.5: Vistas do modelo no passo 273 que mostram onde ocorre a maior tensão. 


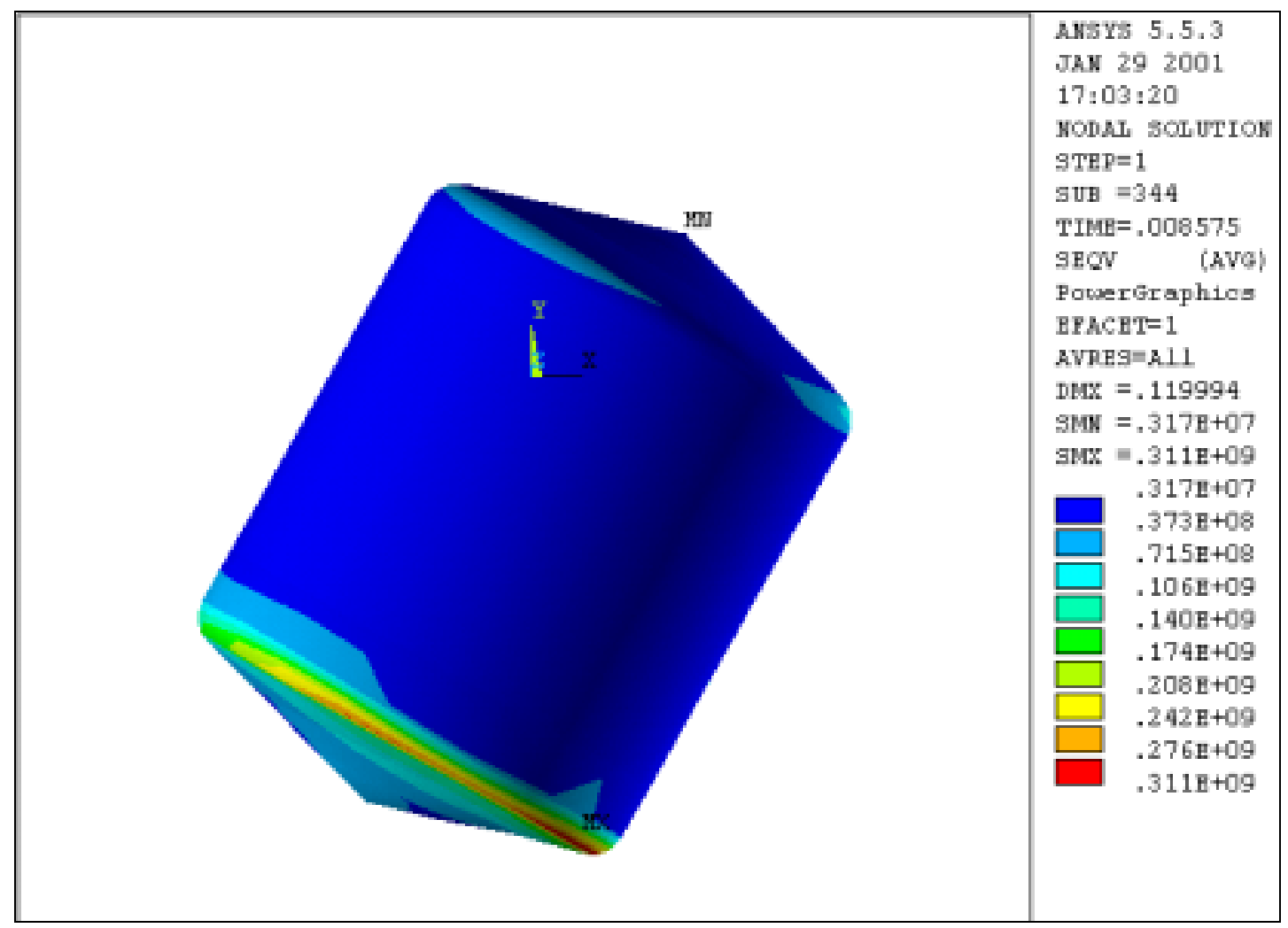

FIGURA 6.6: Vista frontal do componente cápsula no passo 344 e tempo de 0,0086 segundos, onde ocorre a maior tensão para este componente (310,6 MPa).

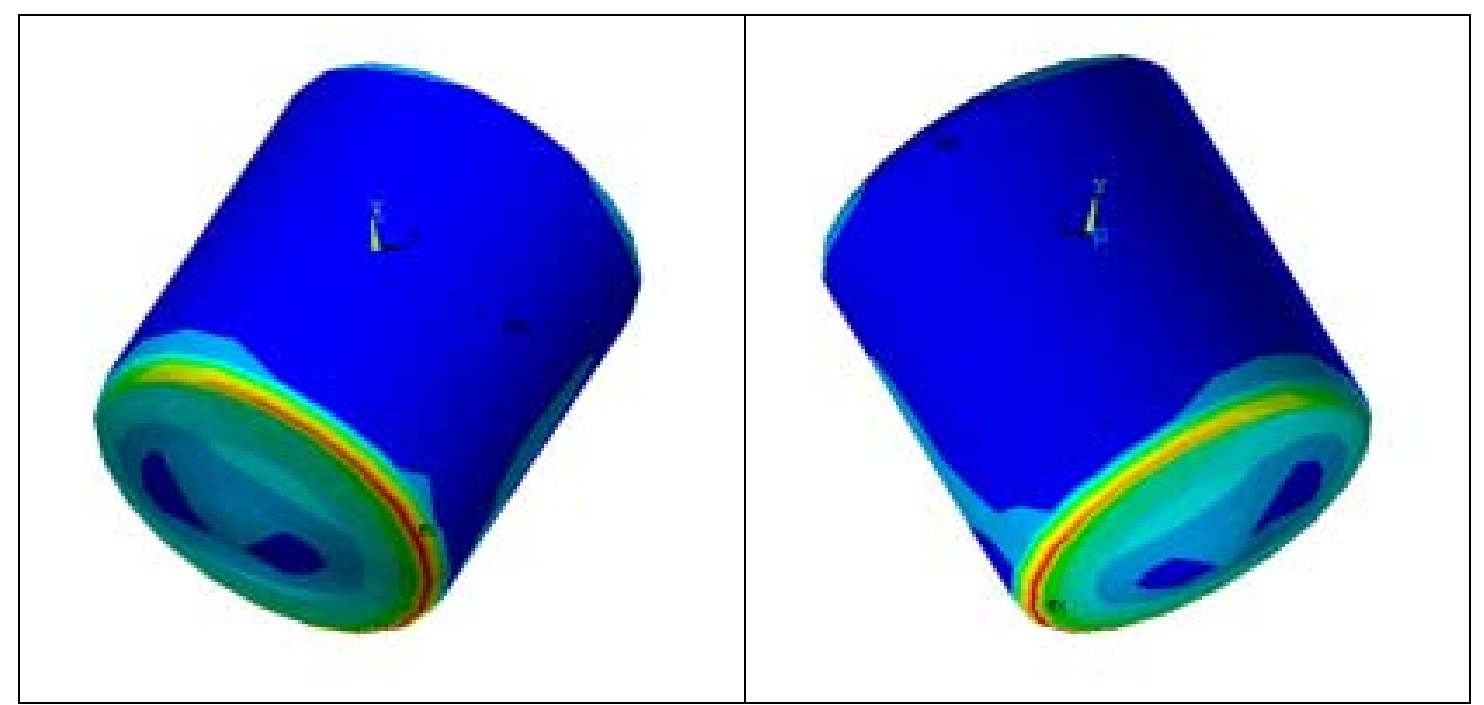

FIGURA 6.7: Vistas do componente cápsula no passo 344 onde ocorre maior tensão para este componente. 
Para efeito de comparação foram gerados gráficos de aceleração do nó mais solicitado do componente cilindro, componente cápsula e de um nó de referência (nó interno da cápsula) mostrado na figura 6.8. Nota-se que as tensões induzidas no cilindro (578 MPa máx) são bastante superiores àquelas obtidas para a cápsula (310,6 MPa max). Isto quer dizer que, a maior parte da energia de impacto é absorvida pelo componente cilindro. Comportamento semelhante foi obtido nas duas outras situações.

O máximo valor de tensão foi localizado no componente cilindro (578 MPa), este valor é $67 \%$ acima da tensão de escoamento (345 MPa) do material (alumínio 2024-T3), isto indica que este componente sofre deformações permanentes. Contudo, o maior valor de tensão localizado no componente crítico cápsula $(310,6 \mathrm{MPa})$ é inferior à tensão de escoamento do material, indicando que a cápsula não sofre deformações permanentes.

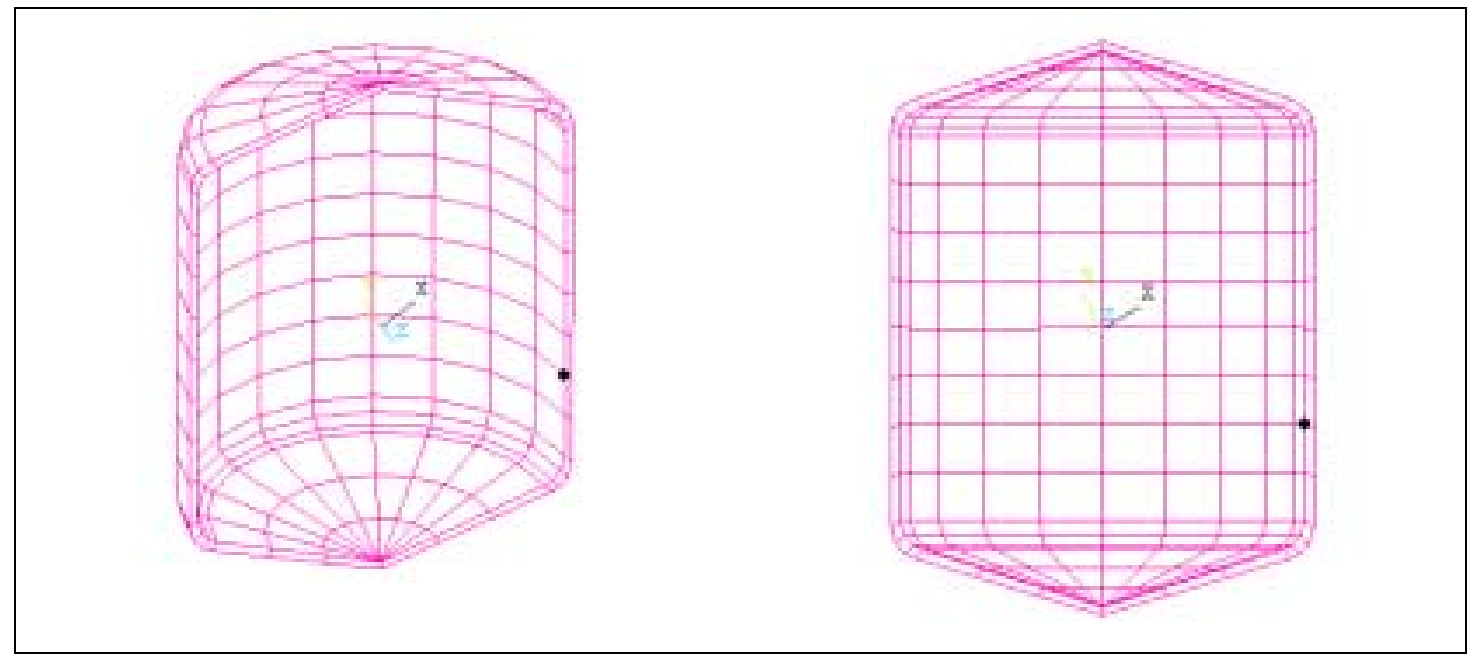

FIGURA 6.8: Vistas em corte do componente cápsula mostrando a localização do nó de referência dentro da cápsula, em todas as situações.

Nas figuras referentes às acelerações, não podem deixar de serem notados dois aspectos relevantes: os altos valores de aceleração atingidos e as fortes oscilações (vibrações). Estes aspectos são comentados a seguir. 


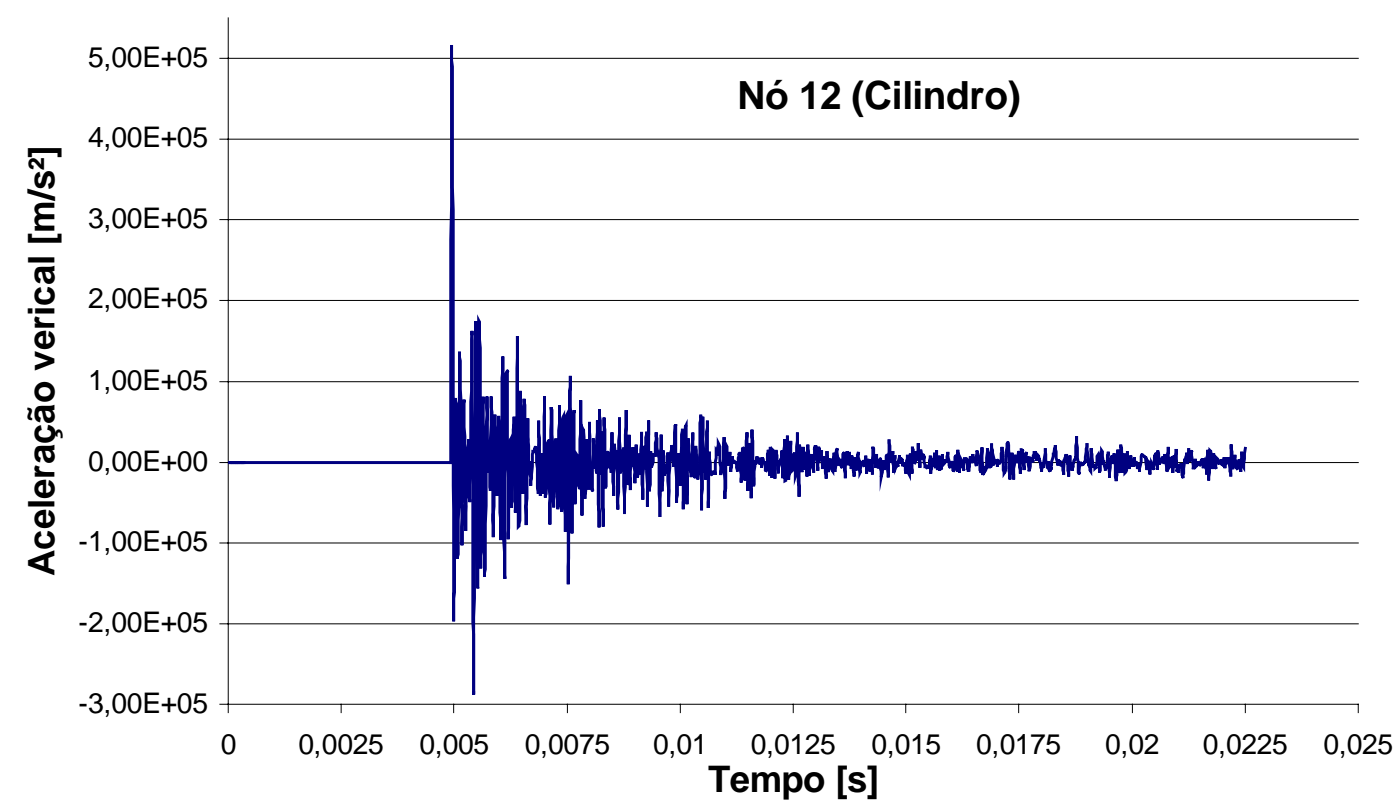

FIGURA 6.9: Aceleração na direção vertical Y do nó 12 do cilindro $\left[\mathrm{m} / \mathrm{s}^{2}\right]$ através dos 1000 passos da simulação.

Neste gráfico pode ser observado um pico máximo de aceleração de 512702 $\mathrm{m} / \mathrm{s}^{2}$, isto é $51270,2 \mathrm{~g}$ 's.

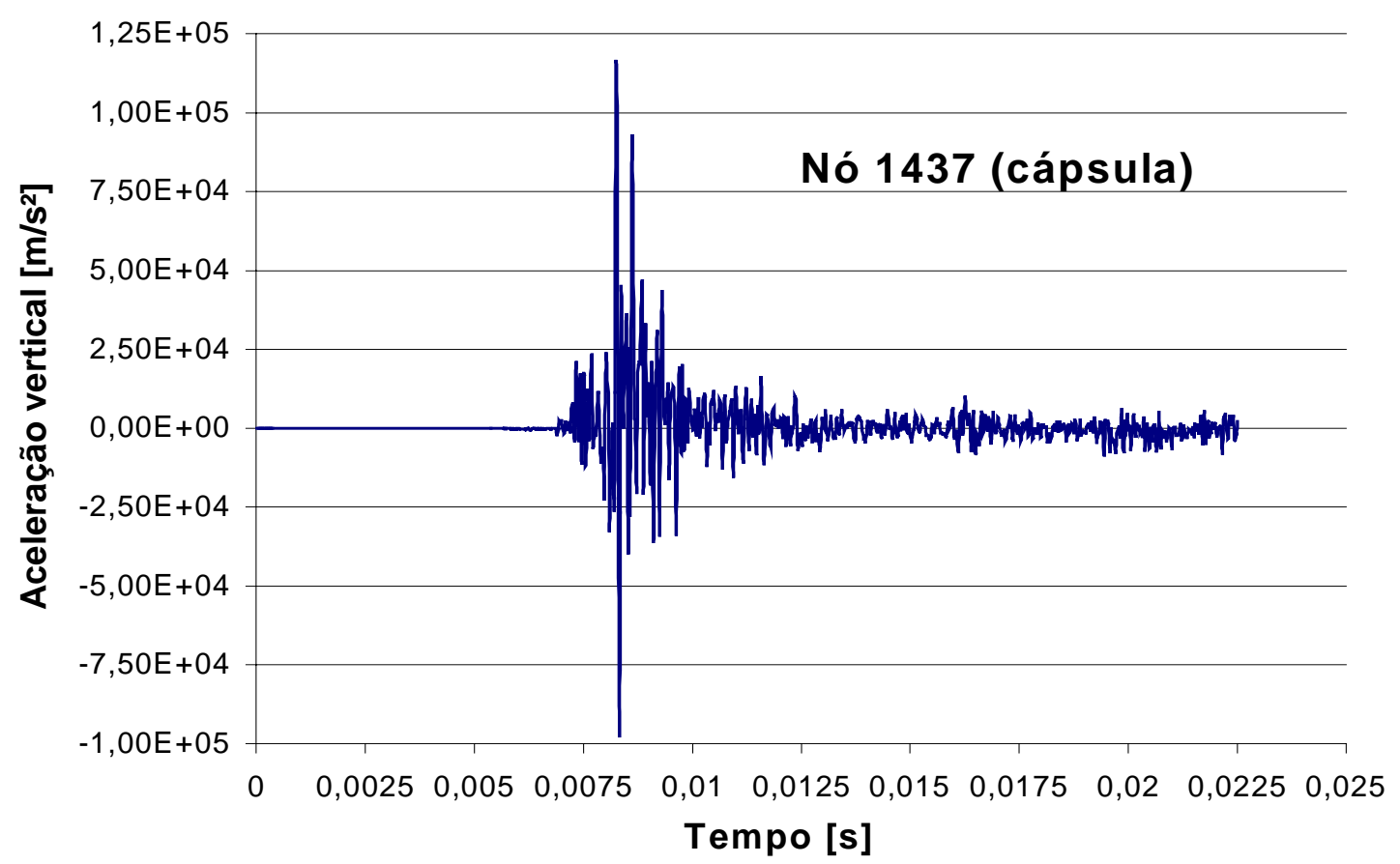

FIGURA 6.10: Aceleração na direção vertical Y $\left[\mathrm{m} / \mathrm{s}^{2}\right]$ do nó 1437 (nó mais tensionado do componente cápsula) através dos 1000 passos da simulação. Mostra um pico máximo de aproximadamente 11540 g's. 


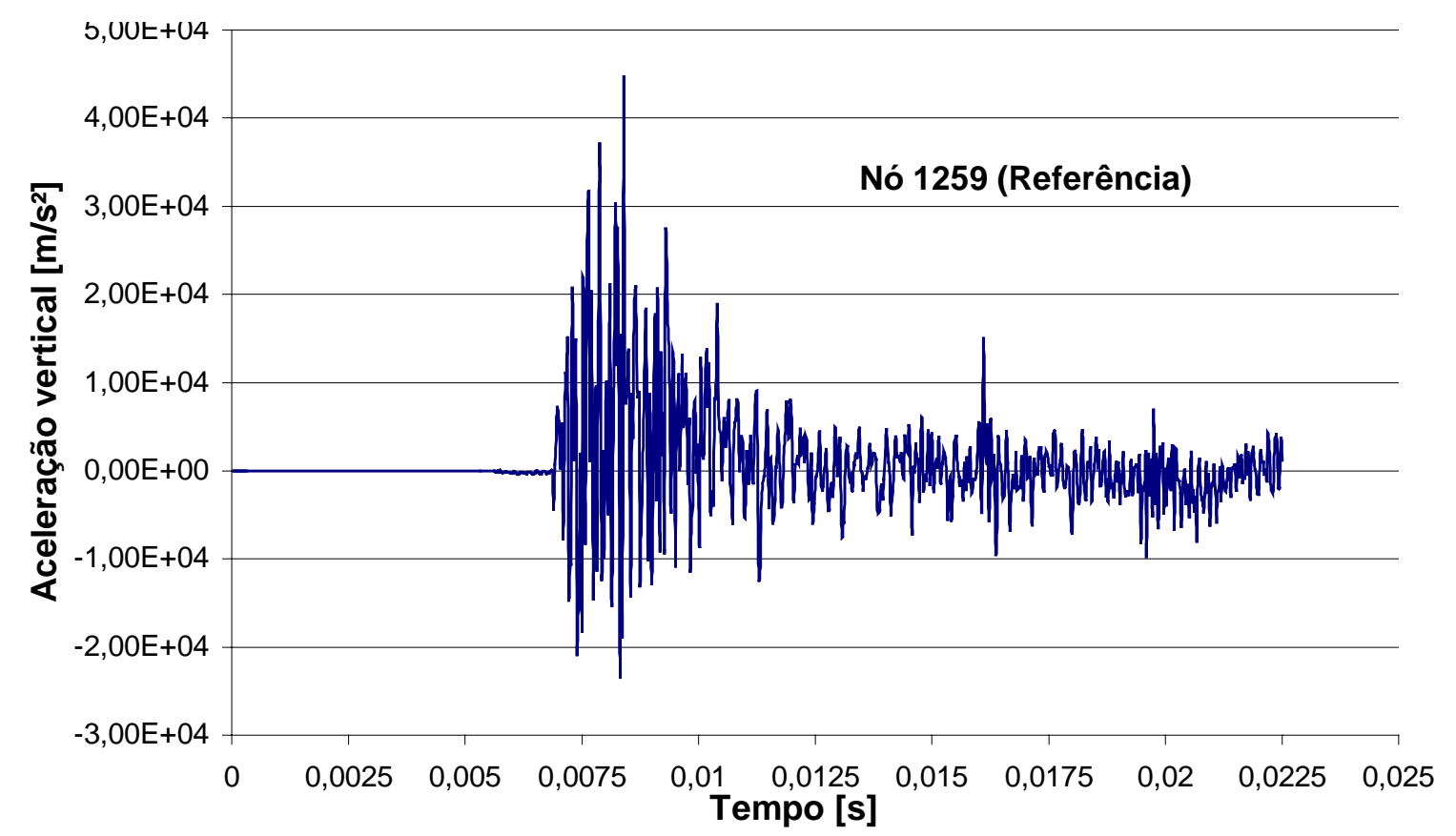

FIGURA 6.11: Aceleração na direção vertical Y $\left[\mathrm{m} / \mathrm{s}^{2}\right]$ do nó 1259 , nó de referência da cápsula, através dos 1000 passos da simulação. Mostra um pico máximo de aproximadamente 4443 g's.

Nas figuras 6.9 a 6.11 apresentadas, as maiores oscilações podem ser atribuídas a três causas principais:

- Sistema de $n$ graus de liberdade: ao contrário do exemplo apresentado no inicio deste capitulo (queda de corpo elástico) feito de apenas um nó, os modelos simulados possuem mais de 1800 nós. Isto é, enquanto alguns nós estão se deslocando livremente, outros estão entrando em contato ou rotacionando, ou seja, existem forte movimento relativo entre os nós. Ou ainda mais, enquanto o centro de massa desloca-se de maneira suave, os pontos podem estar vibrando bastante.

- Instabilidade devida ao algoritmo de contato que considera uma distância de tolerância ao detectar penetração de nós ou superfícies. Ou seja, um nó dentro da zona de tolerância é considerado em contato, mesmo que isto não ocorra geometricamente. Este fato causa instabilidade numérica no algoritmo que resulta, desta forma, em oscilações.

- Devido ao algoritmo de integração no tempo, utilizado pelo programa de elementos finitos, ser explicito, são necessários intervalos de tempo $\Delta \mathrm{t}$ 
extremamente pequenos (da ordem de $2,34 \times 10^{-6}$ segundos). Desta forma modos sumamente elevados tornam-se importantes.

Este tipo de comportamento poderá ser notado também nas figuras correspondentes aos gráficos das situações "chapa" e "chanfro".

\subsection{Situação chapa}

Os resultados da situação chapa são mostrados nas figuras 6.12 a 6.18 .

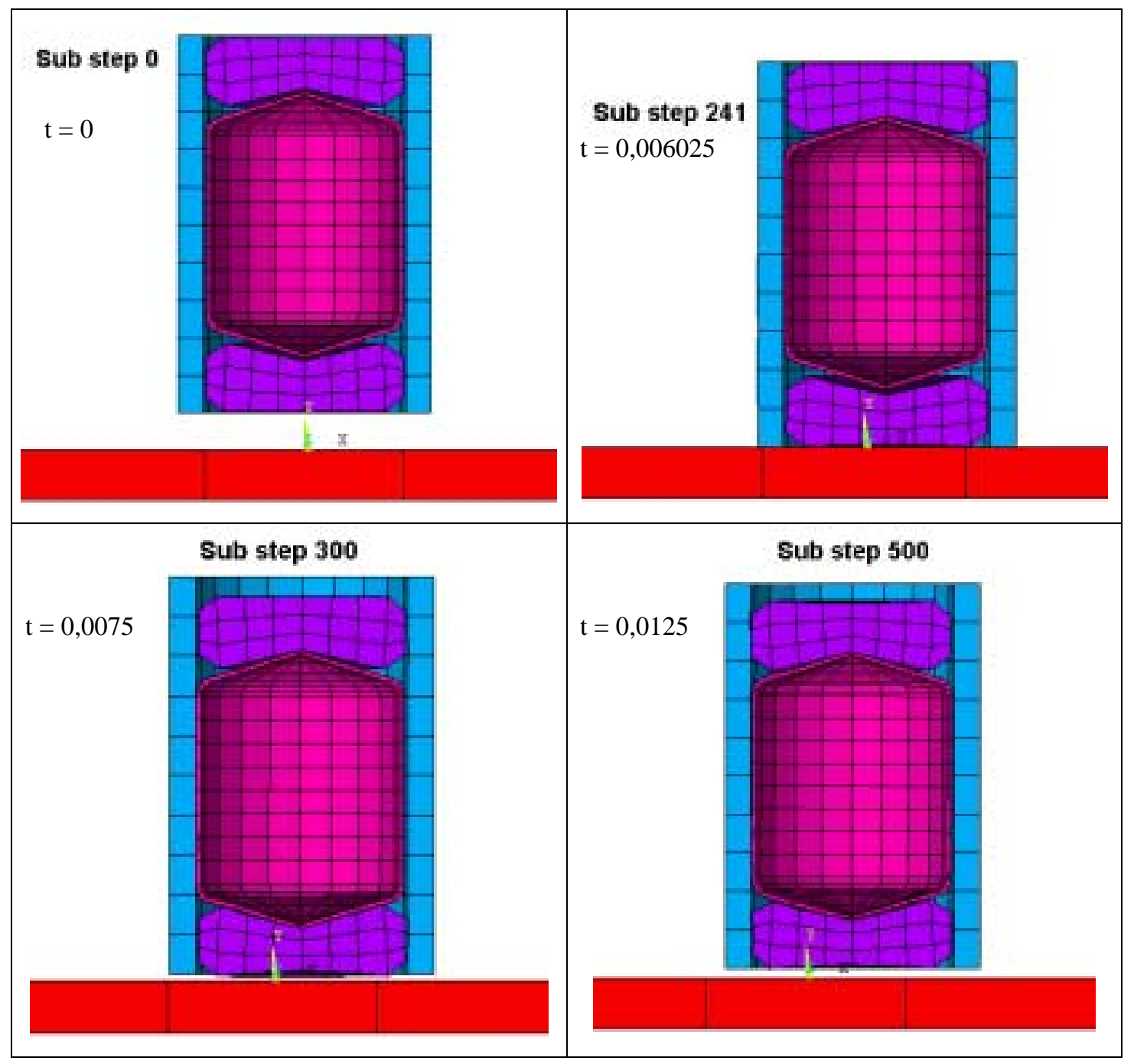




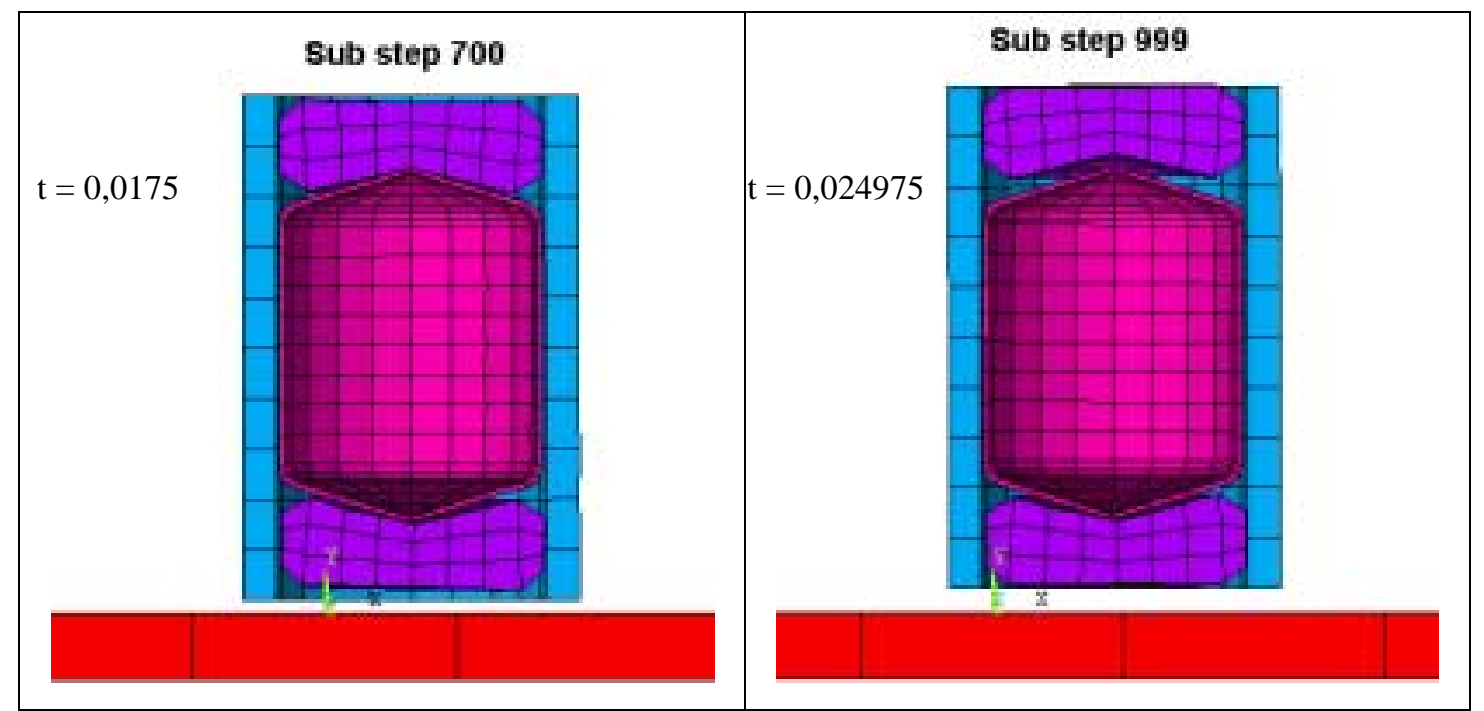

FIGURA 6.12 : Seqüência da simulação do modelo da situação chapa. Mostra o container colidindo, se mantendo em contato contra a superfície e se deslocando verticalmente.

Resultados obtidos através das rotinas APDL implementadas:

\begin{tabular}{|l|c|}
\hline Sub Step onde ocorre a maior tensão* & 241 \\
\hline Nó no qual ocorre a maior tensão* & 32 \\
\hline Valor da maior tensão* [MPa] & 399,67 \\
\hline Componente onde ocorre a maior tensão* & Cilindro \\
\hline Maior tensão no componente cápsula [MPa]* & 359,8 \\
\hline Nó da cápsula no qual ocorre a maior tensão* & 1918 \\
\hline *Tensão de von Mises & \\
\hline
\end{tabular}




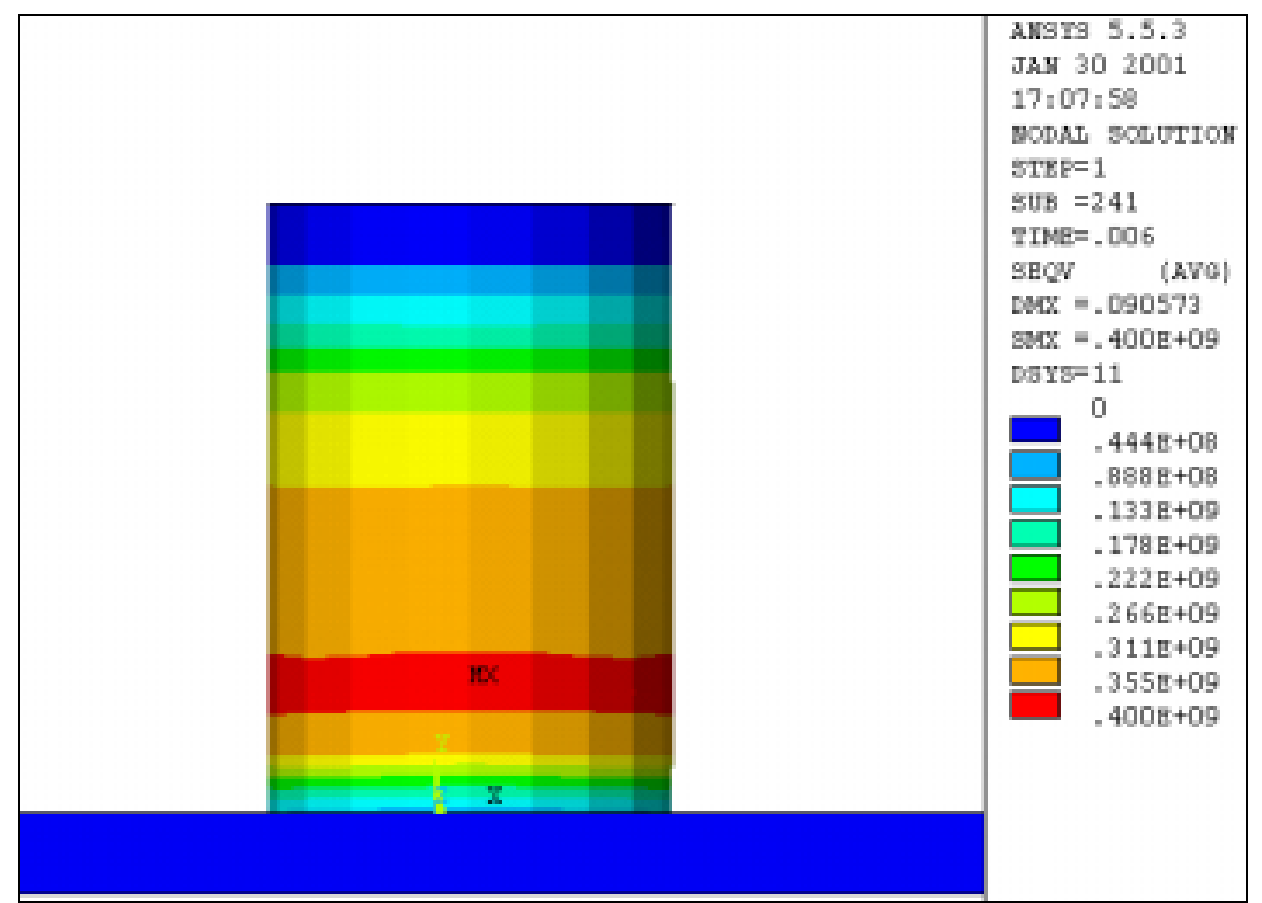

FIGURA 6.13: Vista frontal do modelo na situação chapa no passo 241 e tempo de 0,006 segundos, onde ocorre a maior tensão ao modelo (399,67 MPa).

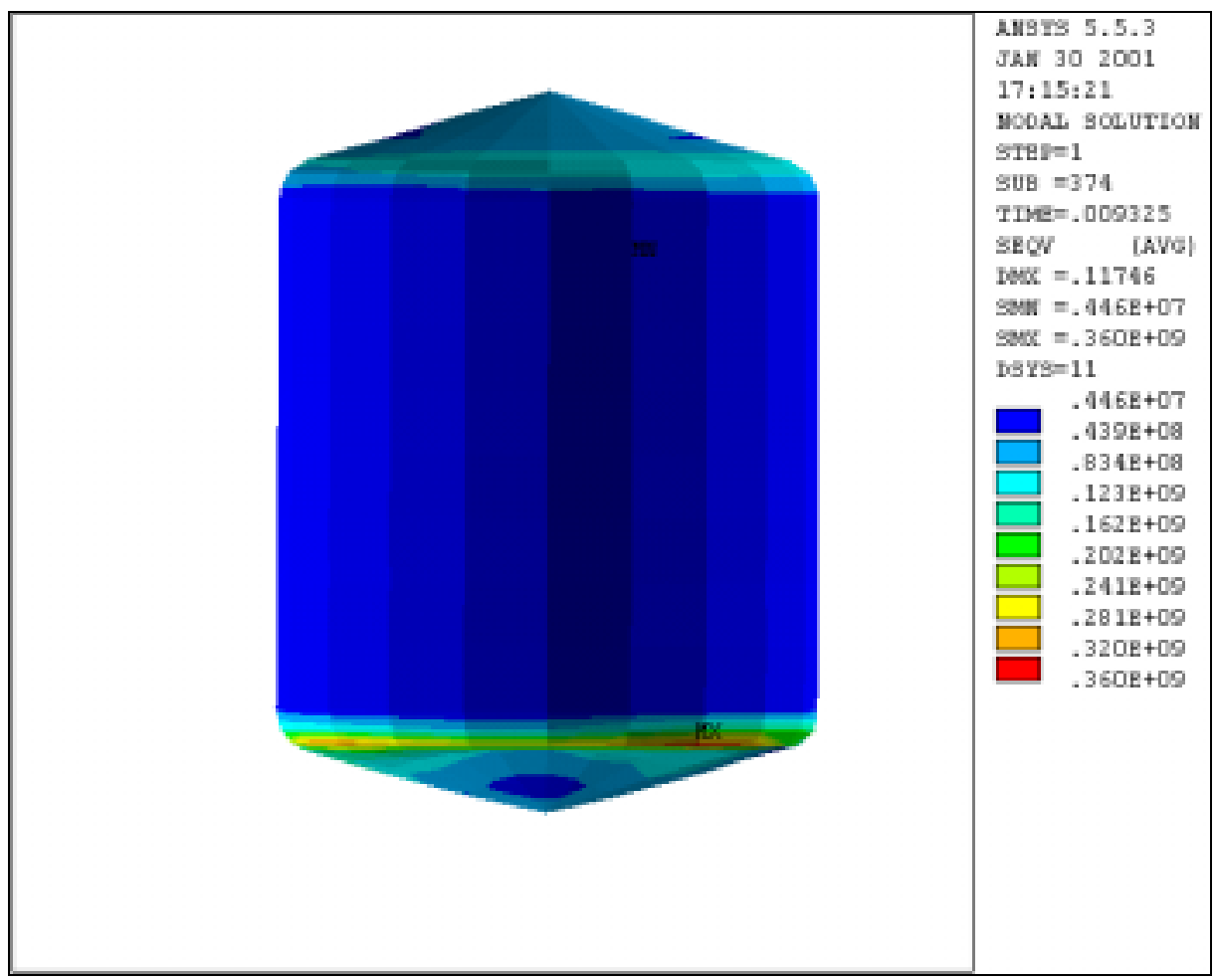

FIGURA 6.14: Vista frontal do componente cápsula da situação chapa no passo de simulação 374 e tempo de 0,0093 segundos, onde ocorre a maior tensão para este componente (360 MPa). 


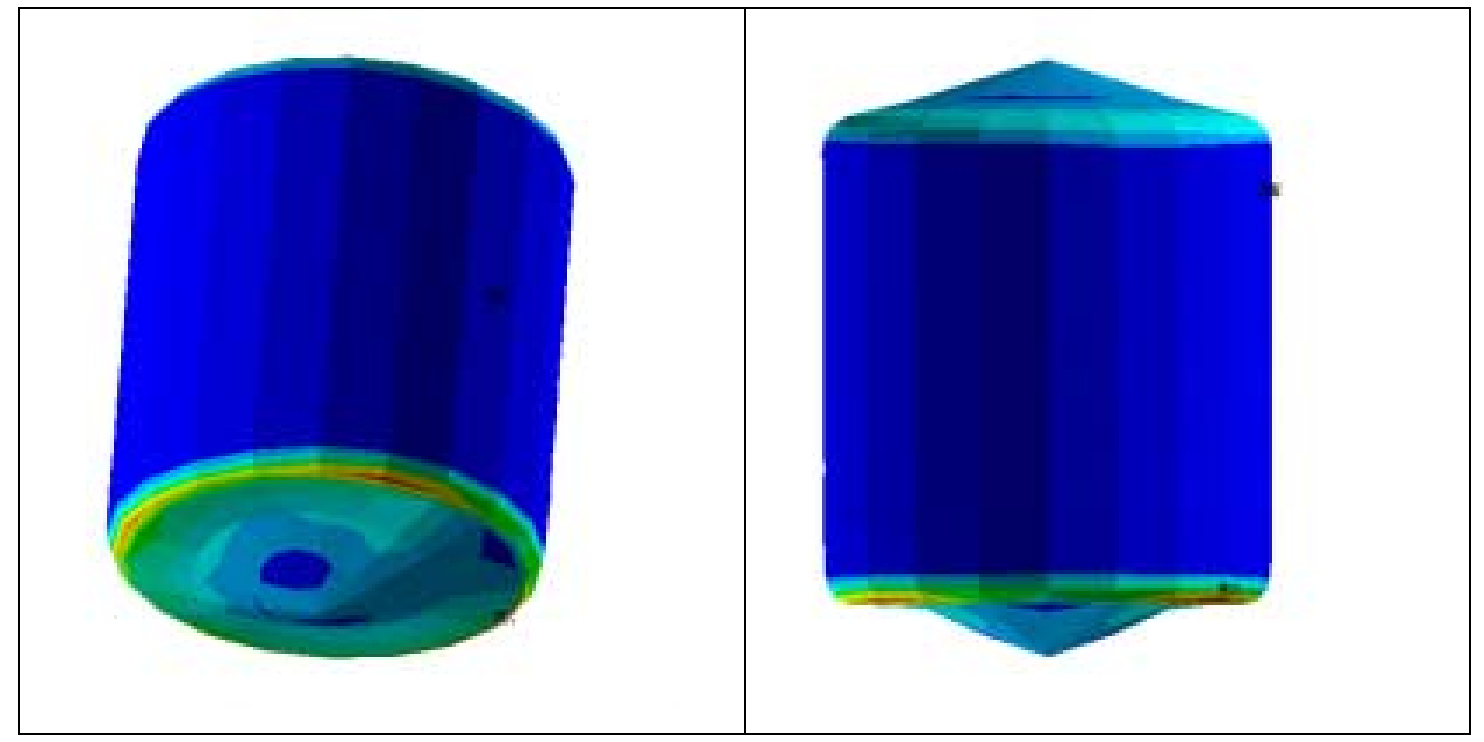

FIGURA 6.15: Vistas do componente cápsula no passo de simulação 374. Mostra deformações ocorridas neste componente.

A maior tensão foi localizada no componente cilindro (399,67 MPa), este valor é aproximadamente $16 \%$ superior a tensão de escoamento do material (alumínio 2024T3). Contudo, a máxima tensão localizada no componente crítico cápsula $(359,8$ $\mathrm{MPa}$ ) é 4,3\% maior que a tensão de escoamento. Isto indica que, tanto os componentes cilindro e cápsula sofrem deformações permanentes. Desta forma constata-se que, os componentes que envolvem a cápsula (cilindro e insertos) não conseguem absorver energia suficiente durante o impacto para manter a cápsula protegida o suficiente. Por outro lado, indica que uma parte da energia cinética foi absorvida para o trabalho plástico (é portanto irrecuperável).

A seguir são apresentadas figuras correspondentes aos gráficos de aceleração do nó mais tensionado, do nó mais tensionado da cápsula e do nó de referência. 


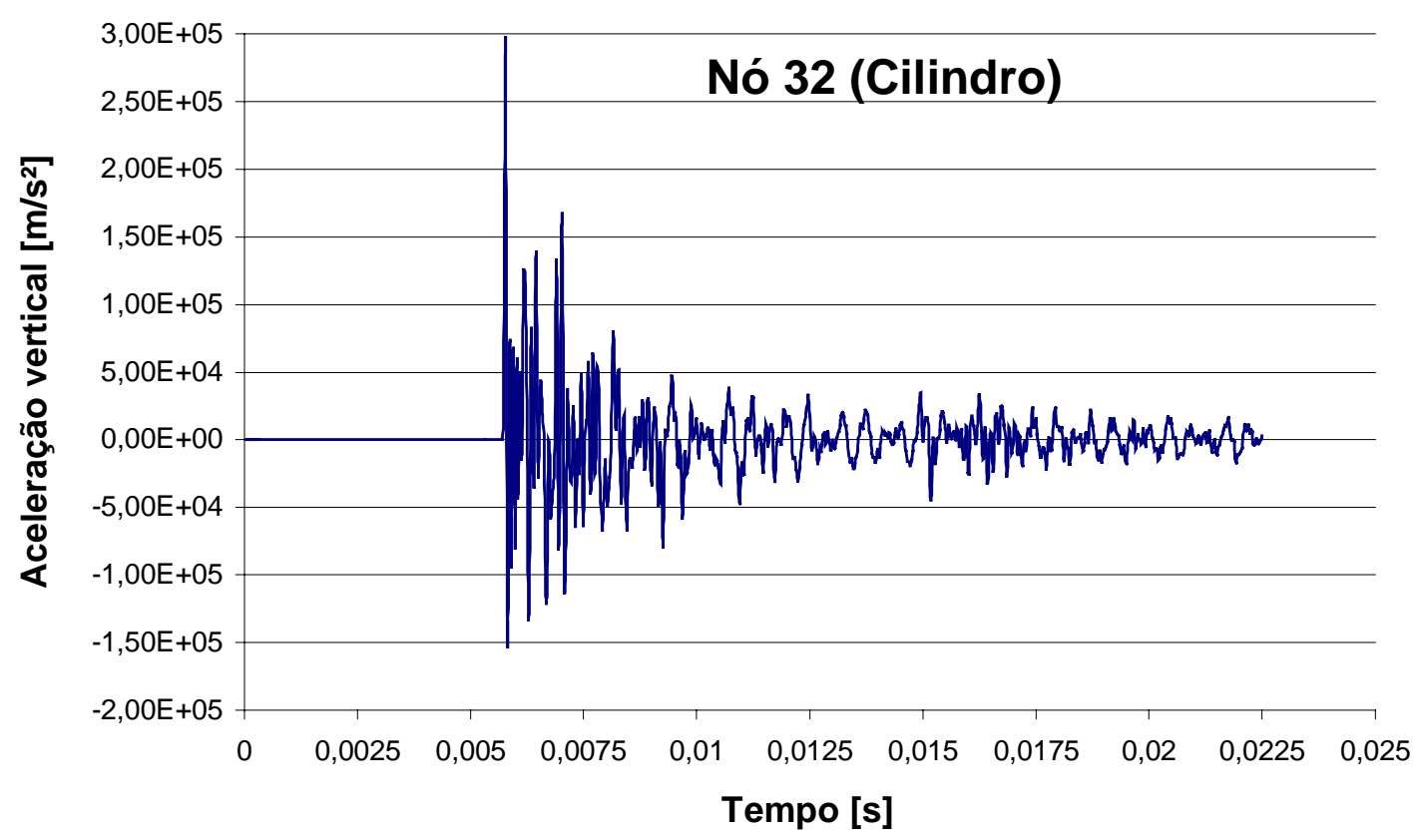

FIGURA 6.16: Aceleração vertical Y do nó 32, mostra um pico máximo de aceleração de $297432 \mathrm{~m} / \mathrm{s}^{2}$.

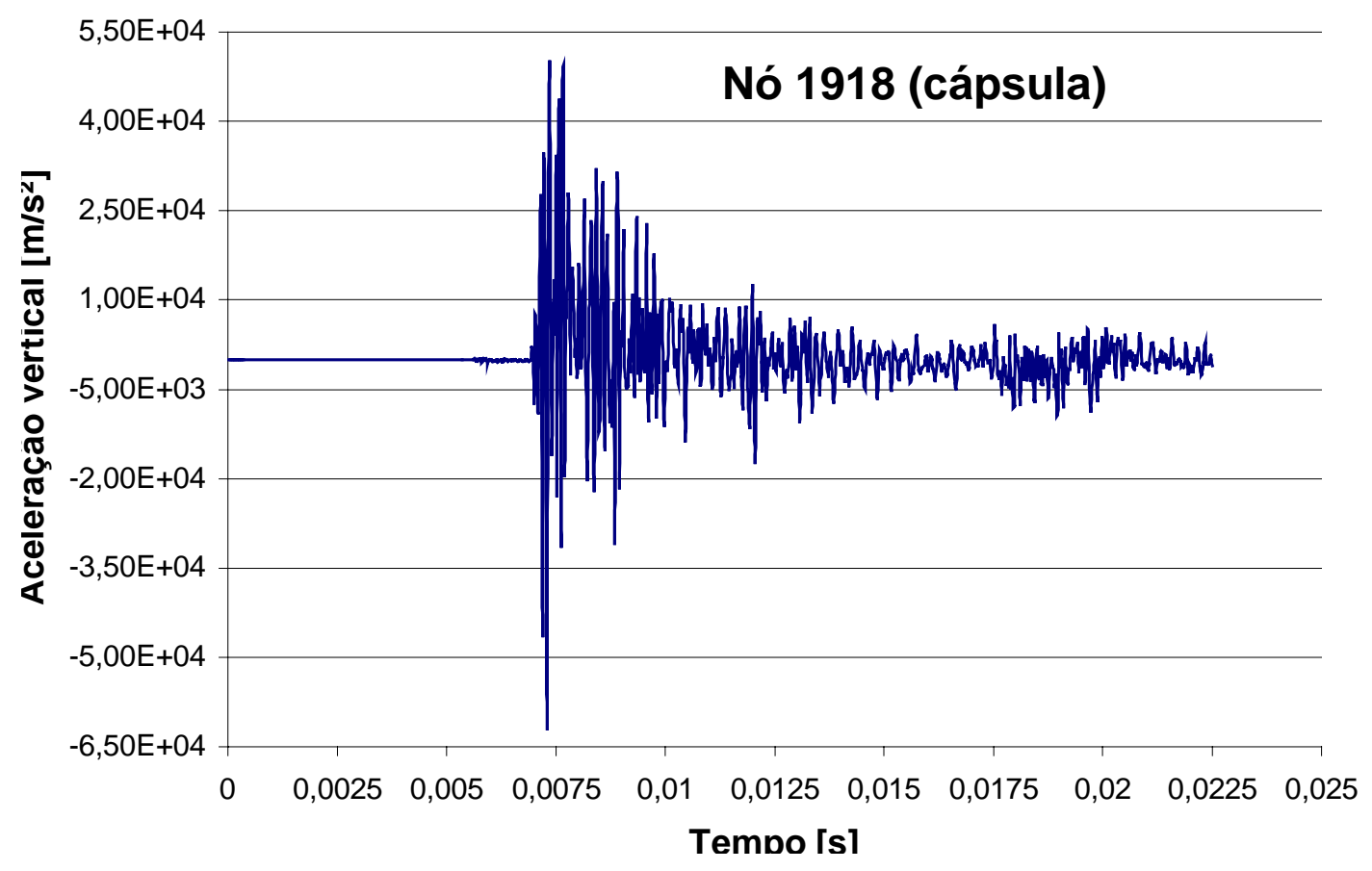

FIGURA 6.17: Aceleração vertical Y do nó 1918, mostra pico máximo de $-61894 \mathrm{~m} / \mathrm{s}^{2}$. 


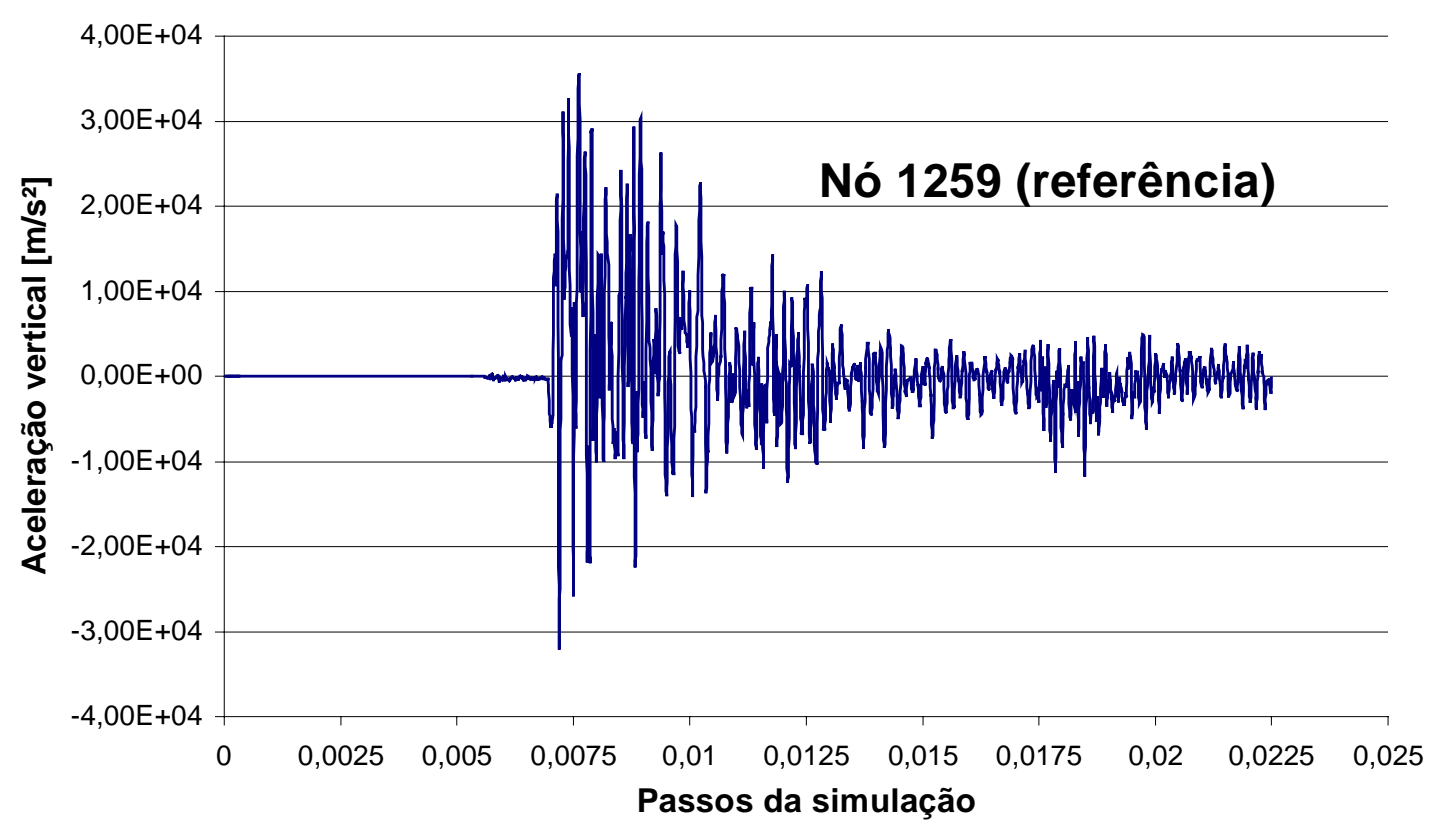

FIGURA 6.18: Aceleração vertical do nó de referência 1259, mostra um pico máximo de aceleração de $35308 \mathrm{~m} / \mathrm{s}^{2}$.

Como foi visto e explicado na situação anterior, podem ser notados nas figuras 6.16 a 6.18 desta situação picos máximos de aceleração muito elevados, assim como oscilações bruscas. 


\subsection{Situação chanfro}

Os resultados da situação chanfro são mostrados nas figuras 6.19 a 6.26.

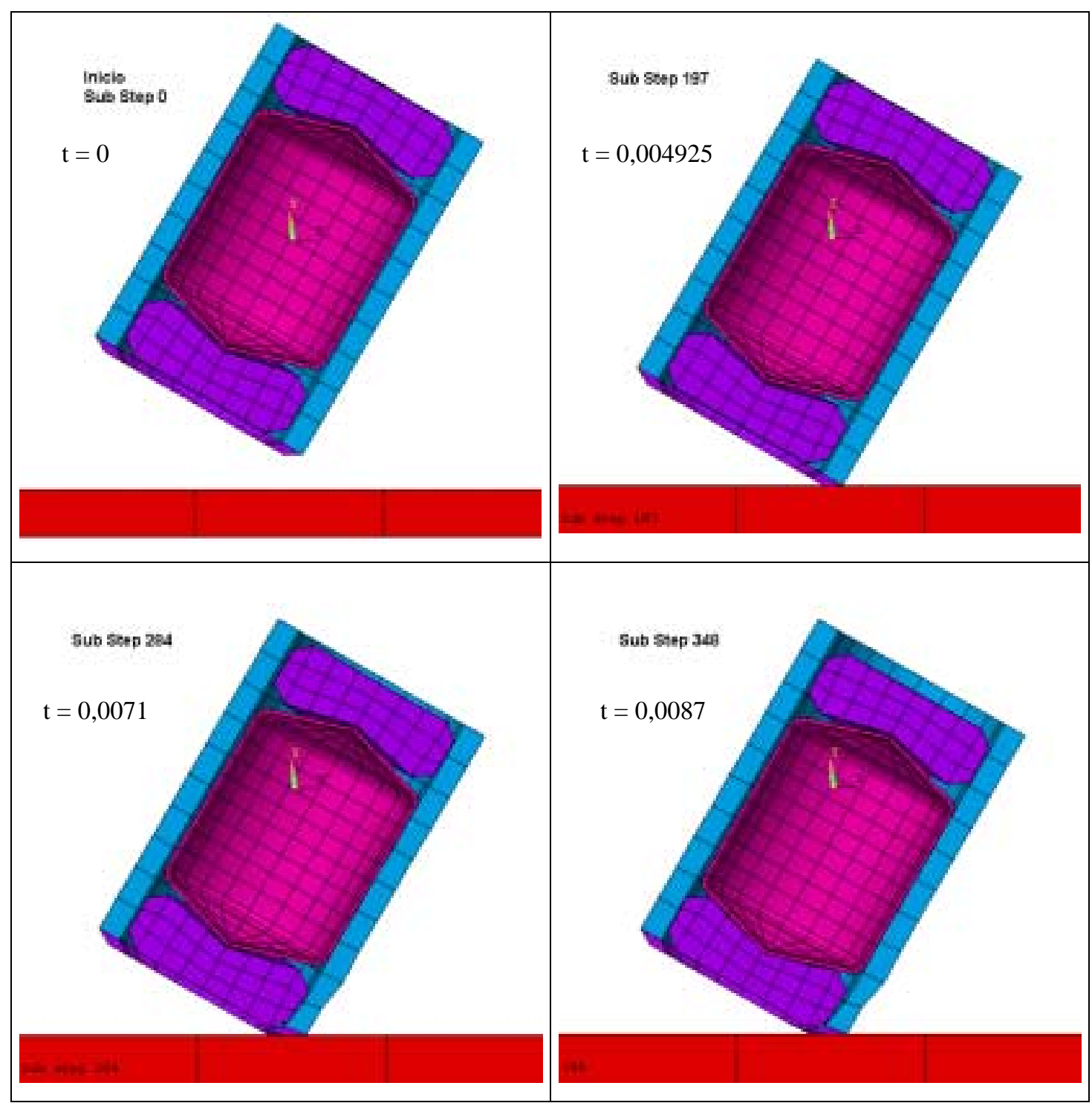




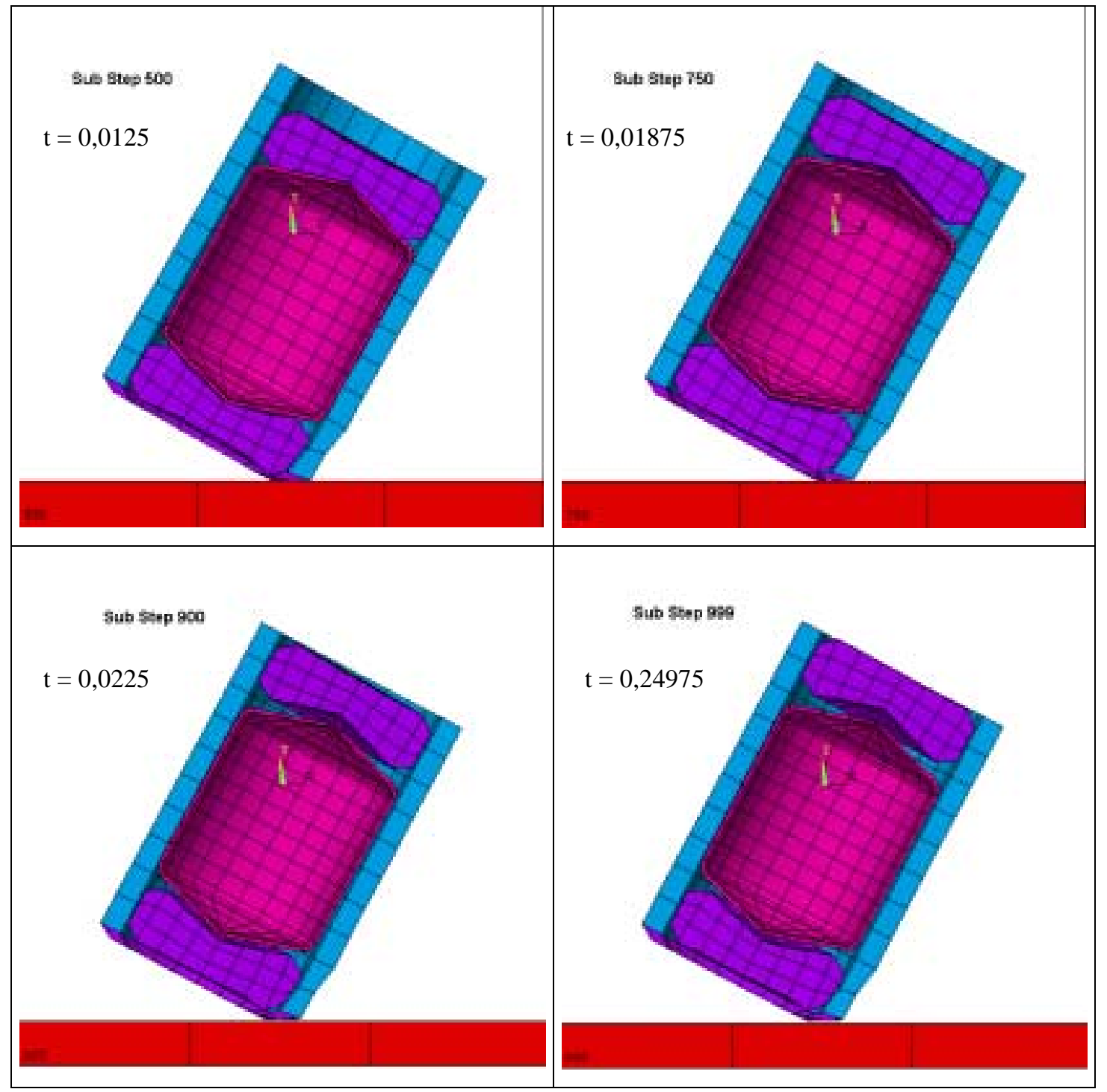

Figura 6.19: Sequiência da simulação do container na situação chanfro (em corte transversal) com tempo total de duração de $0,025 \mathrm{~s}$ e dividida em 1000 passos. Mostra o modelo colidindo, se mantendo em contato contra a superfície e se deslocando verticalmente.

As rotinas APDL implementadas nos proporcionaram os seguintes resultados desta situação: 


\begin{tabular}{|l|c|}
\hline Sub Step onde ocorre a maior tensão* & 284 \\
\hline Nó no qual ocorre a maior tensão* & 2 \\
\hline Valor da maior tensão* [MPa] & 335,86 \\
\hline Componente do Container onde ocorre a maior tensão* & Cilindro \\
\hline Maior tensão no componente cápsula [MPa]* & 185,48 \\
\hline Nó da cápsula no qual ocorre a maior tensão* & 1089 \\
\hline
\end{tabular}

*Tensão de Von Mises

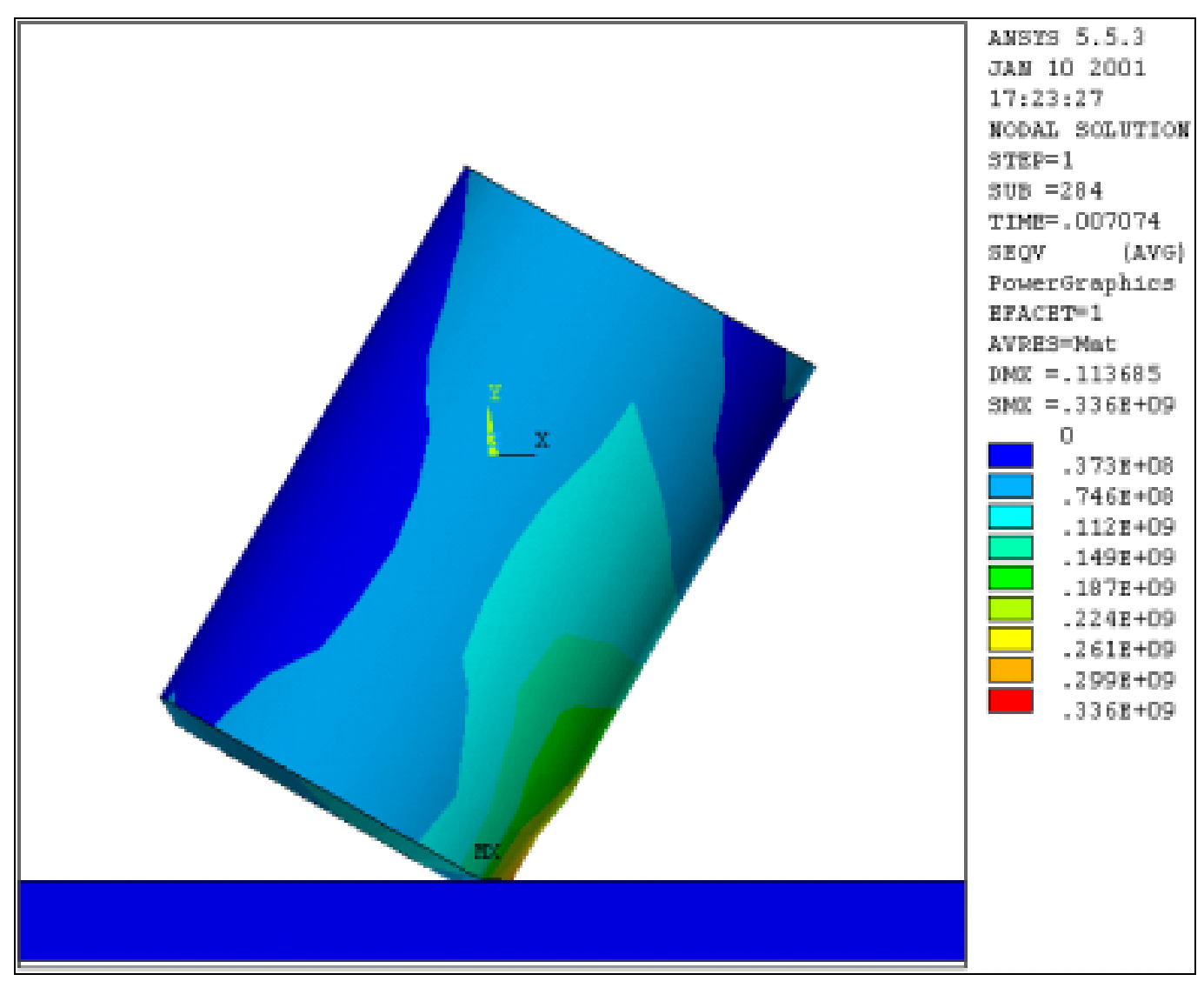

FIGURA 6.20: Vista frontal do modelo da situação chanfro no sub step 284 no qual ocorre a maior tensão $(335,86 \mathrm{MPa})$ no modelo. 


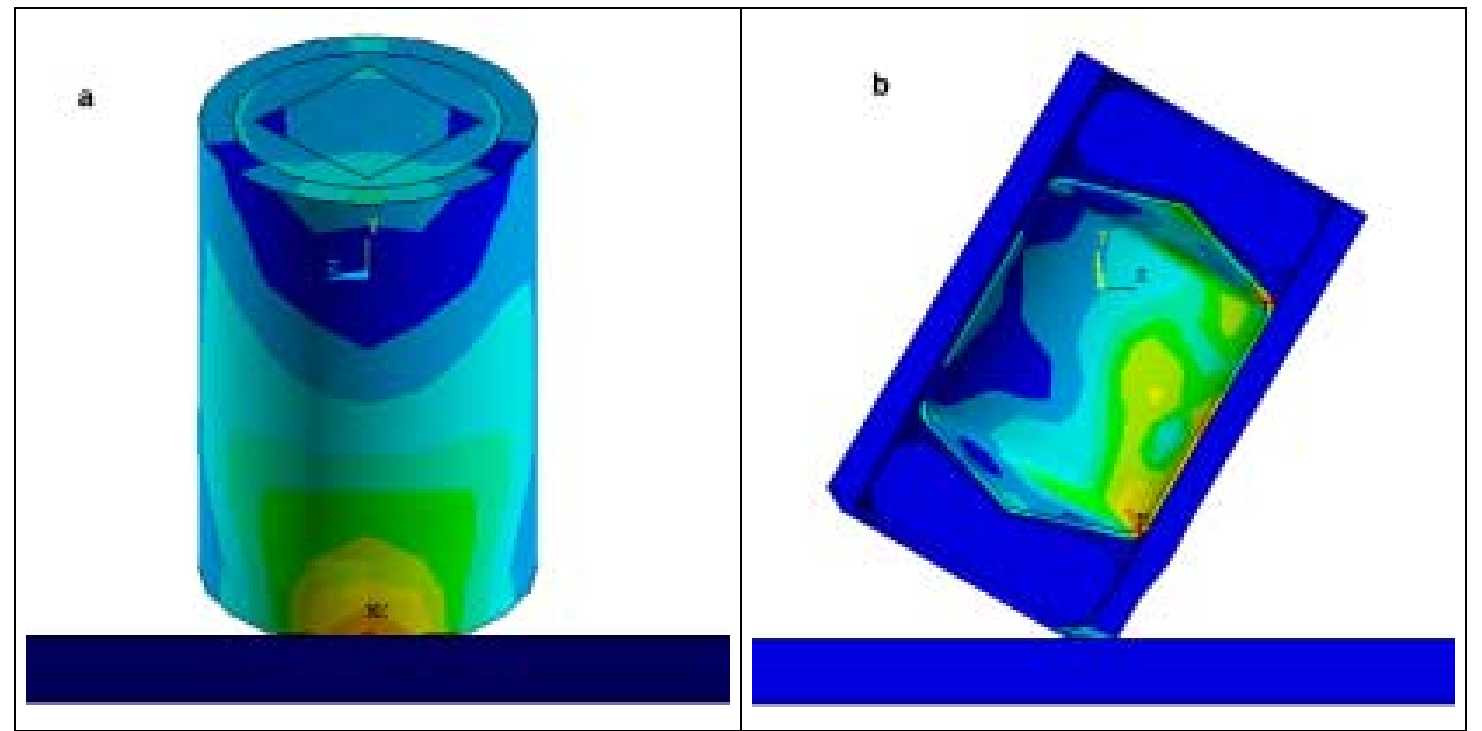

FIGURA 6.21: a) vista lateral do modelo no passo 284 onde é mostrada a maior tensão no modelo.; b) vista em corte de todos os componente do modelo no passo 284.

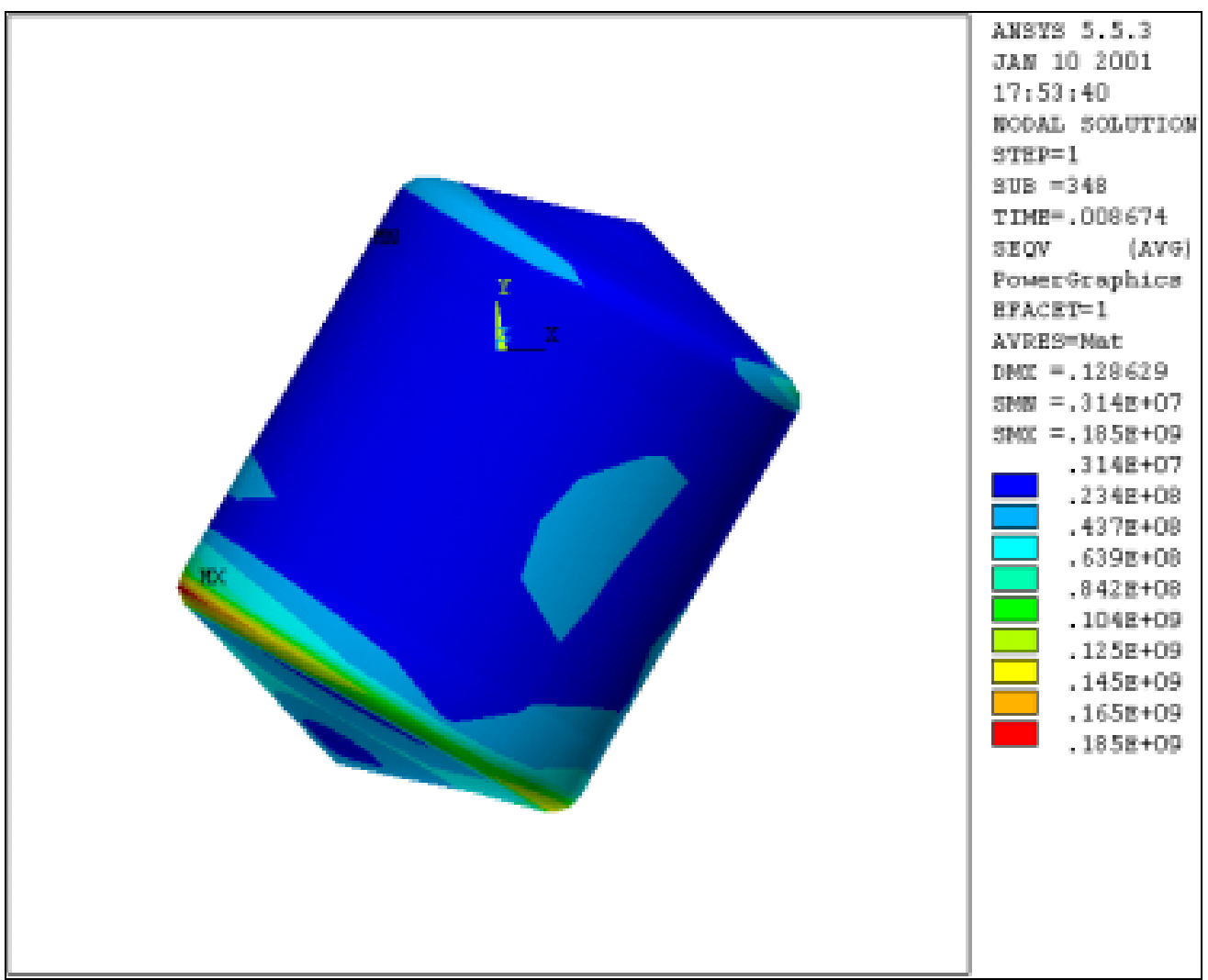

FIGURA 6.22: Vista do componente cápsula no passo 348 no qual ocorre a maior tensão para este componente (185 MPa). 


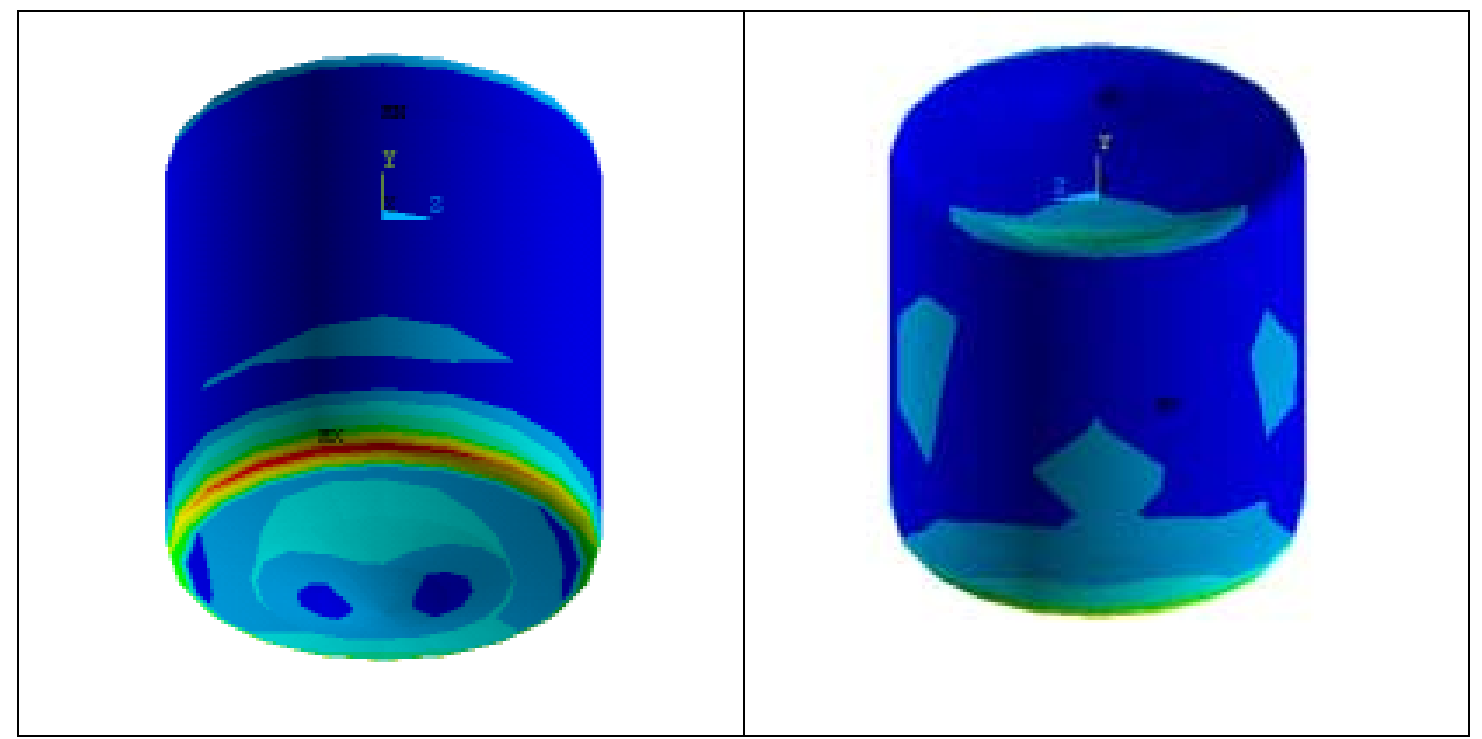

FIGURA 6.23: Vistas do componente cápsula no passo 348. Mostra tensões no componente no instante em que ocorre a maior tensão.

Pode ser notado que a máxima tensão $(335,86 \mathrm{MPa})$ foi localizada no componente cilindro, igual que nas situações anteriores. Este valor máximo é aproximadamente 2,65\% inferior a tensão de escoamento do material (alumínio 2024-T3). Também foi constatado que o máximo valor de tensão para o componente cápsula foi $185 \mathrm{MPa}$, este valor é $46 \%$ inferior a tensão de escoamento do material. Desta forma pode-se afirmar que os componentes cilindro e cápsula não sofrem deformações permanentes resultantes do impacto da queda.

Esta situação apresenta-se como a melhor, comparada com as anteriores, devido a que os componentes que envolvem a cápsula (cilindro, insertos e anel) conseguem absorver grande parte da energia de impacto e desta forma, são eficientes em proteger o componente crítico cápsula.

A seguir, como foi feito nas situações anteriores, foram obtidos gráficos de aceleração nó mais tensionado do cilindro (nó 2), nó mais tensionado da cápsula (1089) e do nó de referência da cápsula (587).

Estes gráficos de aceleração apresentam as mesmas caraterísticas dos gráficos das situações apresentadas anteriormente, isto é, picos de aceleração elevados e 
oscilações bruscas. Os motivos destes fenômenos são os mesmos explicados anteriormente.

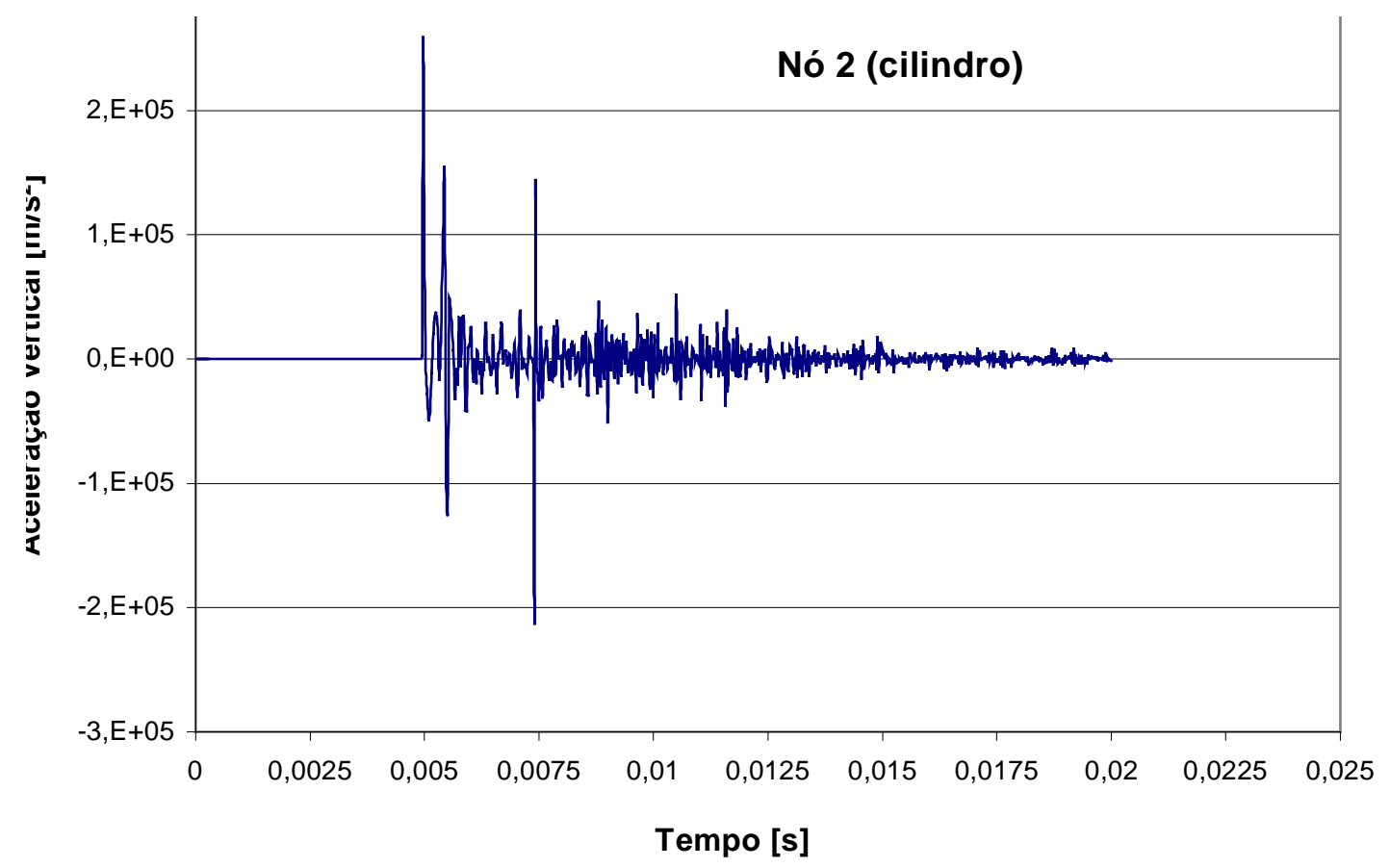

FIGURA 6.24: Aceleração vertical Y do nó 2 do cilindro (situação chanfro), através dos 1000 passos da simulação. Mostra pico máximo de $258334 \mathrm{~m} / \mathrm{s}^{2}$.

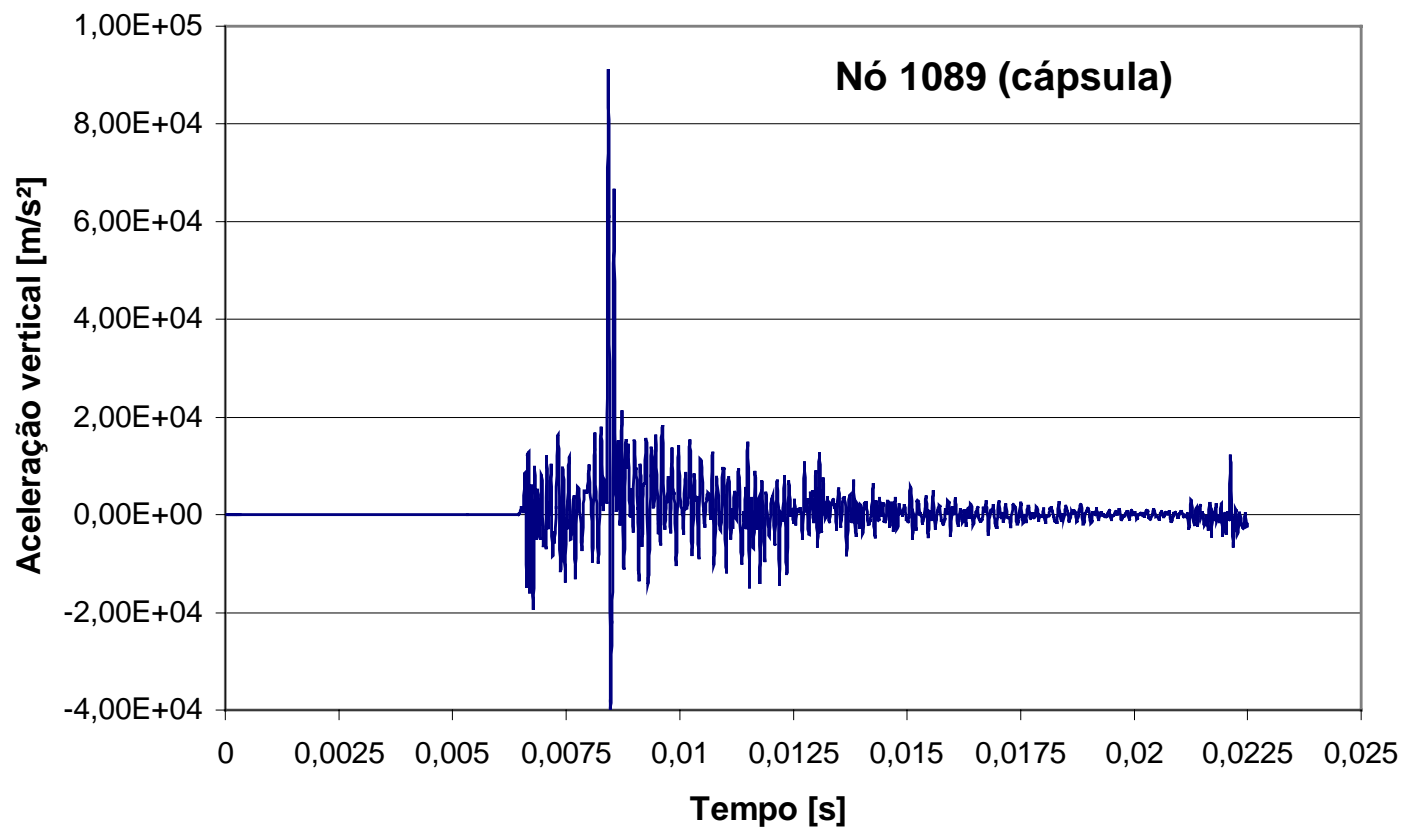

FIGURA 6.25: Aceleração vertical Y do nó 1089 do componente cápsula ( situação chanfro), através dos 1000 passos da simulação. Valor máx. de $89884 \mathrm{~m} / \mathrm{s}^{2}$. 


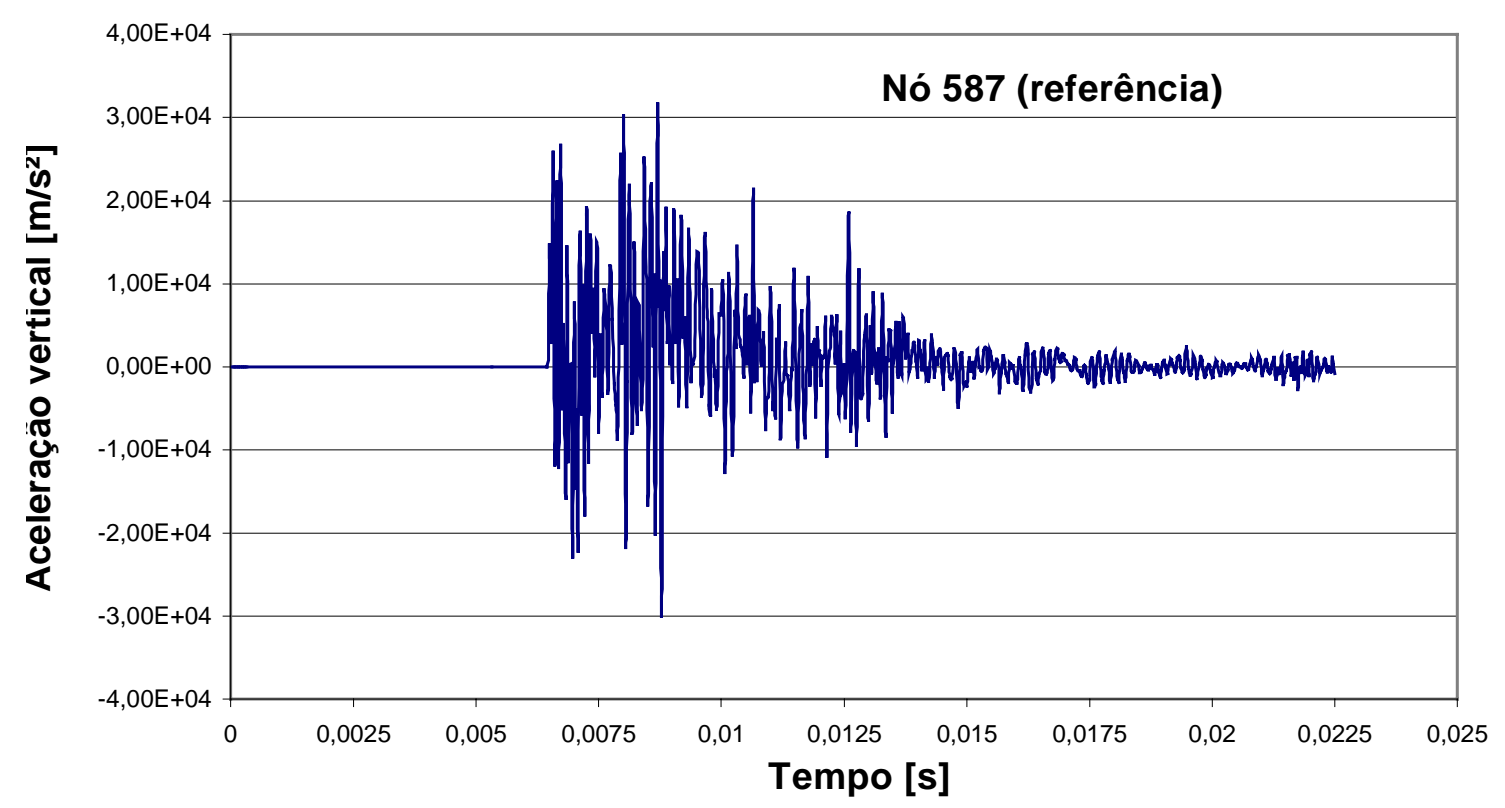

FIGURA 6.26: Aceleração vertical Y do nó 587 (no de referência do componente cápsula da situação chanfro), através dos 1000 passos da simulação. Mostra valor máximo de $31733 \mathrm{~m} / \mathrm{s}^{2}$.

\subsection{COMENTÁRIOS}

Os valores de tensão obtidos nas simulações foram coerentes, de acordo com as situações (tabela 1). Ficou claro que a melhor situação foi de "chanfro".

TABELA 6.1: Valores máximos de tensão alcançados nos componentes cilindro e cápsula em cada uma das situações de teste.

\begin{tabular}{|l|c|c|}
\cline { 2 - 3 } \multicolumn{1}{c|}{} & $\begin{array}{c}\text { Maior tensão } \\
\text { componente Cilindro }\end{array}$ & $\begin{array}{c}\text { Maior tensão } \\
\text { componente Cápsula }\end{array}$ \\
\hline Sit. Quina & 578,40 & 310,60 \\
\hline Sit. Chapa & 399,67 & 359,80 \\
\hline Sit. Chanfro & 335,86 & 185,48 \\
\hline
\end{tabular}

Todos os gráficos de aceleração apresentados mostram valores de aceleração obtidos a cada 0,000025 segundos. Os valores obtidos com este intervalo de tempo, à primeira vista, aparentam ser inaceitavelmente elevados: por exemplo, o maior valor de aceleração obtido foi de $512.702 \mathrm{~m} / \mathrm{s}^{2}$ !. Contudo, se este valor for 
introduzido na equação 4.1 (GSI - Gadd Severity Index) apresentada no capítulo 4 desta dissertação ter-se-á:

$$
\mathrm{GSI}=\int_{0}^{T} \mathrm{a}^{2,5} \mathrm{dt}
$$

Onde: $a=f / g$

f : aceleração linear

$\mathrm{g}$ : constante gravitacional

$\mathrm{t}:$ tempo

$\mathrm{T}:$ tempo do pulso $=\mathrm{Tc}$ : tempo de contato

Considere-se um pico máximo de aceleração representado na figura abaixo.

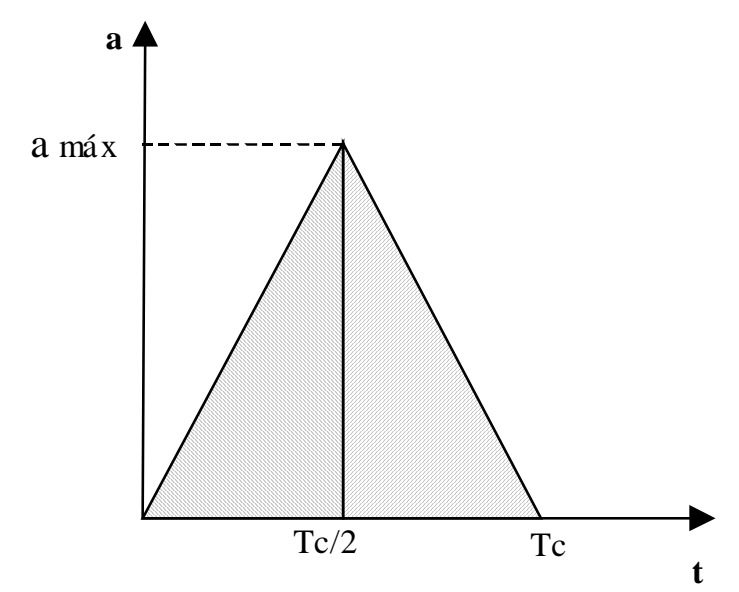

A equação 4.1 pode ser dividida em duas partes da seguinte forma:

$$
\mathrm{GSI}=\int_{0}^{\Gamma c} \mathrm{a}^{2.5} \mathrm{dt}=\underbrace{\int_{0}^{\Gamma c / 2} \mathrm{a}^{2.5} \mathrm{dt}}_{\mathrm{I}}+\underbrace{\int_{\Gamma c / 2}^{T c} \mathrm{a}^{2.5} \mathrm{dt}}_{\mathrm{II}}
$$

Onde:

$\mathrm{I}: \mathrm{a}=\frac{(\text { Amáx })(2)}{\mathrm{Tc}} * \mathrm{t}$

Resolvendo a integral da parte I obtém-se: 0,1429 Amáx ${ }^{2.5}$.Tc

II: $a=\operatorname{Amáx}\left(1-\frac{(\mathrm{t}-\mathrm{Tc} / 2)}{\mathrm{Tc} / 2}\right)$

Resolvendo a integral da parte II obtém-se: 0,1429 Amáx ${ }^{2.5}$.Tc 
Assim a equação 4.1 nos dá: GSI $=0,2857$.Amáx ${ }^{2.5}$.Tc

Considerando-se agora o valor limite de GSI $=1000$, tem-se para um tempo de contato $\mathrm{Tc}=0,01 \mathrm{~s}$.

$$
\text { GSI }=165 \text { g's }
$$

Ou seja, da ordem de $1650 \mathrm{~m} / \mathrm{s}^{2}$ na região da cabeça estando o ocupante dentro da cabine. Esta situação é similar a um ponto de referência dentro da cápsula e, para um ponto na periferia da cápsula, seria de se esperar valores ainda maiores. Portanto, a aceleração máxima da ordem de $44.000 \mathrm{~m} / \mathrm{s}^{2}$ (situação quina) obtida para a periferia da cápsula parece não ser um valor absurdo.

Um valor de GSI igual ou superior a 1000 é considerado severo em colisões veiculares e pode ser atingido e superado facilmente em colisões a altas velocidades. Portanto, os valores de aceleração obtidos nas simulações parecem estar dentro de valores obtidos na prática.

Além dos gráficos de aceleração mostrados neste capítulo, no apêndice III são mostrados outros para as três situações descritas anteriormente. Estes gráficos foram obtidos utilizando o que chamamos de filtros numéricos de 10, 4 e $1 \mathrm{kHz}$. Estes filtros consistem na obtenção de dados de aceleração com intervalos maiores de tempo, ou seja freqüência de amostragem menores ( sampling rate menores). Desta forma, os filtros de 10, de 4 e de $1 \mathrm{kHz}$ obtém dados a cada 0,0001 - 0,00025 e 0,001 segundos respectivamente. Com isto, tenta-se mostrar os dados que seriam obtidos com frequiências mais baixas, típicas de acelerômetros utilizados na prática.

Foi decidido realizar estes filtros devido a que, GRUDA \& YORK (1996), no artigo que foi utilizado como principal referência para este trabalho, apresentam gráficos de aceleração contra tempo utilizando este tipo de filtro. 

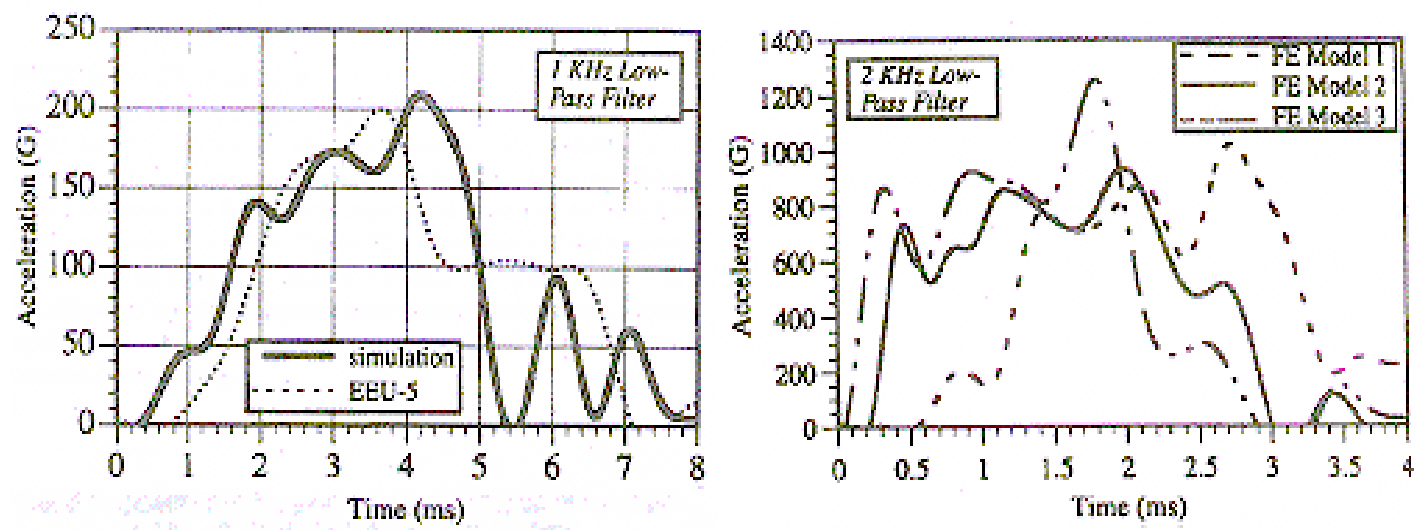

FIGURA 6.27: Gráficos apresentados por GRUDA \& YORK. Nestes gráficos pode ser notado que os autores utilizam filtros passa baixa de 1 e $2 \mathrm{kHz}$. Observe-se que para filtro de $2 \mathrm{KHz}$ foi obtida uma aceleração para o ponto de referência na cápsula da ordem de $12.000 \mathrm{~m} / \mathrm{s}^{2}$.

Na tabela 6.1 são apresentados os máximos valores de aceleração obtidos nos gráficos apresentados neste capítulo e de cada um dos gráficos apresentados no apêndice III.

TABELA 6.2: Valores de aceleração obtidos filtrando os gráficos de aceleração.

\begin{tabular}{|c|c|c|c|c|c|}
\hline \multirow[b]{2}{*}{ Situação } & & \multicolumn{4}{|c|}{ Aceleração [m/s²] } \\
\hline & & Filtro $40 \mathrm{kHz}$ & Filtro $10 \mathrm{kHz}$ & Filtro 4 kHz & Filtro $1 \mathrm{kHz}$ \\
\hline \multirow{3}{*}{ Quina } & Nó máx $\sigma$ & 512702 & (-) 285584 & 150976 & (-) 94849 \\
\hline & Nó máx $\sigma$ (cápsula) & 115408 & $(-) 97510$ & 93180 & 23396 \\
\hline & Nó referência & 44429 & 30468 & 27634 & 10183 \\
\hline \multirow{3}{*}{ Chapa } & Nó máx $\sigma$ & 297432 & 166959 & 297432 & 166959 \\
\hline & Nó máx o (cápsula) & (-) 61894 & 32689 & 27911 & 15912 \\
\hline & Nó referência & 35308 & 35308 & 31094 & 13760 \\
\hline \multirow{3}{*}{ Chanfro } & Nó máx $\sigma$ & 258334 & 155499 & $(-) 31365$ & (-) 31365 \\
\hline & Nó máx $\sigma$ (cápsula) & 89884 & 89884 & (-) 19244 & (-) 11807 \\
\hline & Nó referência & 31733 & 26659 & (-) 30221 & 18545 \\
\hline
\end{tabular}

Como pode ser visto na tabela 6.1 os valores de aceleração obtidos com estes filtros diminuem consideravelmente. Isto acontece devido a que o programa de elementos finitos ANSYS/LS DYNA utiliza o método das diferenças centrais onde, para calcular a aceleração utiliza a equação 2.36 apresentada no capítulo 2 desta dissertação. 


$$
\{\ddot{u}\}=\frac{1}{(\Delta t)^{2}}\left\{u_{n+1}-2 u_{n}+u_{n-1}\right\}
$$

É importante que seja notado que o intervalo de tempo $\Delta$ t está elevado ao quadrado, assim, valores muito pequenos de $\Delta \mathrm{t}$ proporcionaram valores elevados de aceleração como os obtidos nas simulações aqui apresentadas. 


\section{CONCLUSÕES, COMENTÁRIOS FINAIS E SUGESTÕES PARA TRABALHOS FUTUROS}

A seguir serão apresentadas conclusões finais, comentários e sugestões para trabalhos futuros, tendo como referência os resultados apresentados no capítulo anterior desta dissertação.

\section{Situação quina}

- Pelo critério de escoamento de von Mises a máxima tensão alcançada no componente cápsula durante o impacto do container foi menor que a tensão de escoamento do material (alumínio). Isto é, o material da cápsula não escoa.

- A máxima tensão foi localizada no componente cilindro, a qual foi superior a tensão de escoamento do material. Devido a isto ocorreram deformações permanentes no componente cilindro.

- Parte do container (cilindro, tampas e insertos) deformou-se permanentemente absorvendo a maior parte da energia do impacto. Com isto, o objetivo de proteger a cápsula interna do container foi alcançado.

\section{Situação chapa}

- Pelo critério de escoamento de von Mises as máximas tensões alcançada nos componentes cilindro e cápsula durante o impacto do container foram superiores à tensão de escoamento do material (alumínio). Isto é, o cilindro e cápsula sofrem deformações permanentes devido ao escoamento do material. O objetivo de dar proteção ao componente crítico cápsula não foi atingido nesta situação. 


\section{Situação chanfro}

- A máxima tensão (von Mises) alcançada no componente cápsula (185,48 MPa) durante o impacto do container nesta situação foi aproximadamente $40 \%$ inferior à tensão alcançada por este mesmo componente na situação quina, e $46 \%$ inferior à tensão de escoamento do material (alumínio). Com isto, pelo critério de escoamento de von Mises, fica garantido que o material do qual é composto o componente cápsula não escoa.

- Com a modificação implementada (adição de anel) a máxima tensão foi localizada no componente cilindro, da mesma forma nas outras situações apresentadas, mas esta tensão resultou ser inferior à tensão de escoamento do material. Devido a isto não devem ocorrer deformações permanentes ao componente cilindro.

- A modificação realizada permitiu diminuir substancialmente as tensões sofridas por todos os componentes do modelo.

Das três situações apresentadas nesta dissertação a situação chanfro nos forneceu os resultados mais satisfatórios. O anel chanfrado, colocado na parte inferior do container, nesta situação mostrou ser eficiente.

Os objetivos propostos inicialmente foram alcançados e os resultados obtidos nos proporcionaram dados que geraram discussões e dúvidas de caráter científico, o que veio a enriquecer este trabalho.

\subsection{Comentários finais}

- As simulações realizadas utilizando o programa de elementos finitos ANSYS/LSDYNA nos permitiram a obtenção de resultados em freqüências de amostragem que não seriam possíveis de ser obtidas através de testes físicos. Com isto é comum a obtenção de valores muito elevados de aceleração. Contudo a medida que são utilizadas frequiências menores de amostragem para o obtenção de dados (filtros do apêndice III) os valores de aceleração diminuem consideravelmente. 
- Os valores de tensão obtidos foram coerentes.

- Neste trabalho foi possível, com auxilio do software ANSYS/LS-DYNA, aplicarmos conceitos de engenharia, modelarmos e simularmos diversas vezes, o que não teria sido viável por meio de testes físicos. Assim, o programa mostrouse uma ferramenta poderosa e eficaz para o estudo de problemas complexos de engenharia.

- Para se interpretar de forma coerente os resultados obtidos é necessário aliar à experiência em engenharia um amplo conhecimento da teoria por trás dos programas que executam este tipo de análise.

- Por ser o método dos Elementos Finitos um procedimento numérico de análise é necessário amplo conhecimento do fenômeno estudado para considerar se a solução está dentro dos limites de acuracidade.

- Apesar da caraterística CAI ser de muita importância, infelizmente no Brasil a aplicação deste tipo de estudo ainda é pouco aplicado em média e pequenas indústrias. Alguns fatores que influenciam esta situação são o alto investimento necessário para efetuar este tipo de análise e o conhecimento necessário para interpretar de maneira correta os resultados obtidos.

\subsection{Sugestões para trabalhos futuros}

- Realizar testes computacionais acompanhados de testes físicos onde sejam utilizadas mesmas condições e obtidos resultados de pontos iguais em ambos modelos assim como com as mesmas freqüências de aquisição de resultados. Desta forma, ambos testes poderão ser comparados de forma a poder homologar os resultados obtidos através de simulações.

- Tendo como referência o trabalho apresentado nesta dissertação, realizar testes com outros tipos de estruturas, de preferência crash test em estruturas veiculares. 


\section{REFERÊNCIAS BIBLIOGRÁFICAS:}

ALMEIDA, F. (1992) Projeto e implementação de pré-pós processador gráfico para exibir tensões calculadas pelo método de elementos finitos. São Carlos. 251p. Dissertação (Mestrado) - Escola de Engenharia de São Carlos, Universidade de São Paulo.

ALTAN, T.; OH, S.; GEGEL, H. (1999). Conformação de metais - fundamentos e aplicações. Trad. por Reginaldo Teixeira Coelho. 1 ed. São Carlos, EESC/USP.

ANSYS User's Manual. Theory manual. (1995). ANSYS revision 5.2.

APARICIO, F.; SAN ROMÁN , J.; DÍAZ V. (1996). Theoretical model to analyse the collision of an automobile vehicle. International journal of vehicle design, v.17, n.4, p415-429.

BATHE, K. J. (1996). Finite Element procedures. New Jersey, Prentice Hall, 1037p.

BELINGARDI, G.; VADORI, R. (1993). On the role of geometrical imperfections in the impact collapse of thin-welded beam: numerical and experimental results. Crashworthiness and occupant protection in transportation systems, v.169, p115-125.

COUNCIL, F.; STEWART, J.; COX, C. (1997). A new method for predicting crashworthiness. Accident analys and prevention. v.29, n.1, p.109-123.

DAMHAUG, A.; REID, J.; BERGSETH, A. (1999). The impact of an efficient linear solver on finite element analyses. Computers and Structures, v.72, p595-604.

FARAHANI, K.; MOFID, M.; VAFAI, A. (2000). A solution method for general contact-impact problems. Computer methods in appied mechanics and engineering. V.187, p69-77.

GALLAGHER, R. (1975). Finite element analysis - fundamentals. New Jersey, Prentence Hall Inc., cap 1. 
GANDHI, U.; HU, J. (1995). Data-based approach in modeling automobile crash. International journal of impact engineering. v.16, n.1, p.95-118.

GANDHI, U.; HU, J. (1996). Data based models for automobile side impact analysis and design evaluation. International journal of impact engineering. v.18, n.5, p.517-537.

GRUDA, J.; YORK, A. (1996). Crashworthiness of the AT-400T shipping container. Development, validation, and application of inelastic methods for structural analysis and design. v. 343, p. 115-121.

HAMADA, H.; RAMAKRISHNA, S. (1997). A FEM method for prediction of energy absorption capability of chashworthy polymer composite materials. Journal or reinforced pastics and composites. v.16, n.3, p.226-241.

HUEBNER, K.; THORNTON, E. (1982). The finite element method for engineers. 2 ed. New York, John Wiley \& Sons.

HALLQUIST, J. O. (1993) LS-DYNA3D theoretical manual. Livermore, Livermore Software Technology Corporation.

JOHNSON, W. (1990). The elements of crashworthiness: scope and actuality. Journal of automobile engineering, v.204, p255-273.

KARK, S. (1974). Dynamic analysis of machine tool, structures by the finite elements method. Manchester. Cap 2. Thesis (Doutorado) - The Victoria University of Manchester - Institute of Science and Technology.

KECMAN, D. (1997). An engeneering approach to crashworthiness of thin-walled beams and joints in vehicle structures. Thin-walled structures. v.28, n.3-4, p.309320 .

KUSCHFELD, S.; HOLZNER, M. (1998). Efficient visualization of crashworthiness simulations. IEEE Computer graphics and applications, p60-65.

LIRANI, J. (1985). Apostila de elementos finitos. Escola de Engenharia de São Carlos, Universidade de São Paulo.

LIRANI, J. (2000). Notas de aula curso de elementos finitos - Embraer. Escola de Engenharia de São Carlos, Universidade de São Paulo.

MAHMOOD, H.; WHEATLEY, D. (1993). On the front end design of automotive vehicle for crashworthiness. Crashworthiness and occupant protection in transportation systems, v.169, p311-319. 
MAHMOOD, H. (1997). Front end design of vehicle structure subjected to frontal crash load. Crashworthiness, occupant protection and biomechanics in transportation systems, v.225, p233-240.

MAMALIS, A,; MANOLAKOS, D,; BALDOUKS, A. (1996). On the finite-element modelling of the deep-drawing of square section of coated steels. Journal of materials processing technology. v.58, p.153-159.

MAMALIS, A.; ROBINSON, M.; et al. (1997). Crashworthy capability of composite material structures. Composite strutures. v.37, p.109-134.

MAYER, R.; KIKUCHI, N,; SCOTT, R. (1996). Application of topological optimization techniques to structural crashworthiness. International journal for numerical methods in engineering. v.39, p.1383-1403.

McGREGOR, et al. (1993). Impact performace of aluminium strutuctures. In: Jones \& wierzbicki., ed., Estructural crahsworthiness and failure. London, Elsevier Applied Science.. Cap. 10, p.385-421.

MENDELSON, A. (1983).Plasticity: theory and application. Malabar, Robert E. Krieger Publishing Company, 353p.

MILLER, P.; CARNEY, J. (1997). Computer simulations of roadside crash cushion impacts. Journal of transportation engineering - ASCE. v.123i5, p.270-376.

MORENO, M. 2000. Desenvolvimento e implementação de metodologia de otimização da geometria do blank em processo de conformação de chapas metálicas. São Carlos. 84p. Dissertação (Mestrado) - Escola de Engenharia de São Carlos, Universidade de São Paulo.

NATIONAL HIGHWAY TRAFFIC SAFETY ADMINISTRATION - NHTSA. (1999) Federal motor vehicle safety standards (FMVSS). Side impact protection. 49 CFR part 571.

OWEN, D.; HINTON, E. (1980). Finite elements in plasticity: theory and pratice. Swansea, UK, Pineridge Press Ltda.

PALUSZNY, A. (1992) State of the art review of automobile structural crashworthiness. American iron and steel institute - Technical report.

PARK, S.; HAN, D. (1996). Crashworthiness improvement of vehicle side Rail. Proceedings of the NATO-ASI on Crashworthiness of transportation systems structural impact and occupant protection., p273-285.

RAO, S. (1989). The finite element method in engineering. Oxford, Pergamon Press. 
REDDY, J. (1985). An introduction to the finite element method. Singapore, McGraw-Hill International Editions.

REID, J.; SICKING, D.; PAULSEN, G. (1996). Design and analysis of approach terminal sections using simulation. Journal of transportation engineering ASCE. v. 122i5, p. 399-405.

REID, J. (1996). Towards the understanding of material property influence on automotive crash strutures. Thin-walled structures. v.24, p.285-313.

RUAN, J; KHALIL, T.; KING, A. (1994). Dynamic response of the human head to impact by three-dimensional finite element analysis. Journal of biomechanical engineering, v.116, p.44-50.

THACKER, J.; REAGAN, J.; et al. (1998). Experiences during development of a dynamic crash response automobile model. Finite elements in analysis and design; v.30, p.279-295.

TITA, V. (1999). Análise dinâmica teórica e experimental de vigas fabricadas a partir de materiais compósitos poliméricos reforçados. São Carlos, 125p. Dissertação (Mestrado) - Escola de Engenharia de São Carlos, Universidade de São Paulo.

UCHIKAWA, Y.; ITABASHI, M.; KAWATA, K. (1997). On crashworthiness of FRP thin-walled circular tubes under dynamic axial compression. Advanced composites materials. v.6, n.3, p.239-252.,

WHIRLEY, R.; ENGELMANN, B. (1994). Automatic contact algorithm in DYNA3D for crashworthiness and impact problems. Nuclear Engineering and Design. V.150, p225-233.

ZAOUK, A.; et al. (1996). Validation of a non-linear finite elements vehicle model using multiple impact data. Proceedings of the 1996 ASME International Mechanical Engineering Congress and Exposition, Atlanta, GA, p. 91-106.

ZAOUK, A., MARZOUGUI, D., KAN, C. (1996). Development and Evaluation of a C-1500 Pickup Truck Model for Roadside Hardware Impact Simulation. Proceedings of the FHWA Vehicle Crash Analysis Crash Conference, Mclean, VA, p 1-31.

ZAOUK, A., MARZOUGUI, D., KAN, C. (1998). 1996 Plymouth neon body-inwhite frontal impact validation. 5th International LS-DYNA Users Conference, Southfield, Michigan. 


\section{PRINCIPAIS SITES CONSULTADOS.}

NATIONAL HIGHWAY TRAFFIC SAFETY ADMINISTRATION - United States Departament of Transportation. http://www.nhtsa,dot,gov. $(15 / 03 / 00)$

INSURANCE INSTITUTE FOR HIGHWAY SAFETY. http://www.hwysafety,org/ (20/10/99)

NSW RTA Road safety bureau. http://www.nrma.com.au/crashtests (15/03/00)

NATIONAL ORGANIZATION FOR AUTOMOTIVE SAFETY \& VICTIMS AID. http://www.osa.go.jp $(20 / 10 / 99)$

NATIONAL CRASH ANALYSIS CENTER. http://www.ncac.gwu.edu/ncac $(28 / 02 / 00)$.

NATIONAL AUSTRALIAN.

http://www.nrma.com.au/motoring/safety/ncap/index.html (28/02/00).

ASSOCIATION FOR THE ADVANCEMENT OF AUTOMOTIVE MEDICINE. http://www.carcrash.org $(10 / 01 / 00)$.

NATIONAL ARCHIVES AND RECORD ADMINISTRATION - Code of Federal Regulamentations.http://www.access.gpo.gov/nara/cfr/cfr-tablesearch.html\#page1 $(16 / 03 / 00)$.

MATWEB - http://www.matweb.com (08/00). 


\section{Apêndice I - Descrição dos tipos de elementos utilizados nas simulações}

- Elemento: SHELL 163:

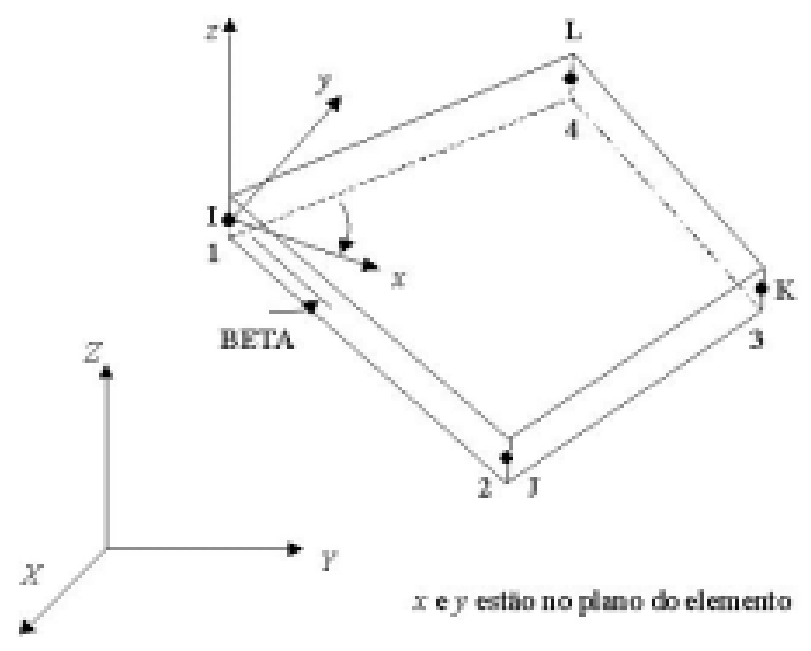

FIGURA AI - 1: Elemento SHELL 163

Utilizamos o elemento SHELL 163 para modelarmos os seguintes componentes do container: tampas, cilindro (chapas de alumínio) e insertos (chapas de alumínio). Este elemento possui 4 nós com propriedades de flexão (bending) e membrana, e aceita carregamentos em seu plano e normais a ele. Possui 12 graus de liberdade por nó: translação, velocidade e aceleração nas direções nodais $x, y$, e $z$ e rotação em torno dos eixos nodais $x, y$, e $z$. [ANSYS Elements Reference e HALLQUIST (1993)]. Para o elemento, dentre as formulações permitidas, foi escolhida a formulação Belytschko-Lin-Tsay; baseada numa combinação das formulações corotacioal e deformação-velocidade. A parte co-rotacional da formulação evita as complexidades decorrentes do comportamento não linear embutindo um sistema de 
coordenadas dentro do elemento. A parte de velocidade-deformação ou taxa de deformação, facilita a avaliação constitutiva [LS DYNA Theoretical Manual (1998)].

rotational) Hughes-Liu, que deve apresentar ganho de tempo de CPU, mas pode ter os resultados comprometidos em alguns casos de grandes deformações do elemento.

Para este elemento, devem ser informados a espessura (constante ou em cada nó) e a localização da superfície de referência (plano superior, intermediário ou inferior do elemento). No nosso modelo este elemento foi associado ao alumínio ao qual the foi imposta uma formulação de material bilinear cinemática. No entanto, este tipo de elemento aceita outros tipos de formulação de material.

- Elemento: SOLID 164
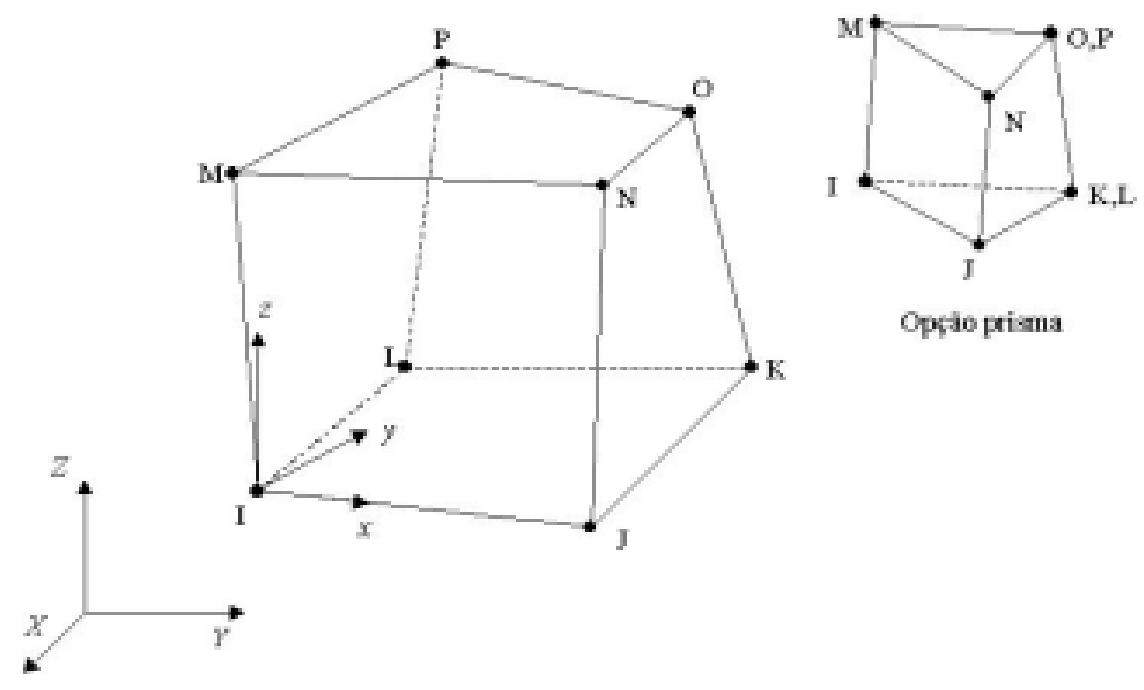

FIGURA AI - 2: Elemento SOLID 164

Este elemento possui 8 nós e, foi utilizado na modelagem de estruturas sólidas que formam parte do container: cápsula, superfície e espuma que preenche as cavidades do cilindro e dos insertos. Para cada nó são definidos os seguintes graus de liberdade: translação, velocidade e aceleração nas direções nodais $x, y$, e $z$. As velocidades e acelerações não são graus de liberdade fisicamente atuantes, mas são armazenados como tal e armazenados para o pós-processamento. São utilizados apenas para análises dinâmico-explícitas. 
Neste tipo de elemento, pode-se aplicar acelerações-base e velocidades angulares, sendo necessária a criação de um componente formado por nós e a aplição do carregamento ao nó. Pressões podem ser aplicadas nas superfícies do elemento, sendo adotada a convenção que uma pressão positiva atua sobre o elemento. Se os elementos são definidos como corpos rígidos, podem ser aplicados deslocamentos, forças etc.

As principais propriedades de material que este elemento aceita são: material rígido, ortotrópico (elástico), bilinear isotrópico, bilinear cinemático e formulação por lei de potência. 


\section{Apêndice II- Rotinas APDL implementadas para obtenção de resultados}

As rotinas apresentadas a seguir foram criadas com o objetivo de capturar dados dos arquivos de resultados que o software de elementos finitos gera após rodar cada situação. Estas rotinas nos permitiram elaborar gráficos e tabelas fundamentais para a exposição de resultados.

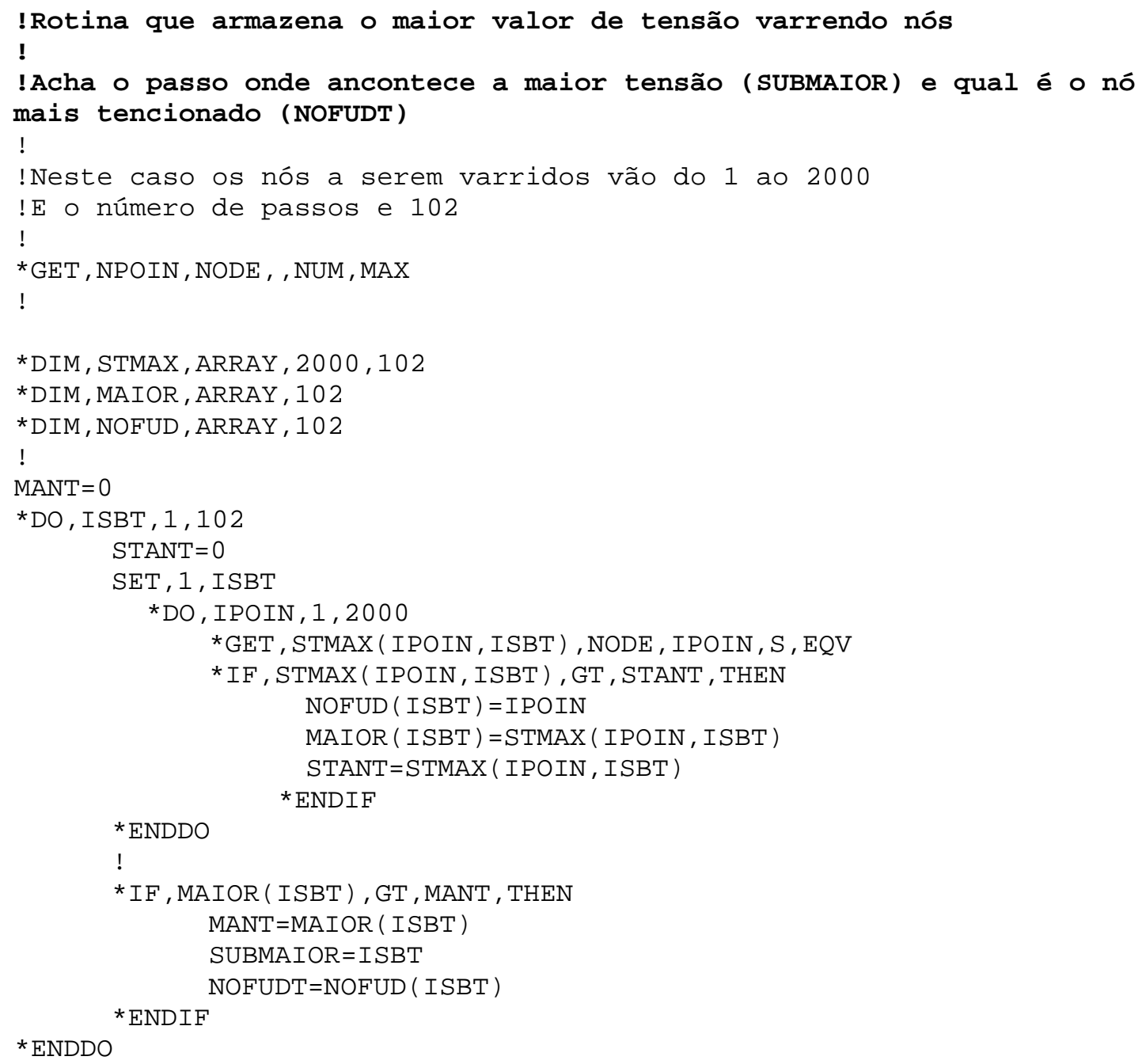




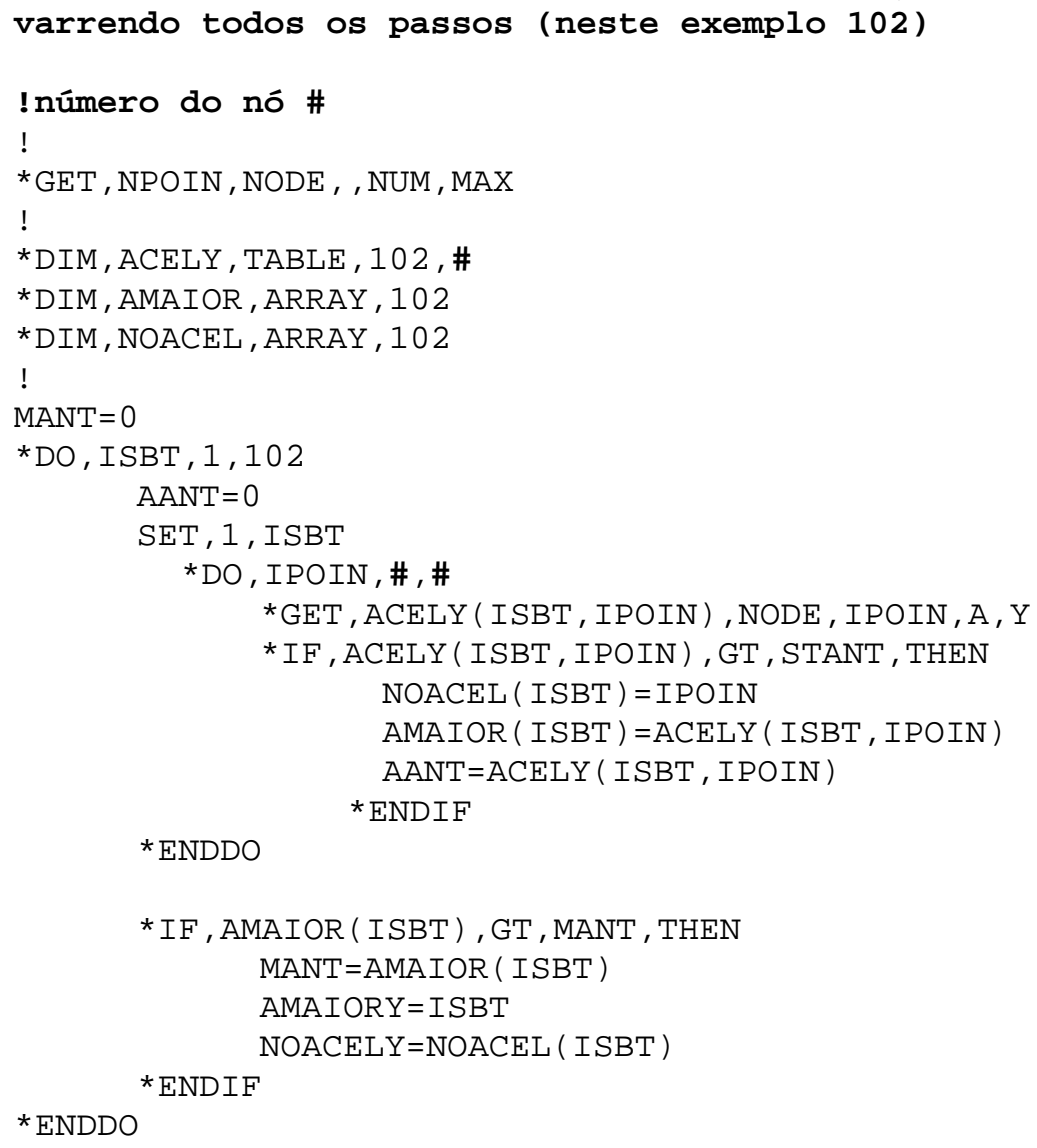

!Rotina que armazena os valores de ACELERAÇÃo de determinado nó (\#) varrendo todos os passos (neste exemplo 900).

!Nó da cápsula (12) filtro de $40 \mathrm{kHz}$

! 


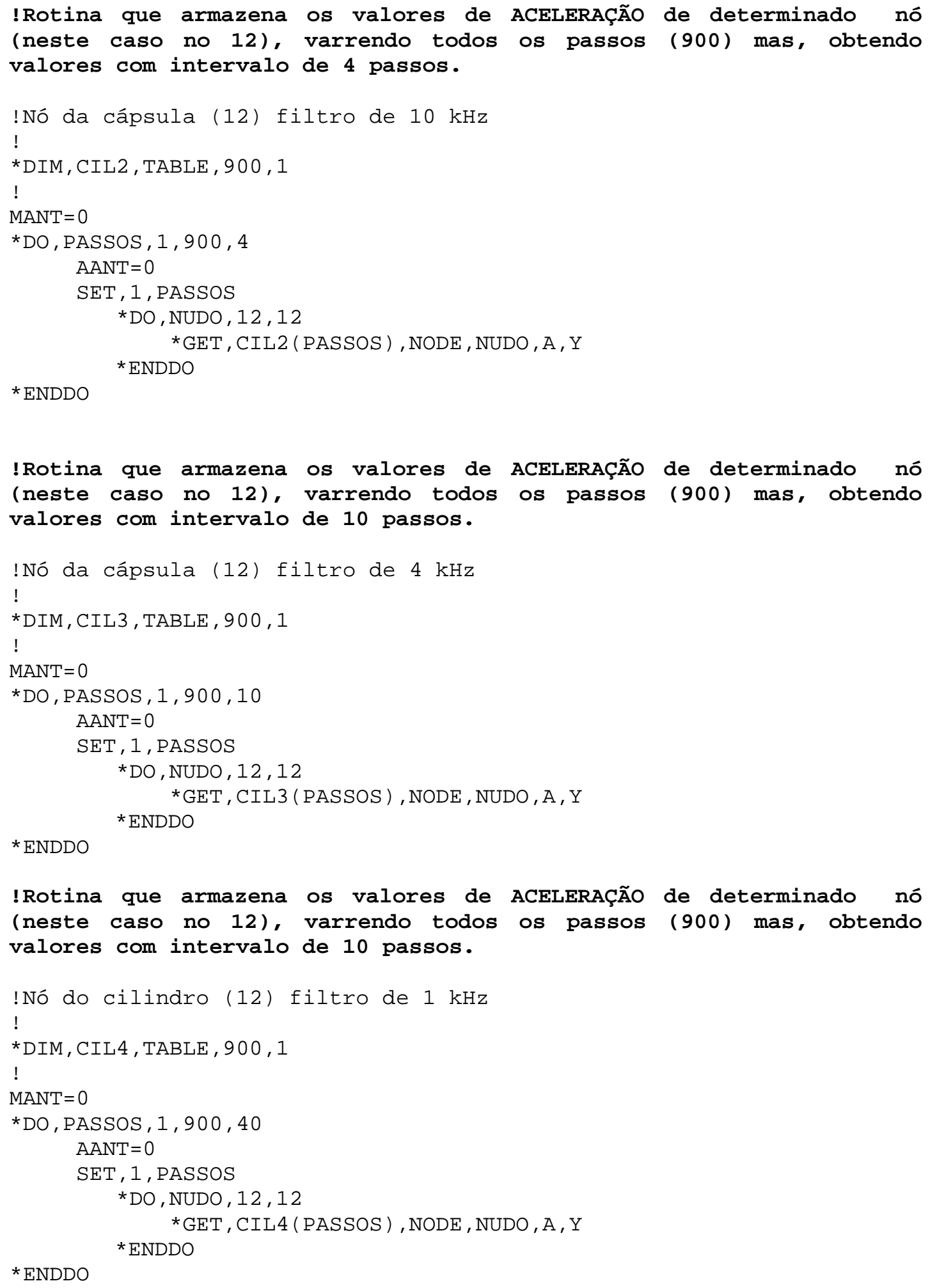




\section{Apêndice III}

Neste apêndice são apresentadas figuras que mostram gráficos obtidos de cada uma das situações abordadas nos capítulos 5 e 6 desta dissertação. Estes gráficos foram gerados utilizando "filtros numéricos" de 10,4 e $1 \mathrm{kHz}$ como pode ser visto a seguir:

\section{Situação quina - Gráficos obtidos usando filtro numérico}

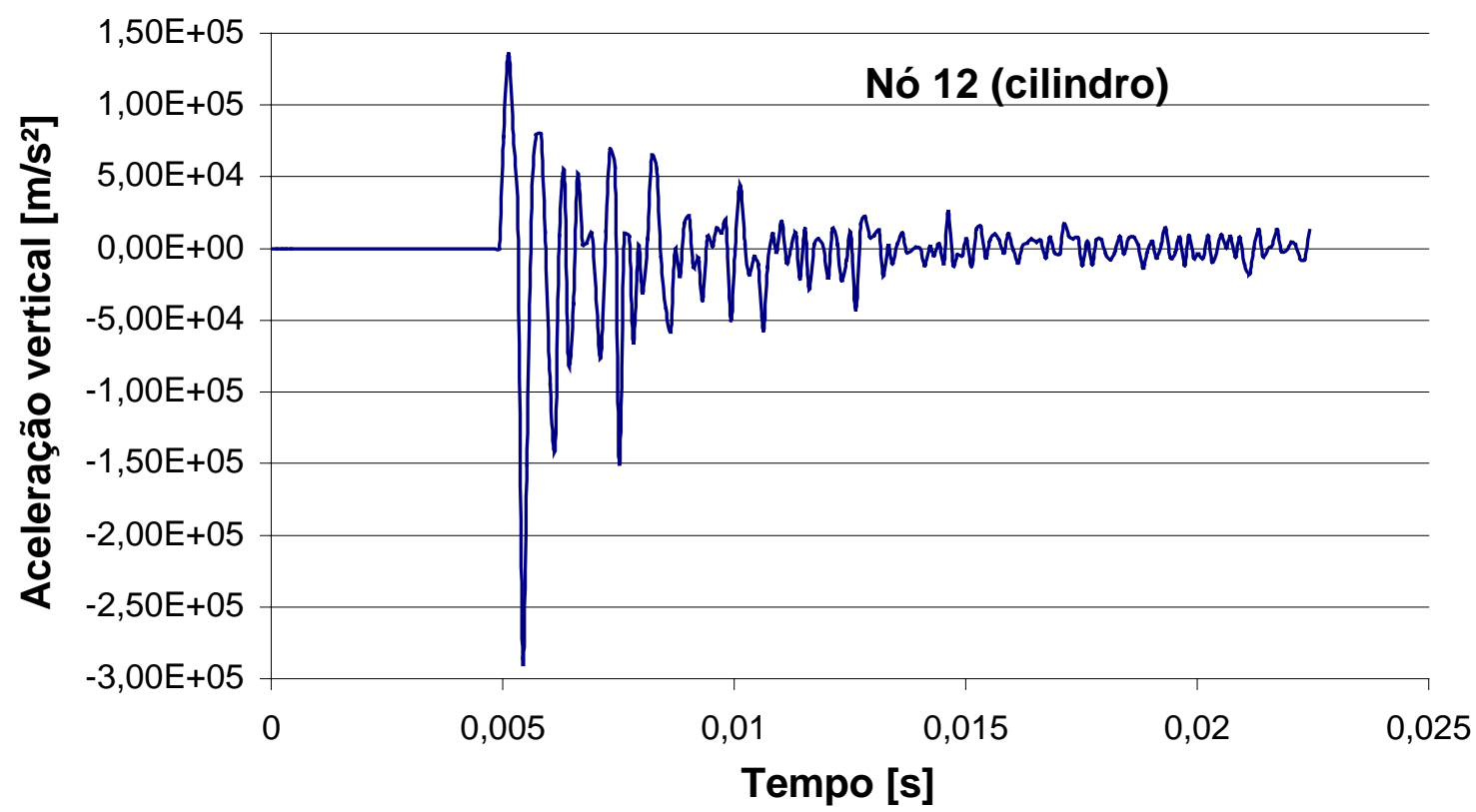

FIGURA A1: Aceleração vertical Y do nó 12 do cilindro através dos 1000 passos da simulação. Mostra pico máximo de aceleração de $-285584 \mathrm{~m} / \mathrm{s}^{2}$. Estes seriam os dados de aceleração obtidos com um acelerômetro de $10 \mathrm{kHz}$. 


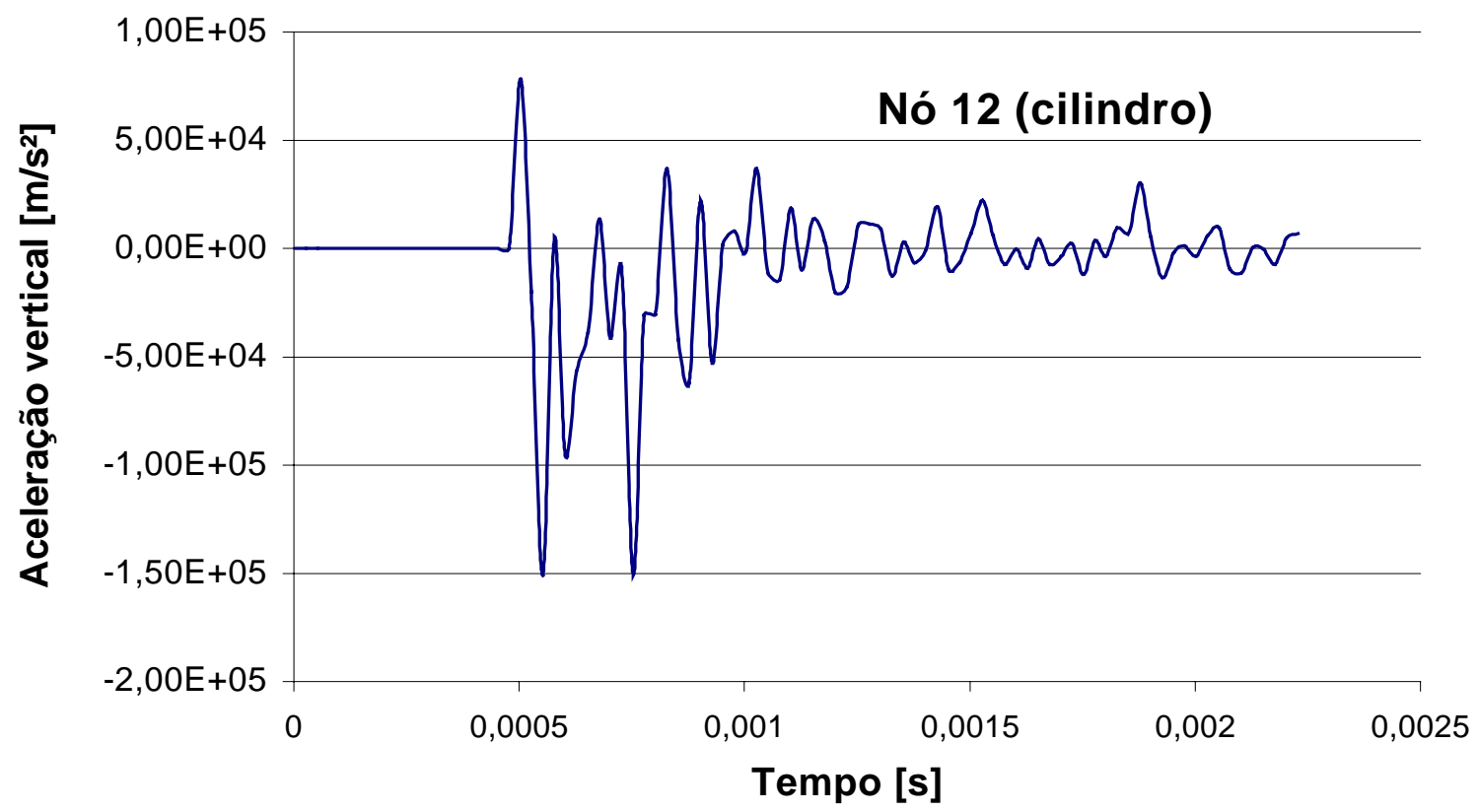

FIGURA A2: Aceleração vertical $\mathrm{Y}\left[\mathrm{m} / \mathrm{s}^{2}\right]$ do nó 12 do cilindro através dos 1000 passos da simulação. Mostra pico máximo de aceleração de $-150976 \mathrm{~m} / \mathrm{s}^{2}$. Estes seriam os dados de aceleração obtidos com um acelerômetro de $4 \mathrm{kHz}$.

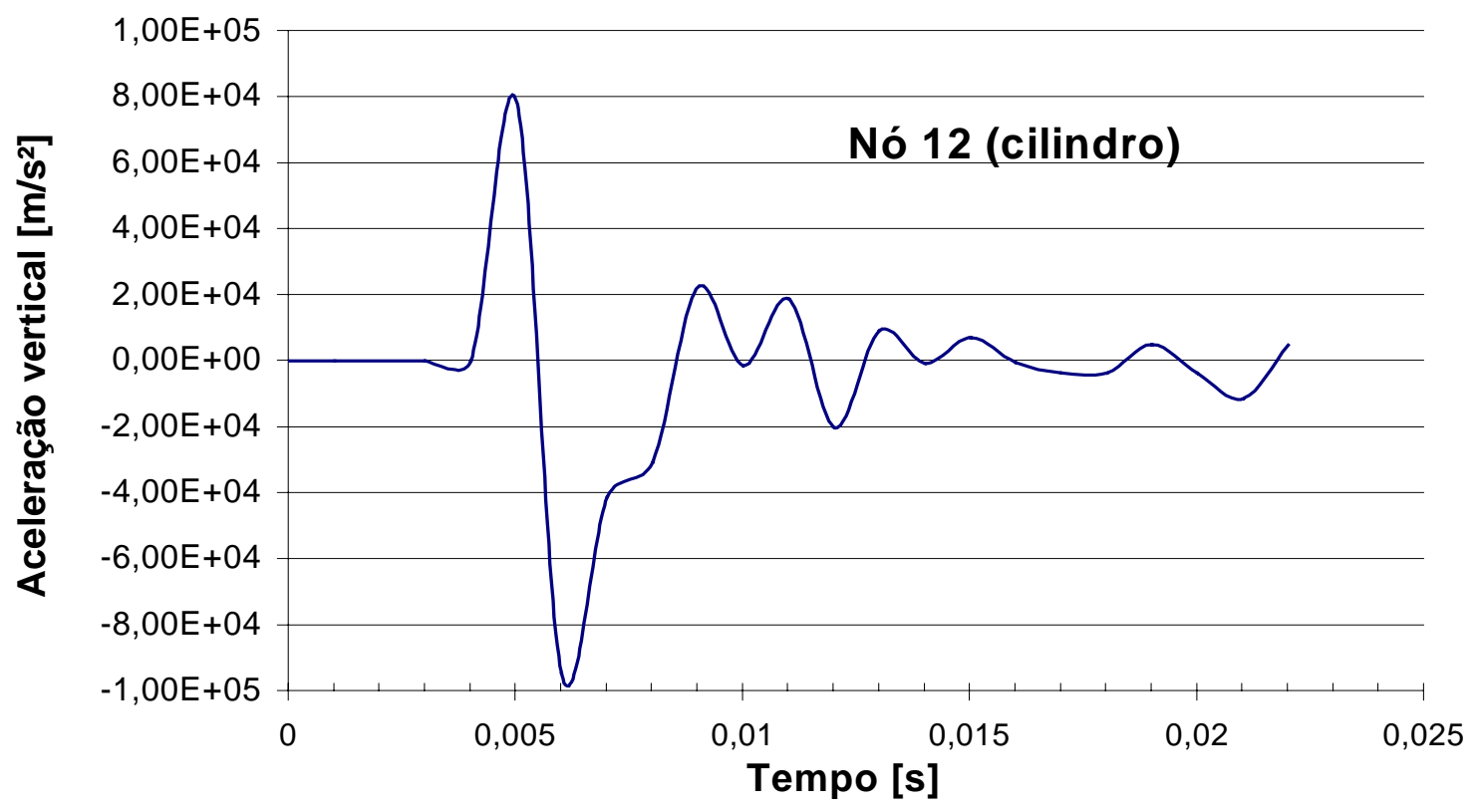

FIGURA A3: Aceleração vertical $\mathrm{Y}\left[\mathrm{m} / \mathrm{s}^{2}\right]$ do nó 12 do cilindro através dos 1000 passos da simulação. Mostra pico máximo de aceleração de $-94849 \mathrm{~m} / \mathrm{s}^{2}$. Estes seriam os dados de aceleração obtidos com um acelerômetro de $1 \mathrm{kHz}$. 


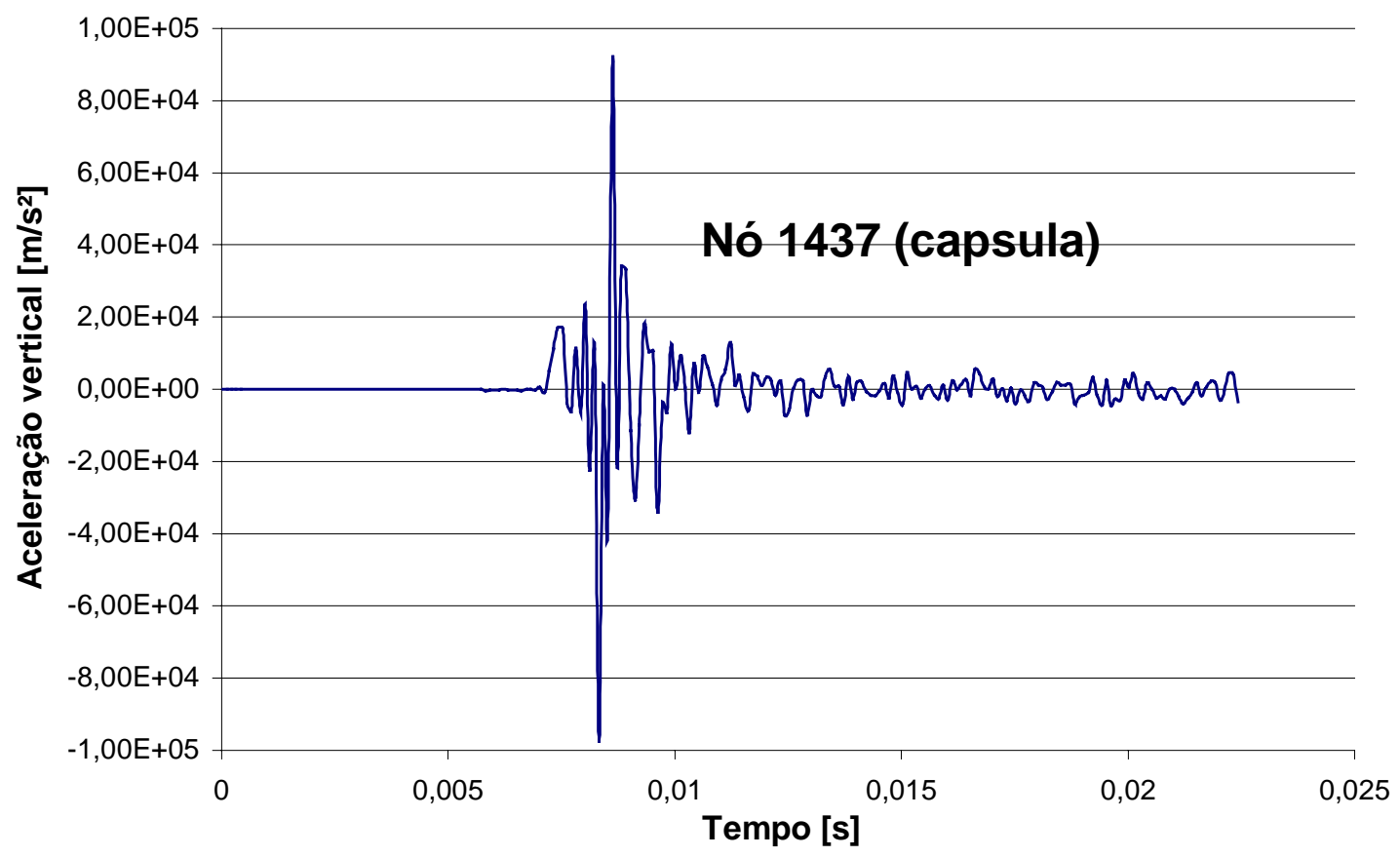

FIGURA A4: Aceleração vertical Y do nó 1437 da cápsula através dos 1000 passos da simulação. Mostra pico máximo de aceleração de $-97510 \mathrm{~m} / \mathrm{s}^{2}$. Estes seriam os dados de aceleração obtidos com um acelerômetro de $10 \mathrm{kHz}$.

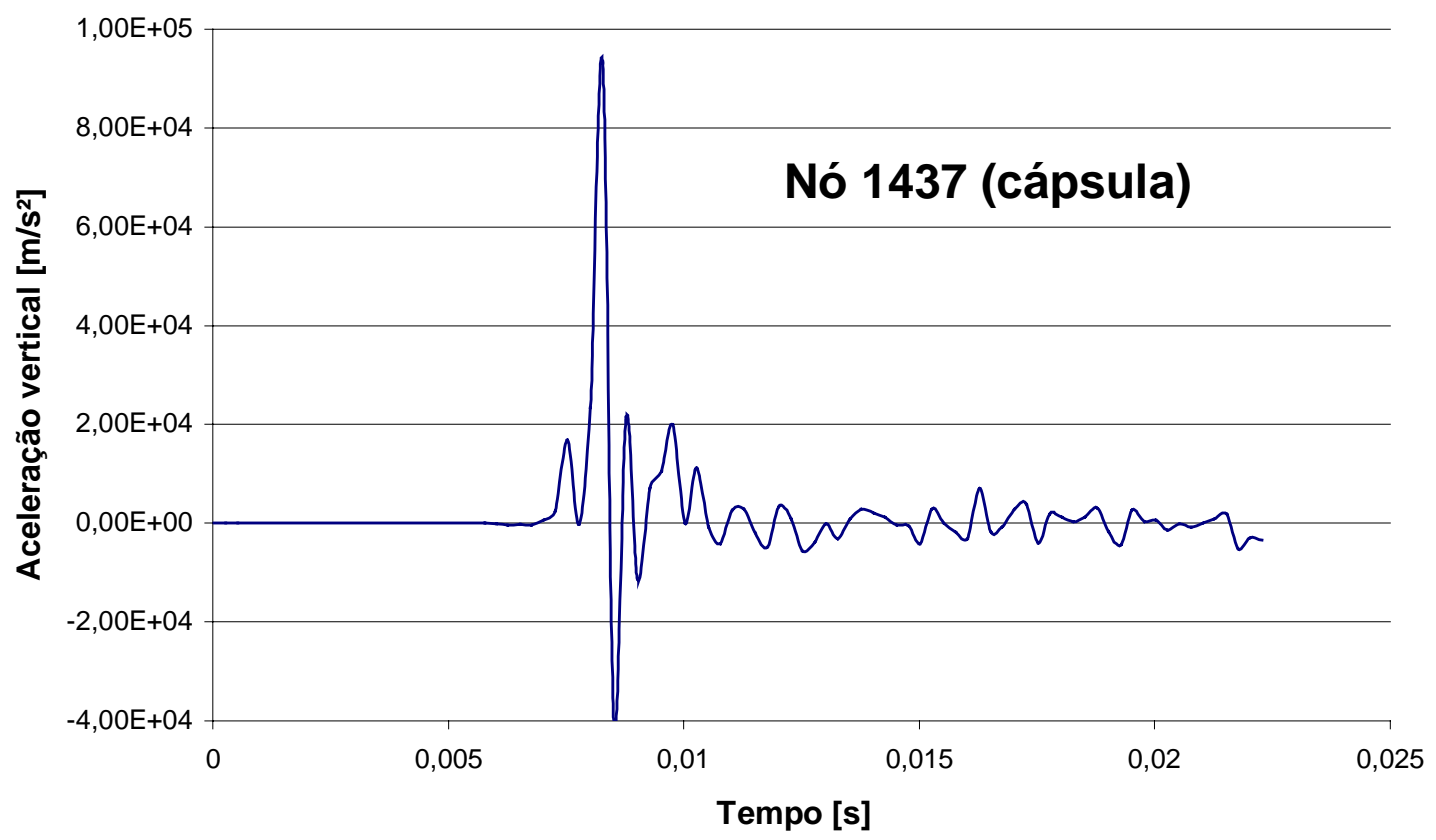

FIGURA A5: Aceleração vertical Y do nó 1437 da cápsula através dos 1000 passos da simulação. Mostra pico máximo de aceleração de $93180 \mathrm{~m} / \mathrm{s}^{2}$. Estes seriam os dados de aceleração obtidos com um acelerômetro de $4 \mathrm{kHz}$. 


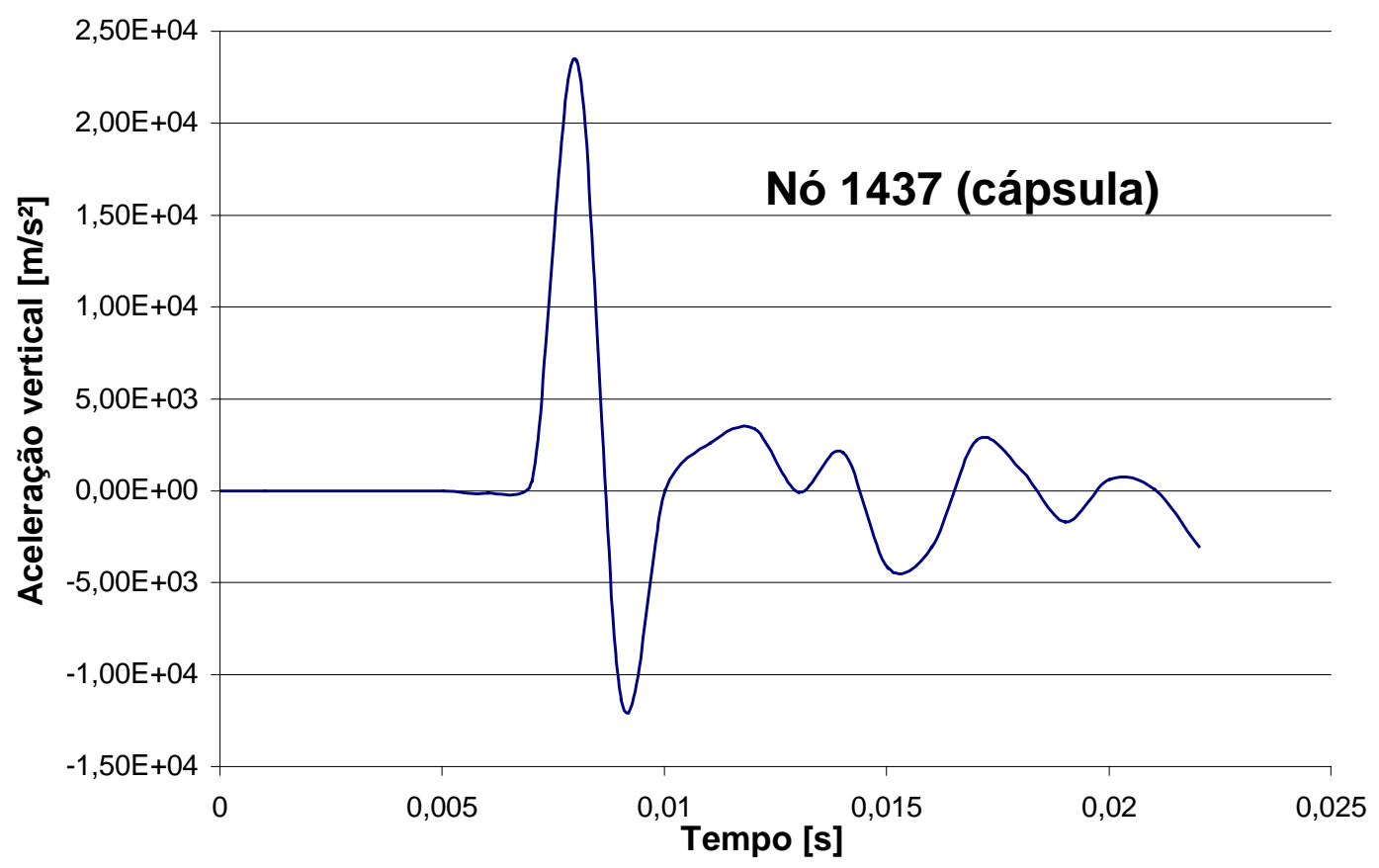

FIGURA A6: Aceleração vertical Y do nó 1437 da cápsula através dos 1000 passos da simulação. Mostra pico máximo de aceleração de $23396 \mathrm{~m} / \mathrm{s}^{2}$. Estes seriam os dados de aceleração obtidos com um acelerômetro de $1 \mathrm{kHz}$.

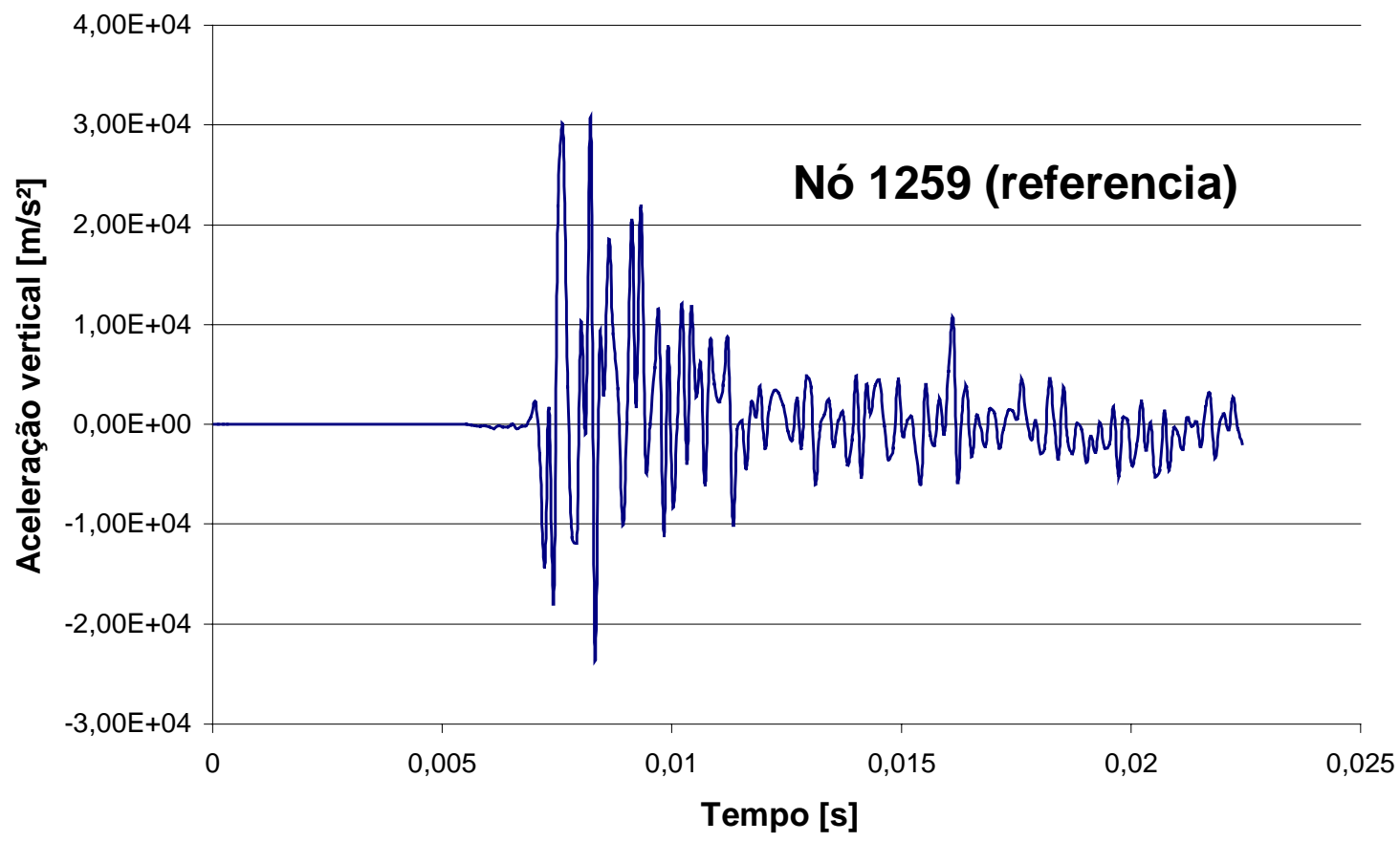

FIGURA A7: Aceleração vertical Y do nó de referência da cápsula 1259, através dos 1000 passos da simulação. Mostra pico máximo de aceleração de $30468 \mathrm{~m} / \mathrm{s}^{2}$. Estes seriam os dados de aceleração obtidos com um acelerômetro de $10 \mathrm{kHz}$. 


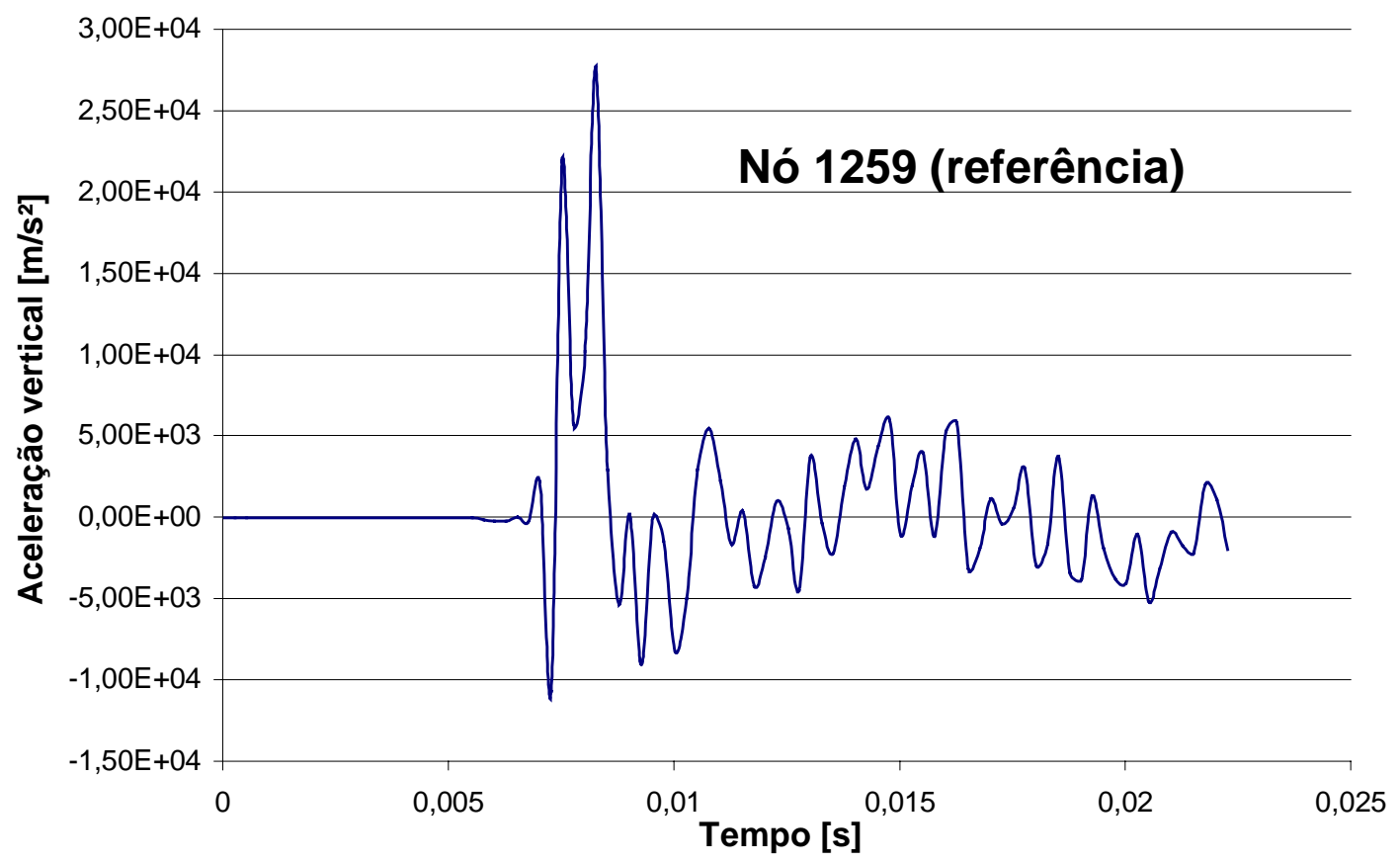

FIGURA A8: Aceleração vertical Y do nó de referência da cápsula 1259, através dos 1000 passos da simulação. Mostra pico máximo de aceleração de $27634 \mathrm{~m} / \mathrm{s}^{2}$. Estes seriam os dados de aceleração obtidos com um acelerômetro de $4 \mathrm{kHz}$.

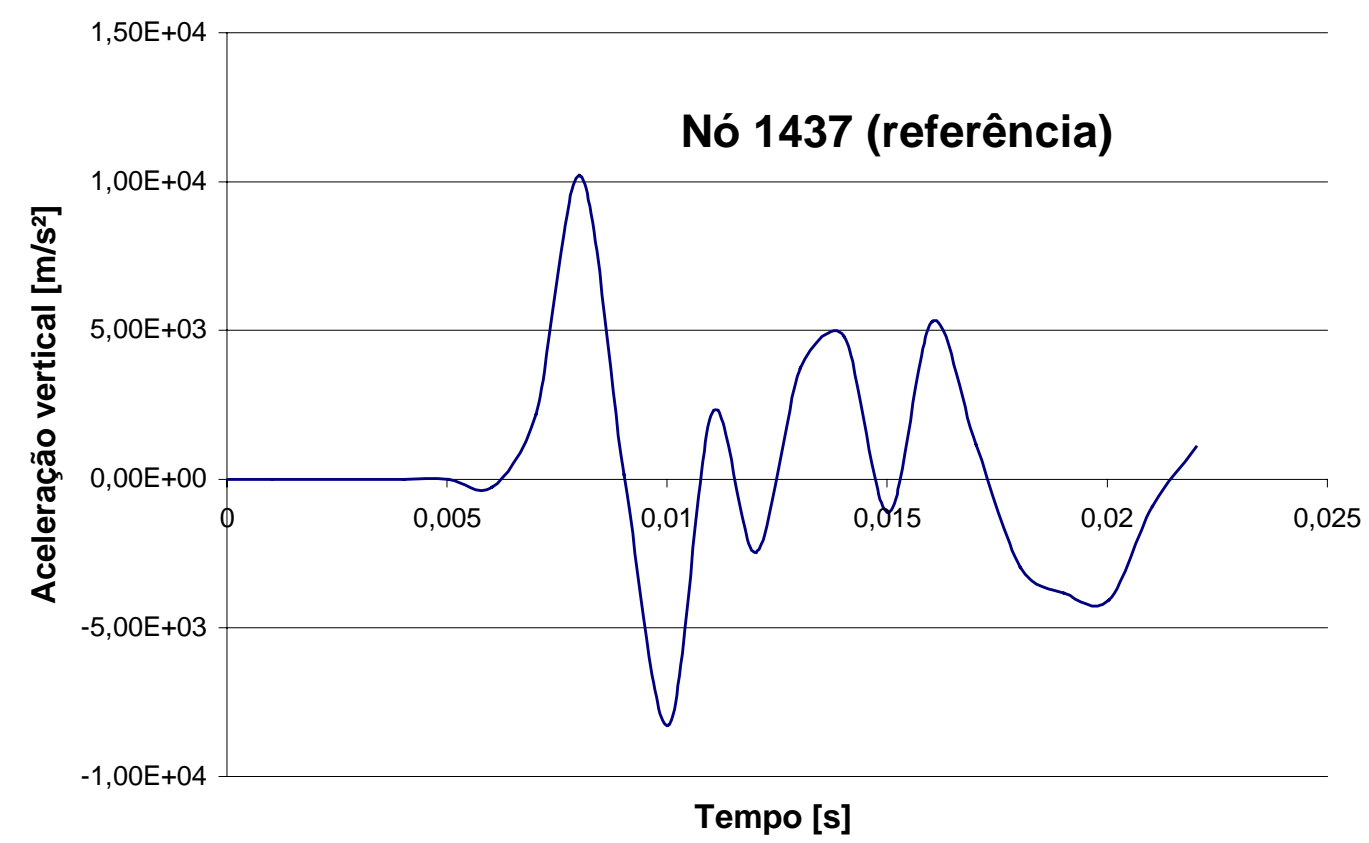

FIGURA A9: Aceleração vertical Y do nó de referência da cápsula 1259, através dos 1000 passos da simulação. Mostra pico máximo de aceleração de $10183 \mathrm{~m} / \mathrm{s}^{2}$. Estes seriam os dados de aceleração obtidos com um acelerômetro de $1 \mathrm{kHz}$. 


\section{Situação chapa - Gráficos obtidos usando filtros numéricos}

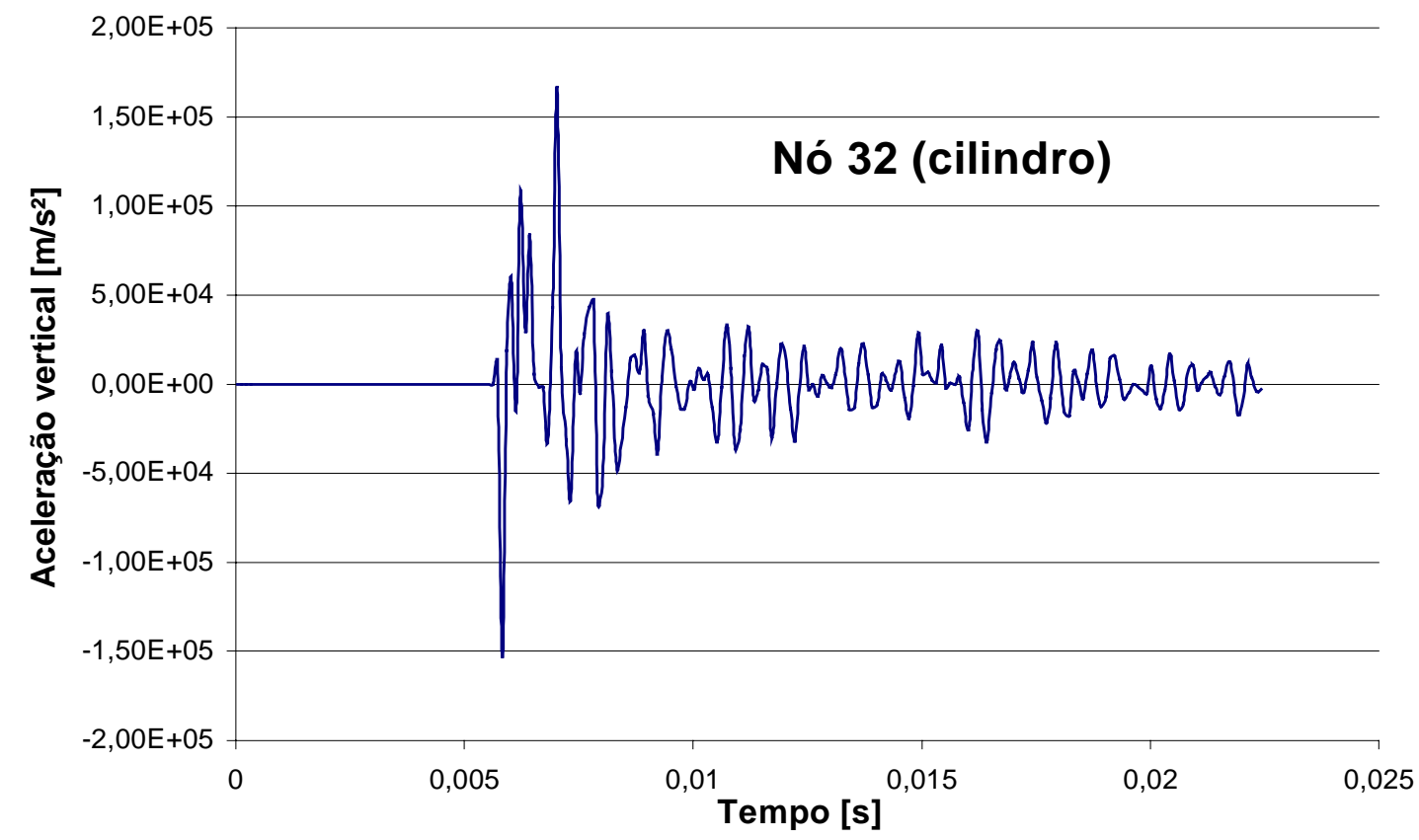

FIGURA A10: Aceleração vertical Y do nó 32 do cilindro, através dos 1000 passos da simulação. Mostra pico máximo de aceleração de $166959 \mathrm{~m} / \mathrm{s}^{2}$. Estes seriam os dados de aceleração obtidos com um acelerômetro de $10 \mathrm{kHz}$.

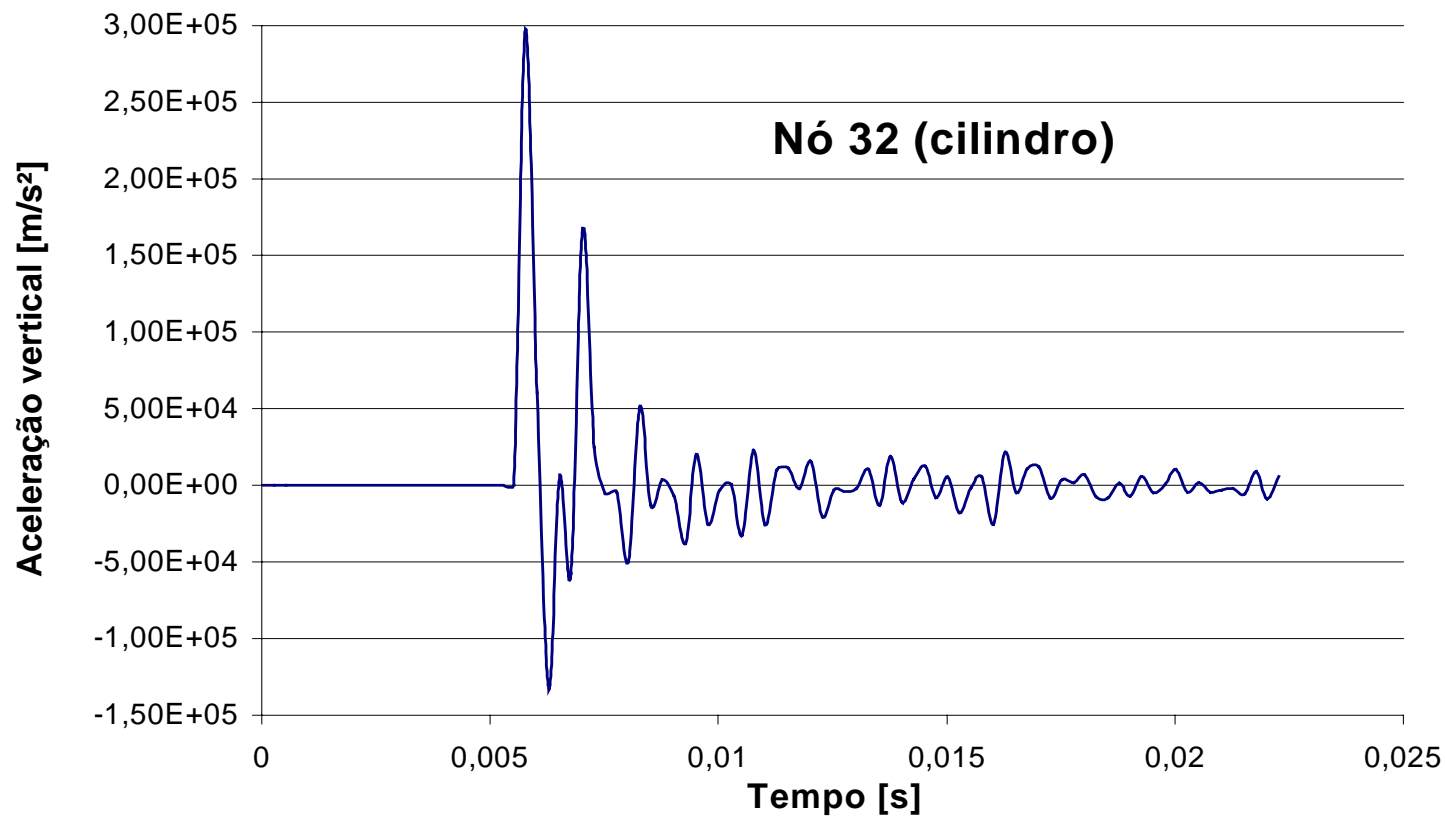

FIGURA A11: Aceleração vertical Y do nó 32 do cilindro, através dos 1000 passos da simulação. Mostra pico máximo de aceleração de $297432 \mathrm{~m} / \mathrm{s}^{2}$. Estes seriam os dados de aceleração obtidos com um acelerômetro de $4 \mathrm{kHz}$. 


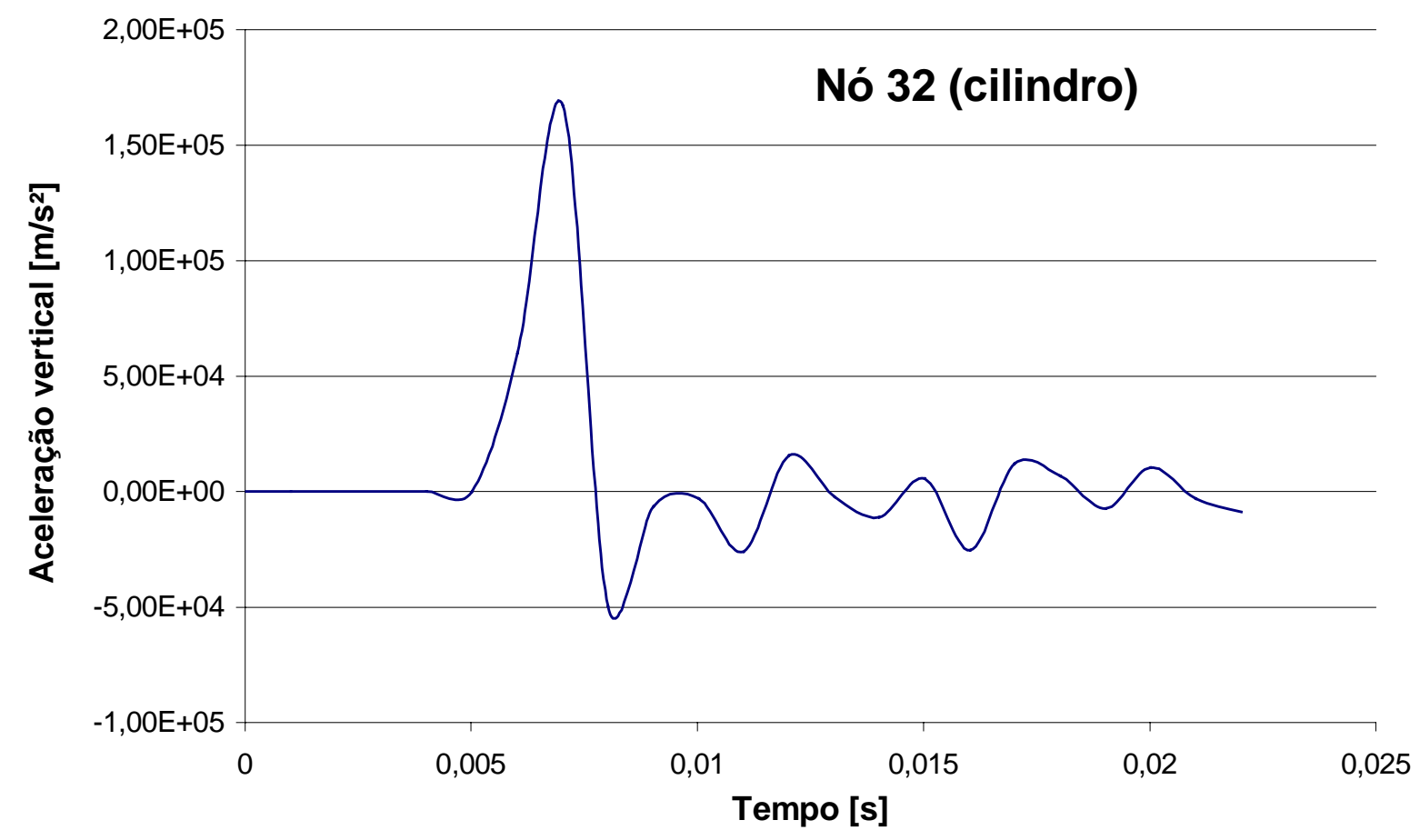

FIGURA A12: Aceleração vertical Y do nó 32 do cilindro, através dos 1000 passos da simulação. Mostra pico máximo de aceleração de $166959 \mathrm{~m} / \mathrm{s}^{2}$. Estes seriam os dados de aceleração obtidos com um acelerômetro de $1 \mathrm{kHz}$.

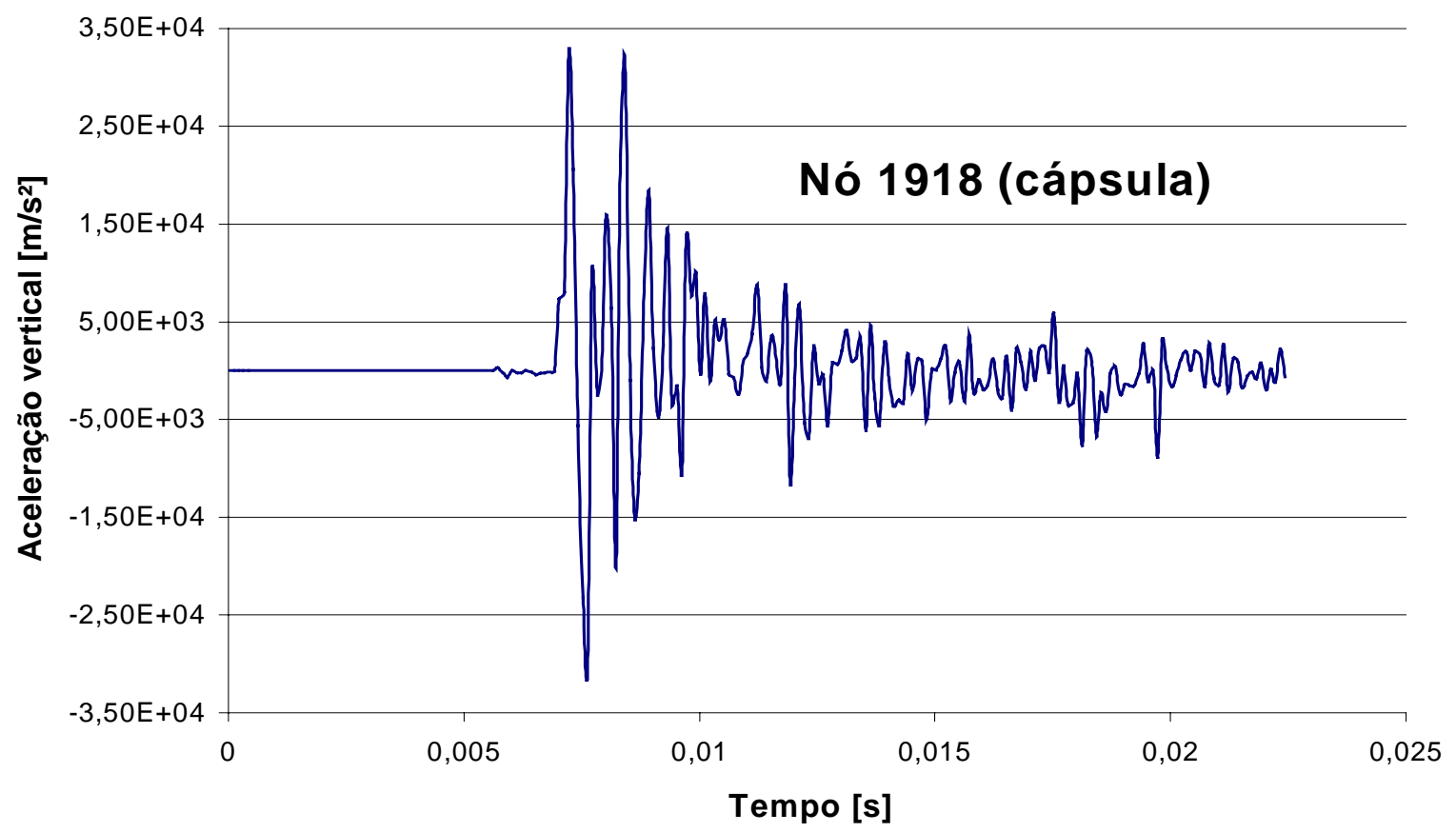

FIGURA A13: Aceleração vertical Y do nó 1918 da cápsula, através dos 1000 passos da simulação. Mostra pico máximo de aceleração de $32689 \mathrm{~m} / \mathrm{s}^{2}$. Estes seriam os dados de aceleração obtidos com um acelerômetro de $10 \mathrm{kHz}$. 


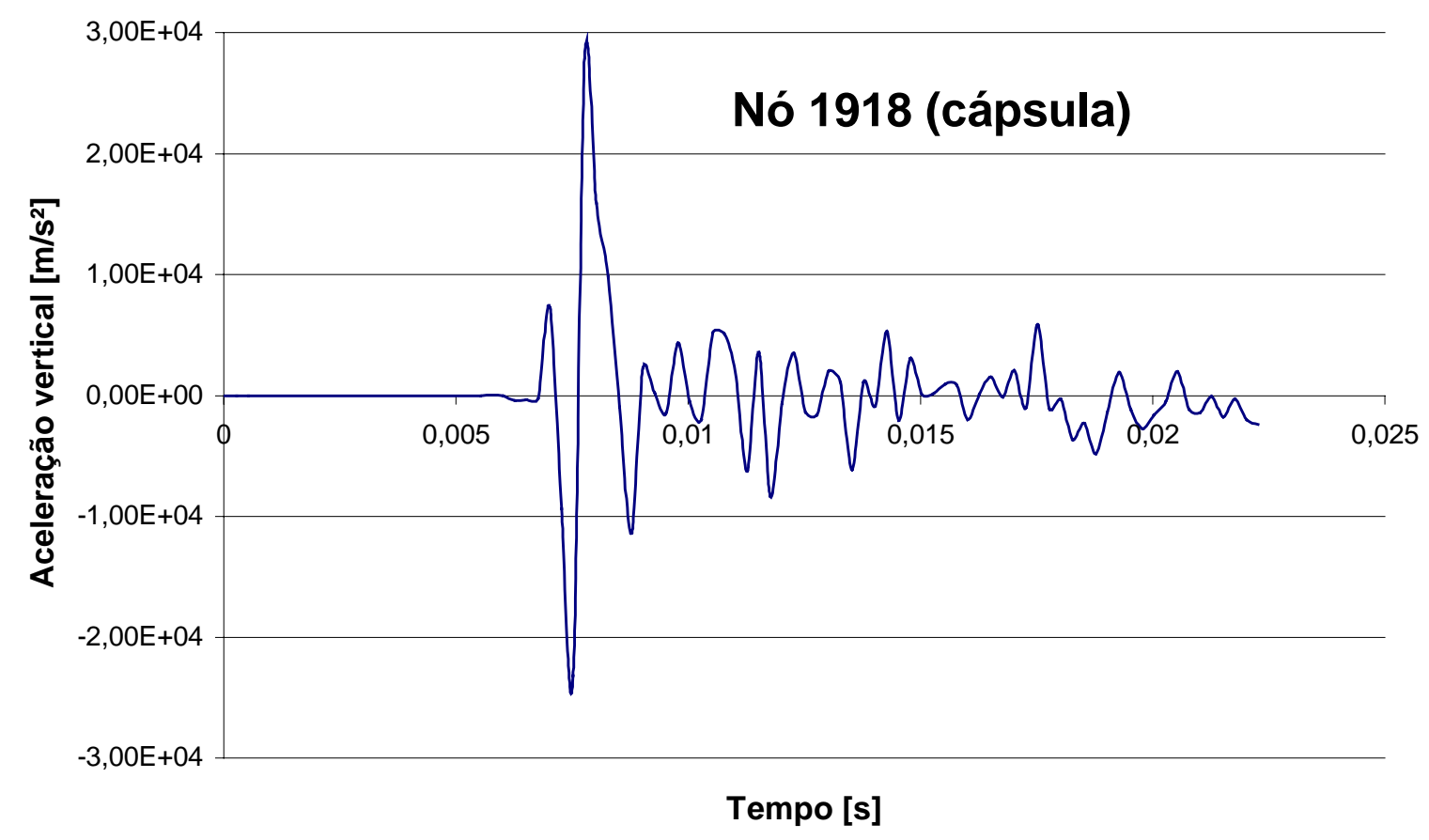

FIGURA A14: Aceleração vertical Y do nó 1918 da cápsula, através dos 1000 passos da simulação. Mostra pico máximo de aceleração de $27911 \mathrm{~m} / \mathrm{s}^{2}$. Estes seriam os dados de aceleração obtidos com um acelerômetro de $4 \mathrm{kHz}$.

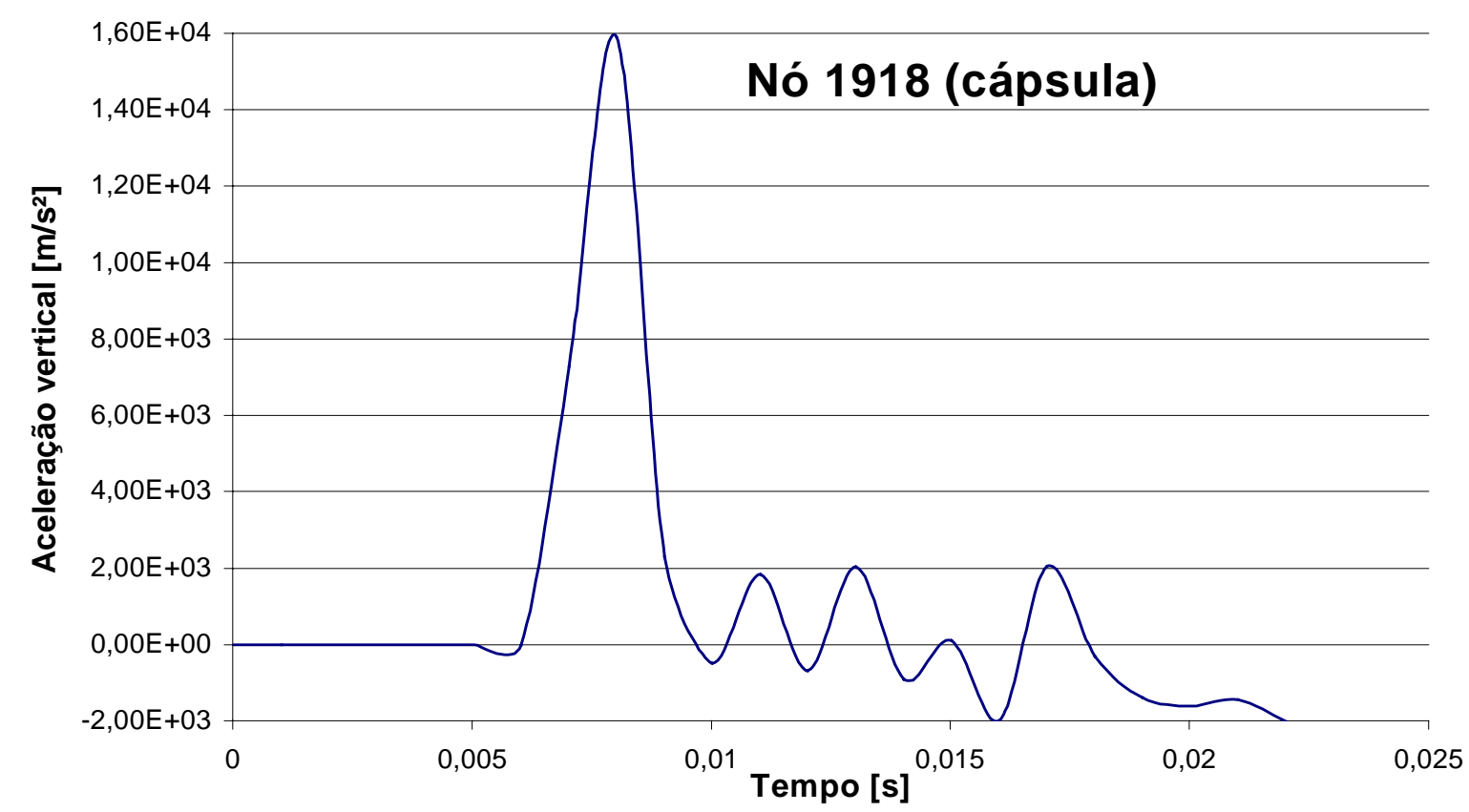

FIGURA A15: Aceleração vertical Y do nó 1918 da cápsula, através dos 1000 passos da simulação. Mostra pico máximo de aceleração de $15912 \mathrm{~m} / \mathrm{s}^{2}$. Estes seriam os dados de aceleração obtidos com um acelerômetro de $1 \mathrm{kHz}$. 


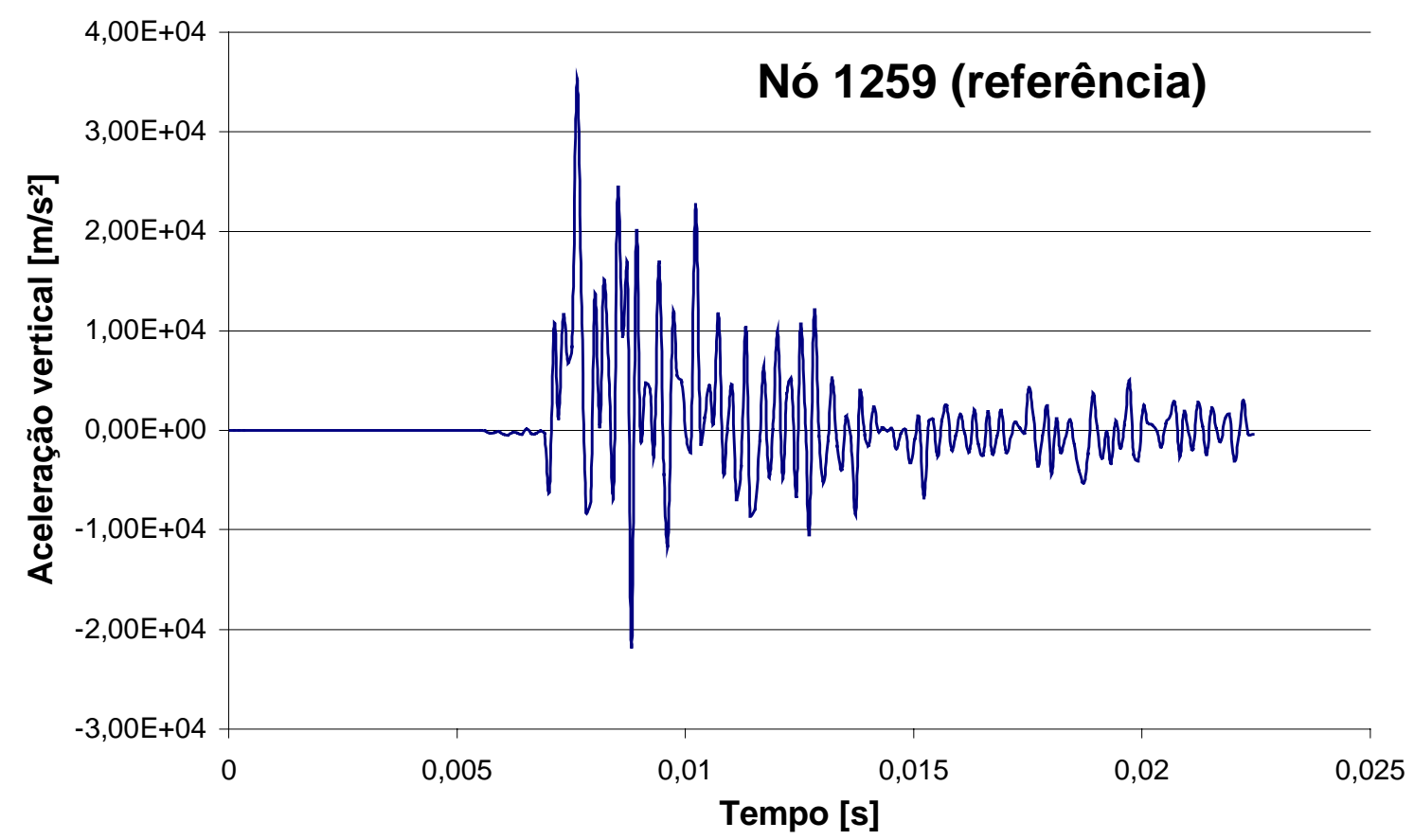

FIGURA A16: Aceleração vertical Y do nó de referência do componente cápsula (1259), através dos 1000 passos da simulação. Mostra pico máximo de aceleração de $35308 \mathrm{~m} / \mathrm{s}^{2}$. Estes seriam os dados de aceleração obtidos com um acelerômetro de $10 \mathrm{kHz}$.

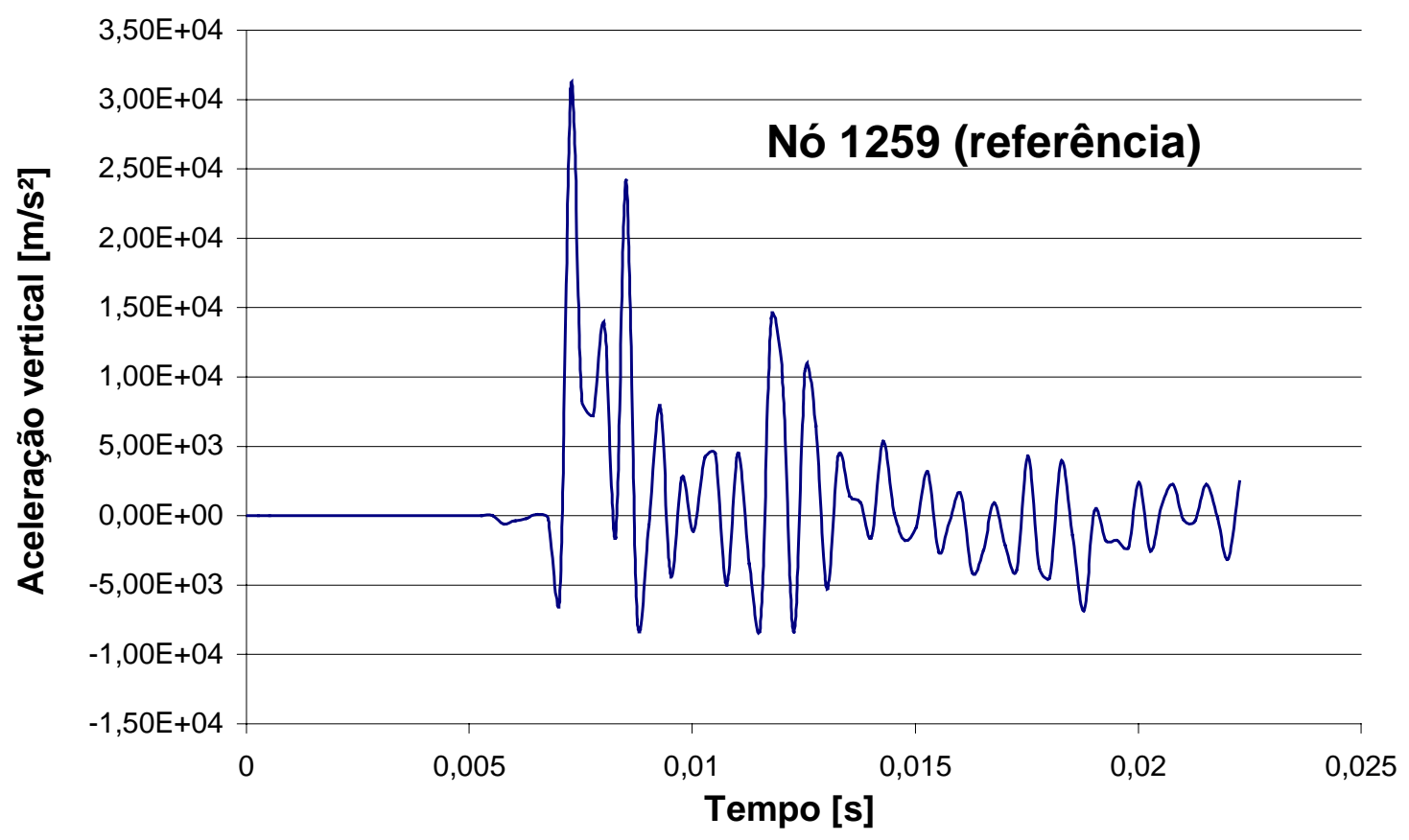

FIGURA A17: Aceleração vertical Y do nó de referência do componente cápsula (1259), através dos 1000 passos da simulação. Mostra pico máximo de aceleração de $31094 \mathrm{~m} / \mathrm{s}^{2}$. Estes seriam os dados de aceleração obtidos com um acelerômetro de $4 \mathrm{kHz}$. 


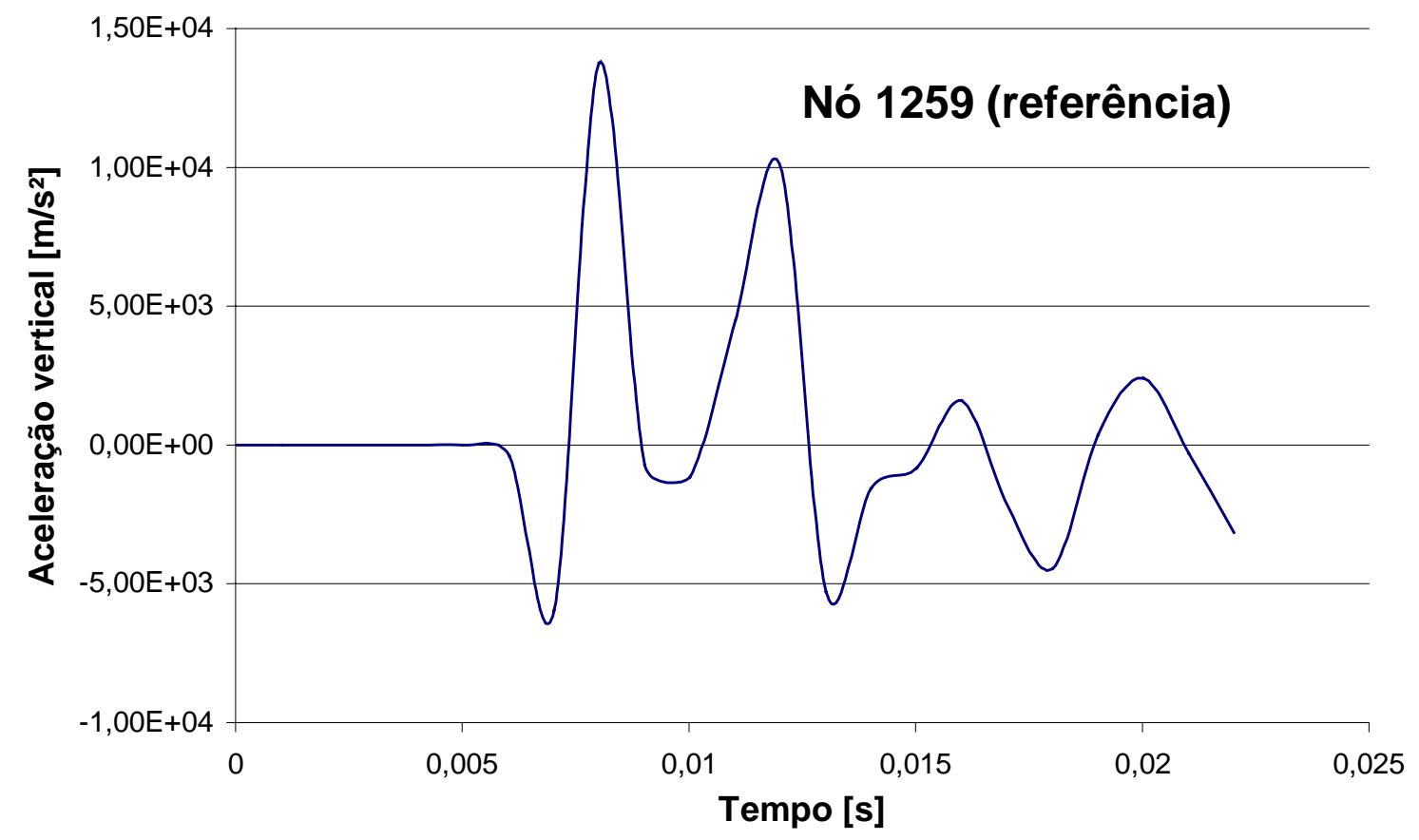

FIGURA A18: Aceleração vertical Y do nó de referência do componente cápsula (1259), através dos 1000 passos da simulação. Mostra pico máximo de aceleração de $13760 \mathrm{~m} / \mathrm{s}^{2}$. Estes seriam os dados de aceleração obtidos com um acelerômetro de $1 \mathrm{kHz}$. 


\section{Situação chanfro - Gráficos obtidos usando filtros numéricos}

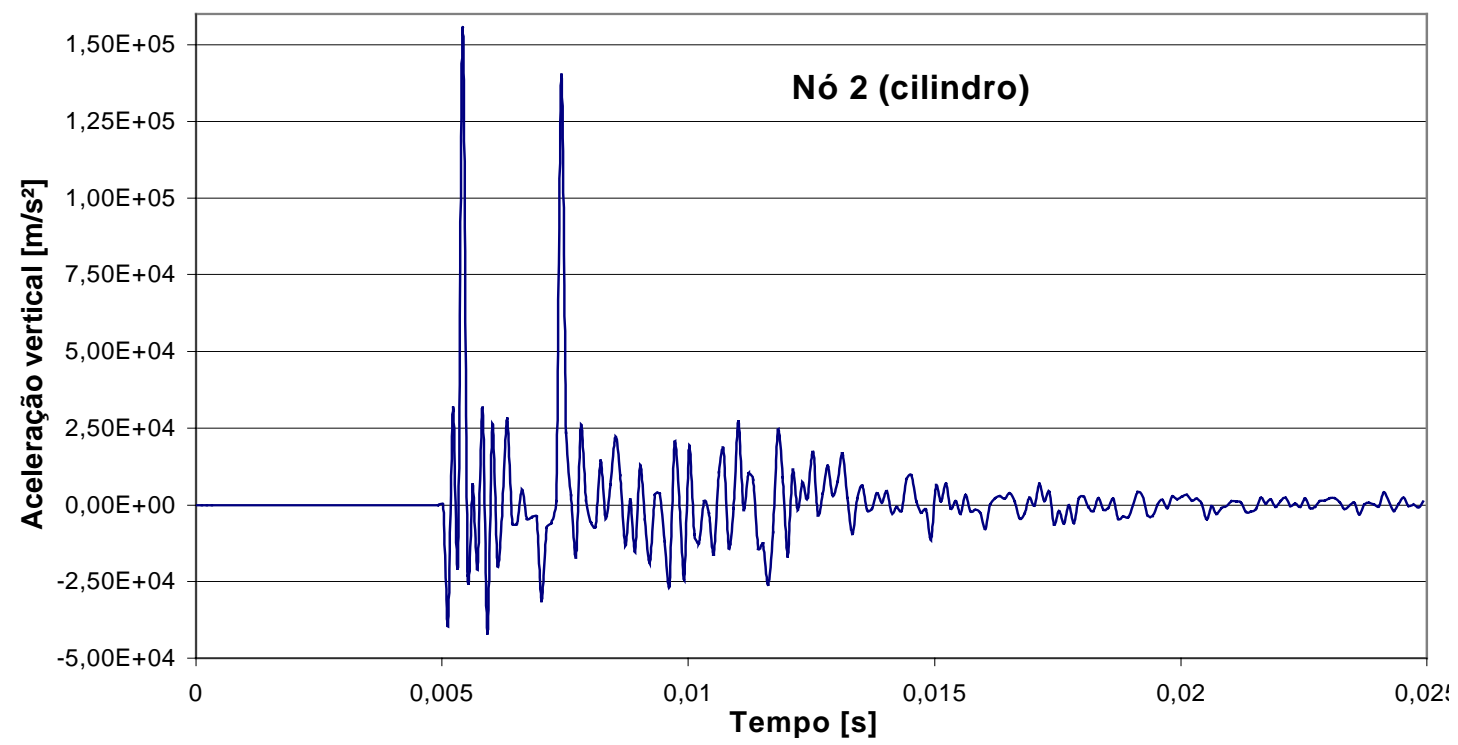

FIGURA A19: Aceleração vertical Y do nó 2 do cilindro através dos 1000 passos da simulação. Mostra pico de aceleração de $155499 \mathrm{~m} / \mathrm{s}^{2}$. Estes seriam os dados de aceleração obtidos com um acelerômetro de $10 \mathrm{kHz}$.

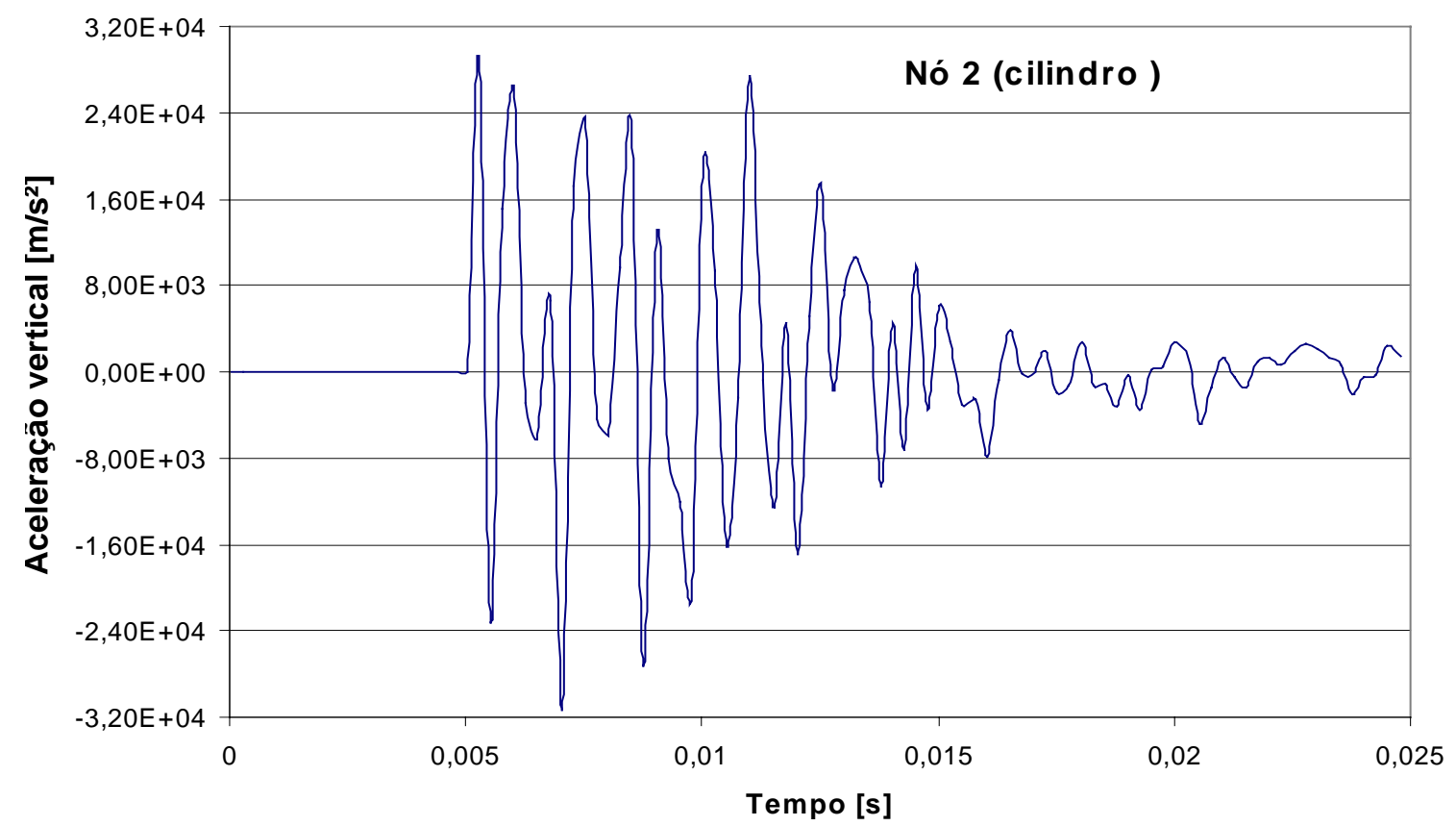

FIGURA A20: Aceleração vertical Y do nó 2 do cilindro, através dos 1000 passos da simulação. Mostra pico de aceleração de $-31365 \mathrm{~m} / \mathrm{s}^{2}$. Estes seriam os dados de aceleração obtidos com um acelerômetro de $4 \mathrm{kHz}$. 


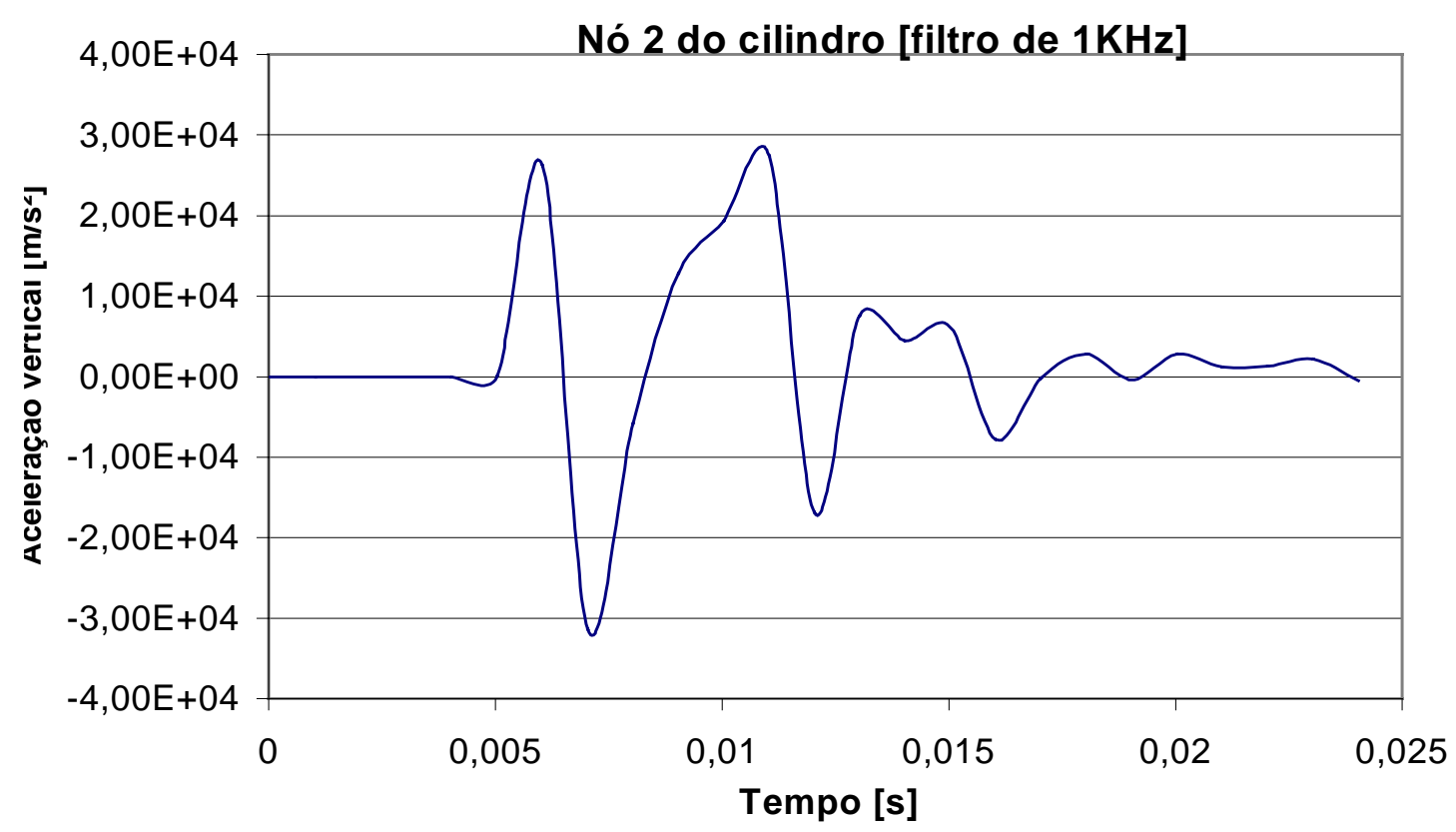

FIGURA A21: Aceleração vertical Y do nó 2 do cilindro, através dos 1000 passos da simulação. Mostra pico de aceleração de $-31365 \mathrm{~m} / \mathrm{s}^{2}$. Estes seriam os dados de aceleração obtidos com um acelerômetro de $1 \mathrm{kHz}$.

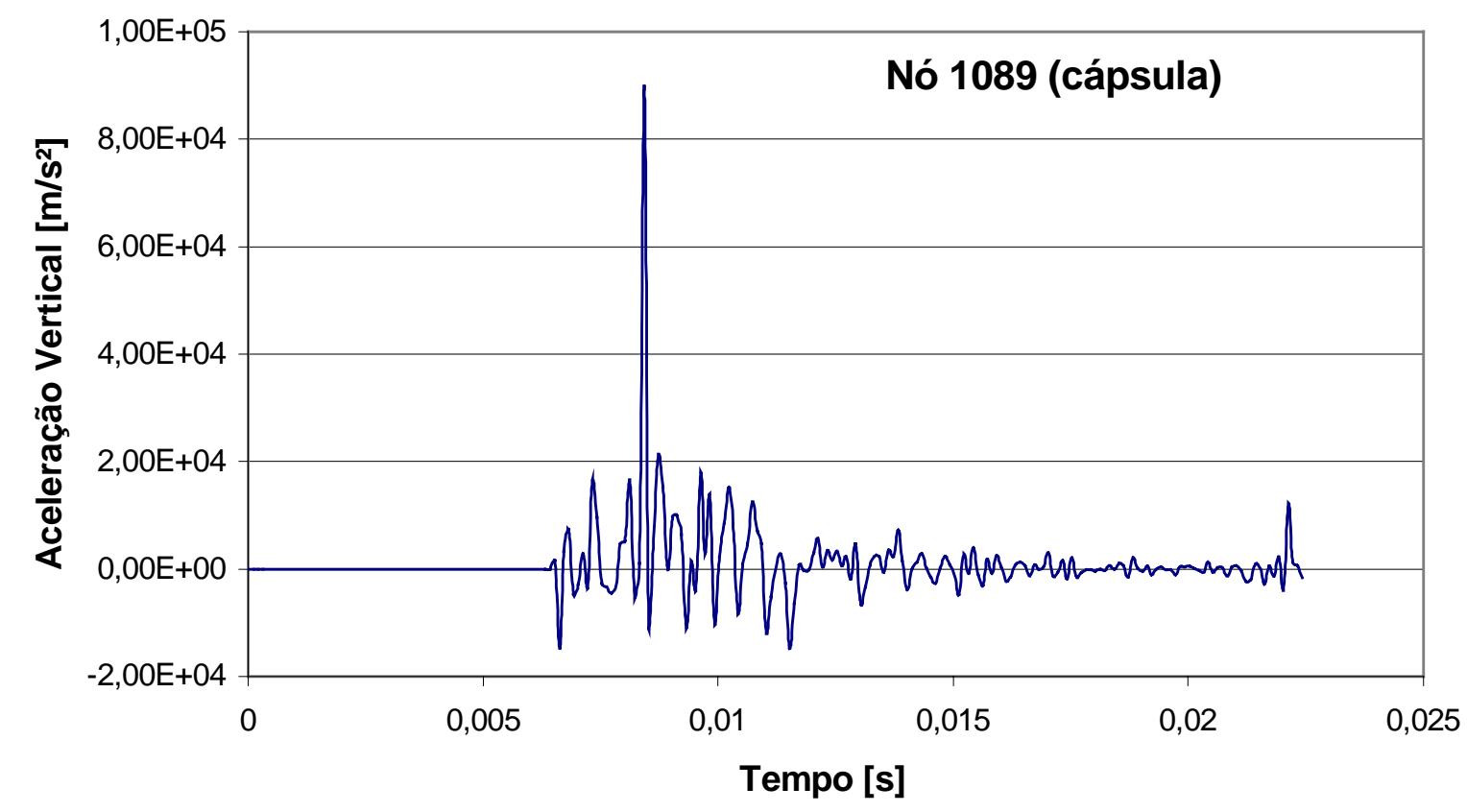

FIGURA A22: Aceleração vertical Y do nó 1089 do componente cápsula, através dos 1000 passos da simulação. Mostra pico de aceleração de $89884 \mathrm{~m} / \mathrm{s}^{2}$. Estes seriam os dados de aceleração obtidos com um acelerômetro de $10 \mathrm{kHz}$. 


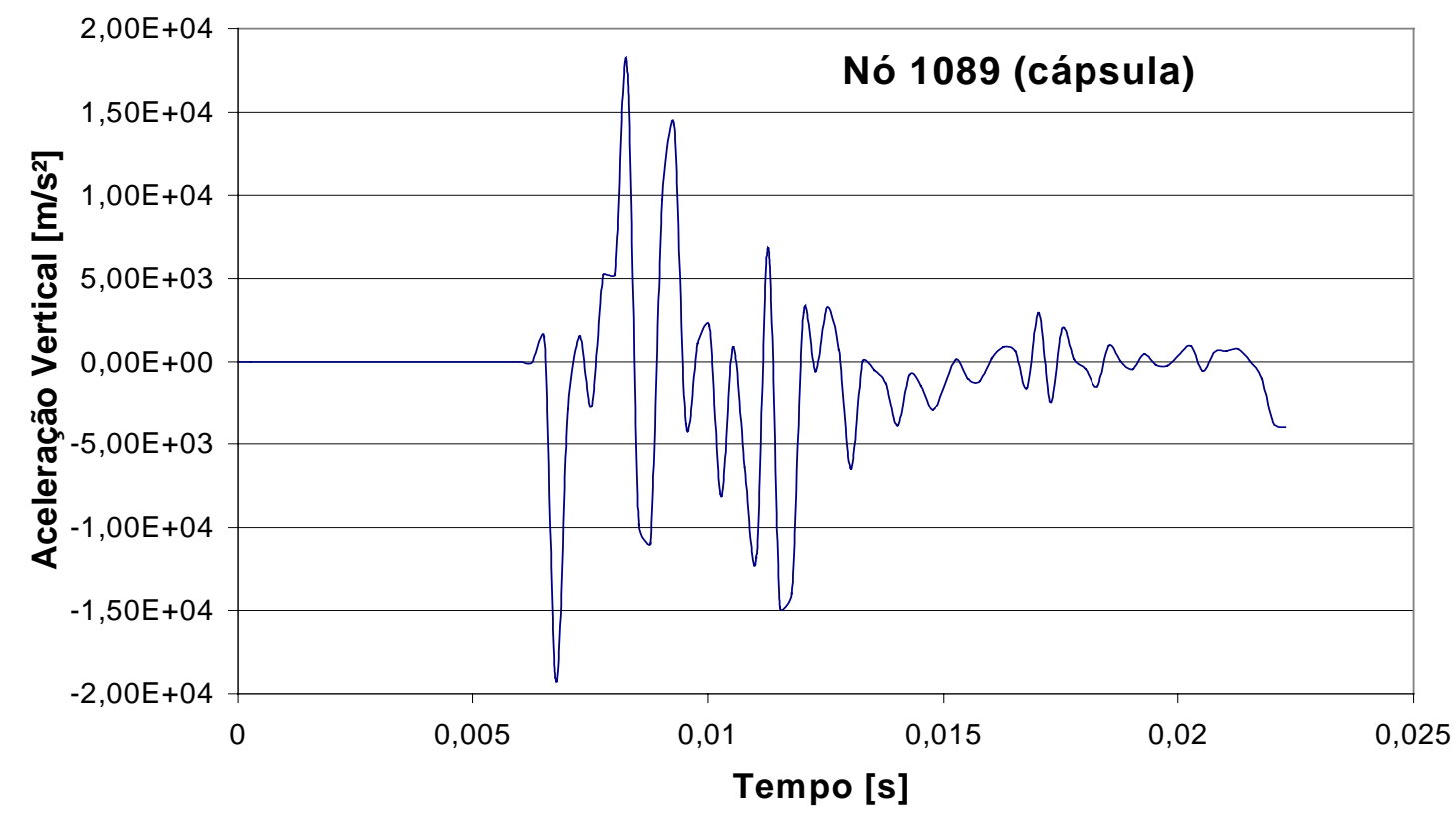

FIGURA A23: Aceleração vertical Y do nó 1089 do componente cápsula, através dos 1000 passos da simulação. Mostra pico de aceleração de $-19244 \mathrm{~m} / \mathrm{s}^{2}$. Estes seriam os dados de aceleração obtidos com um acelerômetro de $4 \mathrm{kHz}$.

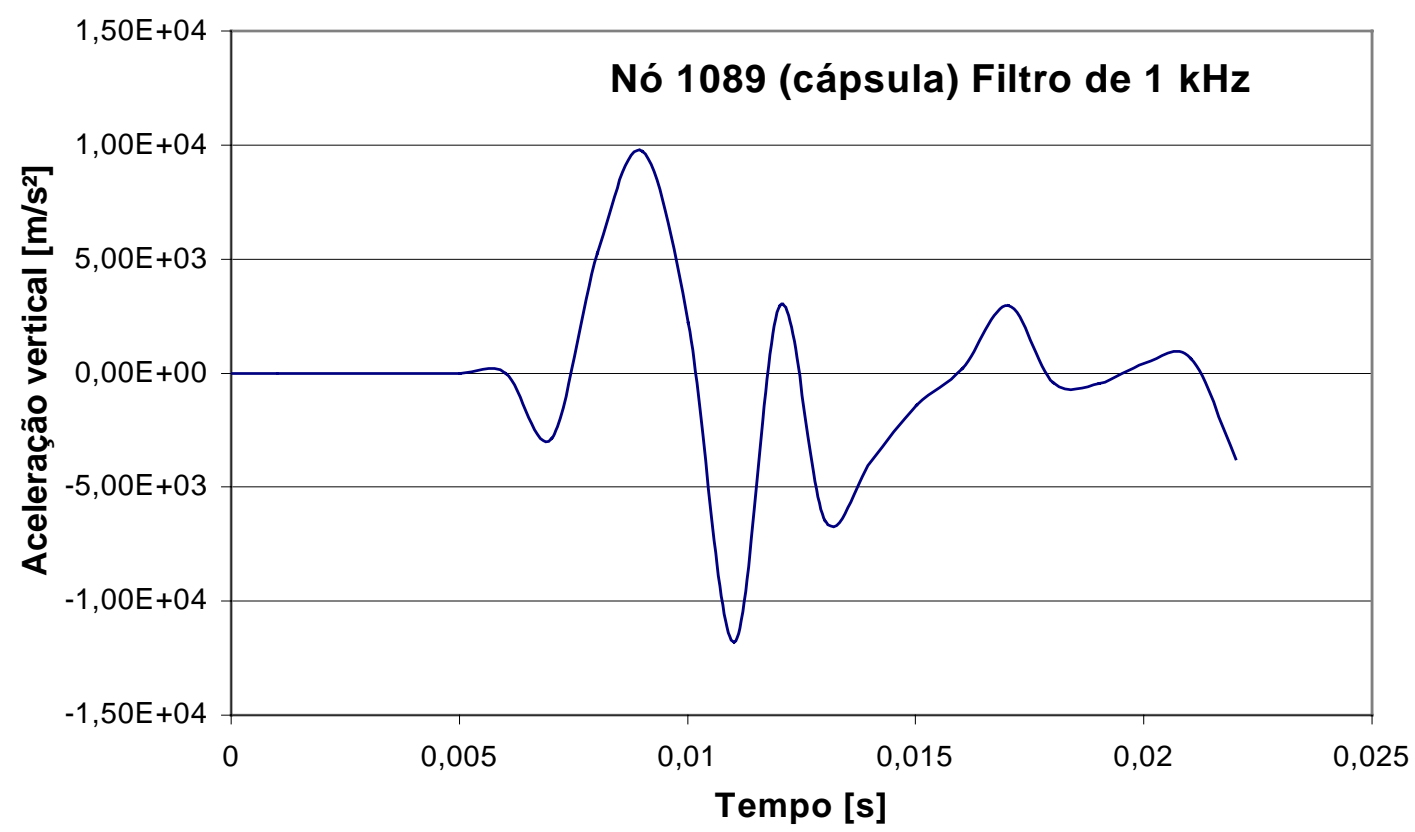

FIGURA A24: Aceleração vertical Y do nó 1089 do componente cápsula, através dos 1000 passos da simulação. Mostra pico de aceleração de $-11807 \mathrm{~m} / \mathrm{s}^{2}$. Estes seriam os dados de aceleração obtidos com um acelerômetro de $1 \mathrm{kHz}$. 


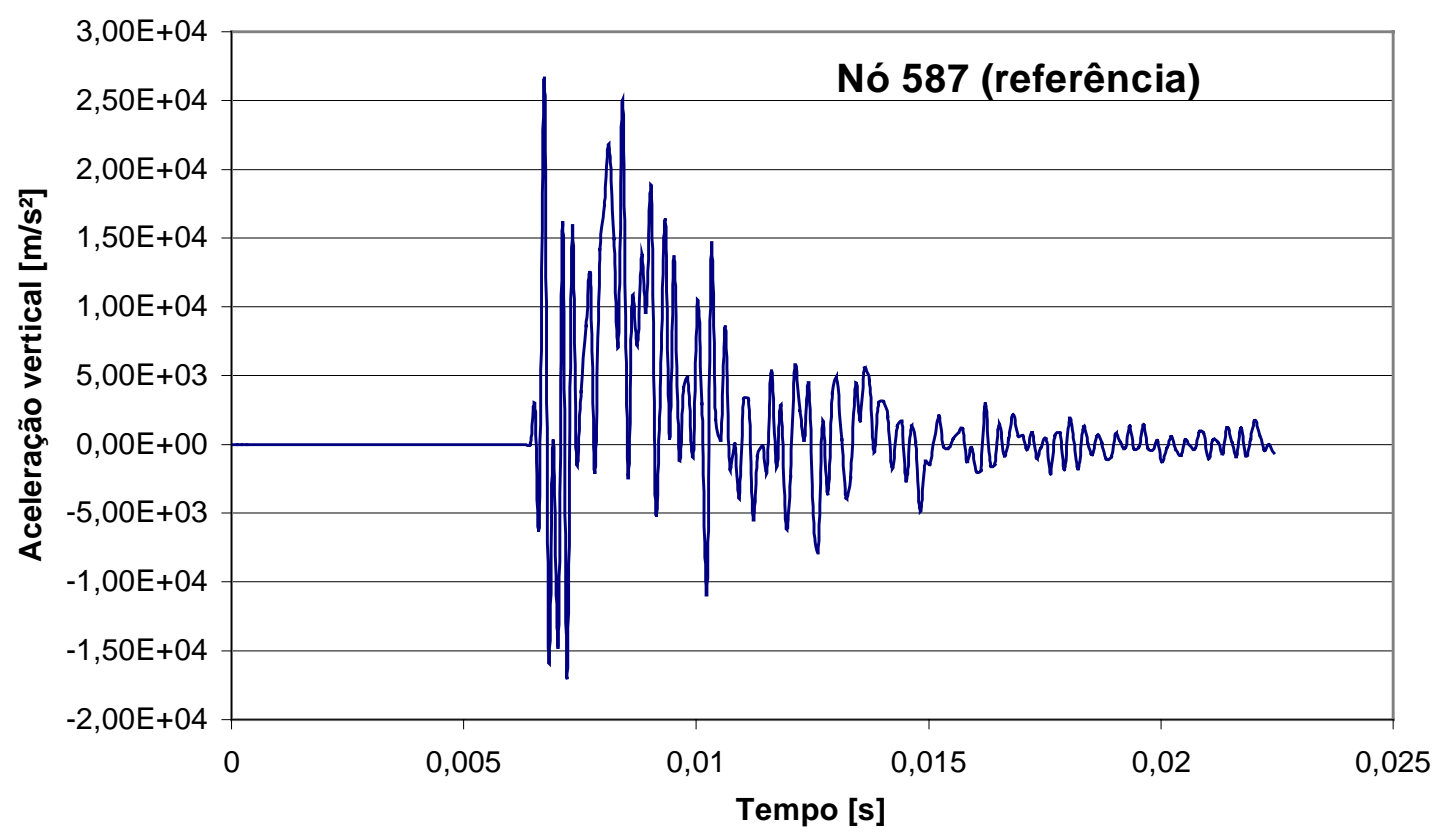

FIGURA A.25: Aceleração vertical Y do nó 587 (no de referencia do componente cápsula da situação chanfro), através dos 1000 passos da simulação. Mostra pico de aceleração de $26659 \mathrm{~m} / \mathrm{s}^{2}$. Estes seriam os dados de aceleração obtidos com um acelerômetro de $10 \mathrm{kHz}$.

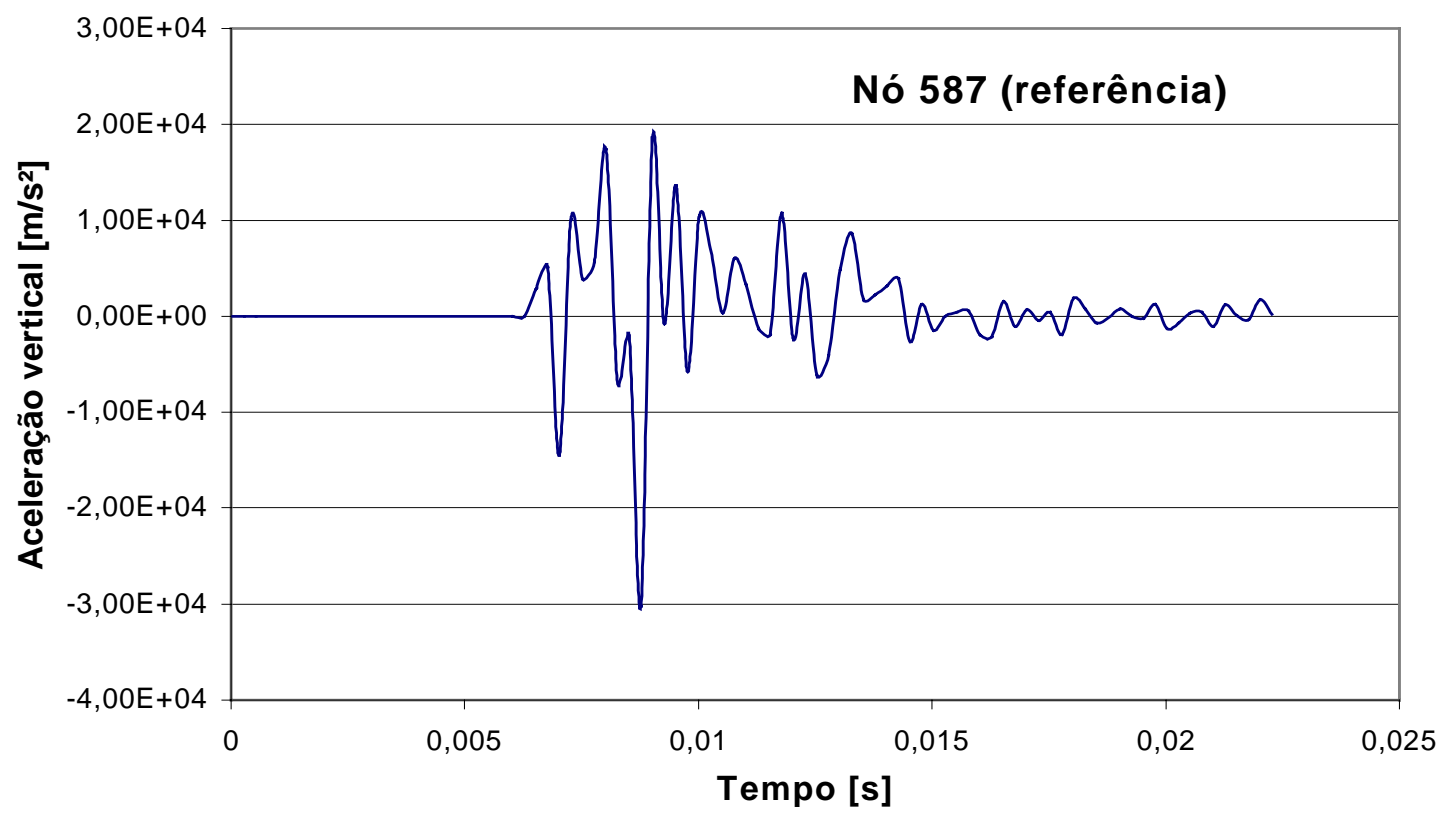

FIGURA A.26: Aceleração vertical Y do nó 587 (no de referencia do componente cápsula no modelo modificado), através dos 1000 passos da simulação. Mostra pico de aceleração de $-30221 \mathrm{~m} / \mathrm{s}^{2}$. Estes seriam os dados de aceleração obtidos com um acelerômetro de $4 \mathrm{kHz}$. 


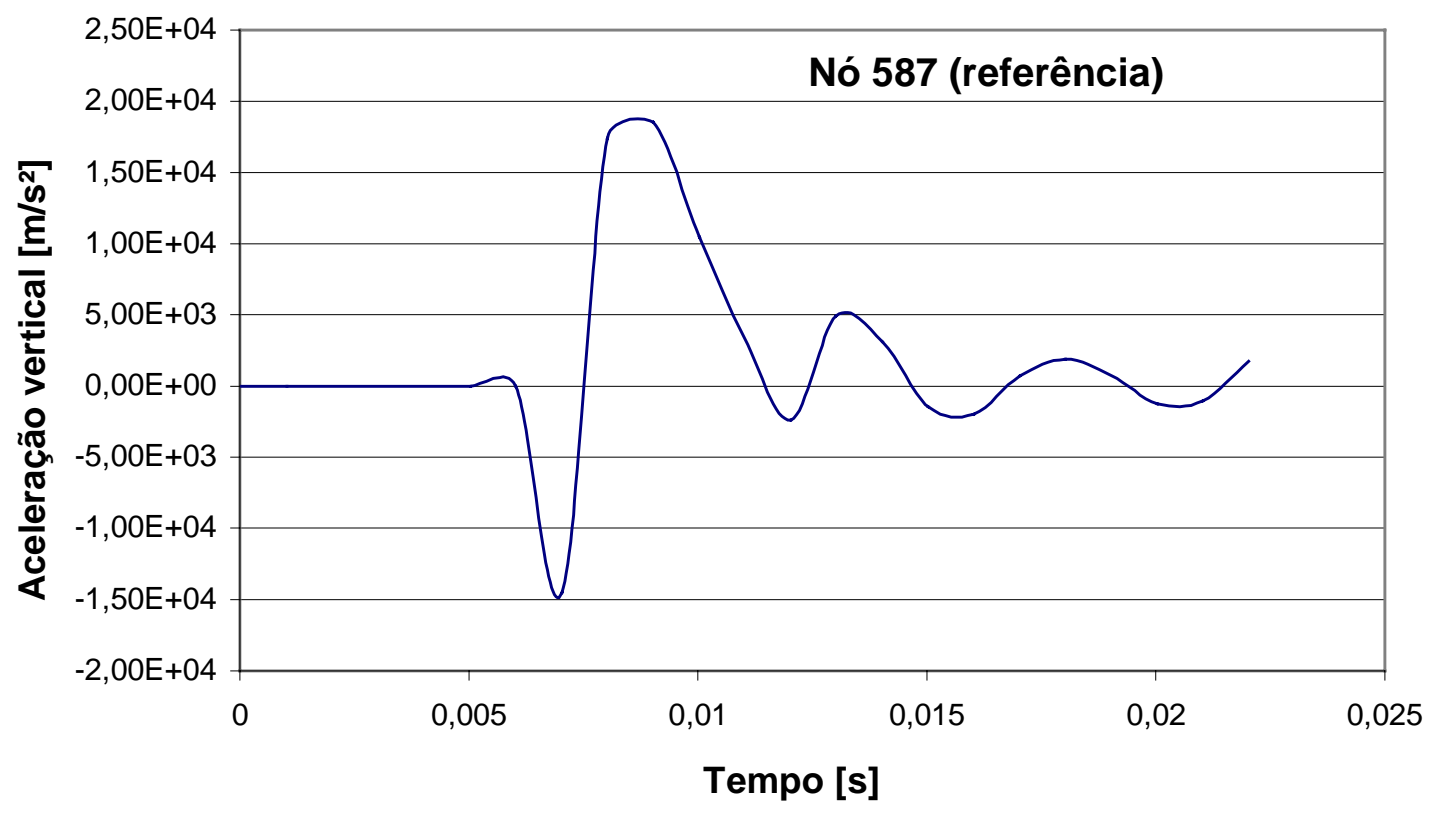

GRÁFICO 6.27: Aceleração vertical Y do nó 587 (no de referencia do componente cápsula no modelo modificado), através dos 1000 passos da simulação. Mostra pico de aceleração de $18545 \mathrm{~m} / \mathrm{s}^{2}$. Estes seriam os dados de aceleração obtidos com um acelerômetro de $1 \mathrm{kHz}$. 